\title{
Using the community informant based (Made-In and Made-For) methodology for estimating MMR in Punjab
}

\author{
Ali M. Mir \\ Population Council \\ Saleem Shaikh \\ Population Council \\ Mumraiz Khan \\ Population Council \\ Irfan Masood
}

Follow this and additional works at: https://knowledgecommons.popcouncil.org/departments_sbsr-rh

Part of the Demography, Population, and Ecology Commons, Family, Life Course, and Society Commons, International Public Health Commons, Maternal and Child Health Commons, and the Women's Health Commons How does access to this work benefit you? Let us know!

\section{Recommended Citation}

Mir, Ali M., Saleem Shaikh, Mumraiz Khan, and Irfan Masood. 2015. "Using the community informant based (Made-In and Made-For) methodology for estimating MMR in Punjab." Islamabad: Population Council. 


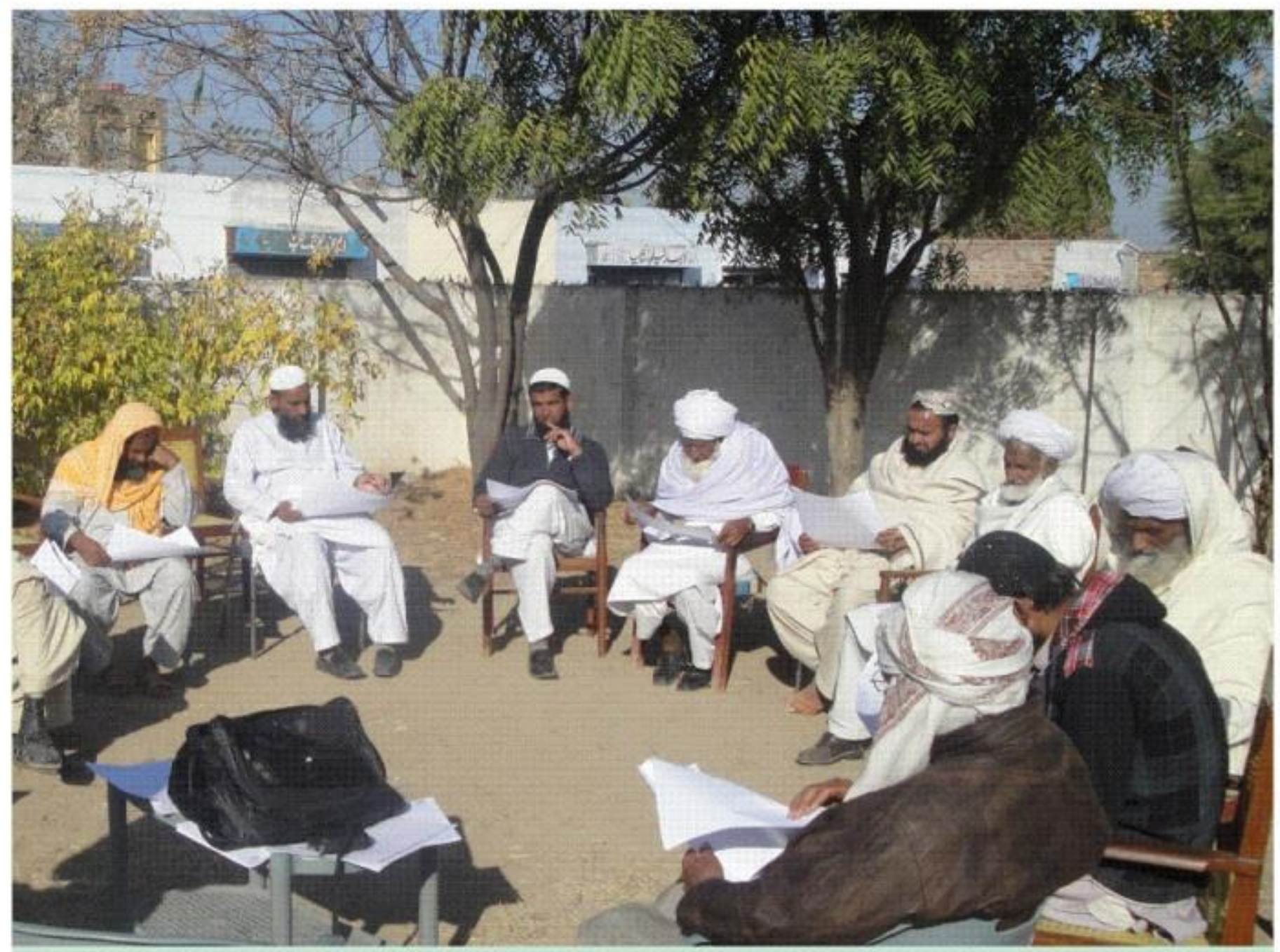

\section{Using the Community Informant Based (Made-In and Made-For) Methodology for Estimating MMR in Punjab}

Ali Mohammad Mir Saleem Shaikh Mumraiz Khan Irfan Masood 



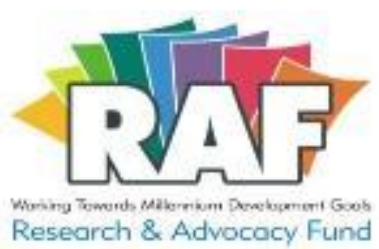

\title{
Immpact
}

POPULATION

\section{Using the Community Informant Based (Made-in and Made-for) Methodology for Estimating MMR in Punjab}

\author{
A Study Funded by \\ The Maternal and Newborn Health Programme \\ Research and Advocacy Fund (RAF)
}

ALI MOHAMMAD MIR, SALEEM SHAIKH, MUMRAIZ KHAN, AND IRFAN MASOOD

Implemented by

The Population Council

February 2015 


\section{Promunow COUNCIL \\ Ideas. Evidence. Impact.}

The Population Council confronts critical health and development issues-from stopping the spread of HIV to improving reproductive health and ensuring that young people lead full and productive lives. Through biomedical, social science, and public health research in 50 countries, we work with our partners to deliver solutions that lead to more effective policies, programs, and technologies that improve lives.

(c) 2015 The Population Council, Inc.

\section{Declaration:}

"I have read the report titled "Using the Community Informant Based (Made-in and Made-for) Methodology for Estimating MMR in Punjab", and acknowledge and agree with the information, data and findings contained".

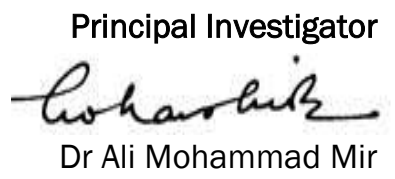

\section{Acknowledgment:}

"Using the Community Informant Based (Made-In And Made-For) Methodology for Estimating MMR in Punjab" is a project funded by the Maternal and Newborn Health Programme-Research and Advocacy Fund (RAF), and is implemented by the Population Council, Pakistan.

\section{Disclaimer:}

This document is an output from a project funded by the UK Department for International Development (DFID) and the Australian Department of Foreign Affairs and Trade (DFAT) for the benefit of developing countries. The views expressed and information contained in it are not necessarily those of or endorsed by DFID, DFAT or the Maternal and Newborn Health Programme - Research and Advocacy Fund (RAF), which can accept no responsibility or liability for such views, for completeness or accuracy of the information, or for any reliance placed on them. 


\section{Table of Contents}

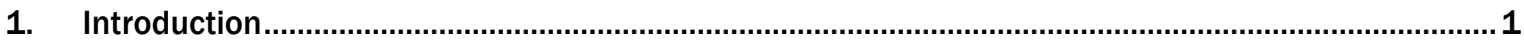

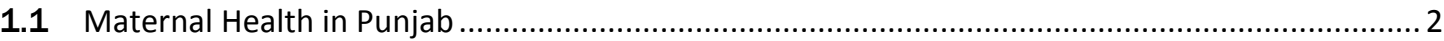

1.2 Approaches to Measuring Maternal Mortality ................................................................... 2

1.3 Measurement of Maternal Mortality in Pakistan .................................................................. 10

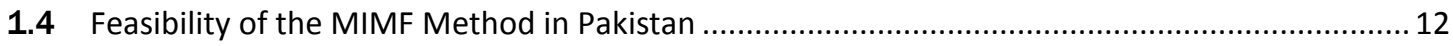

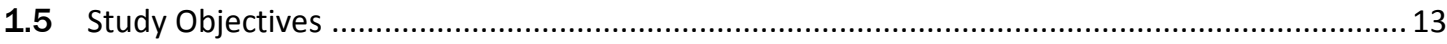

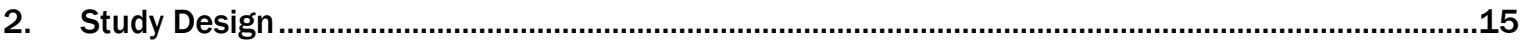

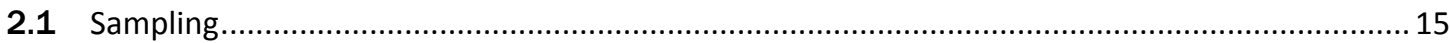

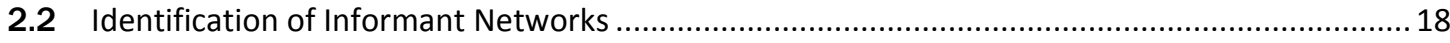

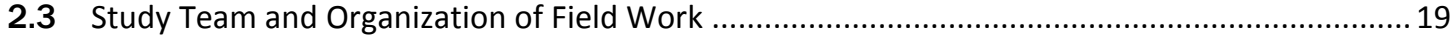

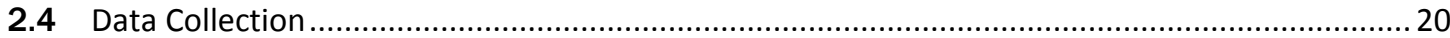

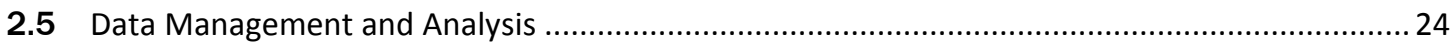

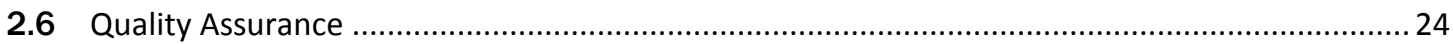

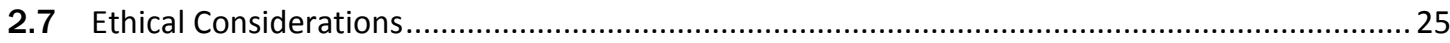

3. Maternal Mortality: Socio-Demographic Features, Incidence, and Causes ....................................27

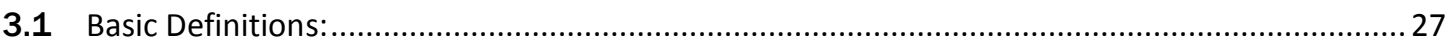

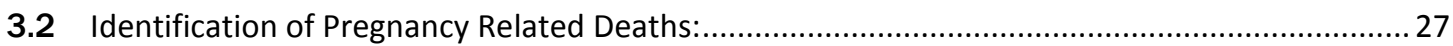

3.3 Socio-demographic Characteristics of the Deceased Women ............................................ 29

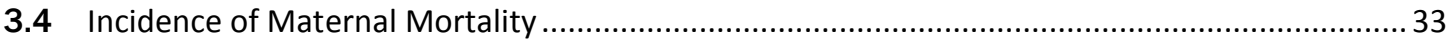

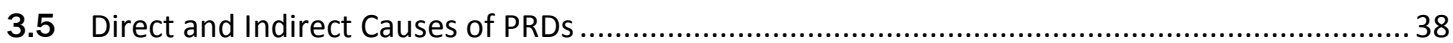

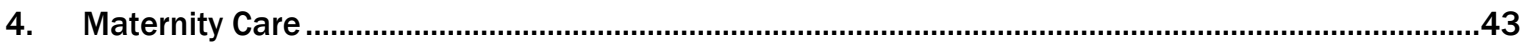

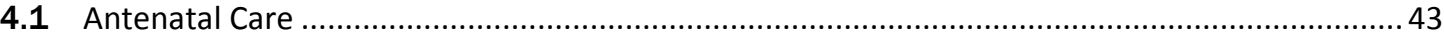

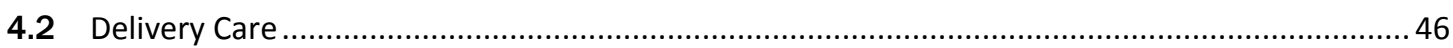

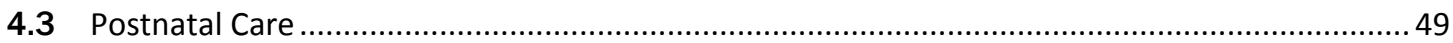

5. Circumstances of Death: Time, Place, and Care-Seeking Behaviour ...........................................53

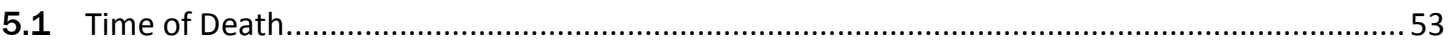

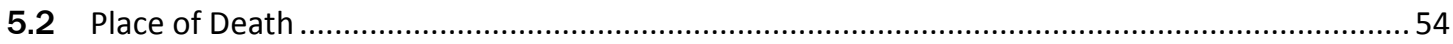

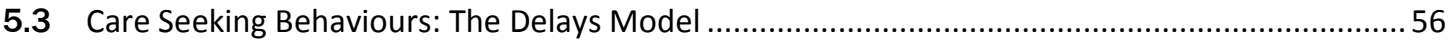

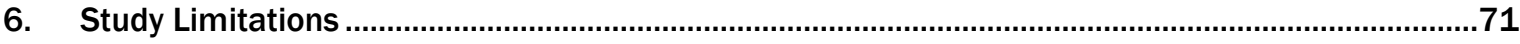

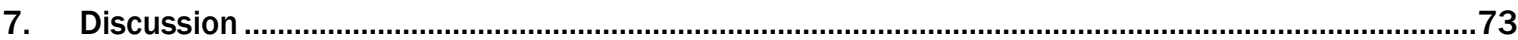

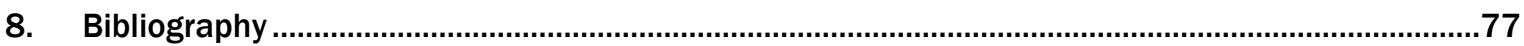

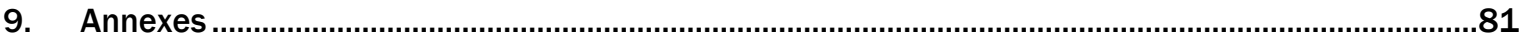

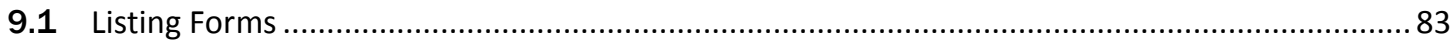

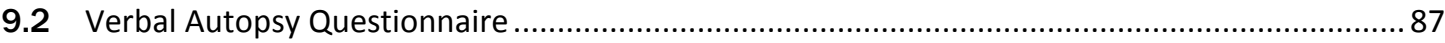

9.3 Ethical Approval from National Bioethics Committee of Pakistan and the Institutional Review Board of the Population Council, New York 


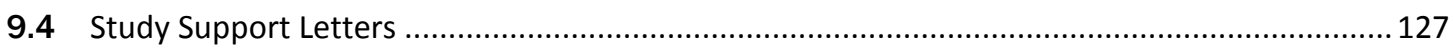

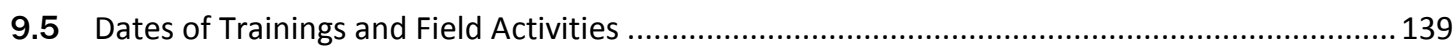

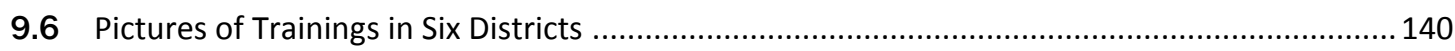

9.7 List of Health Department Staff Who Were Trained ........................................................ 141

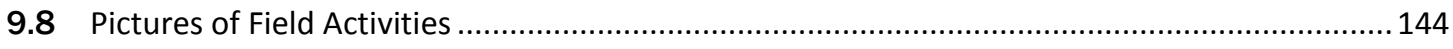

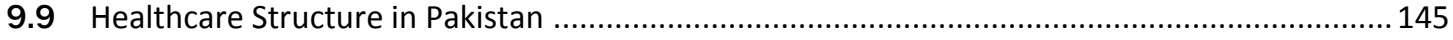

9.10 Indicators for Measuring Maternal Mortality ................................................................. 147

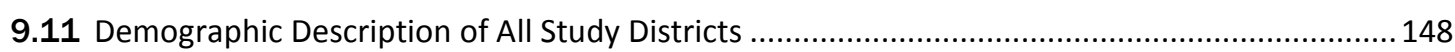

9.12 Identified networks for data collection.......................................................................... 151

9.13 Probability of individual network in capturing the case ..................Error! Bookmark not defined. 


\section{List of Tables}

Table 1.1: Various options for measuring maternal mortality in Pakistan ..............................................8

Table 1.2: Previous sources of data used to estimate MMR in Pakistan ................................................ 10

Table 2.1: Distribution of districts by geographical region, population, level of urbanization, and

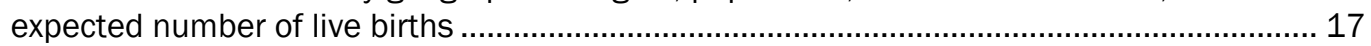

Table 2.2: Participation of key informants in listing meetings--Made-In ................................................. 22

Table 2.3: Key reproductive health indicators for all six districts and Punjab ....................................... 24

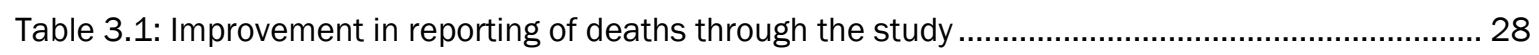

Table 3.2: Age of deceased women by district...................................................................................... 29

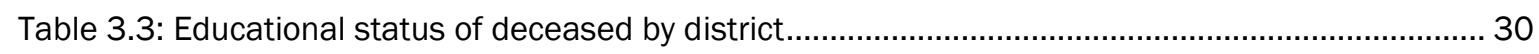

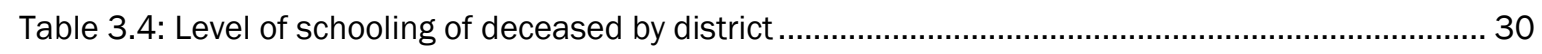

Table 3.5: Level of schooling of the of deceased's husband, \% ............................................................ 31

Table 3.6: Socioeconomic status of households by district, \% ............................................................ 32

Table 3.7: Death rates of women of reproductive age per 100,000 (excluding women aged $<15$ or $>49$ years) ............................................................................................................................. 33

Table 3.8: Adjusted Estimation of PRDs after Capture-Recapture Analysis ............................................ 35

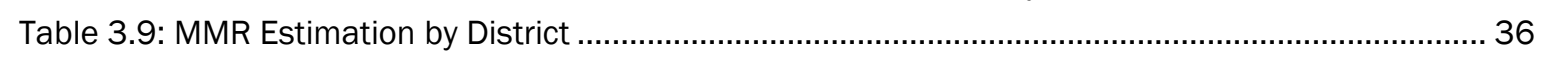

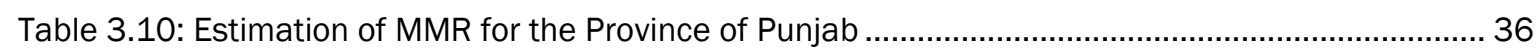

Table 3.11: Age-specific unadjusted MMR by district ....................................................................... 37

Table 3.12: Comparison of direct and indirect causes of maternal deaths by district............................ 38

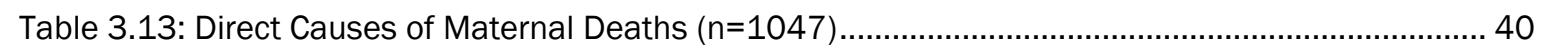

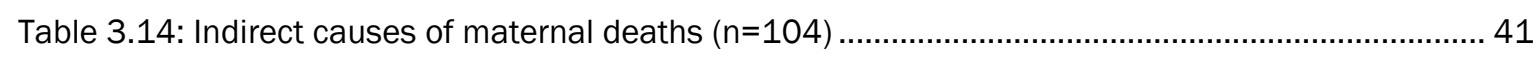

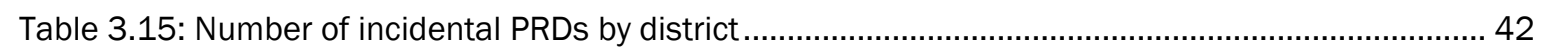

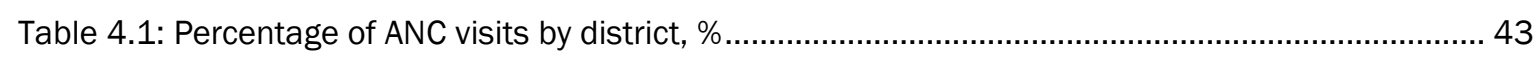

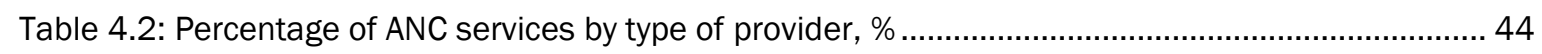

Table 4.3: ANC services obtained by type of health facility, \%……..................................................... 44

Table 4.4: Proportion of Different ANC services availed, \% .................................................................. 45

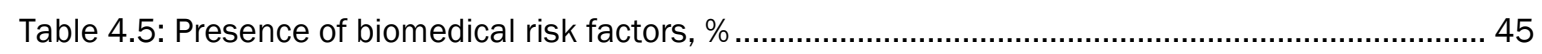

Table 4.6: Reasons identified for referral to hospital during ANC visits, $\%$........................................... 46

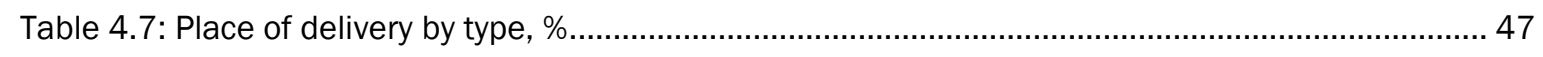

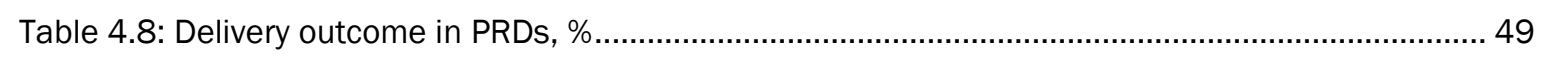

Table 4.9: Problems faced during postpartum period by deceased, $\%$................................................ 50

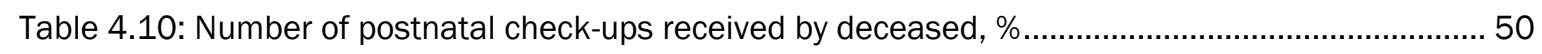

Table 5.1: Time of PRDs by district, \% ……………..................................................................... 54

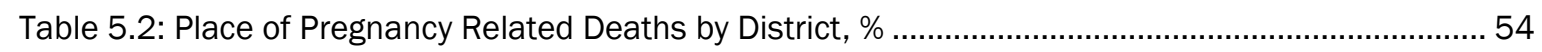

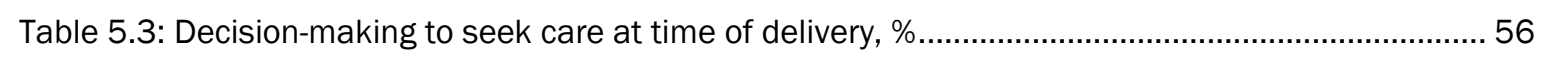

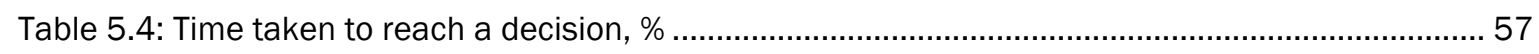

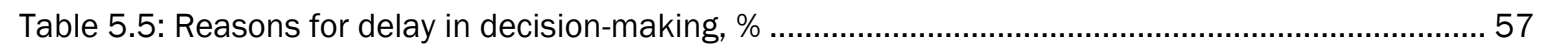

Table 5.6: Proportion of respondents with knowledge of danger signs ............................................... 59

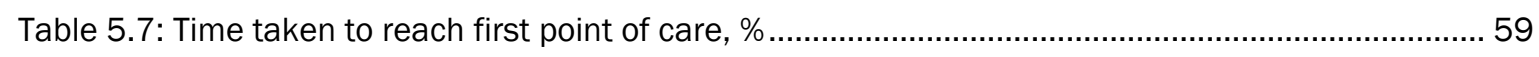

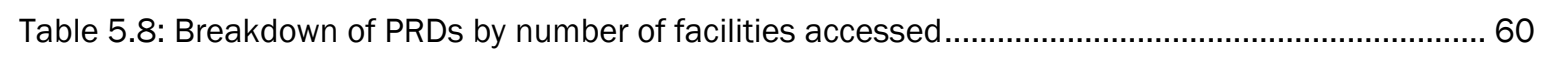

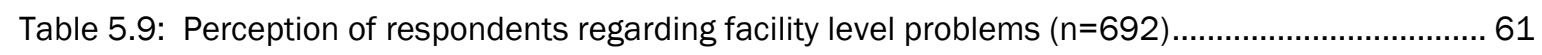




\section{List of Figures}

Figure 2.1: Map of Punjab showing Location of Study Districts..................................................... 18

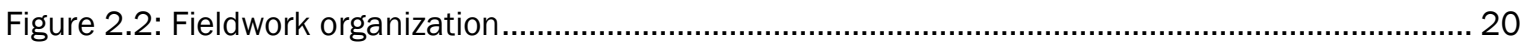

Figure 2.3: Sequence of data collection activities (Oct-Dec 2014) .................................................... 21

Figure 3.1: Number of cases or deaths in women of reproductive age found ....................................... 28

Figure 3.2: Distribution of verbal autopsies by type of respondent, \% .................................................... 29

Figure 3.3: Overall level of schooling of deceased women, $\%$................................................................. 31

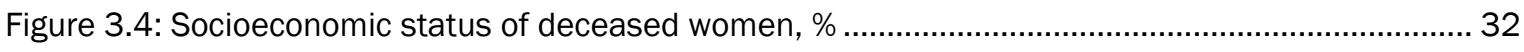

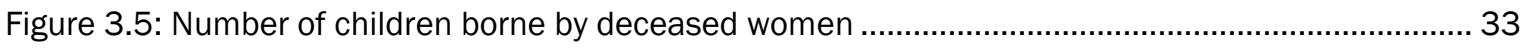

Figure 3.6: Formula to estimate the total numbers of cases through capture and re-capture

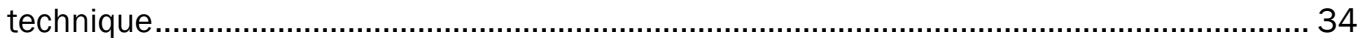

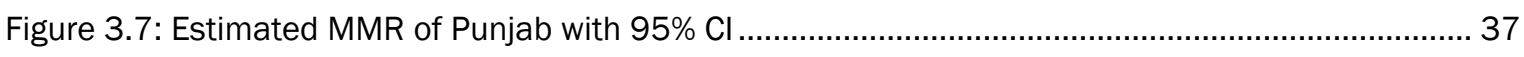

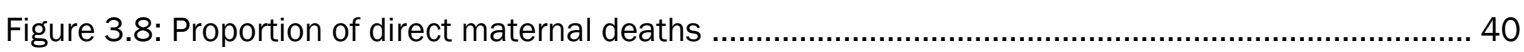

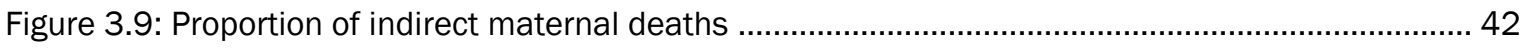

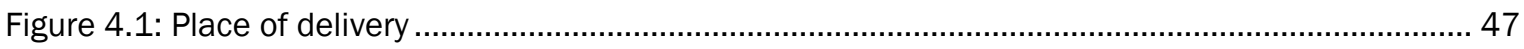

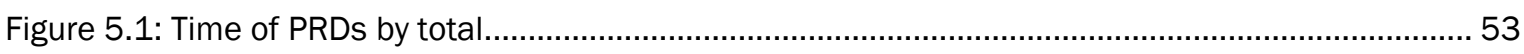

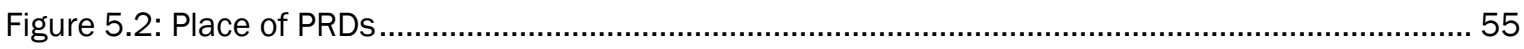

Figure 5.3: Costs of care and treatment prohibit other household payments ........................................ 58

Figure 5.4: Care Seeking Behaviour and Experiences of Deceased Women around Time of Death....... 63

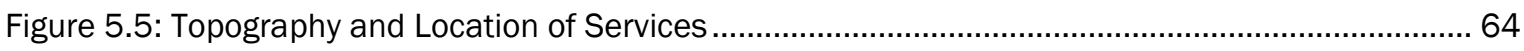

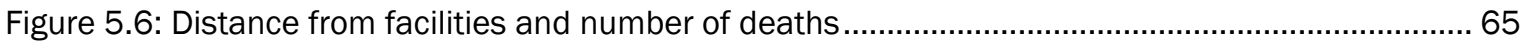

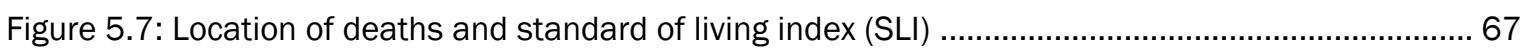




\section{Acknowledgements}

The study on "Using the Community Informant Based (Made-in And Made-for) Methodology for Estimating MMR in Punjab" was funded by the Maternal and Newborn Health Programme - Research and Advocacy Fund (RAF). The aim of this study was to obtain an MMR estimate of Punjab province using a regionally representative sampling approach.

We would like to express our gratitude to Dr. Zeba A. Sathar (T.I.) Country Director at the Population Council Islamabad Office who provided invaluable guidance and support right from the inception of the project to its completion.

We would like to thank the external reviewer for having painstakingly reviewed the report and for providing valuable suggestions. We are truly grateful to Ms Tahira Parveen for her meticulous review and providing appropriate advice in tabular and graphical presentation of numbers.

Apart from the contribution of the authors, several individuals have also played a major role in the conduct of this study and in the preparation of this report. We are very much grateful to the programmatic inputs provided by Dr. Gul Rashida Shaikh, Senior Director, Population Council. Mr Muhammad Ali worked very hard and often late hours to complete the data entry and analysis on time. Mr Maqsood Sadiq, Senior Program Officer, was actively involved in data analysis. Mr Imran Ahmed, Director Finance, Admin and HR and his team expertly handled all logistic and financial matters. Mr. Ali Ammad was responsible for the final formatting of the report. Mr. Waqas Abrar, Project Coordinator, has worked tirelessly in providing the logistics support during field activities, helping with the preparation of the list of references and compiling the report. We are also thankful to Dr Nasira Tasneem, Consultant Gynecologist, Pakistan Institute of Medical Sciences and Dr Sadiqua N. Jafarey, President, NCMNH for their valuable inputs and feedback. We also acknowledge the excellent editorial support extended by Ms Kiren Khan. Thanks are also due to Ms. Tahira Parveen and Mr. Rehan Niazi for their useful comments.

We would like to offer our appreciation and gratitude to the DG Health Punjab and officials of the health and administration departments particularly EDO Health, DOH Health, DCO, District Coordinators MNCH and LHW Program Coordinators and Program Directors of District Health Development Centres (DHDC) of district Chiniot, Jhelum, Bhakkar, Bahawalpur, Layyah and Toba Tek Singh, for their all-out support and help in facilitating the implementation of this study.

We also thank colleagues at the University of Aberdeen, UK, who originally developed the MIMF technique, particularly Dr. Siti Nurul Qomariyah, Dr. Julia Hussein, Ms Jacqueline Bell and Mr. Selvaraj Sivasubramaniam for their assistance with computing the mortality estimates. The team was involved right from the inception of the study. We are also grateful to Dr. Anrudh Jain, Distinguished Scholar, Population Council, for his expert advice and comments.

We would also like to thank the interviewers and team supervisors for their hard work in collecting the data in a timely manner. Finally we owe a debt of gratitude to the community informants and relatives/family members of the deceased women who willingly gave their time to participate and share their insights surrounding the deaths of their near ones. 


\section{Abbreviations and Acronyms}

\begin{tabular}{|c|c|}
\hline ADC & Assistant District Coordinator \\
\hline ANC & Antenatal Care \\
\hline APH & Antepartum Haemorrhage \\
\hline AusAID & Australian Agency for International Development \\
\hline BEmOC & Basic emergency obstetric care \\
\hline $\mathrm{BHU}$ & Basic health unit \\
\hline CEmOC & Comprehensive Emergency Obstetric Care \\
\hline CSPro & Census and Survey Processing System \\
\hline DCO & District Coordination Officer \\
\hline DFID & UK Department for International Development \\
\hline $\mathrm{DHQ}$ & District headquarters hospital \\
\hline DHS & Demographic and Health Survey \\
\hline DOCO & District Officer Community Organization \\
\hline $\mathrm{DOH}$ & District Officer Health \\
\hline EDO $(\mathrm{H})$ & Executive District Officer Health \\
\hline $\mathrm{KP}$ & Khyber Pakhtunkhwa \\
\hline LHV - & Lady Health Visitor \\
\hline LHW & Lady Health Worker \\
\hline LHWP & Lady Health Workers Program \\
\hline MADE-FOR & Maternal death follow-on review \\
\hline MADE-IN & Maternal death from informants \\
\hline MDG & Millennium Development Goal \\
\hline MICS & Multiple Indicator Cluster Survey \\
\hline MIMF & Made-In Made-For \\
\hline MIMS & Maternal and Infant Mortality Survey \\
\hline MMR & Maternal Mortality Rate \\
\hline $\mathrm{MNCH}$ & Maternal, Newborn and Child Health \\
\hline NR & Nikah Registrar \\
\hline PDHS & Pakistan Demographic and Health Survey \\
\hline PMDF & Proportion of Maternal Deaths of Females of Reproductive Age \\
\hline $\mathrm{PPH}$ & Postpartum Haemorrhage \\
\hline
\end{tabular}




\begin{tabular}{ll} 
PRD & Pregnancy-related death \\
PRMR & Pregnancy Related Mortality Ratio \\
RAF & Research and Advocacy Fund \\
RAMOS & Reproductive-age mortality studies \\
RHC & Rural Health Centre \\
RL & Religious Leaders \\
SBA & Skilled Birth Attendant \\
SDG & Sustainable Development Goal \\
SRS & Sample Registration System \\
SVR & Sample Vital Registration \\
TBA & Traditional Birth Attendant \\
TFR & Total Fertility Rate \\
THQ & Tehsil Headquarters Hospital \\
UNFPA & United Nations Population Fund \\
UNICEF & United Nations Children's Fund \\
VA & Verbal Autopsy \\
WHO & World Health Organization \\
WMO & Women Medical Officer \\
WRA & Women of Reproductive Age \\
\hline
\end{tabular}




\section{Executive Summary}

Pakistan is one of the six countries that account for more than $50 \%$ of the world's maternal deaths (Hogan et al., 2010). According to Population Council estimates, each year, nearly 8.6 million women become pregnant in the country. Of these, 15\%, i.e., 1.2 million women are likely to face obstetric complications. Each year, there are nearly 14,000 pregnancy-related deaths (PRDs)-one maternal death occurs every 40 minutes. Although maternal mortality has fallen from 533 per 100,000 live births in 1990-91 (NIPS) to 276 in 2006-07 (PDHS 2006-07), Pakistan has not been able to achieve its Millennium Development Goal (MDG) target of reducing maternal mortality to 140 per 100,000 live births by 2015 .

Planners in Pakistan require a method that can provide reliable sub-national estimates easily, costeffectively and with greater regularity. In this regard, the Research and Advocacy Fund (RAF) offered support to the Government of Pakistan to assess the feasibility of testing a new community informantbased approach, "Made-In Made-For" (MIMF), for estimating the MMR at the community level. A pilot study was conducted by the Population Council to test the approach in Chakwal, a district of Punjab, with promising results. Subsequently, in view of the diversity within Pakistan, particularly across the four major provinces, and to gauge the potential and modalities of the approach at a broader level, senior national and provincial government officials indicated their interest in seeing the approach scaled up in at least one province, i.e., Punjab, to provide reliable provincial level estimates.

The primary objectives of the study were:

- To apply the community informants networks technique (Made-In Made-For) to obtain a provincially representative current estimate of MMR for Punjab and to identify the causes of deaths.

- To build capacity within Punjab to obtain district and provincial maternal mortality estimates routinely, on a sustainable basis.

Secondary Objectives of the study were

- To identify the networks available within rural and urban communities of Punjab that can act as key informants for routine information on maternal deaths;

- To determine differential characteristics of maternal deaths by economic, urban and rural, and geographical distribution so as to gain a better understanding of the predisposing factors contributing to women's death during pregnancy, delivery and the postpartum period;

- To assess the mechanism that can be employed at the community level to determine the cause of deaths.

For calculating the MMR estimate for Punjab, the province was stratified into three geographical regions: North (consisting of 14 adjacent districts), Centre (comprising of 11 districts), and South (consisting of 11 geographically adjacent districts). A two-step approach was then adopted to derive a sample of districts for each region. For this, districts in each region were listed in descending order from most to least urbanized, based on urban-rural population proportions reported in Punjab Development Statistics 2013 (Bureau of Statistics, 2013). The selected districts included Jhelum (more urbanized) and Bhakkar (less urbanized) in the North; Chiniot (more urbanized) and Toba Tek (TT) Singh (less urbanized) in the Centre; and Bahawalpur (more urbanized) and Layyah (less urbanized) in the South. 
The total population of the six study districts is about 11 million, i.e., 11 percent of the total population of Punjab (Bureau of Statistics, 2013). In all, there were 373 union councils in the study area.

The Made-In Made-For technique applies two steps. In the first step (Made-In), village-level informants identify deaths of women of reproductive age (WRA) (aged 15-49 years) in their communities. The second step (Made-For) consists of follow-up interviews conducted with family members of deceased women to confirm if deaths are maternal or non-maternal and to explore cause of death. Data about WRA deaths was collected in all six districts and sought to present a full census of deaths among women of reproductive age for a two year period i.e. January 2012 to December 2013.

Based on discussion with the districts' officials, the study team opted to use the following networks: LHWs; religious leaders, including village mosque imams; male and female lady councillors; Nikah registrars-the functionaries who perform and solemnize marriages; and community midwives, who have recently been trained and deployed by the $\mathrm{MNCH}$ Program. The District Coordination Officer (DCO) and Tehsil Municipal Officers (TMOs) in all districts helped in identifying and developing lists of the networks.

Six five-member teams were constituted for each of the districts. Field activities were supervised by field coordinators, the study manager and the principal investigator.

A Rapid Facility Assessment was carried out by a medical doctor and two trained social scientists in each study district. The objective was to examine the capacity of facilities to provide emergency obstetric care in terms of staff availability, and availability of essential supplies and equipment.

All maternal deaths identified were mapped on GIS maps by plotting the coordinates of the deceased women's homes. This not only served to authenticate deaths but also to develop a better understanding of the context of these deaths.

A qualitative component was added to the study by using in-depth interviews with relatives of deceased women to obtain information on care seeking behaviour during the pregnancy, delivery and the postpartum period, to examine socio-cultural practices, barriers and obstacles in assessing care, and perceptions regarding care offered in the health facilities.

To calculate the number of live births, an estimate of the female population aged 15 to 49 and the agespecific fertility rate was taken from Social and Demographic Indicators for Punjab that are published annually in the Punjab Development Statistics, district-level pattern presented in Pakistan Social and Living Standards Measurement Survey (PSLMS) 2012-13 and the Age-Specific Fertility Rates from the Punjab Multiple Cluster Indicator Survey (MICS) 2011.

Collectively, in the six sampled districts, 12,334 WRA deaths were identified to have taken place during the period 2012-13. Of these, 1,735 were identified as PRDs based on the listing data. Post-autopsy, it was found that, in 381 cases, the deaths had not taken place in the last two years and these were therefore excluded. In addition, 22 respondents refused to participate; in 107 cases, the address was not found; and in 51, cases the names had been duplicated. After the exclusion of these cases, 1,182 PRDs remained for the final analysis. The capture recapture technique was applied to adjust the number of pregnancy related deaths that may have been missed by the networks.

\section{Key Findings:}


- The unadjusted composite MMR for the province of Punjab, before applying the CRC technique, is 204 per 100,000 live births $(95 \% \mathrm{Cl})$.

- The adjusted composite MMR for the province of Punjab, after applying the capturerecapture technique, is 302 per 100,000 live births (95\% Cl 258-346).

- $\quad$ By district, the lowest adjusted MMR is estimated for Jhelum at 215 (95\% Cl 180-250) and the highest adjusted MMR is for Bhakkar at 365 (95\% Cl 320-415).

- $\quad$ Direct causes accounted for 89 percent of the PRDs, 9 percent were due to indirect causes and 3 percent deaths associated with incidental causes.

- Disaggregation of Direct Causes: About 43 percent of women died due to postpartum haemorrhage (PPH) while in 5 percent of the cases, death occurred due to antepartum haemorrhage. Slightly more than a quarter of the deaths had occurred due to pregnancyinduced hypertension (eclampsia), while in a tenth of cases, death had been caused by puerperal sepsis.

- Disaggregation of Indirect Causes: Nearly a third of deaths occurred due to anaemia of pregnancy followed by 14 percent due to renal failure, and 13 percent due to respiratory complications

- About 62 percent of pregnancies ended with a live birth while stillbirths occurred in nearly 24 percent of the cases. Nearly 3 percent of the pregnancy outcomes were miscarriages and 2 percent were induced abortions.

- Nearly, three quarters of the infants born alive had survived till the time of interviews. The highest proportion of surviving infants was in TT Singh, 79 percent; followed by Bhakkar, 76 percent; Bahawalpur, 75 percent; Layyah, 72 percent; Jhelum, 71 percent; and Chiniot, 69 percent.

- Breakdown of PRDs by Time: Nearly a third of all PRDs occurred before childbirth (antepartum period); nearly 6 percent during the delivery (intra-partum period); and nearly a third in the first 24 hours after delivery (immediately postpartum).

- Breakdown of PRDs by Place: Of the total 1,182 pregnancy related deaths in all 6 districts, slightly more than a quarter of women (26 percent) died at home. Among these 306 women, 37 percent died without receiving any medical attention, while 21 percent had been assisted by a TBA, community midwife (CMW), LHW or hakeem (traditional medicine practitioner), and in 4 percent cases, an LHV nurse had been present. Among the rest (844 women), i.e. 71 percent died at a facility. Among overall deaths, a third of deaths took place at a public sector facility, a quarter at private facilities, and 26 percent at home. By type of facility, the majority of deaths took place at a private clinic, 25 percent, closely followed by public sector tertiary care hospitals (29 percent). Among women who did reach health facilities, two-fifths of deaths took place at the first contact facility, 27 percent died upon reaching a second contact facility, and an additional 11 percent had been moved from the second contact facility to the tertiary care facility when they died.

- In majority of the cases, it was woman's husband (83 percent) who decided whether she should seek care at a health facility. 
- In 92 percent cases, the decision to seek care at a health facility was taken in less than an hour, which is quite swift.

- Nearly half the women, who had died at a facility, had reached the first contact facility within half an hour of leaving their homes. However, for a fifth of women, it took about an hour to reach a facility.

- Staff Availability: Except for Layyah, all sanctioned positions for gynaecologists had not been filled in any district. In Jhelum, nearly half the sanctioned positions for gynaecologists were vacant. In Bahawalpur, only 5 out of 13 sanctioned posts of women medical officers had been filled. In Bhakkar, against 15 sanctioned posts, only 5 women medical officers were working, while in Chiniot, only 4 out of 18 posts for WMOs had been filled. In Bahawalpur, only 2 anaesthetists had been appointed against 16 sanctioned posts, while in Jhelum 4 had been appointed against 9 positions. In the other districts, half of the posts had been filled.

- Equipment and Supplies: Injectable anti-convulsants and antibiotics were not available in 13 out of the 24 facilities visited. Injectable calcium for the management of eclampsia was available in 4 out of 6 facilities in Bahawalpur, 2 out of 4 facilities in Bhakkar, and 1 out of 3 facilities in T.T. Singh. Blood transfusion services were available in only half of the THQ hospitals in Bhakkar, while all THQs in the other five districts had transfusion facilities. Dilation and curettage $(D \& C)$ was available at all facilities except half of the facilities in T.T. Singh.

- GIS Maps showed that comprehensive emergency obstetric care are few and far between in many areas of both Jhelum and Bahawalpur, implying that women have to travel long distances to reach a facility. In both districts, the proportion of deaths in a facility's catchment increased with distance from the facility. In Jhelum, the number of deaths occurring in the zone 5-15 kilometres $(\mathrm{km})$ away from the facility was almost twice as high as the number occurring within a radius of $5 \mathrm{~km}$. In Bahawalpur, the difference between the 0-5 km range and the 5-15 km range was relatively less pronounced; however, the number of deaths in the $15-25 \mathrm{~km}$ range was significantly higher than the number in the $5-15 \mathrm{~km}$ range.

- GIS Maps illustrated that on an average, low socio-economic status had to travel on an average nearly $20 \mathrm{kms}$ to reach an appropriate facility. The mapping exercise also revealed that health facilities are more concentrated in urban centres, large densely populated rural communities remain devoid of services.

The main strength of this study was the participation of entire district administration and health officials who have now become more cognisant of the maternal health problems that rural women face. They are now considering measures to avert such deaths. The district officers for community development, additional district officers (coordination), secretaries of the union councils, and their naib qasids have become fully familiar with the process of collecting data and could continue to use it in the future.

In the long run, these networks could be used to report additional events, e.g., case detection and the incidence of communicable diseases and this was established as another major strength of the study.

The MMR estimate for Punjab of 302 (95\% Cl 290-320) may be tilted towards the higher side because of adjustments that need to be introduced for areas that are geographically large and have small widely dispersed populations; however, even the unadjusted MMR, which is based on 1,182 physically verified deaths that have been plotted on GIS maps, is quite high. 
In our study, we found that almost two-third of the women had at least one biomedical risk factor, the most important being high parity.

The study highlights the conspicuously more acute suffering of poor rural women, reaffirming that economic barriers persist and affect poor women's ability to access appropriate care. The majority of PRDs occurred among women of lower socioeconomic status, and respondents admitted that the cost of treatment for the deceased had been prohibitive and beyond their means.

We found that a large proportion of women, realizing the importance of antenatal care, were more frequently getting antenatal check-ups. Husbands were seen to be more supportive and were the main decision-makers in deciding as to when and where to seek care.

The ability of this study to identify cause of death through verbal autopsies and their subsequent disaggregation into direct and indirect causes is important from a policy and programmatic perspective.

Moreover, the study demonstrates the utility of GIS maps, which can help in identifying the catchment population of facilities, and in establishing a referral system in which a cluster of facilities refers to the same higher level facility based on spatial considerations.

\section{Conclusions and Recommendations:}

This study has identified specific areas that need strong policy and programmatic interventions to improve maternal health outcomes. It confirms that maternal mortality persistently remains a major public health issue in Pakistan and this problem may be much larger than we assumed.

- The study has successfully identified different networks that can be used at the community level to capture data on deaths in Pakistan. For instance, we have established that the LHW network is a reliable source of mortality information. However, LHWs' ability to capture women's deaths could be improved through proper training and by expanding the age band for capturing women's deaths from 15-45 years to 12-50 years. The information obtained by the LHWs can be further supplemented by the various community networks, especially in areas that are not covered by them. In the long run, these networks could be used to report additional events, e.g., case detection and the incidence of communicable diseases and this was established as another major strength of the study. They could also play a role in controlling epidemics (by identifying the source of outbreaks). Information collected at the union council level could be collated at the district level and communicated to all relevant departments as well as the provincial headquarters.

- The two major causes of deaths identified among PRDs were obstetric haemorrhage and pregnancy-induced hypertension. These conditions should be kept in mind when designing any future interventions as there are now simple strategies available to prevent the occurrence of both these conditions.

- Our findings show that women's lives cannot be saved until or unless SBAs are integrated with a good referral system that is able to transport women in acute emergencies to facilities that can provide comprehensive obstetric care.

- The study also raises important issues related to the quality of emergency obstetric care available at the facility level and the lack of a functional referral system in all districts. Sadly, we 
found that a large proportion of deaths in all 6 districts had occurred during transportation from one facility to other.

- Another aspect highlighted by the study is the lack of advanced resuscitation facilities available at public sector tertiary care facilities to deal with severe complications. This is an aspect that needs the government's urgent attention.

- While no single approach can adequately meet all the requirements for estimating maternal mortality efficiently and with reliable precision, complementary measurement options and opportunities, such as the household census and periodic demographic and health surveys, must also be considered in order to validate results.

- Finally, we would like to stress that this study has very clearly highlighted the plight of women who, despite poverty, a stringent caste system, and restrictive socio-cultural norms still managed to reach a health facility but died because of a poorly functioning health system. If progress is to be made and health outcomes for women improved, the health system needs to be revamped. 



\section{Introduction}

Pakistan is one of the six countries that account for more than $50 \%$ of the world's maternal deaths (Hogan et al., 2010). According to Population Council estimates, each year, nearly 8.6 million women become pregnant in the country. Of these, 15\%, i.e., 1.2 million women are likely to face obstetric complications. Each year, there are nearly 14,000 pregnancy-related deaths (PRDs)-one maternal death occurs every 40 minutes. Although maternal mortality has fallen from 533 per 100,000 live births in 1990-91 (NIPS) to 276 in 2006-07 (PDHS 2006-07), Pakistan has not been able to achieve its Millennium Development Goal (MDG) target of reducing maternal mortality to 140 per 100,000 live births by 2015 .

The last maternal mortality rate (MMR) estimate to be based on a national survey was determined in 2006-07 by the Pakistan Demographic and Health Survey (PDHS); since then, there has been no survey-based update. The only estimates available are based on projections with very wide levels of uncertainty. For instance, the Global Burden of Diseases (GBD) estimates the MMR for Pakistan at 401 per 100,000 live births with uncertainty between 233 and 560 .

The Government of Pakistan has, in recent years, initiated a number of major projects to improve maternal health outcomes in the country. Several important initiatives have also been launched to address the lack of maternal healthcare. However, updated maternal mortality estimates, especially at the provincial and district levels, are required to monitor and evaluate existing maternal, neonatal and child health (MNCH) programs; to introduce greater accountability; and to plan new initiatives. Apart from updating numbers, it is also important from a programmatic perspective that the underlying causes of maternal mortality be well understood. This information can also help in advocacy efforts to increase awareness about maternal health issues among the public, and increase the focus of policymakers on this neglected area, thereby maintaining pressure towards achieving the new Sustainability Development Goals (SDGs) beyond 2015.

Unfortunately, in the absence of a fully developed vital registration system in Pakistan, the costs of conventional means of maternal mortality estimation are prohibitive. In recent years, the need for more precise sub-national estimates has increased.

Post-devolution, after the $18^{\text {th }}$ Constitutional Amendment, the provincial health departments are responsible for identifying priorities and developing provincial policies. Districts have also been empowered to develop their own health plans and seek the required allocation of resources from the district administration. The availability of reliable MMR estimates at both provincial and district level is essential for planning, monitoring, and evaluating maternal healthcare interventions.

Planners in Pakistan require a method that can provide reliable sub-national estimates easily, costeffectively and with more regularity. In this regard, the Research and Advocacy Fund (RAF) offered support to the Government of Pakistan to assess the feasibility of testing a new community informantbased approach, "Made-In Made-For" (MIMF), for estimating the MMR at the community level. A pilot study was conducted by the Population Council to test the approach in Chakwal, a district of Punjab, with promising results. Subsequently, in view of the diversity within Pakistan, particularly across the four major provinces, and to gauge the potential and modalities of the approach at a broader level, senior national and provincial government officials indicated their interest in seeing the approach scaled up in 
at least one province, i.e., Punjab, to provide reliable provincial level estimates. ${ }^{1}$ This report documents the RAF-supported study conducted by the Population Council to apply the MIMF approach to assess maternal mortality in Punjab.

\subsection{Maternal Health In Punjab}

Among provinces, Punjab houses the largest proportion of Pakistan's population: 53 percent.

Maternal mortality is a leading cause of death among women of reproductive age in the province: PDHS 2006-07 found about $16 \%$ of deaths in this category to be pregnancy-related.

Since 1991, some maternal health indicators have improved. More than half the women in Punjab received antenatal care (ANC) in 2012-a rise of 56 percentage-points since 1991. Overall, the proportion of women assisted by a skilled birth attendant (SBA) during childbirth has also risen threefold, from $16 \%$ in 1991 to $53 \%$ in 2012, although wide disparities exist between urban areas (69\%) and rural areas (46\%) of the province (PDHS 2012-13).

Despite the recent improvement in reproductive health indicators, however, approximately 6,000 women die each year in Punjab due to pregnancy-related factors. Risk of maternal death is higher in pregnancies that occur too early, too late, or too frequently. (Population Council - Briefing Paper Punjab 2014)

The Provincial Health and Nutrition Programme (PHNP) was established in March 2013 to support delivery of an 'Essential Health Services Package' (EHSP) by the Governments of Punjab and Khyber Pakhtunkhwa (KP) through earmarked non-budget support financial aid ( $£ 130$ million). The programme aims to improve health outcomes in reproductive, maternal, newborn and child health (RMNCH) as well as nutrition. In Punjab, DFID, in partnership with the World Bank, is supporting the health sector with a four-year, results based investment. In KP, DFID is working in partnership with the Australian Government's Department for Foreign Affairs and Trade (DFAT) on nutrition, which disburses funds through the World Bank's multi-donor trust fund (MDTF).

In 2005, the Government of Pakistan also launched a countrywide comprehensive maternal, newborn, and child health $(\mathrm{MNCH})$ program that aimed at improving access to skilled birth attendance by employing a new cadre of community midwives (CMWs)-rural women who belong to the same community as their clients. They were given 18 months of training in antenatal, intrapartum, postpartum, and newborn care. The program aimed to train and deploy around 12,000 CMWs nationwide to increase the coverage of $\mathrm{MNCH}$ services by skilled providers. However, to date only 6,000 midwives have been deployed.

\subsection{Approaches to Measuring Maternal Mortality}

Although the Maternal Mortality Ration (MMR) is accepted as an important development indicator at the international and national levels, the range of simple, reliable, and feasible methods for measuring maternal mortality is still limited, especially in developing countries. Maternal mortality is difficult to measure for a number of reasons. First, maternal death is a rare event and difficult to capture; large samples are needed for it to be reliable. For the same reason, it is also expensive to gauge. Second, at

\footnotetext{
${ }^{1}$ Such a study was recommended to RAF, in particular, by the Chief Health, Planning Commission of Pakistan; the DG Health, Ministry of National Health Services, Regulations and Coordination; the Provincial Coordinator, $\mathrm{MNCH}$ Program Punjab; and the President, National Committee on Maternal and Neonatal Health.
} 
present there is no standard method that can be universally applied for measuring mortality. According to WHO, three elements need to be identified: (1) all deaths of women of reproductive age (WRA); (2) their pregnancy-related status; and (3) the cause of death. Without complete vital registration systems and certification of the cause of death, all three components are difficult to measure accurately (WHO, 2004; Hill et al., 2006).

This section presents a brief overview of the different approaches used to measure MMR, including their strengths and disadvantages. As the next section will show, some of these approaches have been tried in Pakistan.

\subsubsection{Vital Registration}

A vital registration system can most accurately estimate maternal mortality if the system includes questions on pregnancy-related status and cause of death. In developed countries, information on maternal mortality derives from the vital registration of deaths by cause. However, even where coverage is complete and all deaths medically certified, maternal deaths are frequently missed or misclassified in the absence of active case funding (Hill et al. 2001).

In middle- or low-income countries, female deaths from all causes are frequently under-recorded (Hill et al. 2001). In many countries, periodic confidential enquiries or surveillance are used to assess the extent of misclassification and underreporting. Few developing countries have a vital registration system that ensures sufficient coverage and quality to enable it to serve as the basis for assessing levels and trends in cause-specific mortality, including maternal mortality (AbouZahr and Wardlaw, 2003).

\subsubsection{Sample Vital Registration}

Sample vital registration (SVR) is a variant of the complete vital registration system, and is defined as "Iongitudinal registration of demographic events, including cause of death by verbal autopsy, in a nationally representative sample of clusters" (Setel et al., 2007).

The system's objective is to provide reliable estimates of birth and death rates and other measures of fertility and mortality, including total fertility, infant mortality at the national and provincial levels, and separately by urban and rural place of residence. The Sample Registration System (SRS) being applied in India is one of the world's largest continuous demographic household sample enquiries.

The Indian SRS is a dual-record system that employs (1) a resident part-time enumerator who continuously records births and deaths in each household within the sample unit every month, and (2) a full-time supervisor who, thereafter, independently records vital events and other related details for each of the preceding two six-month periods during the calendar year. The two sets of figures are then matched. Partially matched and unmatched events are verified in the field to remove any duplication of events (Registrar General India, 2006).

In 2005, the SRS covered 1.3 million households and 6.8 million people. However, some authors have questioned the reliability of its estimates, suggesting that it covers only half a million of an estimated annual 9.5 million deaths (Bhutta, 2006). Other published sources question the representativeness of the SRS, claiming it overlooks urban and peri-urban slums, where healthcare and health outcome indicators are often worse than for rural populations (Sclar et al., 2005). 


\subsubsection{Census Studies}

A national census that covers the entire population can produce PRD estimates with the addition of a limited number of questions. This approach eliminates sampling errors (because the entire population is covered), allowing a more detailed breakdown of results, including time trends, geographic subdivisions, and social strata. In addition, it enables the identification of household deaths over a relatively short reference period (1-2 years), thereby providing recent maternal mortality estimates (Hill et al., 2007).

The approach has two disadvantages, however: it is conducted at 10-year intervals, which limits the monitoring of maternal mortality (Hill et al., 2001).

\subsubsection{Reproductive-Age Mortality Studies}

Reproductive-age mortality studies (RAMOS) involve systematic efforts to combine data on maternal deaths from multiple sources. The starting point is usually to list all WRA deaths, which are then investigated through verbal autopsies (VAs) and medical records (when available) to identify maternal deaths (WHO, 1987). The sources of information on WRA deaths vary. Where feasible, the initial list is drawn from civil or sample registration records, but when the registration of deaths is incomplete, other methods have to be used. These include reviewing hospital records, discussions with traditional birth attendants (TBAs), examining funeral records, interviewing religious and community leaders, and even visiting schools (Smith and Burnham, 2005).

Such mortality studies are necessarily complex, and in developing countries, are mostly carried out in small areas (often at the district level). If properly conducted, RAMOS can generate reliable estimates of maternal mortality. However, they are complicated, time-consuming, and expensive, particularly when carried out on a large scale (Atrash et al., 1995, Hill et al., 2006). Additionally, RAMOS do not generate complete data on live births (AbouZahr, 1998)-which is needed to calculate the MMR-especially in settings where most women deliver at home. This is a major weakness. Therefore, the proportion of maternal deaths of females of reproductive age (PMDF) from such studies is often applied to an independent external source of data on live births (e.g., by calculating expected births using birth data extrapolated from the most recent census).

\subsubsection{Household Surveys}

Population-based household surveys are widely used to generate data on maternal mortality in many developing countries. In addition to providing data on child and maternal mortality, these surveys produce information on fertility, contraception, maternal health, nutrition, use of services, and knowledge and practices related to maternity care.

Maternal deaths are identified using either direct or indirect methods. The direct method involves asking respondents about recent deaths in the household and, when any WRA deaths are identified, asking additional questions about the timing of the death in relation to pregnancy (Graham et al., 2008). These methods can generate estimates with a reference period of about 2-3 years before the survey, which is acceptable for monitoring purposes (Graham et al., 2008). However, large samples are needed to produce reliable estimates and the MMR estimates obtained have very wide confidence intervals, which makes it difficult to monitor changes over time (WHO, 2004). Both methods are described below. 


\subsubsection{Sisterhood Method}

The sisterhood method is an indirect technique for deriving population-based estimates of maternal mortality, and is often recommended by WHO and UNICEF, especially for countries with inadequate registration systems and low-income resources. The method was developed for the relative ease of data collection and the smaller sample it entails (Stanton et al., 1997, Hill et al., 2006). It has been widely adopted and has become an important tool in developing countries.

In the sisterhood method, a representative sample of respondents is interviewed about the survival of their adult sisters in order to determine: the number of ever-married sisters; how many are alive; how many are dead; and how many died during pregnancy, delivery, or within six weeks of pregnancy. The method has two variants. However, this method is not appropriate in settings where fertility levels are low, i.e., the total fertility rate (TFR) is less than $4(<4)$, or where substantial migration or other social dislocation has occurred.

On the other hand, the direct sibling history-based variant, used in large-scale demographic and health surveys (DHS), collects more information than the indirect method by identifying all female deaths in the household for a particular reference period. It provides estimates of male and female mortality (from all causes) among 15- to 50-year-olds, and can estimate pregnancy-related mortality, including fertility, age of all siblings, age at death, and year of death. The limitation of this technique is that it requires a larger sample (WHO, 1997).

The sisterhood method is relatively cost-effective because it needs smaller samples than surveys that use direct methods. However, the wide confidence intervals that arise make trend analysis difficult. The sibling survival method produces retrospective rather than current estimates of maternal mortalityaround 5-7 years pre-survey with the direct sisterhood method, and 10-12 years pre-survey with the indirect method. The sibling survival method may also underestimate overall mortality because of inherent biases in the survey data, e.g., survival and recall bias (Obermeyer et al., 2010).

\subsubsection{Key Informant Surveillance Systems}

Barnett et al. (2008) have piloted a prospective key informant-based system for identifying births and deaths that was designed to be cheaper and simpler than conventional surveillance systems. The system aimed to measure crude birth rates and maternal mortality in a remote, predominantly indigenous population in eastern India. It also aimed to identify pregnancy-related and late maternal deaths to ascertain the breakdown of maternal deaths by cause, and determine the timing and place of death.

Most key informants were TBAs, each covering approximately 250 households, who were paid a specific amount as incentive for every accurate birth or death identified. The interviewers would visit the relevant households to verify these births and deaths before paying the identifier. This low-cost surveillance system produced high but plausible birth and death rates for the population concerned. However, the authors caution that the system could not capture a sufficient number of births to yield precise maternal mortality estimates.

Another study conducted in a rural service unit in Vellore, India, showed that regular death surveillance systems could be augmented by a community-based death surveillance system. The community system, relying on information obtained from community leaders, identified twice as many maternal deaths than previously recorded, and could be applied in other settings (Kim et al., 2004). 
In Tanzania, the Ministry of Health established a national sentinel system based on demographic surveillance to monitor cause-specific mortality in several districts (Mswia et al., 2003). The mortality surveillance used an active reporting system based on a network of respected individuals within each community. The cause of death was determined through a VA interview with family members of the deceased.

In order to investigate the level and causes of maternal deaths in Andhra Pradesh, India, maternal health enquiries were made at the grassroots level (Bhatia 1988). Informants included opinion leaders, schoolteachers, revenue officials, TBAs, and village children. The system also examined records of health facilities and compared the cases recorded by informants with those recorded in official documents. It was found that informants had been able to record a higher number of deaths than the hospital records.

In Honduras, a population-based health information system was designed and implemented by the Catholic Relief Service to estimate the magnitude of maternal and early neonatal health problems; document its distribution and spread at a population level; and evaluate the impact on maternal and neonatal mortality of an intervention using TBAs. The starting point of the system were TBAs, who identified pregnant women and reported this information to a health educator every month. The information was subsequently communicated to a field supervisor. The study showed that maternal information used to prioritize, plan, implement, and sustain effective intervention strategies could be produced and sustained by community structures at a low cost. The information produced also complied with WHO standards (Rosales et al. 2004).

\subsubsection{Health Facility Reporting}

In most developing countries, only a limited proportion of births takes place in healthcare facilities. Unless nearly all women deliver in healthcare institutions, facility-based data (or data derived from systems for the management of routine health information) are rarely sufficient for obtaining populationbased estimates of maternal mortality. Additional limitations include the poor quality and unavailability of medical records, and poor death certification by physicians and private sector facilities responsible for maintaining records. Facility-based data may also overlook maternal deaths occurring in nonobstetric wards. However, health service data may provide useful information on trends over time and, in particular, on geographic regions, the relative importance of various diseases, and causes of death (Graham et al., 2008).

\subsubsection{Community-Based Informants to Capture Maternal Deaths}

A number of studies report using community-based informants to capture maternal deaths. These informants either provide information on deaths or are responsible for the recording or reporting process. Most such studies have been conducted in Asia and Africa, with just two in Latin America. A study by Maskey et al. (2011) uses a community-based method (i.e., the "motherhood method") to measure maternal and child mortality in a developing country setting. The method was field-tested at the district and sub-regional levels in Bara District, Nepal. Information on births, deaths, and risk factors was collected within a defined geographic area, but without visiting every household. The main informants were groups of women who shared social bonds formed by motherhood. The groups included all women who had given birth, including those whose babies had died during the survey period. 


\subsubsection{Sampling at Service Sites}

This method is based on interviews with women that are held at busy centers of activity, such as markets or health facilities. Respondents are asked about any maternal deaths among their sisters. Allowing the respondent to come to the interviewer rather than sending the interviewer to the respondent (as in traditional household surveys) reduces both the cost and time required to collect data. Maternal mortality estimates obtained using this approach in Ghana were consistent with those from the 1999/2000 Ghana World Health Survey (Immpact, 2007) but the potential biases of this method have not been quantified for other contexts.

\subsubsection{Community-Based Informants Network Technique (Made-In Made-For)}

The maternal death from informants (MADE-IN/MADE-FOR) approach was developed by the Initiative for Maternal Mortality Programme Assessment (Immpact project) at the University of Aberdeen. It enables the measurement of maternal mortality down to the community level, together with an analysis of the causes of maternal deaths. It is also less costly than household surveys, especially in lower-fertility, lower-mortality contexts. The approach goes beyond simply counting deaths; it also develops an understanding of why they happened and how they could have been averted. It can also be used for collecting data prospectively. The MADE-IN/MADE-FOR technique has, so far, been successfully applied by Impact in two districts of Indonesia (Qomariyah et al., 2010), Somaliland, and as a pilot in Chakwal district of Pakistan. Unlike some alternative methods, such as the sisterhood method, MADE-IN/MADEFOR allows surveys to record all maternal deaths in a defined area, enabling more precise estimates of maternal mortality in relatively small populations. It also raises community awareness of maternal health issues and acts as an advocacy tool. Its limitations include the possible underreporting of sensitive deaths, such as those related to abortion, and overlooking of early-pregnancy deaths. The approach relies on the availability of existing networks of persons who can report on Pregnancy Related Deaths (PRDs) within a community.

Some of the methods previously used to measure maternal mortality, along with their merits and demerits and feasibility of application in Pakistan, are summarized in Table 1.1. 
Table 1.1: Various options for measuring maternal mortality in Pakistan

\begin{tabular}{|c|c|c|c|}
\hline Methods & Measures & Precision & Option for Pakistan \\
\hline $\begin{array}{l}\text { Civil registration } \\
\text { with medical } \\
\text { certification of } \\
\text { cause of death }\end{array}$ & Maternal mortality & $\begin{array}{l}\text { - Entails total count } \\
\text { - Misclassification of deaths is possible } \\
\text { - } 50 \% \text { underreporting possible } \\
\text { - Provides estimate of specified year }\end{array}$ & $\begin{array}{l}\text { - Information could be collected at the union } \\
\text { council level (TMO-DCO) } \\
\text { - The National Database and Registration } \\
\text { Authority (NADRA) can collect this data (if } \\
\text { recording of births and deaths is made } \\
\text { mandatory) }\end{array}$ \\
\hline SVR with VA & Maternal mortality & $\begin{array}{l}\text { - Entails representative count based on random selection of district } \\
\text { - Deaths may be misclassified } \\
\text { - Has been tried in India and China } \\
\text { - Specified year }\end{array}$ & $\begin{array}{l}\text { - Feasible for Pakistan if registration system is } \\
\text { improved and VA included }\end{array}$ \\
\hline $\begin{array}{l}\text { Household survey } \\
\text { with indirect } \\
\text { sisterhood method }\end{array}$ & $\begin{array}{l}\text { Pregnancy-related } \\
\text { mortality }\end{array}$ & $\begin{array}{l}\text { - Large sampling error depending upon sample size (20-30\%) } \\
\text { - Potential misreporting of sensitive deaths among unmarried women or } \\
\text { abortion-related deaths } \\
\text { - Non-sampling error underestimation possible } \\
\text { - Difficult to apply in low-literacy settings } \\
\text { - Definition of "sister" not clear; cultural issues may lead to underreporting } \\
\text { - Cause-of-death misreporting possible } \\
\text { - Difficult to measure in low-fertility areas }\end{array}$ & $\begin{array}{l}\text { - Has been tried out in Pakistan as part of } \\
\text { PRHFPS 2000/01 (period 1990-99) }\end{array}$ \\
\hline $\begin{array}{l}\text { Household survey } \\
\text { with direct } \\
\text { estimation (sibling } \\
\text { method) }\end{array}$ & $\begin{array}{l}\text { Pregnancy-related } \\
\text { mortality } \\
\text { Can be used to } \\
\text { calculate maternal } \\
\text { mortality if combined } \\
\text { with VA }\end{array}$ & $\begin{array}{l}\text { - Depends on large sample which generally leads to wide confidence } \\
\text { intervals (Cls) (there is an inverse relationship between sample size and } \\
\text { Cls) } \\
\text { - No trends can be ascertained due to wide Cls } \\
\text { - Usually give information for } 1-2 \text { years prior to survey } \\
\text { - Analysis is complicated } \\
\text { - Misreporting in later years } \\
\text { - Early deaths, stillbirths, ectopic pregnancies, and abortions are not } \\
\text { reported }\end{array}$ & $\begin{array}{l}\text { - PDHS used this methodology } \\
\text { - Covered a period of } 3 \text { years } \\
\text { - Provincial estimates were not reliable } \\
\text { - All adult mortality (male and female) } \\
\text { estimated }\end{array}$ \\
\hline
\end{tabular}




\begin{tabular}{|c|c|c|c|}
\hline Methods & Measures & Precision & Option for Pakistan \\
\hline Census & $\begin{array}{l}\text { Pregnancy-related } \\
\text { mortality }\end{array}$ & $\begin{array}{l}\text { - Entails total count } \\
\text { - Potential misreporting of age and pregnancy status of deceased women } \\
\text { - 1-2 years prior to census, depends on recall, so estimates are recent } \\
\text { - Enumerators need additional specialized training on collecting mortality } \\
\text { - } \text { data, so cost increases } \\
\text { - Estiminates sampling error, covers entire country } \\
\text { - Results must be adjusted to completeness of birth and deaths declared }\end{array}$ & $\begin{array}{l}\text { - Could be included in next census as a nested } \\
\text { survey. However, censuses have not been } \\
\text { held regularly. Last census was } 1998 \\
\text { - Time lag long decennial }\end{array}$ \\
\hline $\begin{array}{l}\text { Health facility } \\
\text { reporting }\end{array}$ & Maternal mortality & $\begin{array}{l}\text { - Overlooks maternal deaths outside healthcare facility } \\
\text { - Overlooks deaths in emergency room and other non-obstetric units }\end{array}$ & $\begin{array}{l}\text { - Few facility deaths are recorded } \\
\text { - Deliveries still take place at home } \\
\text { - DHIS covers public sector }\end{array}$ \\
\hline RAMOS & $\begin{array}{l}\text { Combination of } \\
\text { maternal and } \\
\text { pregnancy-related } \\
\text { mortality }\end{array}$ & $\begin{array}{l}\text { - Depends on triangulation, multiple sources, etc.; quality of records and VA } \\
\text { covers multiple years } \\
\text { - Household- and facility-based data } \\
\text { - Birth data difficult to obtain } \\
\text { - Complex and labour-intensive }\end{array}$ & $\begin{array}{l}\text { - Has been tried out in an Afghan refugee } \\
\text { camps in Pakistan }\end{array}$ \\
\hline $\begin{array}{l}\text { MADE-IN/MADE- } \\
\text { FOR }\end{array}$ & $\begin{array}{l}\text { Maternal mortality at } \\
\text { community level }\end{array}$ & $\begin{array}{l}\text { - Does not require large sample } \\
\text { - Depends on community-level reporting of deaths } \\
\text { - Requires two networks } \\
\text { - Software classifies deaths } \\
\text { - Low cost } \\
\text { - Good advocacy tool } \\
\text { - Provides sub-national estimates } \\
\text { - Recall-bias misreporting is possible } \\
\text { - Denominator requires live births survey or data from existing source }\end{array}$ & $\begin{array}{l}\text { Could be tried as alternative to household } \\
\text { survey and facilities where good networks } \\
\text { exist, e.g., LHWs and their support groups, } \\
\text { religious leaders and local community } \\
\text { councillors }\end{array}$ \\
\hline
\end{tabular}




\subsection{Measurement of Maternal Mortality in Pakistan}

In Pakistan, the vital registration system is still in the process of developing and there is no provision for mandatory registration of deaths. Inclusion of mortality-related questions in the census questionnaire is an alternative method that has not yet been applied in the country. Many countries with poor vital registration systems, including Pakistan, use indirect techniques, such as household surveys, to generate mortality estimates. Although they are the next best option to vital registration, most household survey methods are only able to capture pregnancy-related mortality unless accompanied by detailed VAs. Moreover, household surveys are costly, require large samples, and are time-consuming. Additionally, the estimates have very wide confidence intervals, making it difficult to monitor changes over time.

Several of the approaches outlined in Table 1.1 have been applied in Pakistan to produce estimates of maternal mortality. These efforts and their findings are summarized Table 1.2.

Table 1.2: Previous sources of data used to estimate MMR in Pakistan

\begin{tabular}{|c|c|c|c|c|}
\hline $\begin{array}{l}\text { Reference } \\
\text { Period }\end{array}$ & Study/Source & Estimation Method & $\begin{array}{c}\text { Geographical } \\
\text { Coverage }\end{array}$ & $\begin{array}{c}\text { MMR } \\
\text { Estimate }\end{array}$ \\
\hline $1990-91$ & $\begin{array}{l}\text { National Reproductive Health } \\
\text { and Family } \\
\text { Planning Survey } 2001 \text { (National } \\
\text { Institute of } \\
\text { Population Studies 2002) }\end{array}$ & $\begin{array}{l}\text { Indirect sisterhood } \\
\text { method }\end{array}$ & Pakistan & 533 \\
\hline $1988-93$ & $\begin{array}{l}\text { Maternal and Infant Mortality } \\
\text { Survey } \\
\text { (Midhet et al. 1998) }\end{array}$ & VA & $\begin{array}{l}\text { Selected rural } \\
\text { districts of } \\
\text { Balochistan and KP }\end{array}$ & 392 \\
\hline $2000-01$ & $\begin{array}{l}\text { Maternal and Infant Mortality } \\
\text { Survey } \\
\text { (Midhet 2001) }\end{array}$ & $\begin{array}{l}\text { Statistical modelling } \\
\text { using district } \\
\text { characteristics as } \\
\text { independent variables } \\
\text { and projected into the } \\
\text { future }\end{array}$ & Pakistan & 279 \\
\hline 2000 & $\begin{array}{l}\text { Estimates developed by WHO, } \\
\text { UNICEF, and } \\
\text { UNFPA (Abou Zahr and Wardlaw } \\
\text { 2004) }\end{array}$ & $\begin{array}{l}\text { Statistical modelling } \\
\text { using country } \\
\text { characteristics as } \\
\text { independent variables }\end{array}$ & Pakistan & 500 \\
\hline 2005 & $\begin{array}{l}\text { Estimates developed by WHO, } \\
\text { UNICEF, UNFPA, and the World } \\
\text { Bank (WHO 2005) }\end{array}$ & $\begin{array}{l}\text { Statistical modelling } \\
\text { using country } \\
\text { characteristics as } \\
\text { independent variables }\end{array}$ & Pakistan & 320 \\
\hline 2006-07 & $\begin{array}{l}\text { Pakistan Demographic and } \\
\text { Health Survey }\end{array}$ & $\begin{array}{l}\text { Direct sibling method } \\
\text { through household } \\
\text { survey }\end{array}$ & Pakistan & 276 \\
\hline 2014 & $\begin{array}{l}\text { The Feasibility of Using } \\
\text { Community Informant Networks } \\
\text { to Estimate Maternal Mortality in } \\
\text { Pakistan }\end{array}$ & Made-In and Made-For & District Chakwal & $\begin{array}{l}309 \\
(95 \% \mathrm{Cl} \\
266-358)\end{array}$ \\
\hline 2014 & Global Burden of Diseases & Statistical Modelling & Pakistan & $\begin{array}{l}401 \\
(233-560)\end{array}$ \\
\hline
\end{tabular}

Source: PDHS $2006-07$. 
As the table shows, the 1998 Maternal and Infant Mortality Survey (MIMS) conducted VAs in selected rural districts of Balochistan and KP and obtained an MMR of 392. The 2001 MIMS employed statistical modelling using district characteristics as independent variables and projected into the future to yield an MMR of 279. For the period 1995-2005, maternal mortality was calculated using indirect measures or statistical modelling that employed country characteristics as independent variables developed by WHO, UNICEF, and UNFPA. These estimates were found to vary considerably, i.e., between 140 and 490 (WHO 2012).

The National Institute of Population Studies (NIPS) had used the indirect sisterhood method as part of the Pakistan Reproductive Health and Family Planning Survey for 2000-01, estimating an MMR of 553 per 100,000 for 1990-91.

Examples of hospital-based studies conducted in Pakistan include a Civil Hospital (Karachi) study for 1979-83 (Ahmed 1985), which reported an MMR of 2,736 per 100,000 live births, and an Aga Khan University Hospital (Karachi) study (Qureshi et al. 2001), which reported an MMR of 20 per 100,000 live births among booked clients during 1988-99. Even among hospitals, the figures vary greatly according to whether the hospital is in the public or private sector or in a particular city. A private tertiary hospital in Karachi reported an MMR of 28 per 100,000 live births, whereas public hospitals report estimates that range from 225 in Lahore to 1,442 in Peshawar and 2,608 in Hyderabad (Jafarey 2002).

The Pakistan Demographic and Health Survey (PDHS) 2006-07 provides information on all deaths and live births in the country. Female deaths in the age group 12-49 years were identified and investigated using a VA questionnaire administered by especially trained interviewers. The survey has estimated an MMR of 276 per 100,000 live births with reference to the ten-year period prior to 2006-07. The PDHS 2006-07 also provides valuable data on the causes and risk factors of maternal mortality as well as on a number of process indicators.

Since the survey, there has been considerable investment in maternal health and the need for updated estimates has become an important priority. Specifically, there is a need to start planning for national and sub-national estimates of maternal mortality to compare subsequent changes with acceptable statistical precision while adhering to the sampling procedures employed by the 2006-07 PDHS.

However, in the absence of a vital registration system, obtaining accurate estimates is difficult. Large surveys are required for even moderately precise estimates (Hill et al. 2006), but such surveys are too expensive to be undertaken frequently in Pakistan. The latest PDHS, conducted in 2012-13, did not estimate maternal mortality due to cost implications. The MIMF methodology tested and applied in one district as a pilot successfully demonstrated the feasibility of using community based networks to identify deaths among women of reproductive age who were later followed up to assess cause and circumstances of these deaths.

To motivate policymakers and program managers to prioritize maternal health and evaluate interventions, national and sub-national estimates of recent maternal death rates need to be obtained using a relatively cheap and reliable method. 


\subsection{Feasibility of the MIMF Method in Pakistan}

The community-based informant technique for measuring maternal mortality, MIMF, has been previously tested in in two provinces in Indonesia (Qomariyah et al 2010) and the Somaliland. It was also tested as a pilot in Chakwal district in Punjab from January to April 2014.

To test the feasibility of the MIMF technique in the pilot study in Chakwal, community-based informant networks were used to identify the deaths of women of reproductive age (WRA), which were later confirmed through home visits, during which the cause of death was ascertained by verbal autopsies.

This study proved that the MIMF technique is feasible and can be introduced in Pakistan. Its primary advantages are:

- For the first time, to the study team's knowledge, a district estimate of maternal mortality has been generated and the direct and indirect causes of maternal deaths identified. The estimate is for a recent period, the previous two years (2012 and 2013), and includes progress monitoring and current intervention evaluation.

- The method has been able to successfully identify the different networks that can be used at the community level for capturing information on deaths in Pakistan. The study has established that the LHW network is a reliable source for capturing mortality information; however, its ability to capture women's deaths can be further improved with proper training and by expanding the age range for women's deaths, from 15-45 years to 12-49 years. Supplementing the information captured with a second network can further enhance the probability of capturing deaths. The other networks that can be included in areas not covered by LHWs are religious leaders, Nikah registrars, and lady councilors.

- The cost of applying the technique to obtain maternal mortality estimates at the district level came to Rs. 12 (12 cents) per WRA, while the cost of a survey would have been several times higher. The methodology can be repeated biannually because of its lower costs.

- The methodology is based on a census of maternal deaths and therefore does not require estimation of confidence intervals, and concerns about sampling errors are obviated. The technique can also be applied to measure maternal deaths prospectively, providing an ongoing way of measuring maternal deaths over longer periods. 


\subsection{Study Objectives}

\section{Primary Objectives}

- To apply the community informants networks technique (Made-In Made-For) to obtain a provincially representative current estimate of MMR for Punjab and to identify the causes of deaths.

- To build capacity within Punjab to obtain district and provincial maternal mortality estimates routinely, on a sustainable basis.

\section{Secondary Objectives}

- To identify the networks available within rural and urban communities of Punjab that can act as key informants for routine information on maternal deaths;

- To determine differential characteristics of maternal deaths by economic, urban and rural, and geographical distribution so as to gain a better understanding of the predisposing factors contributing to women's death during pregnancy, delivery and the postpartum period;

- To assess the mechanism that can be employed at the community level to determine the cause of deaths. 



\section{Study Design}

The study entailed scaling up of the MIMF approach, already pilot-tested in Chakwal district, to arrive at a provincial estimate of Punjab's MMR. In the MIMF method, collection of data about maternal mortality essentially consists of two main steps:

- $\quad$ Listing of deaths by informants (Made-In): Village-level informant networks identify WRA deaths in their communities. Specific listing forms developed for this purpose are used to collect data.

- $\quad$ Follow-up with verbal autopsies (Made-For): Follow-up interviews are then conducted with family members of the deceased women to confirm whether their deaths were maternal or non-maternal, and to explore the cause of and circumstances surrounding the death.

Apart from estimating Punjab's MMR and demonstrating the applicability of the Made-In/Made-for approach, the study was also aimed at exploring modalities for continuing such estimation efforts on a sustainable basis. It established suitable modes of operation for 'enrolling' community-based informant networks, efficiently arranging meetings, and determining, in detail, the steps required for such studies. We were then able to recommend the most suitable networks for each of the three zones.

The study was conducted in a sample of six districts, and sought to present a full census of deaths among women of reproductive age for the two-year period from January 2012 to December 2013.

This section describes how key stages of the study were conducted from sampling to data analysis.

\subsection{Sampling}

For calculating the MMR estimate for Punjab, the province was stratified into three geographical regions: North (consisting of 14 adjacent districts), Centre (comprising of 11 districts), and South (consisting of 11 geographically adjacent districts). The derivation of these regions was based on the distribution of the nine administrative "divisions." 2 i.e. three divisions per zone. Precedents exist of such regional divisions of the province in other social sector related studies and research initiatives. ${ }^{3}$

A two-step approach was then adopted to derive a sample of districts for each region. In the first step, the regions were divided into "more urbanized" and "less urbanized" segments. For this, districts in each region were listed in descending order from most to least urbanized, based on urban-rural population proportions reported in Punjab Development Statistics 2013 (Bureau of Statistics, 2013). Districts in the top half of each list (seven districts in the North, and five districts each in the Centre and South) were labelled as the more urbanized districts, while the other half were labelled as less urbanized. The segmentation is shown in Table 2.1, with the more urbanized districts shaded in grey and the less urbanized shaded in green.

As the total universe of the population-in this case, the number of districts in Punjab, which is 36-was small, standard sample size calculation approaches (based on large sample statistical methodologies) could not be applied. Therefore, a proportional quota sampling approach was adopted to ensure "equal" representation from each segment and derive a representative sample of districts from each region.

\footnotetext{
2 A "division" in Pakistan refers to an administrative demarcation of a cluster of adjacent districts by provincial governments.

3 Pakistan Institute for Peace Studies, 2011. Understanding North Punjab in the Context of Pakistani
} 
Representation of more than 10 percent of the total population in the sample is usually considered adequate for ensuring the statistical robustness for estimates derived.

Accordingly, using simple random sampling, one district was selected from each of the two segments in each of the three regions, bringing the total sample size to six districts. Since this sample comprised approximately 16 percent of the total universe of districts in Punjab, it was considered adequate for yielding statistically robust estimates for MMR in Punjab. Representation of more than 10 percent of the total population in the sample is usually considered adequate for ensuring the statistical robustness of estimates derived. The selected districts included Jhelum (more urbanized) and Bhakkar (less urbanized) in the North; Chiniot (more urbanized) and Toba Tek (TT) Singh (less urbanized) in the Centre; and Bahawalpur (more urbanized) and Layyah (less urbanized) in the South. The total population of the six study districts is about 11 million, i.e., 11 percent of the total population of Punjab (Bureau of Statistics, 2013). In all, there were 373 union councils in the study area. 
Table 2.1: Distribution of districts by geographical region, population, level of urbanization, and expected number of live births

\begin{tabular}{|c|c|c|c|c|c|c|c|}
\hline & Districts & Population & $\begin{array}{c}\text { Urban } \\
\text { Population }\end{array}$ & $\begin{array}{c}\text { Rural } \\
\text { Population }\end{array}$ & $\begin{array}{c}\text { Rural } \\
\%\end{array}$ & $\begin{array}{l}\text { Urban } \\
\%\end{array}$ & $\begin{array}{l}\text { Expected } \\
\text { number of } \\
\text { births }\end{array}$ \\
\hline & PUNJAB & 98,223 & 31,312 & 66,911 & 68 & 32 & $2,652,021$ \\
\hline & REGION 1 (North) & 30,819 & 9,806 & 21,013 & 68 & 32 & 832,113 \\
\hline 1 & Rawalpindi & 4538 & 2,536 & 2002 & 44 & 56 & 122,526 \\
\hline 2 & Gujranwala & 4628 & 2,340 & 2288 & 49 & 51 & 124,956 \\
\hline 3 & Sargodha & 3318 & 934 & 2384 & 72 & 28 & 89,586 \\
\hline 4 & Jhelum & 1181 & 327 & 854 & 72 & 28 & 31,887 \\
\hline 5 & Gujrat & 2618 & 726 & 1892 & 72 & 28 & 70,686 \\
\hline 6 & Hafizabad & 1069 & 291 & 778 & 73 & 27 & 28,863 \\
\hline 7 & Sialkot & 3566 & 934 & 2632 & 74 & 26 & 96,282 \\
\hline 8 & Khushab & 1136 & 287 & 849 & 75 & 25 & 30,672 \\
\hline 9 & Attock & 1630 & 347 & 1283 & 79 & 21 & 44,010 \\
\hline 10 & Mianwali & 1368 & 285 & 1083 & 79 & 21 & 36,936 \\
\hline 11 & Bhakkar & 1412 & 226 & 1186 & 84 & 16 & 38,124 \\
\hline 12 & M. B. Din & 1430 & 217 & 1213 & 85 & 15 & 38,610 \\
\hline 13 & Narowal & 1574 & 192 & 1382 & 88 & 12 & 42,498 \\
\hline \multirow[t]{2}{*}{14} & Chakwal & 1351 & 164 & 1187 & 88 & 12 & 36,477 \\
\hline & REGION 2 (Central) & 36,351 & 15,024 & 21,327 & 59 & 41 & 981,477 \\
\hline 1 & Lahore & 9159 & 7522 & 1637 & 18 & 82 & 247,293 \\
\hline 2 & Faisalabad & 7141 & 3049 & 4092 & 57 & 43 & 192,807 \\
\hline 3 & Sheikhupura & 3028 & 951 & 2077 & 69 & 31 & 81,756 \\
\hline 4 & Chiniot & 1203 & 323 & 880 & 73 & 27 & 32,481 \\
\hline 5 & Jhang & 2392 & 584 & 1808 & 76 & 24 & 64,584 \\
\hline 6 & Kasur & 3162 & 722 & 2440 & 77 & 23 & 85,374 \\
\hline 7 & Okara & 2910 & 670 & 2240 & 77 & 23 & 78,570 \\
\hline 8 & T.T.Singh & 2050 & 386 & 1664 & 81 & 19 & 55,350 \\
\hline 9 & Sahiwal & 2338 & 383 & 1955 & 84 & 16 & 63,126 \\
\hline 10 & Nankana Sahib & 1276 & 193 & 1083 & 85 & 15 & 34,452 \\
\hline \multirow[t]{2}{*}{11} & Pakpattan & 1692 & 241 & 1451 & 86 & 14 & 45,684 \\
\hline & REGION 3 (South) & 31,053 & 6,482 & 24,571 & 79 & 21 & 838,431 \\
\hline 1 & Multan & 4193 & 1770 & 2423 & 58 & 42 & 113,211 \\
\hline 2 & Bahawalpur & 3391 & 927 & 2464 & 73 & 27 & 91,557 \\
\hline 3 & R.Y.Khan & 4431 & 870 & 3561 & 80 & 20 & 119,637 \\
\hline 4 & Bahawalnagar & 2683 & 511 & 2172 & 81 & 19 & 72,441 \\
\hline 5 & Khanewal & 2705 & 477 & 2228 & 82 & 18 & 73,035 \\
\hline 6 & Vehari & 2803 & 450 & 2353 & 84 & 16 & 75,681 \\
\hline 7 & Lodhran & 1579 & 229 & 1350 & 85 & 15 & 42,633 \\
\hline 8 & Rajanpur & 1569 & 228 & 1341 & 85 & 15 & 42,363 \\
\hline 9 & D.G.Khan & 2346 & 327 & 2019 & 86 & 14 & 63,342 \\
\hline 10 & Muzaffargarh & 3786 & 491 & 3295 & 87 & 13 & 102,222 \\
\hline 11 & Layyah & 1567 & 202 & 1365 & 87 & 13 & 42,309 \\
\hline
\end{tabular}

Source: Bureau of Statistics, “Population projections as on 31-12-2013,” Punjab Development Statistics 2013 (Lahore: Government of Punjab). 
The location of the study districts is shown in Figure 2.1

Figure 2.1: Map of Punjab showing Location of Study Districts

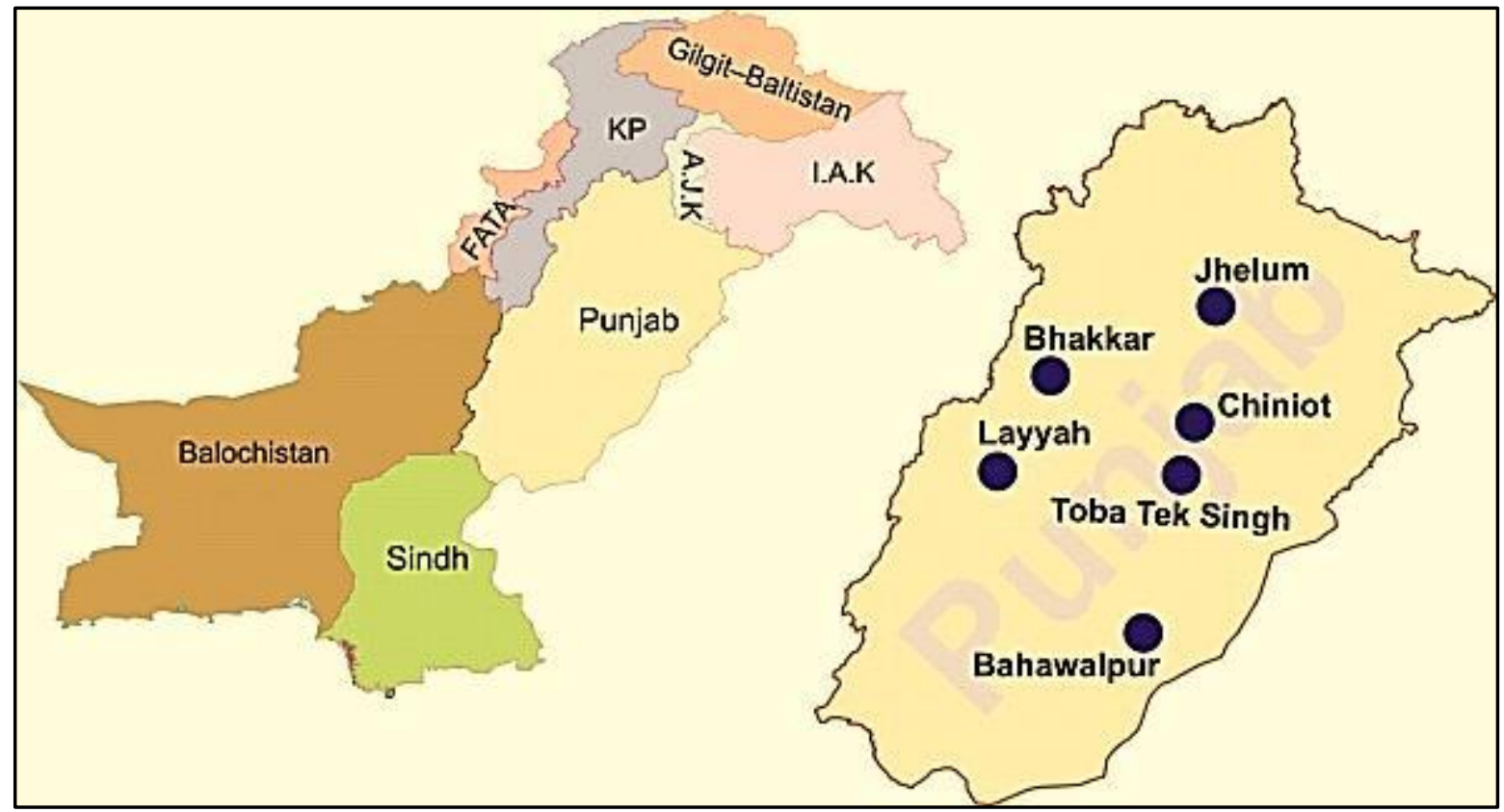

\subsection{Identification of Informant Networks}

In the Chakwal pilot study, networks of religious leaders, LHWs, Nikah registrars, and lady councillors had been utilized. Variations in these networks were anticipated across districts.

After extensive discussions with officials of the district administrations and health departments, a number of potential networks were identified, including community midwives, schoolteachers, traditional birth attendants (TBAs), vaccinators, religious leaders, Nikah (marriage) registrars, village chowkidars (watchmen), numberdars ${ }^{4}$, lady health workers (LHWs), and women councillors. For its key informants, the study team opted to use the existing networks of LHWs; religious leaders, including village mosque imams; male and female lady councillors; Nikah registrars-the functionaries who perform and solemnize marriages; and community midwives, who have recently been trained and deployed by the MNCH Program.

The LHW network was selected in all districts since it covers the entire country (albeit with variation in specific local coverage). LHWs were established in communities during the launch of the National Program for Family Planning and Primary Health Care, also known as the Lady Health Workers Program (LHWP), in 1994. Each LHW provide services to a well-defined catchment population of 1,000. The quality of care provided by LHWs in communities is maintained by a well-established supportive supervisory network from the community to provincial levels. The monitoring and supervisory cadres

\footnotetext{
4 Numberdar (Definition): The headman of a village is called Numberdar. He is appointed by the executive district officer in a village. Numberdar has to collect and supervise the collection of revenue of an estate. He is the representative of the people of an estate and a link between the government and public.
} 
include Lady Health Supervisors (each supervises 20 to 25 LHWs), Field Program Officers (FPOs), and well-integrated district and provincial management.

Based on the pilot results, two informant networks were used in the majority of the tehsils. In LHWcovered areas, these included the LHW network and one additional 'independent' network, i.e., religious leaders, Nikah registrars or female councillors. In the various communities/areas not covered by LHWs, two independent networks were employed. These include religious leaders \& Nikah registrars or male/female councillors \& community midwives.

The network of religious leaders was selected keeping in mind the universal availability of religious leaders and their standing in the community. Since they also lead funeral prayers, it was assumed they would be fairly knowledgeable about recent deaths in their area.

TBAs were not considered since they tended to be illiterate and would not have been able to develop a list of deaths. Moreover, a conflict of interest would have arisen in cases where a TBA was responsible for the death of a woman and, therefore, reluctant to report it.

As a first step, briefings were given on the study to provincial and district health department officials and district administration officials, and then assistance and cooperation sought for conducting the study. The District Coordination Officer (DCO) and Tehsil Municipal Officers (TMOs) in all districts helped in identifying and developing lists of the networks.

\subsection{Study Team and Organization of Fleld Work}

Six five-member teams were constituted for each of the districts. Three teams carried out the Made-In part of the technique, including assembling, briefing and obtaining data from key informants, and two teams of female interviewers carried out the Made-For part, which entailed visiting the homes of deceased women and conducting verbal autopsies to identify the possible cause of death. Data collectors with master's or bachelor's degrees in sociology or anthropology as well as prior research work experience were recruited to work on a full-time basis.

Field activities were supervised by field coordinators, the study manager and the principal investigator. Every day, after fieldwork, each team conducted a debriefing session to discuss the data collection that day and solve any problems encountered. The supervisory framework for fieldwork is shown in Figure 2.2 .

It was ensured that district administration staff was fully involved in each stage of implementation to facilitate the institutionalization and sustainability of the process. To this end, provincial mechanisms that could be used for institutionalizing the approach in all districts were also identified. 
Figure 2.2: Fieldwork organization

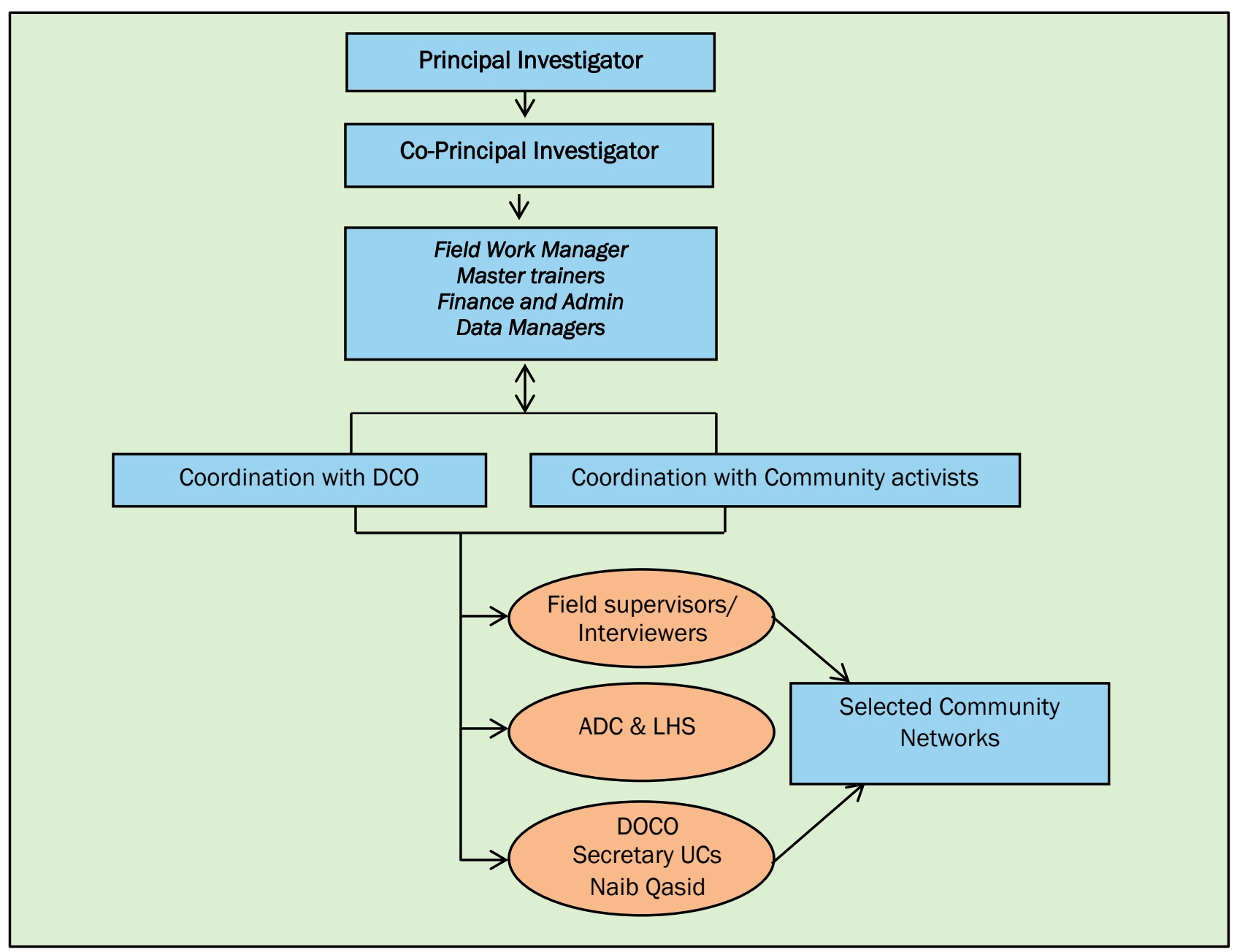

\subsection{Data Collection}

Figure 2.3 summarizes the activities undertaken in data collection for the study. The activities comprise both the Made-In and Made-For components of the study. 
Figure 2.3: Sequencing of data collection activities (Oct-Dec 2014)

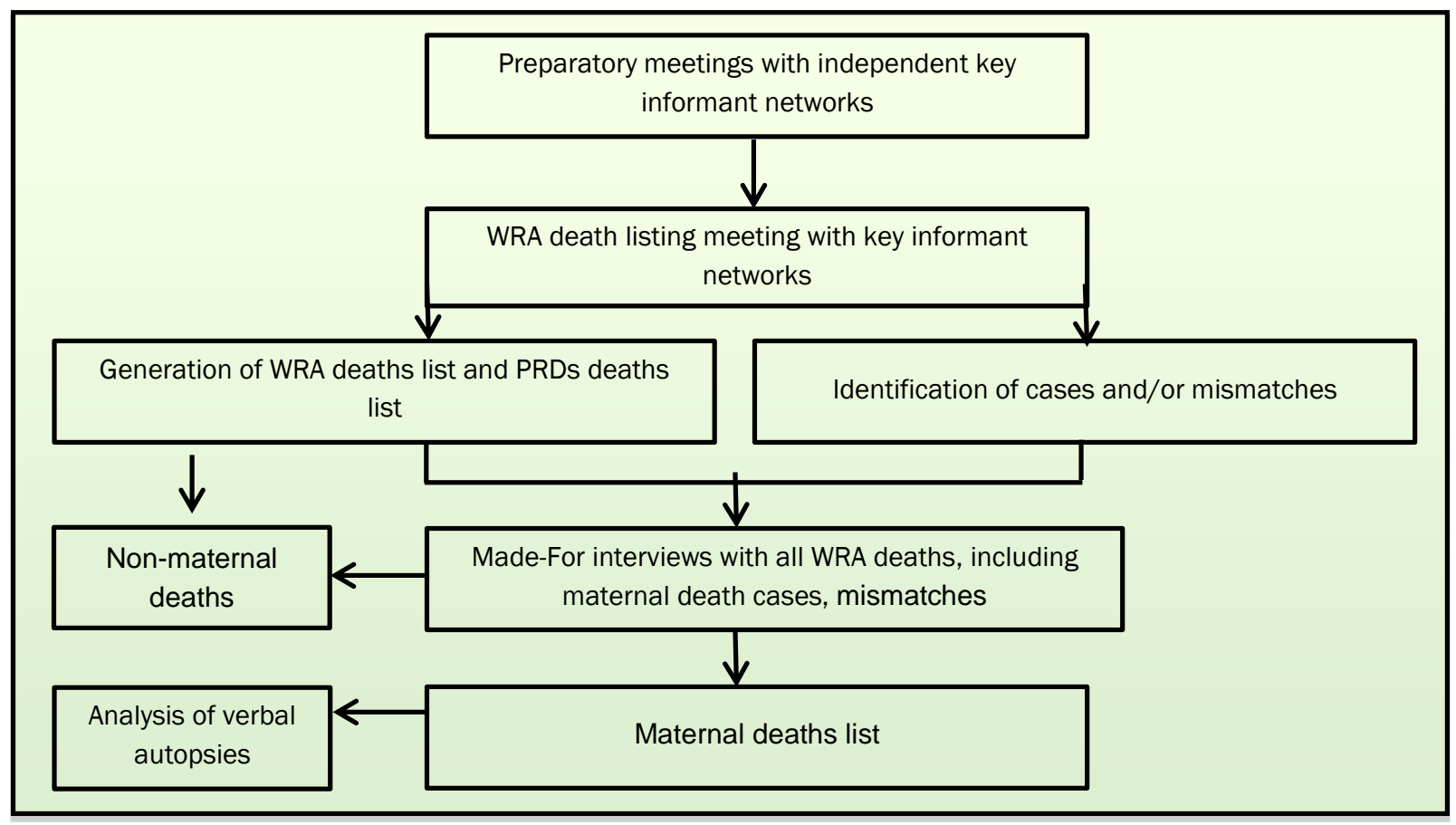

\section{Made-In: Listing of Deaths by Community Informants}

Data was gathered through meetings of the informant networks in each union council, the smallest local governmental administrative unit. Local researchers trained the selected informants in collecting data and listing possible deaths of women of reproductive age and pregnancy related deaths.

The Made-In component of the data collection process entailed four main steps, as outlined below.

Preparatory Meeting with Identified Informants. A series of preparatory meetings were held with the identified key informants at the tehsil and union council levels at the offices of the union council secretaries. The LHWs were assembled at the District Health Development Centre (DHDC) and health facilities in the catchment areas. The objectives of these meetings were to:

- Introduce the networks to the study's objectives and methodology;

- Seek their cooperation in all data collection activities, including the type of information to be gathered;

- Explain the ethical considerations that applied when collecting information, especially how to seek informed consent and provide assurance of confidentiality; and

- $\quad$ Decide on a time and venue to reconvene for the WRA death-listing meeting.

During the meetings, each informant was given a WRA Death Listing Form. They were asked to use the forms to especially document information on the deaths of women aged 12-50 years who lived in the same union council as the informant. The additional information they had to collect included whether the women had died during pregnancy, delivery, or within six weeks postpartum; the date and place of death; and the age, name of husband, and residential address (Annex 9.1). The informants were 
provided a comprehensive briefing on all aspects of the study, especially on the importance of safe motherhood, the status of women in religion and society, and the poor maternal health situation in Pakistan.

Data Collection by Informants. After the preparatory meetings, informants were asked to collect the data and return with their completed listing forms within three days. The informants worked individually.

WRA Death Listing Meeting. The area's field coordinator arranged a separate listing meeting with each network at the union council office and health facilities. On average, 30-35 informants were invited to a WRA death listing meeting. These meetings were mostly conducted about two or three days after the first meeting.

During the meeting, participants discussed all the deaths they had listed, collectively agreed on a second list of WRA deaths, and identified likely PRDs. The address of each deceased woman's household was also verified to ensure that no information was missing. To ensure complete coverage of deaths, the Made-In process also included a visit to village informants who had not attended the meeting.

Table 2.2: Participation of key informants in listing meetings-Made-In

\begin{tabular}{|c|c|c|c|c|c|c|c|}
\hline District Name & & LHWs & $\begin{array}{l}\text { Religious } \\
\text { Leaders }\end{array}$ & $\begin{array}{l}\text { Male and } \\
\text { Female } \\
\text { Councillors }\end{array}$ & $\begin{array}{l}\text { Nikah } \\
\text { Registrar }\end{array}$ & CMW & Total \\
\hline \multirow{4}{*}{ Jhelum } & No. of Informants & 828 & 626 & 56 & 404 & 4 & 1918 \\
\hline & No. of Listing Meetings & 28 & 27 & 3 & 18 & 1 & 77 \\
\hline & Response Rate (\%) & 99 & 89 & 99 & 99 & 100 & 99 \\
\hline & Refusal Rate (\%) & 0.0 & 0.32 & 0.0 & 0.0 & 0.0 & 0.1 \\
\hline \multirow{4}{*}{ T.T. Singh } & No. of Informants & 1011 & 908 & 79 & 97 & na & 2095 \\
\hline & No. of Listing Meetings & 34 & 42 & 3 & 4 & na & 83 \\
\hline & Response Rate (\%) & 100 & 93 & 95 & 95 & na & 97 \\
\hline & Refusal Rate (\%) & 0.0 & 0.99 & 0.0 & 0.0 & na & 0.43 \\
\hline \multirow{4}{*}{ Chiniot } & No. of Informants & 430 & 521 & 132 & 259 & 16 & 1358 \\
\hline & No. of Listing Meetings & 15 & 25 & 7 & 13 & 2 & 62 \\
\hline & Response Rate (\%) & 100 & 98 & 97 & 100 & 100 & 99 \\
\hline & Refusal Rate (\%) & 0.0 & 0.58 & 0.76 & 0.39 & 0.0 & 0.22 \\
\hline \multirow{4}{*}{ Bhakkar } & No. of Informants & 980 & 1144 & 110 & 324 & 14 & 2572 \\
\hline & No. of Listing Meetings & 33 & 53 & 6 & 15 & 2 & 109 \\
\hline & Response Rate (\%) & 100 & 100 & 100 & 100 & 100 & 100 \\
\hline & Refusal Rate (\%) & 0 & 0 & 0 & 0 & 0 & 0 \\
\hline \multirow{4}{*}{ Bahawalpur } & No. of Informants & 1552 & 771 & 312 & 514 & na & 3149 \\
\hline & No. of Listing Meetings & 53 & 35 & 14 & 24 & 0 & 126 \\
\hline & Attendance Rate (\%) & 100 & 97 & 97 & 99 & na & 99 \\
\hline & Refusal Rate (\%) & 0 & 1.82 & 0.64 & 0.78 & na & 0.64 \\
\hline \multirow{3}{*}{ Layyah } & No. of Informants & 866 & 111 & 24 & 643 & na & 1644 \\
\hline & No. of Listing Meetings & 29 & 5 & 2 & 29 & na & 65 \\
\hline & Response Rate (\%) & 100 & 100 & 91 & 97 & na & 99 \\
\hline
\end{tabular}




\section{Made-For: Follow-up with Verbal Autopsies}

The aim of this review was to gather information on the circumstances and causes of women's deaths. Through the listing meetings, lists of WRA deaths for each village were developed with information on the time of death in relation to pregnancy status. The lists included information on women usually resident in the village as well as those resident elsewhere but living in the village at the time of death. Based on the Chakwal pilot study, we found a high sensitivity 98\% and specificity 99\% (PPV 90\% NPV 99\%) and a Kappa score of 0.93 showing almost perfect agreement between the Made-In and Made-For steps. On this basis, it was decided that verbal autopsies would be carried out for all pregnancy-related deaths.

During the home visits, detailed information was obtained on each death, using the revised WHO VA 2012 questionnaire (Annex 9.2) with additional questions on the socioeconomic characteristics of the family, health-seeking behaviour, and quality of care. The VAs were conducted with the deceased's next of kin. In total 22 verbal autopsy respondents refused to participate in the study.

Subsequently, estimates of cause of death were obtained using a computerized algorithm compatible with the WHO questionnaire, InterVA-M (Fottrell et al., 2007). Together, these two steps-Made-In and Made-For-provided village-level estimates of the number of WRA deaths, and in particular the number of PRDs and maternal deaths in a defined period. The Inter VA-M data was independently verified by a medical practitioner in each district. Final verification was carried out by a Consultant at the Department of Gynaecology and Obstetrics, Pakistan Institute of Medical Sciences, Islamabad.

\subsubsection{Rapid Facility Assessment}

A Rapid Facility Assessment was carried out by a medical doctor and two trained social scientists in each study district. In total, 24 secondary and tertiary care public sector facilities, i.e. all Tehsil Headquarters (THQ) and District Headquarter (DHQ) hospitals, were visited. The objective was to examine the capacity of facilities to provide emergency obstetric care in terms of staff availability, and availability of essential supplies and equipment. The main aim of this activity was to be able to better understand the capacity of these facilities in managing maternal complications.

\subsubsection{Mapping of All Pregnancy-related Deaths}

All maternal deaths identified were geo-referenced on GIS maps by plotting the coordinates of the deceased women's homes. This not only served to authenticate deaths but also to develop a better understanding of the context of these deaths, in terms of location and clustering of deaths and distance to facilities, availability of facilities according to population density and access to services by socioeconomic status of deceased women.

\subsubsection{Qualitative Component}

A qualitative component was added to the study by using in-depth interviews with relatives of deceased women to obtain information on care seeking behaviour during the pregnancy, delivery and the postpartum period, to examine socio-cultural practices, barriers and obstacles in assessing care, and perceptions regarding care offered in the health facilities. The in-depth interviews were conducted after 
reviewing the verbatim account of deaths recorded in the verbal autopsy questionnaire and identify these causes which could better help in understanding the role of socio-cultural determinants and weaknesses in the health system.

\subsection{Data Management and Analysis}

All VA questionnaires and listing forms were crosschecked by the data collectors themselves before being double-checked by the field supervisor. The next steps involved a recheck by the team leader and a final check by the study manager. A data entry template using an Excel program was developed for entering the listing data; CsPro (version 5.1) was used to enter the VA data. The InterVA-M software (version 4.0) was used to determine the cause of death. Table 2.3 shows the reproductive health indicators of the six study districts and an overall measure for Punjab province.

Table 2.3: Key reproductive health indicators for all six districts and Punjab

\begin{tabular}{|c|c|c|c|c|c|}
\hline & $\begin{array}{c}\text { Total Fertility } \\
\text { Rate } \\
\text { (TFR) }\end{array}$ & $\begin{array}{c}\text { Contraceptive } \\
\text { Prevalence Rate } \\
\text { (CPR) }\end{array}$ & $\begin{array}{l}\text { Unmet Need } \\
\text { for Family } \\
\text { Planning } \\
\end{array}$ & $\begin{array}{c}\text { Percent } \\
\text { distribution of } \\
\text { delivery by an } \\
\text { SBA } \\
\end{array}$ & $\begin{array}{c}\text { Infant Mortality } \\
\text { Rate } \\
\text { (IMR) }\end{array}$ \\
\hline Punjab & 3.58 & 35.2 & 17.1 & 58.5 & 82 \\
\hline \multicolumn{6}{|l|}{ District } \\
\hline Jhelum & 3.45 & 34.8 & 15.5 & 79.7 & 60 \\
\hline Chiniot & 3.81 & 41.4 & 13.7 & 57.9 & 97 \\
\hline T.T. Singh & 3.43 & 33.6 & 14.2 & 58.4 & 85 \\
\hline Bhakkar & 3.56 & 21.8 & 19.3 & 49.8 & 91 \\
\hline Bahawalpur & 3.53 & 34.3 & 17.5 & 37.3 & 100 \\
\hline Layyah & 3.97 & 26.3 & 18.0 & 48.6 & 74 \\
\hline
\end{tabular}

Source: Multiple Indicator Cluster Survey (MICS), Punjab 2011

\subsection{Quality Assurance}

A number of measures were instituted to ensure that the study maintained the highest quality standards, both in data collection and analysis. These are outlined below:

- Standard operating procedures. The Population Council developed a field manual and standard operating procedures for carrying out all activities.

- Determination of roles and responsibilities. The roles and responsibilities of team members and field coordinators were clearly identified and each team member was provided written instructions that he/she was required to follow.

- Training. The training component included training of field staff in conducting preparatory and listing meetings, obtaining data from the network participants, pretesting the data collection, and reviewing the pretesting and adapting the methods and tools accordingly. Field interviewers received six days' training in the use of listing forms and VAs. This included sessions on research protocol, ethics, obtaining informed consent, maintaining privacy during the interview process, and 
interviewing techniques, as well as how to adhere to the standard operating procedures and study objectives.

- $\quad$ Monitoring. The field manager remained in the field throughout the study. Each field team had a team supervisor to ensure that data quality standards were met. The principal investigator, project manager, and field coordinators visited randomly selected villages in each tehsil regularly to ensure that all protocols were being followed. They randomly selected and scrutinized the completed questionnaires during monitoring visits to check for completeness and data accuracy, and to determine any re-interviewing requirements.

\subsection{Ethical Considerations}

Ethical approval was obtained from the National Bioethics Committee of Pakistan and the Institutional Review Board of the Population Council (Annex 9.3). Permission was also obtained from the Director General Health, Punjab and District Health Offices (Annex 9.4).

Informed consent was obtained from all study participants after describing to them in detail the issues related to the study. Interviewers described the scope and purpose of the questionnaire and its approximate duration, and stressed that participation was entirely voluntary. The interviews were conducted in private and out of the hearing of other people. When these conditions could not be met, social science interviewers offered participants an alternative venue or time to complete the questionnaire. All individual data was treated in strict confidentiality. 



\section{Maternal Mortality: Socio-Demographic Features, Incidence, and Causes}

\subsection{Basic Definitions:}

\section{Pregnancy Related Death:}

A 'Pregnancy Related Death' (PRD) is defined as "the death of a woman while pregnant or within 42 days of termination of pregnancy, irrespective of the cause of death" (WHO ICD-10, 2012). This definition is sometimes referred to as the time-of-death definition of maternal death and does not need to differentiate accidental/incidental causes from obstetric causes.

\section{Maternal Death:}

In its International Statistical Classification of Diseases and Related Health Problems (1992, ICD-10), WHO defines Maternal Death (MD) as: "the death of a woman while pregnant or within 42 days of termination of pregnancy, irrespective of the duration and site of pregnancy, from any cause related to or aggravated by the pregnancy or its management but not from accidental or incidental causes." The definition implies the inclusion of maternal deaths from direct and indirect obstetric causes of death (WHO, 2012).

\section{Late Maternal Death:}

"Late maternal deaths" are defined as "the death of a woman from direct or indirect obstetric causes more than 42 days but less than one year after termination of pregnancy (WHO ICD-10, 2012).

\subsection{Identification of Pregnancy Related Deaths:}

Collectively, in the six sampled districts, 12,334 WRA deaths were identified to have taken place during the period 2012-13. Of these, 1,735 were identified as PRDs based on the listing data (Figure 3.1).

The next step was to follow-up the PRDs through verbal autopsy interviews with the deceased women's relatives-in most cases, their siblings, in-laws, parents, other relatives, or spouses to ascertain the cause of death.

Post-autopsy, it was found that, in 381 cases, the deaths had not taken place in the last two years and these were therefore excluded. In addition, 22 respondents refused to participate; in 107 cases, the address was not found; and in 51, cases the names had been duplicated. After the exclusion of these cases, 1,182 PRDs remained for the final analysis. 
Figure 3.1: Number of cases or deaths found in women of reproductive age

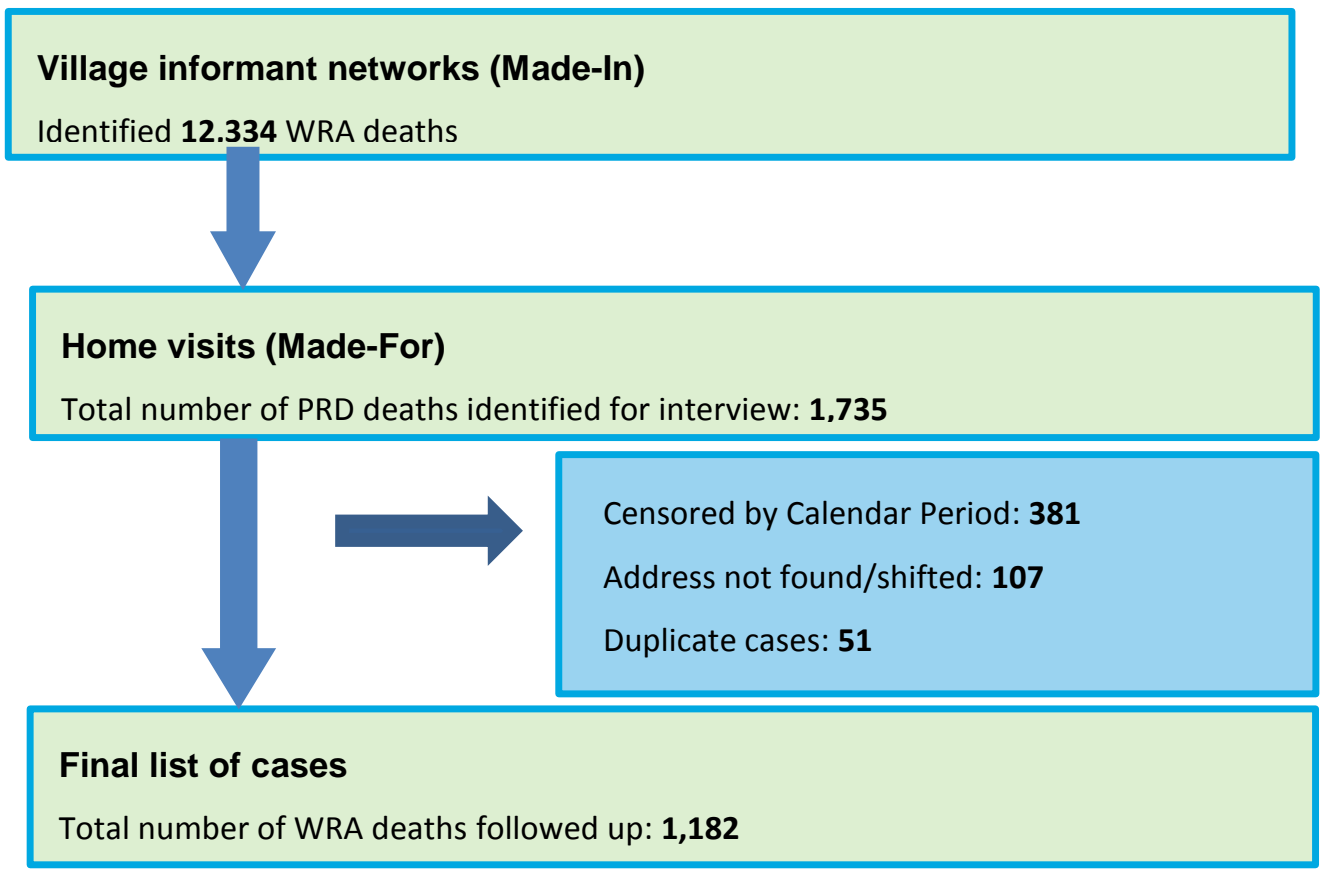

As Table 3.1 shows, the majority of deaths were identified by LHWs. LHWs are tasked with identifying maternal deaths as part of their routine work. For the study, the LHWs were provided a refresher training in identifying maternal deaths. As table shows, the LHWs improved their performance by identifying more pregnancy related deaths (PRDs) than they did previously. There was a further improvement in the identification and reporting of deaths after the inclusion of additional informant networks.

Table 3.1: Improvement in reporting of deaths through the study

\begin{tabular}{|c|c|c|c|c|c|}
\hline District & $\begin{array}{c}\text { Deaths reported } \\
\text { by LHWs before } \\
\text { study }\end{array}$ & $\begin{array}{l}\text { Deaths } \\
\text { reported by } \\
\text { LHWs during } \\
\text { study }\end{array}$ & $\begin{array}{c}\text { Additional cases } \\
\text { identified by LHWs } \\
\text { (Difference - Deaths } \\
\text { Identified Before and } \\
\text { After Study) }\end{array}$ & $\begin{array}{l}\text { Deaths reported by } \\
\text { other networks during } \\
\text { study }\end{array}$ & $\begin{array}{l}\text { Total } \\
\text { deaths } \\
\text { reported }\end{array}$ \\
\hline & $n$ & $n$ & $n$ & $\mathrm{n}$ & $\mathrm{n}$ \\
\hline Bahawalpur & 116 & 218 & 102 & 141 & 359 \\
\hline Chiniot & 29 & 78 & 49 & 86 & 164 \\
\hline T.T. Singh & 64 & 125 & 61 & 55 & 180 \\
\hline Layyah & 83 & 103 & 20 & 64 & 167 \\
\hline Bhakkar & 122 & 150 & 28 & 54 & 204 \\
\hline Jhelum & 83 & 77 & -6 & 31 & 108 \\
\hline Total & 497 & 751 & 254 & 431 & 1182 \\
\hline
\end{tabular}


Figure 3.2 shows the distribution of the verbal autopsies conducted by type of respondents. The majority (nearly half) of VA respondents were in-laws of the deceased, followed by parents, siblings and spouses. In selecting VA respondents, the emphasis was on seeking respondents who had been present at the time of the last illness of the deceased women.

Figure 3.2: Distribution of verbal autopsies by type of respondent, \%

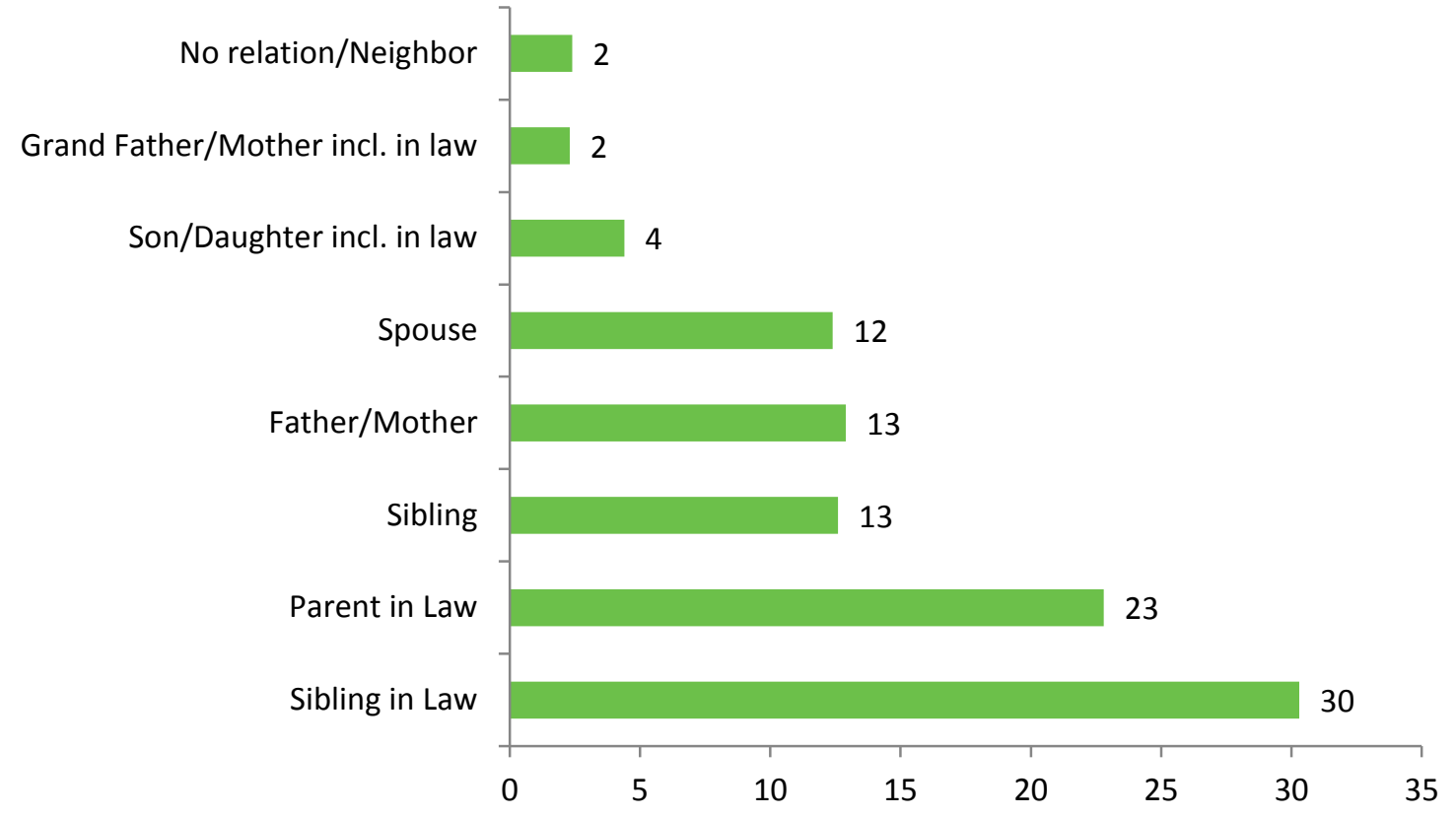

\subsection{Socio-demographic Characteristics of the Deceased Women}

The age distribution of the 1,182 women whose PRDs were covered by the study is presented in Table 3.2.

Table 3.2: Age of deceased women by district

\begin{tabular}{|c|c|c|c|c|c|c|c|c|c|c|c|c|}
\hline \multirow{2}{*}{$\begin{array}{l}\text { Age } \\
\text { (years) }\end{array}$} & \multicolumn{2}{|c|}{ Bahawalpur } & \multicolumn{2}{|c|}{ Bhakkar } & \multicolumn{2}{|c|}{ Chiniot } & \multicolumn{2}{|c|}{ Jhelum } & \multicolumn{2}{|c|}{ Layyah } & \multicolumn{2}{|c|}{ T.T. Singh } \\
\hline & $\%$ & $\mathrm{n}$ & $\%$ & $\mathrm{n}$ & $\%$ & $\mathrm{n}$ & $\%$ & $\mathrm{~N}$ & $\%$ & $\mathrm{n}$ & $\%$ & $\mathrm{n}$ \\
\hline $\begin{array}{l}\text { Less than } \\
20\end{array}$ & 6 & 21 & 6 & 13 & 9 & 15 & 5 & 5 & 7 & 11 & 2 & 4 \\
\hline $20-24$ & 20 & 72 & 13 & 28 & 17 & 28 & 16 & 17 & 24 & 40 & 27 & 49 \\
\hline $25-29$ & 27 & 98 & 25 & 50 & 33 & 54 & 32 & 35 & 21 & 36 & 22 & 39 \\
\hline $30-34$ & 23 & 83 & 27 & 54 & 20 & 32 & 24 & 26 & 26 & 44 & 22 & 39 \\
\hline $35 / 35+$ & 24 & 85 & 29 & 59 & 21 & 35 & 23 & 25 & 22 & 36 & 27 & 49 \\
\hline Total & 100 & 359 & 100 & 204 & 100 & 164 & 100 & 108 & 100 & 167 & 100 & 180 \\
\hline
\end{tabular}


The mean and median age of the deceased women was 29 years. The largest group (26\%) of women was in the 25-29 years age bracket and the smallest group (6\%) in the less than 20 years age bracket.

Nearly all (99.6 percent) of the deceased women were married; $0.2 \%$ were either widowed or divorced and remaining $0.2 \%$ were never married (table 3.3 ).

Education level influences care-seeking behaviour, reproductive intentions, contraceptive use, and hygiene practices within the home (Cleland 2001 \& Bongaarts 1999). As Tables 3.2,3.3,3.4 and figure 3.3 indicate, more than two-thirds of the deceased women had not received any education. One-sixth had completed primary schooling and only 5 percent of all women in the six districts had completed higher secondary school. By districts, in Jhelum and T.T. Singh, half of the women were illiterate and could not read and write; while in Bahawalpur and Chiniot, nearly four-fifths of the women were illiterate.

Table 3.3: Educational status of deceased by district

\begin{tabular}{|c|c|c|c|c|c|c|c|c|c|c|c|c|}
\hline \multirow[b]{2}{*}{ Education } & \multicolumn{2}{|c|}{ Bahawalpur } & \multicolumn{2}{|c|}{ Bhakkar } & \multicolumn{2}{|c|}{ Chiniot } & \multicolumn{2}{|c|}{ Jhelum } & \multicolumn{2}{|c|}{ Layyah } & \multicolumn{2}{|c|}{ T.T. Singh } \\
\hline & $\%$ & $\mathrm{n}$ & $\%$ & $\mathrm{n}$ & $\%$ & $\mathrm{n}$ & $\%$ & $n$ & $\%$ & $\mathrm{n}$ & $\%$ & $n$ \\
\hline Literate & 17 & 61 & 24 & 49 & 21 & 34 & 55 & 59 & 27 & 45 & 48 & 86 \\
\hline Illiterate & 83 & 298 & 76 & 155 & 79 & 130 & 45 & 49 & 73 & 122 & 52 & 94 \\
\hline Total & 100 & 359 & 100 & 204 & 100 & 164 & 100 & 108 & 100 & 167 & 100 & 180 \\
\hline
\end{tabular}

Table 3.4: Level of schooling of deceased by district

\begin{tabular}{l|cc|cc|cc|cc|cc|cc|}
\hline & \multicolumn{2}{|c|}{ Bahawalpur } & \multicolumn{2}{|c|}{ Bhakkar } & \multicolumn{2}{|c|}{ Chiniot } & \multicolumn{2}{|c|}{ Jhelum } & \multicolumn{2}{|c|}{ Layyah } & \multicolumn{2}{c|}{ T.T. Singh } \\
& $\%$ & $\mathrm{n}$ & $\%$ & $\mathrm{n}$ & $\%$ & $\mathrm{n}$ & $\%$ & $\mathrm{n}$ & $\%$ & $\mathrm{n}$ & $\mathrm{n}$ \\
\hline $\begin{array}{l}\text { No formal } \\
\text { education }\end{array}$ & 83 & 298 & 76 & 155 & 79 & 130 & 46 & 49 & 73 & 122 & 52 & 94 \\
Primary & 10 & 35 & 13 & 26 & 17 & 27 & 25 & 27 & 14 & 24 & 27 & 49 \\
Secondary & 5 & 16 & 6 & 13 & 2 & 4 & 19 & 21 & 7 & 12 & 12 & 21 \\
Higher & 2 & 9 & 3 & 7 & 2 & 3 & 10 & 11 & 4 & 6 & 7 & 12 \\
Don't know & 0 & 1 & 2 & 3 & 0 & 0 & 0 & 0 & 2 & 3 & 2 & 4 \\
Total & 100 & 359 & 100 & 204 & 100 & 164 & 100 & 108 & 100 & 167 & 100 & 180 \\
\hline
\end{tabular}




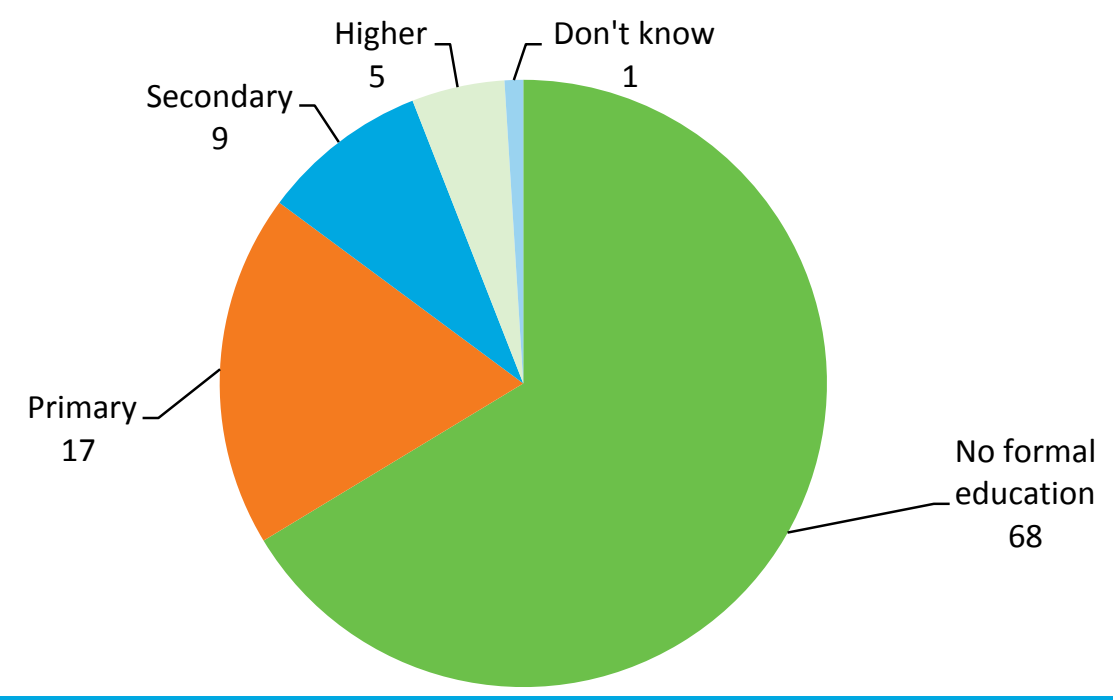

Half of the husbands of the deceased women were illiterate (Table 3.5). By district, the most literate husbands were in district Jhelum where three quarters had received education. The lowest literacy level among husbands was in Bahawalpur, where only a third were educated.

Table 3.5: Level of schooling of the deceased's husband, \%

\begin{tabular}{lcccccc}
\hline Level of Schooling & Bahawalpur & Bhakkar & Chiniot & Jhelum & Layyah & T.T. Singh \\
\hline No formal education & 64 & 53 & 65 & 25 & 51 & 43 \\
Primary & 12 & 17 & 13 & 22 & 18 & 11 \\
Middle & 9 & 9 & 10 & 18 & 9 & 16 \\
Matriculation & 11 & 17 & 8 & 22 & 15 & 19 \\
Higher & 3 & 3 & 2 & 11 & 5 & 8 \\
Don't know & 1 & 1 & 2 & 2 & 2 & 3 \\
\hline Total $(\mathrm{n})$ & 359 & 204 & 164 & 108 & 167 & 180 \\
\hline
\end{tabular}

The wealth index was calculated for each household by running a factor analysis for 25 household amenities and consumer durable goods, energy sources, and sources of drinking water. This procedure is similar to that used by Filmer and Pritchett (1999). As shown in figure 3.4, the majority of the women belonged to households with a low socioeconomic status (nearly 61 percent). Only 16 percent of the cases were from a higher socioeconomic status. By district, a higher proportion of deceased who were well off belonged to Jhelum, followed by T.T. Singh. The most impoverished women were from Bhakkar and Chiniot.

The socioeconomic status of deceased women is shown by districts in Table 3.6. 
Table 3.6: Socioeconomic status of households by district, \%

\begin{tabular}{lcccccc}
\hline & Bahawalpur & Bhakkar & Chiniot & Jhelum & Layyah & T.T. Singh \\
\hline Low & 33 & 44 & 55 & 12 & 38 & 17 \\
Medium & 54 & 52 & 40 & 48 & 45 & 54 \\
High & 13 & 4 & 5 & 40 & 17 & 29 \\
\hline Total (n) & 359 & 204 & 164 & 108 & 167 & 180 \\
\hline
\end{tabular}

Overall, nearly one-third percent PRDs had taken place among women of a lower socioeconomic status, and one-half had occurred among women of medium socioeconomic status, while only 16 percent had occurred among women from a higher socioeconomic status (Figure 3.4). This clearly shows that poverty continues to be a major obstacle for women in accessing appropriate and timely care and contributing to maternal deaths and contributing to maternal deaths.

\section{Figure 3.4: Socioeconomic status of deceased women, \%}

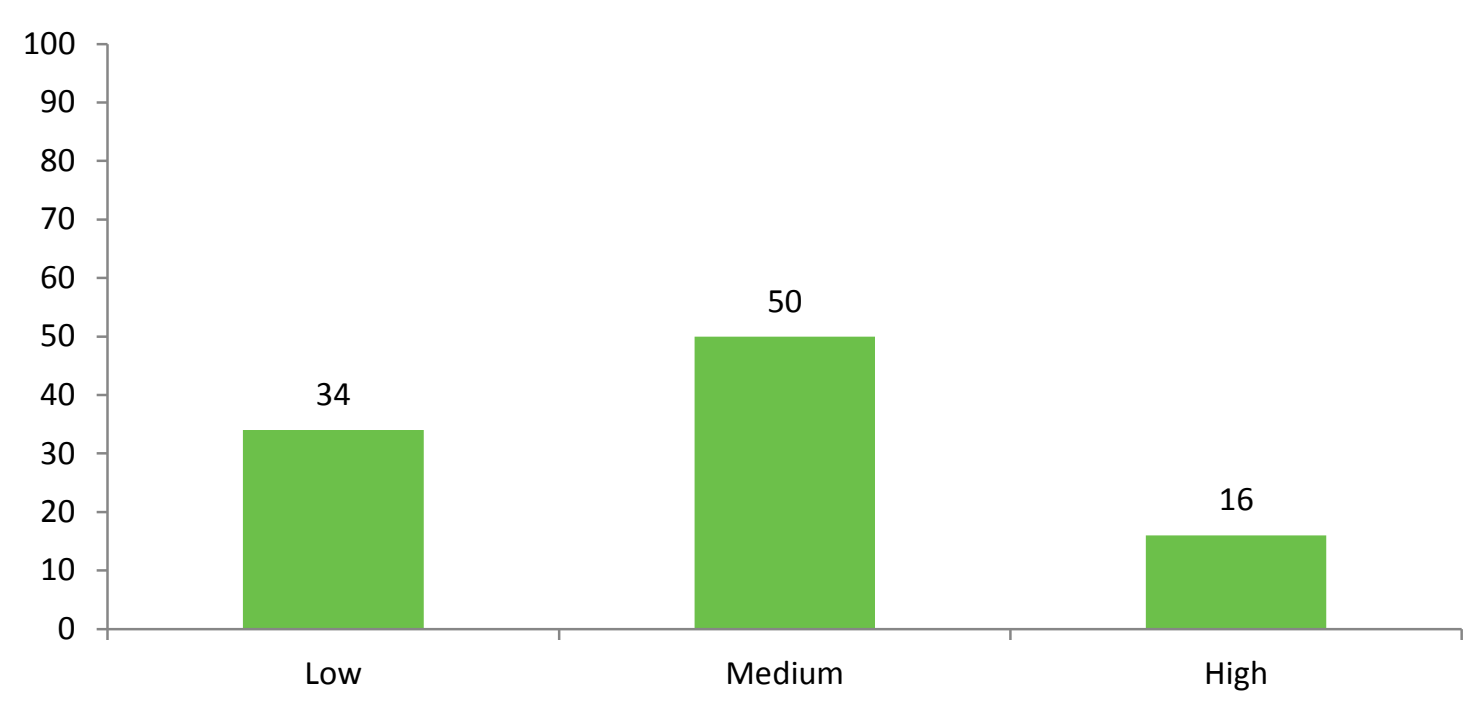

As shown in Figure 3.5, half of the PRDs occurred among women who were multiparous, i.e., had borne 2-5 children. Nearly 16 percent of deaths were among women who had more than five pregnancies, while 34 percent of deaths occurred in women who had one child or none.

Reported contraceptive ever use was 5 percent. The highest reported contraceptive use was in Jhelum, 11 percent, and the lowest use was in Bhakkar, 2 percent (data not shown). 


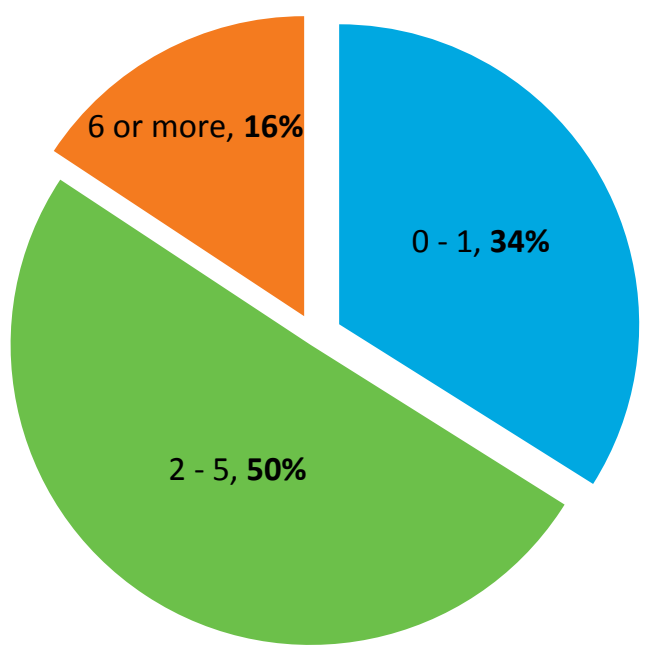

\subsection{Incidence of Maternal Mortality}

This study identified 12,334 deaths of WRA in a total population of 2.6 million WRA, yielding a total death rate of 417 per 100,000 WRA. As Table 3.7 shows, the death rate among WRA varied by district, with the lowest recorded in Jhelum (336) and Bahawalpur (392) and the highest in T.T. Singh (540) and Chiniot (540). The non-pregnancy related death rate was 372 per 100,000 WRA.

The proportion of PRDs among deaths of WRA was 11 percent. This agrees with the "Trends in Maternal Mortality Estimates" report of WHO, UNICEF, UNFPA, and the World Bank, which estimates the proportion of PRDs in WRA deaths at 11.4\% for Pakistan (WHO, 2012).

Table 3.7: Death rates of women of reproductive age per 100,000 (excluding women aged $<15$ or $>49$ years)

\begin{tabular}{lcccccc}
\hline Districts Name & $\begin{array}{c}\text { Population of } \\
\text { WRA }\end{array}$ & $\begin{array}{c}\text { Number } \\
\text { of WRA } \\
\text { deaths }\end{array}$ & $\begin{array}{c}\text { Number of } \\
\text { non-PRDs }\end{array}$ & $\begin{array}{c}\text { Number of } \\
\text { PRDs }\end{array}$ & $\begin{array}{c}\text { Death rate of } \\
\text { WRA per } \\
100,000\end{array}$ & $\begin{array}{c}\text { Non-PRD rate of } \\
\text { WRA per } \\
100,000\end{array}$ \\
\hline Bahawalpur & 801,293 & 3143 & 2784 & 359 & 392 & 347 \\
Bhakkar & 362,134 & 1743 & 1539 & 204 & 481 & 425 \\
Chiniot & 327,019 & 1766 & 1602 & 164 & 540 & 490 \\
Jhelum & 531,770 & 1257 & 1149 & 108 & 236 & 216 \\
Layyah & 303,517 & 1384 & 1217 & 167 & 456 & 401 \\
T.T.Singh & 332,097 & 1793 & 1613 & 180 & 540 & 486 \\
Total & $\mathbf{2 , 6 5 7 , 8 3 0}$ & $\mathbf{1 1 , 0 8 6}$ & $\mathbf{9 , 9 0 4}$ & $\mathbf{1 , 1 8 2}$ & $\mathbf{4 1 7}$ & $\mathbf{3 7 2}$ \\
\hline
\end{tabular}




\subsubsection{Estimating the Probability of Capturing PRDs: Capture-Recapture Technique}

The Made-In Made-For technique acknowledges that the networks tasked with identifying deaths of women of reproductive age would miss out some deaths. To identify these missing deaths, the capture re-capture (CRC) technique was used. This technique provides the number of deaths that have to be adjusted to compensate for the deaths that may have been missed.

The term 'capture-recapture' derives from wildlife applications where a sample of animals from a target population is captured, marked, and released. A second sample is captured at a later time. The number of animals captured each time and both times is noted. In public health applications, individuals are 'captured' on different databases and a key stage is matching, i.e., identifying, individuals who appear on more than one database (Laska and Eugene, 2002) which helps in estimating the "true" number of cases.

We made four critical assumptions in the simple capture-recapture analysis:

- The set of 'individuals' or 'events' to be estimated is fixed, i.e., the number of events cannot increase or decrease.

- Individuals captured by both databases (i.e., more than one informant network) can be matched through follow-up visits and duplicate cases can be resolved.

- Capture in the second sample is independent of capture in the first. Holding separate meetings for the networks and allowing limited time for data collection helped avoid the possibility of contamination and information copying between networks.

- Within each database, the probability of capture does not differ between individuals. This is a limitation of the methodology: some sensitive deaths, such as abortion-related deaths or early pregnancy deaths, may have been missed.

Using the CRC technique, the study team was able to estimate both the total PRDs in the six study districts and the coverage of each network (i.e., the proportion of the total number of PRDs identified by each network). A simple formula was used to estimate the total number of cases:

$\mathrm{T}=\underline{\mathrm{N}}_{1} \underline{\mathrm{XN}} \underline{\underline{2}}$

$\mathrm{M}$

Where $\mathrm{N}$ is the number of cases captured by one or the other networks and $\mathrm{M}$ is the humber or cases captured by both networks (Figure 3.6).

Figure 3.6: Formula to estimate the total numbers of cases through capture and re-capture technique

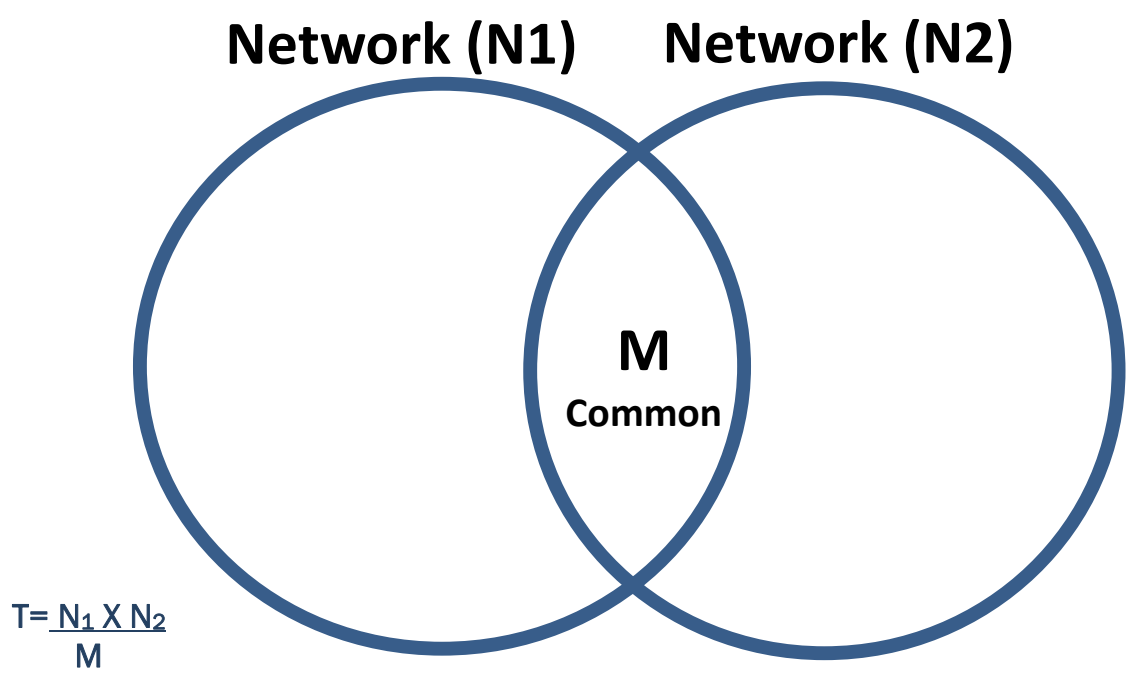


Based on the results of the capture-recapture analysis, estimates of PGDs and of the MMR were revised. The results are presented in Tables 3.9 and 3.10.

\subsubsection{MMR Estimates}

In areas where most deaths occur at home and/or vital registration systems cannot attribute an appropriate cause of death, determining the cause of obstetric deaths is not always possible.

Differentiating the extent to which they are due to indirect or direct obstetric causes or to accidental or incidental events is often problematic. For such circumstances, WHO (in the ICD 10) has introduced the concept of PRDs that has been defined earlier.

In almost all settings, the proportion of all maternal deaths that are incidental or accidental is very small (Geubbels, 2006), so the distinction between PRD and maternal death does not make a significant difference in terms of measuring progress or for program planning. In this study, both terms have been used when we refer to PRDs. We include incidental and accidental causes but exclude them when we refer to maternal deaths.

In order to calculate the MMR, we first estimated the denominator population, i.e., live births.

The denominator population of total live births was based on the size of the estimated WRA population and the total fertility rate. To calculate the number of live births, an estimate of the female population aged 15 to 49 and the age-specific fertility rate were required. These were obtained as follows:

- Social and demographic indicators for Punjab are published annually in the Punjab Development Statistics. This publication also provides yearly population projections at district level. The population for each sample district was obtained from the Punjab Development Statistics 2013.

- The proportion of the female population aged 15-49 was calculated using the district-level pattern presented in Pakistan Social and Living Standards Measurement Survey (PSLMS) 2012-13. This survey is representative at district level and is conducted by the Pakistan Bureau of Statistics.

- To ascertain the number of live births, the Age-Specific Fertility Rates from the Punjab Multiple Cluster Indicator Survey (MICS) 2011 were used. ${ }^{5}$ This is the only survey to provide district-level fertility rates. These rates were used to estimate the number of live births.

Table 3.8: Adjusted Estimation of PRDs after Capture-Recapture Analysis

\begin{tabular}{lcccccc}
\hline District & Recorded PRDs & Unadjusted PRMR & $95 \% \mathrm{Cl}$ & $\begin{array}{c}\text { Adjusted PRDs } \\
\text { after CRC }\end{array}$ & $\begin{array}{c}\text { Adjusted } \\
\text { PRMR }\end{array}$ & $95 \% \mathrm{Cl}$ \\
\hline Jhelum & 108 & 167 & $140-200$ & 137 & 212 & $180-250$ \\
Bhakkar & 204 & 312 & $270-360$ & 252 & 385 & $340-440$ \\
Chiniot & 164 & 231 & $200-270$ & 256 & 361 & $320-410$ \\
T.T. Singh & 180 & 163 & $140-190$ & 378 & 343 & $310-380$ \\
Bahawalpur & 359 & 198 & $180-220$ & 521 & 287 & $260-310$ \\
Layyah & 167 & 217 & $190-250$ & 259 & 336 & $300-380$ \\
Total & $\mathbf{1 , 1 8 2}$ & - & - & 1,803 & - & - \\
\hline
\end{tabular}

${ }^{5}$ Fieldwork for MICS 2014 is complete; however, the report of the survey not yet been released. 
Table 3.9: MMR Estimation by District

\begin{tabular}{lcccccc}
\hline \multicolumn{1}{c}{ District } & Recorded MDs & $\begin{array}{c}\text { Unadjusted } \\
\text { MIMR }\end{array}$ & $95 \% \mathrm{Cl}$ & Adjusted MDs & MIMR & $95 \% \mathrm{Cl}$ \\
\hline Jhelum & 107 & 166 & $135-201$ & 139 & 215 & $180-255$ \\
Bakhhar & 197 & 301 & $260-347$ & 239 & 365 & $320-415$ \\
Chiniot & 162 & 228 & $194-267$ & 249 & 351 & $308-398$ \\
T.T. Singh & 178 & 162 & $138-188$ & 310 & 282 & $251-315$ \\
Bahawalpur & 342 & 189 & $169-210$ & 525 & 289 & $265-316$ \\
Layyah & 167 & 217 & $185-253$ & 259 & 336 & $296-380$ \\
Total & 1153 & - & - & 1721 & $\mathbf{3 0 2}$ & $\mathbf{2 5 8 - 3 4 6}$ \\
\hline
\end{tabular}

The unadjusted composite MMR for the province of Punjab, as shown in table 3.10 before applying the CRC technique, is 204 per 100,000 live births (95\% Cl).

However, after applying the capture-recapture technique, the adjusted composite MMR for the province of Punjab is 302 per 100,000 live births (95\% Cl 258-346). Estimate for the Punjab was obtained by applying population proportions of these six districts to the Punjab population. By district, the lowest adjusted MMR is estimated for Jhelum at 215 (95\% Cl 180-250) and the highest is for Bhakkar, 365 (95\% Cl 320-415).

Table 3.10: Estimation of MMR for the Province of Punjab

\begin{tabular}{lccccc}
\hline District & $\begin{array}{c}\text { District } \\
\text { population }\end{array}$ & $\begin{array}{c}\text { Proportion to } \\
\text { Punjab }\end{array}$ & $\begin{array}{c}\text { Proportion to } \\
\text { 6 district }\end{array}$ & $\begin{array}{c}\text { Unadjusted } \\
\text { Composite } \\
\text { MMR }\end{array}$ & $\begin{array}{c}\text { Adjusted } \\
\text { composite / } \\
\text { MMR after CRC }\end{array}$ \\
\hline Jhelum & $1,181,000$ & 0.012 & 0.109 & 18.15 & 23.50 \\
T.T. Singh & $2,050,000$ & 0.021 & 0.190 & 30.74 & 53.51 \\
Chiniot & $1,203,000$ & 0.012 & 0.111 & 25.39 & 39.08 \\
Bakkhar & $1,412,000$ & 0.014 & 0.131 & 39.34 & 47.70 \\
Bahawalpur & $3,391,000$ & 0.035 & 0.314 & 59.32 & 90.71 \\
Layyah & $1,567,000$ & 0.016 & 0.145 & 31.47 & 48.73 \\
\hline
\end{tabular}




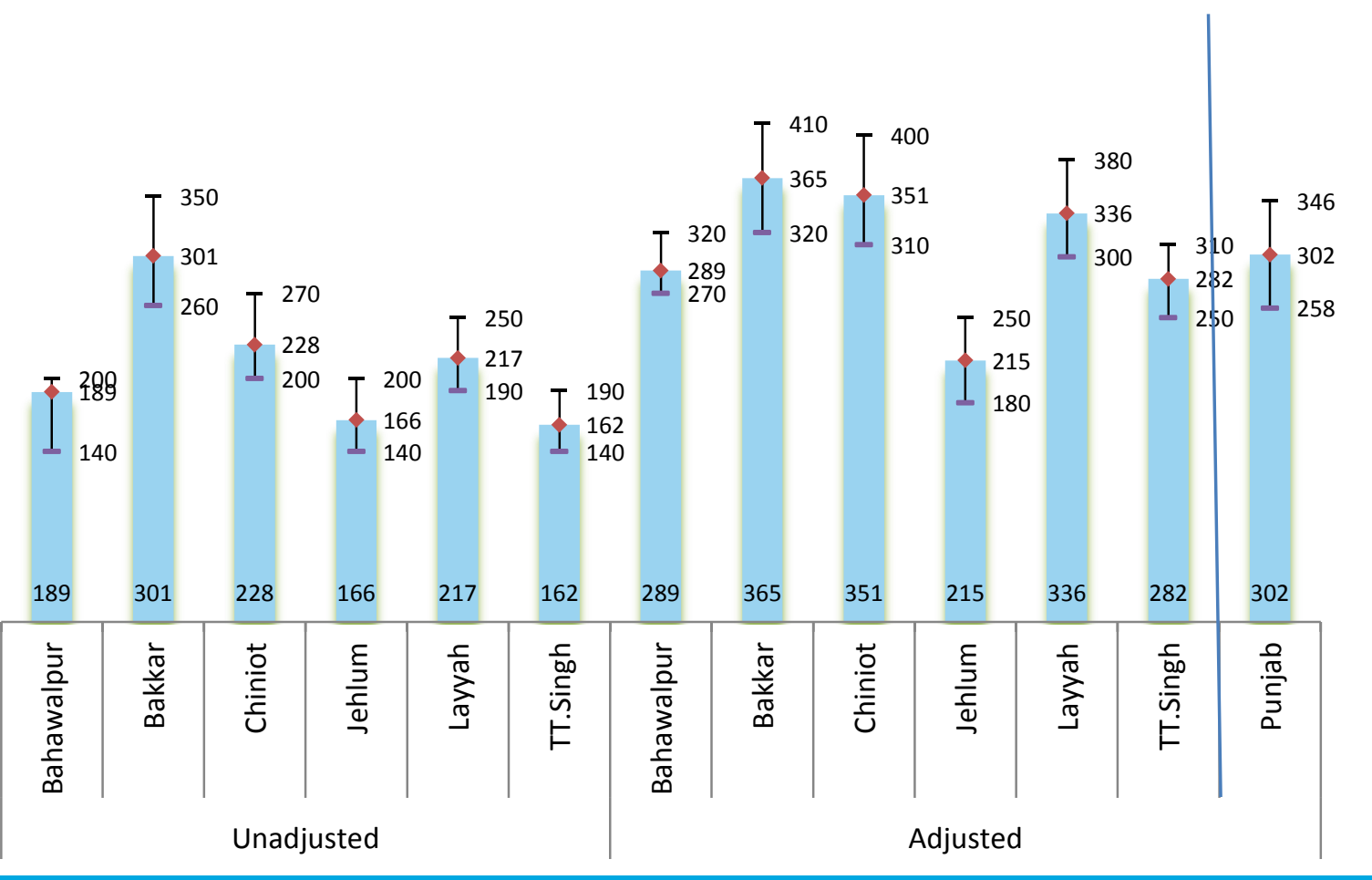

The age-specific MMRs (as shown in Table 3.11) reflect the predicted pattern of being higher among the youngest age group (under the age of 19) except in T.T. Singh and Layyah. Mortality is seen to decline in the 20-24-year age group, but rises steadily and uniformly in the higher age group of 35 years and above. Pregnancy in these two age groups-below 19 and above 35 years-has a significantly higher risk of ending in complications. In the younger age group, the risk is related to the underdevelopment of the osseous tissues, especially the pelvic bones. Older women above 35 are more likely to have conditions such as high blood pressure, diabetes, or cardiovascular disease that could complicate pregnancy outcomes (Stickler, 2012).

Table 3.11: Age-specific unadjusted MMR by district

\begin{tabular}{l|cccccc}
\hline Age in years & Bahawalpur & Bhakkar & Chiniot & Jhelum & Layyah & T.T. Singh \\
\hline Less than 20 & 153 & 269 & 198 & 200 & 111 & 89 \\
$20-24$ & 117 & 181 & 139 & 94 & 170 & 176 \\
$25-29$ & 153 & 270 & 289 & 165 & 219 & 101 \\
$30-34$ & 288 & 331 & 230 & 178 & 334 & 164 \\
$35 / 35+$ & 364 & 471 & 300 & 270 & 258 & 300 \\
Total $(\mathbf{n})$ & $\mathbf{1 8 9}$ & $\mathbf{3 0 1}$ & $\mathbf{2 2 8}$ & $\mathbf{1 6 6}$ & $\mathbf{2 1 7}$ & $\mathbf{1 6 2}$ \\
\hline
\end{tabular}




\subsection{Direct and Indirect Causes of PRDs}

Direct obstetric deaths are those resulting from obstetric complications during pregnancy, delivery, or the postpartum period that are caused by interventions, omissions, incorrect treatment, or a chain of events resulting from any of the above. Indirect obstetric deaths are deaths that occur due to preexisting diseases or diseases that develop during pregnancy that are not due to direct obstetric causes but are aggravated by the physiological effects of pregnancy (WHO, 2012).

In disaggregating the causes of PRD (Table 3.12), it was found that 9 percent of deaths were due to indirect causes and 89 percent due to direct causes, while 3 percent of deaths were due to incidental causes. By district, the highest proportion of deaths by direct causes was in Bhakkar (95 percent), while the highest proportion of death by indirect causes was in Jhelum, 18 percent.

Table 3.12: Comparison of direct and indirect causes of maternal deaths by district

\begin{tabular}{lcc|cc|cc|c}
\hline & \multicolumn{2}{c|}{ Direct cause } & \multicolumn{2}{c|}{ Indirect cause } & \multicolumn{2}{c}{ Incidental death } & \multicolumn{2}{c}{ Total } \\
District & $\%$ & $\mathrm{n}$ & $\%$ & $\mathrm{n}$ & $\mathrm{n}$ & $\mathrm{n}$ \\
\hline Bahawalpur & 84 & 301 & 11 & 41 & 5 & 17 & 359 \\
Bhakkar & 95 & 193 & 1 & 3 & 4 & 8 & 204 \\
Chiniot & 90 & 147 & 8 & 14 & 2 & 3 & 164 \\
Jhelum & 81 & 88 & 18 & 19 & 1 & 1 & 108 \\
Layyah & 93 & 155 & 7 & 12 & & & 167 \\
T.T. Singh & 91 & 163 & 8 & 15 & 1 & 2 & 180 \\
Total & $\mathbf{8 9}$ & $\mathbf{1 0 4 7}$ & $\mathbf{9}$ & $\mathbf{1 0 4}$ & $\mathbf{3}$ & $\mathbf{3 1}$ & $\mathbf{1 1 8 2}$ \\
\hline
\end{tabular}

Among the direct causes, obstetric haemorrhage was identified as the leading cause of death. On disaggregating obstetric haemorrhage, it was found that, in 5 percent of the cases, women had died due to antepartum haemorrhage and 43 percent due to postpartum haemorrhage (PPH). Slightly more than a quarter of the deaths had occurred due to pregnancy-induced hypertension (eclampsia), while in a tenth of cases, death had been caused by puerperal sepsis. The highest proportion of deaths due to PPH was reported in Bhakkar and T.T. Singh (both 56 percent) followed by Chiniot (42 percent) and Layyah (40 percent) and the least proportion was reported in Jhelum (35 percent). 


\section{Case Study: Poor management of postpartum haemorrhage results in a life being lost}

A 34-year-old women from tehsil Sohawa, district Jhelum, asked her husband to take her to a private practice, Dr. Faiza's Clinic, when she started having labour pains. Her husband suggested they go to a major hospital in the city of Sohawa, but she refused, saying they had consulted the same clinic before, and she would like to go there again.

She delivered a normal baby girl, but soon after delivery, she started bleeding heavily. However, the doctor did not take the matter seriously. The patient's family asked the doctor if there was any problem, and whether they should take her to another hospital, but the doctor assured them it was normal for women to bleed after delivery. She gave the woman a drip, and said the bleeding would stop by the time the fluid in the drip ran out. However, the bleeding never stopped, and finally, the woman died.

According to the respondent, had the doctor told them about the patient's true condition, they would have rushed her to a larger tertiary care hospital, but the doctor did not explain her condition and the patient died due to her negligence.

\section{Case Study: A life lost to eclampsia}

A 23-year-old woman from tehsil PD Khan, district Jhelum, had four antenatal care visits. She was diagnosed as having high blood pressure and had frequent headaches. During the last antenatal care visits, the doctor advised her to deliver in a facility. However, she decided against it. When her labour pain started at home, her entire body was swollen. A dai (TBA) was called who said that the membranes had ruptured and bleeding had started profusely. The relatives took her to civil hospital in Jalalpur where there was no doctor to treat her. The nurse tried to give her a drip and some injections. Her relatives decided to move her to a private hospital where she remained for nearly 10 hours. The bleeding did not stop even after delivery. She was transfused blood but her bleeding did not stop and she eventually died.

The specific direct causes of maternal death are listed in Table 3.13 and the proportion of each cause in overall maternal death by direct causes is presented in Figure 3.8. This study's findings are consistent with the finding of WHO, that major direct causes of maternal death in developing countries continue to be severe bleeding, infection, and hypertension (WHO/UNICEF/UNFPA/World Bank, 2010). All the identified direct causes of maternal death, while neither fully preventable nor predictable, can be properly and opportunely treated at primary- and secondary-tier facilities. 
Table 3.13: Direct Causes of Maternal Deaths $(n=1047)$

\begin{tabular}{|c|c|c|c|c|c|c|c|}
\hline & Bahawalpur & Bhakkar & Chiniot & Jhelum & Layyah & T.T. Singh & Total \\
\hline $\begin{array}{l}\text { Abortion-related } \\
\text { death }\end{array}$ & 26 & 3 & 12 & 3 & 5 & 5 & 54 \\
\hline $\begin{array}{l}\text { Anesthesia } \\
\text { related } \\
\text { complication }\end{array}$ & 0 & 1 & 1 & 0 & 0 & 0 & 2 \\
\hline $\begin{array}{l}\text { Antepartum } \\
\text { Hemorrhage }\end{array}$ & 20 & 3 & 10 & 9 & 10 & 4 & 56 \\
\hline Eclampsia & 81 & 54 & 40 & 28 & 42 & 39 & 284 \\
\hline $\begin{array}{l}\text { Ectopic } \\
\text { pregnancy }\end{array}$ & 10 & 1 & 1 & 1 & 3 & 3 & 19 \\
\hline Obstructed labour & 18 & 0 & 4 & 2 & 6 & 4 & 34 \\
\hline $\begin{array}{l}\text { Perforation of } \\
\text { uterus }\end{array}$ & 0 & 0 & 0 & 1 & 0 & 0 & 1 \\
\hline $\begin{array}{l}\text { Placental } \\
\text { abruption }\end{array}$ & 0 & 0 & 0 & 0 & 1 & 0 & 1 \\
\hline $\begin{array}{l}\text { Post-natal } \\
\text { depression }\end{array}$ & 0 & 0 & 0 & 1 & 0 & 0 & 1 \\
\hline $\begin{array}{l}\text { Postpartum } \\
\text { Hemorrhage }\end{array}$ & 95 & 109 & 62 & 31 & 62 & 92 & 451 \\
\hline Pre-eclampsia & 3 & 12 & 1 & 1 & 2 & 0 & 19 \\
\hline Puerperal sepsis & 43 & 10 & 14 & 11 & 23 & 13 & 114 \\
\hline Ruptured uterus & 3 & 0 & 1 & 0 & 1 & 0 & 5 \\
\hline $\begin{array}{l}\text { Surgical } \\
\text { complication }\end{array}$ & 2 & 0 & 1 & 0 & 0 & 2 & 5 \\
\hline Uterine inversion & 0 & 0 & 0 & 0 & 0 & 1 & 1 \\
\hline Total (n) & 301 & 193 & 147 & 88 & 155 & 163 & 1047 \\
\hline
\end{tabular}

Figure 3.8: Proportion of direct maternal deaths

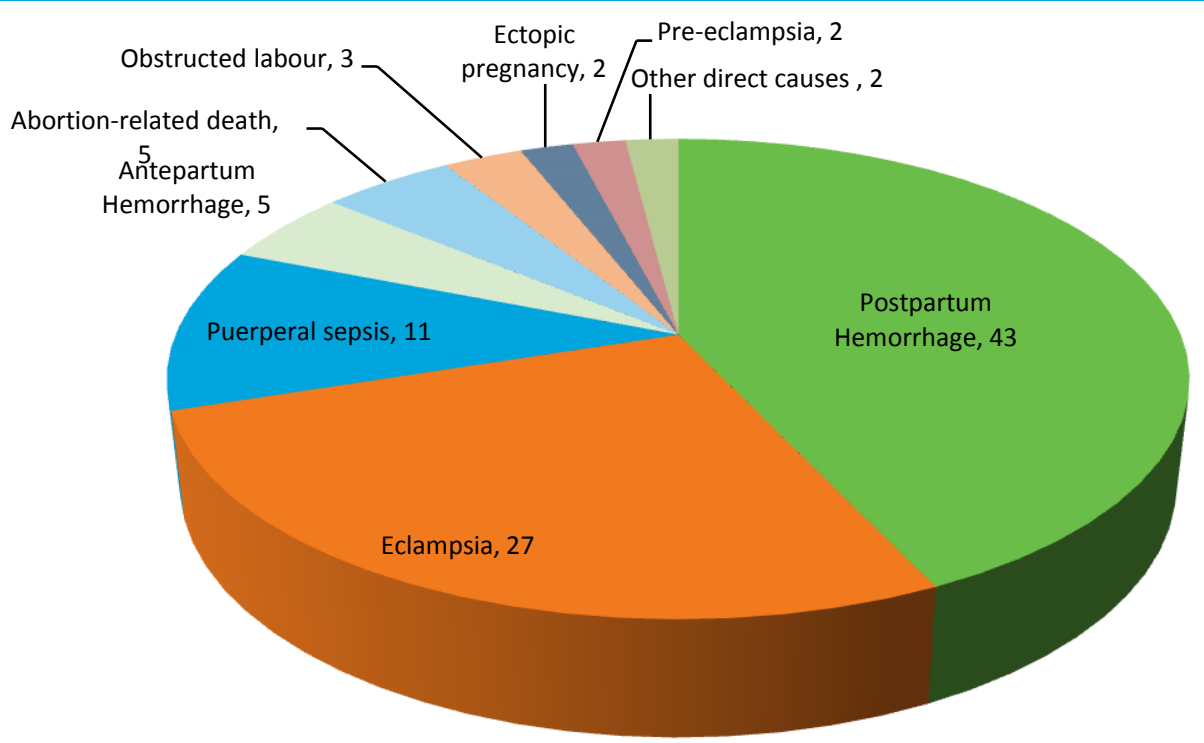


The link between obstetric haemorrhage and eclampsia by parity was also examined. It was found that a higher proportion of multiparous women (those who had borne more than one child) developed obstetric haemorrhage compared to nulliparous women (those who had not borne any child before). The difference was statistically significant $(\mathrm{P}<0.005)$. Obstetric hypertension was higher among nulliparous women. Postpartum haemorrhage was more common among multiparous women (i.e. women having 25 children). In grand multipara (where a woman has more than five children), PPH could occur due to uterine atony, lack of uterine retraction, and injuries and lacerations (Shahid and Mushtaq, 2009; Miller et al., 2004).

\section{Case Study: Preventing repeated pregnancies could have saved her life}

A 30-year-old woman from tehsil Bhowana, district Chiniot had been married five years and had two daughters. In the sixth month of her third pregnancy, she had an ultrasound performed that told her she was expecting another daughter. Wanting a son, and no more daughters, she decided to abort her pregnancy.

She went to her aunt's house, called a birth attendant, and asked her to help her abort. The birth attendant gave her a tablet for this, but it did not work. The birth attendant therefore gave her another tablet to place inside her womb. On the third day of taking the second medicine, the woman started to bleed heavily. The birth attendant said her pregnancy had been aborted. But the bleeding increased and the woman's condition deteriorated. The birth attendant advised the woman to call a doctor. However, eventually, the woman died.

The indirect causes of maternal mortality identified are listed in Table 3.14. Among these, major causes were anaemia of pregnancy, responsible for a third of deaths by indirect causes; followed by renal failure, responsible for 14 percent of such deaths; and respiratory complications, which claimed 13 percent of lives lost to indirect causes. The proportion of individual causes in overall maternal deaths by indirect causes is shown in Figure 3.9.

Table 3.14: Indirect causes of maternal deaths $(n=104)$

\begin{tabular}{l|ccccccc}
\hline & Bahawalpur & Bhakkar & Chiniot & Jhelum & Layyah & T. Singh & Total \\
\hline Acute abdomen & 0 & 0 & 0 & 0 & 0 & 1 & 1 \\
Anemia of pregnancy & 15 & 0 & 5 & 3 & 3 & 6 & 32 \\
Aneurysm rupture/Brain & 0 & 0 & 0 & 1 & 0 & 0 & 1 \\
tumour & & & & & \\
Breast cancer metastatic & 0 & 0 & 0 & 0 & 1 & 0 & 1 \\
CNS & 1 & 1 & 0 & 1 & 1 & 0 & 4 \\
CVS & 4 & 2 & 2 & 0 & 0 & 0 & 8 \\
Diabetes & 1 & 0 & 1 & 5 & 0 & 0 & 7 \\
Diarrheal diseases & 1 & 0 & 0 & 2 & 0 & 1 & 4 \\
Drug reaction & 0 & 0 & 1 & 0 & 0 & 0 & 1 \\
GIT & 0 & 0 & 1 & 0 & 1 & 0 & 2 \\
Infectious disease & 3 & 0 & 0 & 0 & 1 & 0 & 4 \\
Leukemia & 0 & 0 & 0 & 0 & 0 & 1 & 1 \\
Renal failure & 14 & 0 & 0 & 1 & 0 & 0 & 15 \\
Respiratory complication & 1 & 0 & 2 & 5 & 4 & 2 & 14 \\
Suicide & 1 & 0 & 2 & 1 & 1 & $\mathbf{4}$ & 9 \\
\hline Total (n) & $\mathbf{4 1}$ & $\mathbf{3}$ & $\mathbf{1 4}$ & $\mathbf{1 9}$ & $\mathbf{1 2}$ & $\mathbf{1 5}$ & $\mathbf{1 0 4}$ \\
\hline
\end{tabular}




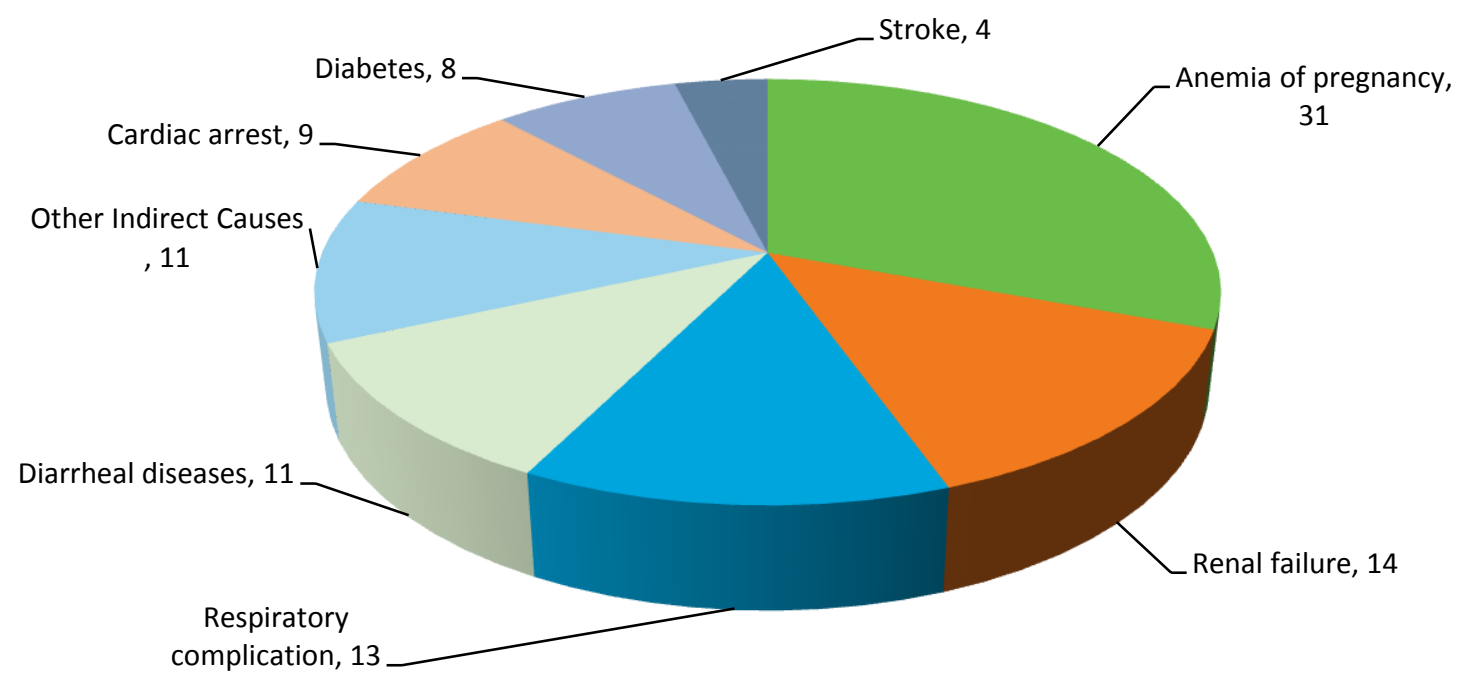

In estimating the MMR, deaths by accidental and homicidal causes (listed in Table 3.15) were excluded. It is debatable whether these deaths should be included as maternal deaths, although there is growing evidence that being pregnant can place women at greater risk of dying from homicide (Ronsmans et al., 2003; Graham \& Hussein 2006).

Among the incidental causes, the highest proportion was in Bahawalpur, where 13 deaths were reported to be due to road traffic accidents. Three cases of homicide and 4 cases of snake bite were also reported. The least number of incidental deaths were reported in Jhelum where there was only one death reported due to an accident.

Table 3.15: Number of incidental PRDs by district

\begin{tabular}{lcccccc}
\hline & Bahawalpur & Bhakkar & Chiniot & Jhelum & T.T. Singh & Total \\
\hline $\begin{array}{l}\text { Assault /Murder / } \\
\text { Poisoning }\end{array}$ & 4 & 4 & 1 & 0 & 1 & 10 \\
$\begin{array}{l}\text { Electric shock / Road } \\
\begin{array}{l}\text { traffic accident / Snake } \\
\text { bite }\end{array}\end{array}$ & 13 & 4 & 2 & 1 & 1 & 21 \\
\hline Total $(\mathrm{n})$ & $\mathbf{1 7}$ & $\mathbf{8}$ & $\mathbf{3}$ & $\mathbf{1}$ & $\mathbf{2}$ & $\mathbf{3 1}$ \\
\hline
\end{tabular}




\section{Maternity Care}

Reproductive healthcare includes provision of antenatal, natal and postnatal care, including family planning services. The aim of reproductive healthcare provision is to reduce maternal morbidity and mortality. The adequacy of maternity care received by women was an important area covered during the study's verbal autopsies of maternal deaths. This section presents the findings of the study regarding antenatal, delivery and postnatal care received by the deceased women.

\subsection{Antenatal Care}

Prenatal or antenatal care (ANC) refers to pregnancy-related healthcare check-ups carried out at a health facility or at home by a healthcare provider prior to delivery. According to WHO, a pregnant woman should have at least four antenatal visits to monitor her pregnancy for early detection and management of pregnancy-related complications. The quality of prenatal care is assessed by the type of provider conducting the check-up, the number of visits, the investigations carried out, and management prescribed.

Table 4.1 shows that nearly two-fifths of the pregnant women documented had had more than three antenatal check-ups. By district, the highest proportion of women who had not availed ANC was reported in Bhakkar followed by Chiniot. Amongst women who had more than three antenatal visits, the highest proportion (nearly two-thirds of women) was reported from Jhelum, followed by T.T. Singh. In Jhelum, only 7 percent women had not received any ANC. In total, nearly 82 percent women had received antenatal care ranging from one to three visits or more; with 41 percent having made more than three visits. Our findings are close to those reported by the PDHS 2012-13, according to which 78 percent women had received antenatal care in Punjab.

Table 4.1: Percentage of ANC visits by district, \%

\begin{tabular}{|c|c|c|c|c|c|c|c|}
\hline $\begin{array}{l}\text { Number of ANC } \\
\text { Visits }\end{array}$ & Bahawalpur & Bhakkar & Chiniot & Jhelum & Layyah & T.T. Singh & Total \\
\hline None & 15 & 28 & 21 & 7 & 14 & 9 & 16 \\
\hline One & 10 & 3 & 11 & 2 & 11 & 4 & 7 \\
\hline Two & 23 & 17 & 15 & 8 & 17 & 10 & 17 \\
\hline $\begin{array}{l}\text { Three or more } \\
\text { than three }\end{array}$ & 53 & 49 & 50 & 78 & 56 & 72 & 57 \\
\hline Don't know & 1 & 3 & 4 & 5 & 1 & 4 & 2 \\
\hline Total (n) & 359 & 204 & 164 & 108 & 167 & 180 & 1182 \\
\hline
\end{tabular}


Table 4.2 indicates that nearly three quarters of the women received care from a doctor. Only 3 percent had received antenatal care from a TBA, and in fact none of the women had received care from a TBA in Jhelum. In 17 percent of cases ANC was obtained from a nurse/lady health visitor. ANC from an LHW was reported by nearly 5 percent of the cases, while nearly a sixth had not sought ANC at all.

Table 4.2: Percentage of ANC services by type of provider, \%

\begin{tabular}{lcccccccc}
\hline Type of Provider & Bahawalpur & Bhakkar & Chiniot & Jhelum & Layyah & T.T. Singh & Total \\
\hline $\begin{array}{l}\text { Doctor/Obstetrician/ } \\
\text { Gynaecologist }\end{array}$ & 84 & 55 & 68 & 75 & 76 & 61 & 72 \\
Nurse/LHV & 11 & 21 & 15 & 23 & 16 & 23 & 17 & 5 \\
LHW & 2 & 19 & 3 & 1 & 2 & 7 & 3 & 3 \\
TBA & 3 & 4 & 5 & 1 & 2 & 4 & 3 & 3 \\
Don't know & 0 & 1 & 9 & 0 & 4 & 142 & $\mathbf{1 5 5}$ & $\mathbf{9 6 1}$ \\
\hline Total $(\mathrm{n})$ & $\mathbf{3 0 5}$ & $\mathbf{1 4 0}$ & $\mathbf{1 2 4}$ & 95 & $\mathbf{1 4 2}$
\end{tabular}

Private facilities were preferred for obtaining ANC services, with more than three-fifths of the deceased women having visited a private clinic or hospital for their antenatal check-up (Table 4.3). Only one out of six women had obtained services from a public sector facility.

Table 4.3: ANC services obtained by type of health facility, \%

\begin{tabular}{lcccccc|c}
\hline $\begin{array}{l}\text { Type of Health } \\
\text { Facility }\end{array}$ & Bahawalpur & Bhakkar & Chiniot & Jhelum & Layyah & $\begin{array}{c}\text { S.T. } \\
\text { Singh }\end{array}$ & Total \\
\hline $\begin{array}{l}\text { Private Clinic/ } \\
\text { Hospital }\end{array}$ & 64 & 41 & 75 & 64 & 59 & 63 & $\mathbf{6 1}$ \\
$\begin{array}{l}\text { Government } \\
\text { hospital }\end{array}$ & 14 & 24 & 9 & 28 & 28 & 8 & $\mathbf{1 7}$ \\
LHW House & 2 & 16 & 3 & 1 & 2 & 7 & $\mathbf{5}$ \\
MNCH Center & 3 & 9 & 4 & 4 & 4 & 4 & $\mathbf{4}$ \\
TBA & 4 & 4 & 2 & 0 & 2 & 2 & $\mathbf{3}$ \\
Don't know & 13 & 6 & 7 & 3 & 8 & 17 & $\mathbf{1 0}$ \\
\hline Total $(\mathbf{n})$ & $\mathbf{3 0 5}$ & $\mathbf{1 4 0}$ & $\mathbf{1 2 4}$ & 95 & $\mathbf{1 4 2}$ & $\mathbf{1 5 5}$ & $\mathbf{9 6 1}$ \\
\hline
\end{tabular}

Slightly more than half of the women were provided iron folate tablets, two-thirds had received tetanus toxoid (TT) vaccination, and slightly more than four-fifths had had a urine and haemoglobin test done (Table 4.4). 
Table 4.4: Proportion of Different ANC services availed, \%

\begin{tabular}{lcccccc|c}
\hline ANC Service & Bahawalpur & Bhakkar & Chiniot & Jhelum & Layyah & T.T. Singh & Total \\
\hline $\begin{array}{l}\text { Used Iron/ Folic } \\
\text { tablets }\end{array}$ & 64 & 17 & 56 & 72 & 61 & 63 & 55 \\
$\begin{array}{l}\text { Received TT } \\
\text { vaccination }\end{array}$ & 67 & 52 & 63 & 84 & 72 & 74 & 67 \\
$\begin{array}{l}\text { Urine test } \\
\text { conducted }\end{array}$ & 31 & 23 & 31 & 79 & 41 & 52 & 39 \\
$\begin{array}{l}\text { Hemoglobin test } \\
\text { conducted }\end{array}$ & 34 & 23 & 29 & 75 & 31 & 54 & 38 \\
\hline \begin{tabular}{l} 
Total $(\mathbf{n})$ \\
\hline
\end{tabular} & 359 & $\mathbf{2 0 4}$ & 164 & 108 & 167 & 180 & 1182 \\
\hline
\end{tabular}

Note: The type of ANC service was a multiple response variable.

In all respects, Jhelum fared better than other districts in terms of provision of ANC services. Iron folate acid use and urine and haemoglobin testing was highest in Jhelum and lowest in Bhakkar, where only a sixth of the women had used iron and folate tablets. In total, nearly 55 percent of women who received ANC had used iron/folate tablets. According to the PDHS 2012-13, 45 percent took iron tablets or syrup during their last pregnancy. Nearly two-thirds of women had received tetanus toxoid injections. A third of women were therefore vulnerable to maternal and neonatal tetanus.

Biomedical risk factors are conditions or behaviours present during pregnancy that might increase the risk of an adverse pregnancy outcome. In its analysis of presence of such factors, the study considered age below 18 or greater than 34 , parity greater than four, the presence of diseases including circulatory system, metabolic diseases (diabetes), and hypertension. It was found that, in total, 64 percent women had at least one identified biomedical risk factor (as shown in table 4.5).

Table 4.5: Presence of biomedical risk factors, \%

\begin{tabular}{lcccccc|c}
\hline & Bahawalpur & Bhakkar & Chiniot & Jhelum & Layyah & T.T. Singh & Total \\
\hline At least one risk factor & 59 & 65 & 68 & 73 & 56 & 69 & 64 \\
\hline Less than 18 years & 2 & 3 & 4 & 1 & 2 & 1 & 2 \\
More than 35 years & 15 & 21 & 10 & 15 & 17 & 12 & 15 \\
Parity above 4 & 25 & 26 & 27 & 26 & 19 & 19 & 24 \\
35+ years old \& parity above 4 & 10 & 13 & 7 & 9 & 10 & 5 & 9 \\
\hline High Blood Pressure & 27 & 39 & 38 & 41 & 24 & 42 & 34 \\
Heart Disease & 5 & 4 & 2 & 10 & 7 & 2 & 5 \\
Diabetes & 0 & 1 & 2 & 6 & 1 & 3 & 2 \\
\hline Previous C-section & 15 & 6 & 18 & 21 & 15 & 26 & 16 \\
\hline Total (n) & 359 & 204 & 164 & 108 & 167 & 180 & 1182 \\
\hline
\end{tabular}

Note: The type of risk factor was a multiple response variable. 
Very importantly, proper ANC screening can identify the various biomedical risk factors that can complicate pregnancy outcomes. Identification of such risk factors and their proper management can significantly lower adverse outcomes. Two of the highly prevalent risk factors present in the mothers who died included presence of previously diagnosed hypertension and having four or more children.

During their antenatal visits, nearly a third of the women had been identified as high-risk by their provider on the basis of an examination or test results and a third were advised to deliver in a health facility (Table 4.6). A high-risk pregnancy is determined by certain markers, such as the height of the woman, pallor, protein in the urine, low haemoglobin, etc. In some women, symptoms can include convulsions and pedal oedema, etc. A third of the deceased women had been identified high risk based on these markers. About 16 percent of the women had been identified as high risk based on complications they had suffered during their last pregnancy. While a fifth had been identified as highrisk on the basis of illness identified during current pregnancy. Complications in previous deliveries could include prolonged labour, pregnancy-induced diabetes, eclampsia, etc.

Table 4.6: Reasons identified for referral to hospital during ANC visits, \%

\begin{tabular}{lcccccc|c}
\hline Reason for Referral & Bahawalpur & Bhakkar & Chiniot & Jhelum & Layyah & T.T. Singh & Total \\
\hline $\begin{array}{l}\text { Complication in } \\
\text { previous delivery }\end{array}$ & 10 & 8 & 23 & 32 & 19 & 15 & 16 \\
$\begin{array}{l}\text { Symptoms during } \\
\text { current pregnancy }\end{array}$ & 17 & 41 & 12 & 23 & 11 & 10 & 19 \\
$\begin{array}{l}\text { High risk } \\
\text { pregnancy }\end{array}$ & 44 & 45 & 14 & 19 & 31 & 37 & 33 \\
$\begin{array}{l}\text { Others } \\
\text { Don't know }\end{array}$ & 15 & 1 & 6 & 15 & 8 & 10 & 9 \\
\hline Total $(\mathrm{n})$ & 14 & 5 & 45 & 11 & 31 & 28 & $\mathbf{2 3}$ \\
\hline
\end{tabular}

Antenatal care was influenced by literacy and socio-economic levels. Women who were literate and belonged to middle or upper socio-economic class were more likely to have had three or more antenatal visits as compared to illiterate and lower socio-economic class women.

From the preceding findings, we can conclude that most women were aware of the importance of ANC, most had received proper attention in terms of tests done and supplements provided, a high proportion had been identified as high-risk and, accordingly, given the correct advice on institutional delivery.

\subsection{Dellvery Care}

One of the key interventions to reduce maternal and neonatal mortality is to encourage women to deliver in an environment that is clean, has technically competent skilled staff, and is equipped with lifesaving supplies. Whether deliveries occur at home or are facility based, the presence of a skilled birth attendant linked to an easily approachable and fully functional health system can avert many deaths. According to the PDHS 2012-13, 48 percent of births in Pakistan take place in a health facility; this study found that nearly 56 percent of deliveries took place at a health facility. Another finding similar to the findings of PDHS 2012-13 was that most of the facility-based deliveries took place in a 
private sector facility (Table 4.7 and Figure 4.1). Based on the verbatim accounts of the deceased's relatives it was seen that preference for private care facilities was based on a perception that the quality of care offered within these facilities was better than in the public sector.

\section{Preference for Private Care}

"We took her to civil hospital for an antenatal check-up. The lady doctor checked her and my daughter liked her because of her good dealing. Then we started going to her private clinic at her home. She used to take Rs. 500 per visit. My daughter wanted the same doctor to conduct her delivery. She asked me to request the doctor to handle her case of delivery at her private health facility. My daughter did not want to go to government hospital because of the very dirty labour room."

\section{Mother of a Deceased Woman, Layyah}

My daughter said that she wanted to get her operation done in Bahawalpur Hospital. Her cousin was operated for appendicitis in the same hospital and, therefore, she liked that hospital. So, we agreed with her.

\section{Mother of a Deceased Woman, Bahawalpur}

Table 4.7: Place of delivery by type, \%

\begin{tabular}{lcccccc|c}
\hline Place of Delivery & Bahawalpur & Bhakkar & Chiniot & Jhelum & Layyah & T.T. Singh & Total \\
\hline Home & 31 & 30 & 27 & 21 & 30 & 27 & 29 \\
DHQ/Teaching Hospital & 22 & 13 & 5 & 19 & 17 & 8 & 15 \\
$\begin{array}{l}\text { Public Secondary Care } \\
\text { Facility }\end{array}$ & 4 & 5 & 3 & 8 & 12 & 4 & 5 \\
Private clinic & 26 & 36 & 46 & 45 & 31 & 46 & 36 \\
On way to health facility & 0 & 0 & 0 & 0 & 1 & 3 & 1 \\
Don't know & 17 & 16 & 19 & 7 & 9 & 12 & 14 \\
\hline Total (n) & $\mathbf{2 4 7}$ & $\mathbf{1 6 5}$ & $\mathbf{1 2 9}$ & $\mathbf{7 5}$ & $\mathbf{1 1 9}$ & $\mathbf{1 4 6}$ & $\mathbf{8 8 1}$ \\
\hline
\end{tabular}

Figure 4.1: Place of delivery

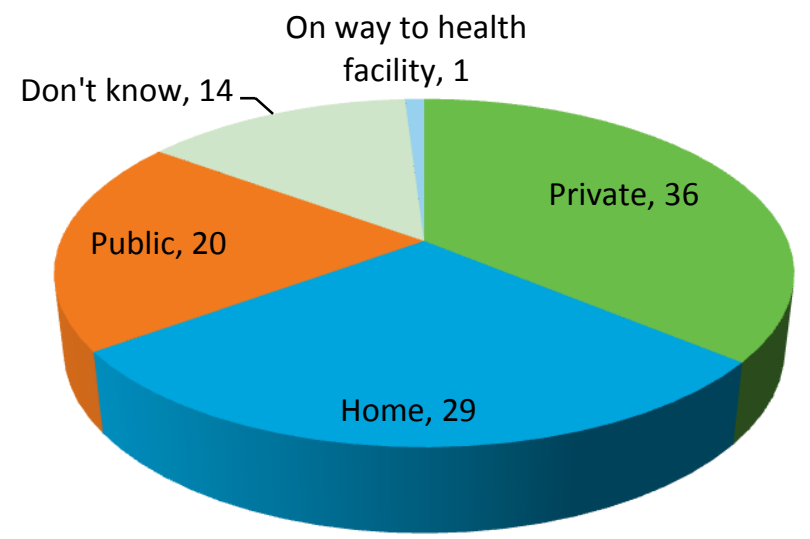




\subsubsection{Caesarean Sections for Maternal Complications}

Caesarean sections (C-sections) are performed when there is a risk to the life of the mother or foetus and when vaginal delivery is either not possible or not recommended. WHO recommends that the Csection rate not be higher than 10-15 percent (WHO, Lancet 1985). This study found that 22 percent of the women had undergone a $\mathrm{C}$-section prior to death. The highest proportion of women who underwent a c-section was in T.T. Singh, 33 percent, followed by Jhelum, 24 percent, and Layyah, 14 percent.

Case Study: A mismanaged caesarean section operation

A 29-year-old woman from tehsil and district Jhelum remained fine during her last pregnancy. However, she used to complain of pain in her lower abdomen. She had regular checkups throughout her pregnancy. During her last check-up, the doctor had told her that her baby would be delivered through a C-section.

On the given date, she was taken to the hospital. The doctors put her on a drip without performing any checkup. The doctor said that she would operate her when labour started. Meanwhile, her membranes ruptured and her mother asked the doctor if she could deliver the baby normally. The doctor disagreed and asked to take the patient somewhere else if they wanted a normal delivery.

She made the woman wait for an hour before taking her to the Operation Theatre. She had only one nurse with her. They took her to the Operation Theatre at about 06:30 pm and the operation lasted for a long time. When they came out, their clothes and hands were covered in blood. They brought the patient out. The doctors said that she needed a blood transfusion as she had lost blood. The relatives arranged for two bottles of blood but doctor asked for more, and they could not arrange more blood. The doctor then asked the relatives to take her to CMH Kharian. According to family members, she had died at that time because she was not moving at all. They faced difficulty in arranging the vehicle as the hospital had no ambulance. When they reached CMH Kharian, doctors told them that she was already dead.

There was some variation in the proportion of women who had undergone a C-section by type of complication. Slightly more than two-fifths of women had undergone a C-section due to high blood pressure (pre-eclampsia), followed by being unconsciousness for more than 24 hours, 33 percent; having fever, 14 percent; convulsions, 12 percent; and prolonged labour, 4 percent. In 16 percent of the cases, there was a previous history of C-sections, which itself is an indication for the procedure.

\subsubsection{Pregnancy Outcomes}

The study found that 62 percent of pregnancies ended with a live birth (Table 4.8), while stillbirths occurred in nearly 24 percent of the cases. Nearly 3 percent of the pregnancy outcomes were miscarriages and 2 percent were induced abortions.

Nearly, three quarters of the infants born alive had survived till the time of interviews. The highest proportion of surviving infants was in T.T. Singh, 79 percent; followed by Bhakkar, 76 percent; Bahawalpur, 75 percent; Layyah, 72 percent; Jhelum, 71 percent; and Chiniot, 69 percent (data not shown). 
Table 4.8: Delivery outcome in PRDs, \%

\begin{tabular}{lcccccc|c}
\hline $\begin{array}{l}\text { Delivery } \\
\text { Outcome }\end{array}$ & Bahawalpur & Bhakkar & Chiniot & Jhelum & Layyah & $\begin{array}{c}\text { T.T. } \\
\text { Singh }\end{array}$ & Total \\
\hline Live birth & 62 & 64 & 56 & 67 & 60 & 63 & 62 \\
Still birth & 22 & 21 & 24 & 25 & 24 & 28 & 24 \\
Miscarriage & 5 & 2 & 7 & 4 & 3 & 1 & 3 \\
$\begin{array}{l}\text { Induced } \\
\text { abortion }\end{array}$ & 1 & 1 & 4 & 1 & 3 & 1 & 2 \\
$\begin{array}{l}\text { Ectopic } \\
\text { pregnancy }\end{array}$ & 0 & 0 & 0 & 0 & 1 & 0 & 0 \\
Multiple births & 0 & 0 & 1 & 0 & 1 & 0 & 0 \\
Don't know & 10 & 12 & 8 & 3 & 8 & 7 & 9 \\
\hline Total (n) & $\mathbf{2 4 7}$ & $\mathbf{1 6 5}$ & $\mathbf{1 2 9}$ & $\mathbf{7 5}$ & $\mathbf{1 1 9}$ & $\mathbf{1 4 6}$ & $\mathbf{8 8 1}$ \\
\hline
\end{tabular}

\subsection{Postnatal Care}

The postpartum period comprising of 42 days after delivery is important for a variety of reasons. During this period, women can develop severe complications even after a safe delivery unless issues are diagnosed and managed at an early stage. Globally, the majority of maternal deaths occur in the postpartum period (Abou Zahr, 1998). Therefore, postnatal care is particularly important in identifying and treating maternal and neonatal complications. At least one post-natal visit is recommended within 24 hours after delivery and at least three additional visits are recommended.

This study found that slightly more than two-thirds of the deceased women experienced postnatal complications. The most common problem faced in the postnatal period was severe bleeding in 46 percent of cases; followed by unconsciousness, 15 percent; and puerperal fever, 12 percent (Table 4.9). 
Table 4.9: Problems faced during postpartum period by deceased, $\%$

\begin{tabular}{|c|c|c|c|c|c|c|c|}
\hline Postnatal Problem & Bahawalpur & Bhakkar & Chiniot & Jhelum & Layyah & T.T. Singh & Total \\
\hline Severe bleeding & 44 & 68 & 36 & 44 & 39 & 41 & 46 \\
\hline Fever & 13 & 11 & 14 & 19 & 16 & 5 & 12 \\
\hline Foul smelling discharge & - & 1 & 2 & 4 & 3 & - & 1 \\
\hline Sudden chest pain \& collapse & - & - & 3 & 1 & 2 & 2 & 1 \\
\hline Unconsciousness & 12 & 9 & 26 & 36 & 13 & 5 & 15 \\
\hline Visual disturbance & - & 3 & - & - & 3 & 1 & 1 \\
\hline Bleeding from multiple sites & 1 & - & - & 3 & 3 & - & 1 \\
\hline Abnormal behaviour & 1 & 1 & 3 & 3 & 1 & - & 2 \\
\hline Abdominal pain & 3 & 2 & 7 & 11 & 3 & - & 4 \\
\hline Vomiting & 4 & 5 & 9 & 16 & 5 & 1 & 6 \\
\hline Fits & 4 & 3 & 21 & 7 & 8 & - & 6 \\
\hline Severe anaemia & 7 & 11 & 6 & 24 & 8 & 2 & 9 \\
\hline Others & 12 & 9 & 11 & 9 & 15 & 20 & 13 \\
\hline Don't know & 22 & 9 & 17 & 5 & 19 & 29 & 18 \\
\hline Total $(n)$ & 234 & 149 & 121 & 75 & 112 & 133 & 824 \\
\hline
\end{tabular}

Note: The type of problem was a multiple response variable.

Among women who developed postnatal complications, slightly more than two-fifths did not have a check-up done. A sixth had at least one check-up done. While a quarter had 2-3 or more visits (as shown in table 4.10).

Table 4.10: Number of postnatal check-ups received by deceased, \%

\begin{tabular}{lcccccc|c}
\hline $\begin{array}{l}\text { Number of } \\
\text { postnatal } \\
\text { check-ups }\end{array}$ & Bahawalpur & Bhakkar & Chiniot & Jhelum & Layyah & T.T. Singh & Total \\
\hline $\begin{array}{l}\text { No postnatal } \\
\text { Check-up }\end{array}$ & 58 & 32 & 45 & 26 & 55 & 38 & 45 \\
$\begin{array}{l}\text { check-up } \\
\text {-3 Check-ups }\end{array}$ & 17 & 27 & 12 & 7 & 12 & 21 & 17 \\
$>3$ Check-ups & 8 & 17 & 9 & 13 & 10 & 11 & 11 \\
Don't know & 2 & 15 & 7 & 23 & 4 & 2 & 7 \\
\hline Total $(\mathbf{n})$ & 15 & 9 & 27 & 31 & 19 & 28 & 20 \\
\hline
\end{tabular}


Case Study: A complete and thorough postnatal checkup and timely treatment could have saved her life

A 32-year-old woman from tehsil Bhowana, district Chiniot reached the end of her nine-month pregnancy. She experienced labour pains for five hours and delivered a baby in the morning. Both mother and child were fine. The birth attendant did not give her any drip or medicine.

The woman did not face any problem for the first two days, except minor bleeding. However, on the third day, her bleeding increased. The birth attendant was called and she told the family to take her to Bhowana. The woman was taken to a private clinic in Haveli Bata. The doctor checked her and advised that she be taken to Faisalabad Allied

Hospital. She was taken to Hafeez Hospital Ameenpur. There too the doctor advised that she be taken to Faisalabad Allied Hospital.

Eventually, she was taken to a private clinic in Faisalabad. The doctor checked and told the relatives that a piece of placenta was retained and that caused the bleeding. She died at the same facility after 20 minutes. 



\section{Circumstances of Death: Time, Place, and Care-Seeking Behaviour}

This section presents the study's findings about the specific circumstances of deceased women on the day of their demise. In particular, it looks at the stage of pregnancy when the death occurs, the location of women at the time of death, and the care-seeking behaviour of women and their families in the days and hours leading up to their death, with a focus on sources of delay in obtaining care.

\subsection{Time of Death}

Figure 5.1 presents the study's findings regarding the stage of pregnancy at which pregnancy related deaths occurred. Nearly a third of all PRDs occurred before childbirth (antepartum period); nearly 6 percent during the delivery (intrapartum period); and nearly a third in the first 24 hours after delivery (immediately postpartum). Thus, 67 percent of PRDs occurred by the end of the first postpartum day while the remaining third of deaths took place between the second and forty-second postpartum day.

This pattern was generally observed in almost all districts (shown in table 5.1). The exception was Bhakkar where slightly more than half, i.e., 55 percent of deaths took place after 24 hours of delivery in the postpartum period. According to the Institute for Health Metrics and Evaluation (IHME), globally, about a quarter of deaths (24 percent) occur antepartum, another quarter intrapartum and immediately postpartum; and a third (35 percent) are delayed postpartum. The study's findings conform to the global evidence.

Although deaths within six weeks of pregnancy were also identified (6 percent), these may have been underestimated as early pregnancy deaths are often missed and not reported. "Late maternal deaths" were also identified among 21 women, i.e., 1.2 percent of all maternal deaths. These are defined as "the death of a woman from direct or indirect obstetric causes more than 42 days but less than one year after termination of pregnancy" (WHO ICD-10, 2012).

\section{Figure 5.1: Time of PRDs by total}

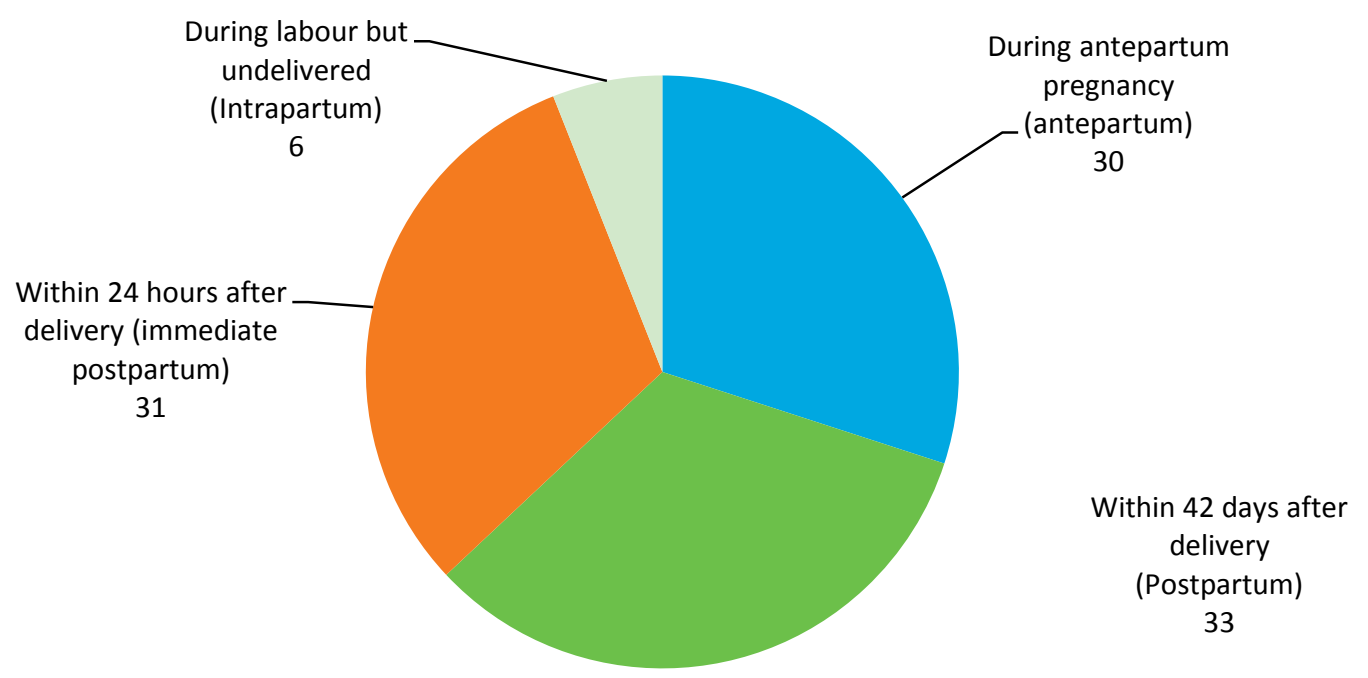


Table 5.1: Time of PRDs by district, \%

\begin{tabular}{|c|c|c|c|c|c|c|}
\hline Time of PRDs & Bahawalpur & Bhakkar & Chiniot & Jhelum & Layyah & T.T. Singh \\
\hline Antepartum & 36 & 23 & 32 & 33 & 33 & 23 \\
\hline $\begin{array}{l}\text { During labour but } \\
\text { undelivered }\end{array}$ & 6 & 8 & 5 & 1 & 4 & 7 \\
\hline $\begin{array}{l}\text { Within } 24 \text { hours after } \\
\text { delivery (intrapartum) }\end{array}$ & 33 & 14 & 35 & 37 & 32 & 36 \\
\hline $\begin{array}{l}\text { Within } 42 \text { days after } \\
\text { delivery (Postpartum) }\end{array}$ & 25 & 55 & 28 & 29 & 31 & 34 \\
\hline Total (n) & 359 & 204 & 164 & 108 & 167 & 180 \\
\hline
\end{tabular}

\subsection{Place of Death}

Of the total 1,182 pregnancy related deaths in all 6 districts, slightly more than a quarter of women (26 percent) died at home. Among these 306 women, 37 percent died without receiving any medical attention, while 21 percent had been assisted by a TBA, community midwife (CMW), LHW or hakeem (traditional medicine practitioner), and in 4 percent cases, an LHV nurse had been present.

Among the rest (844 women), i.e. 71 percent died at a facility. The majority of deaths-nearly three quarters-took place at a health facility (Table 5.2 and Figure 5.2). Among overall deaths, a third of deaths took place at a public sector facility, a quarter at private facilities, and 26 percent at home. By type of facility, the majority of deaths took place at a private clinic, 25 percent, closely followed by public sector tertiary care hospitals (29 percent).

Table 5.2: Place of Pregnancy Related Deaths by District, \%

\begin{tabular}{lcccccc|c}
\hline \multicolumn{1}{c}{ Place } & Bahawalpur & Bhakkar & Chiniot & Jhelum & Layyah & T.T. Singh & Total \\
\hline Home & 24 & 21 & 23 & 15 & 26 & 44 & 26 \\
$\begin{array}{l}\text { DHQ/Teaching } \\
\text { hospital }\end{array}$ & 38 & 25 & 31 & 28 & 30 & 12 & 29 \\
THQ & 3 & 3 & 1 & 2 & 2 & 2 & 2 \\
RHC & 1 & 2 & 1 & 0 & 3 & 0 & 1 \\
Private clinic & 15 & 37 & 28 & 34 & 20 & 32 & 26 \\
On way to health & 14 & 8 & 14 & 20 & 17 & 7 & 13 \\
facility & 5 & 4 & 2 & 1 & 0 & 1 & 3 \\
Incidental death & 5 & 0 & 0 & 0 & 2 & 2 & 1 \\
Don't know & 0 & 204 & 164 & 108 & 167 & 180 & 1182 \\
\hline Total (n) & 359 & & & & & & \\
\hline
\end{tabular}




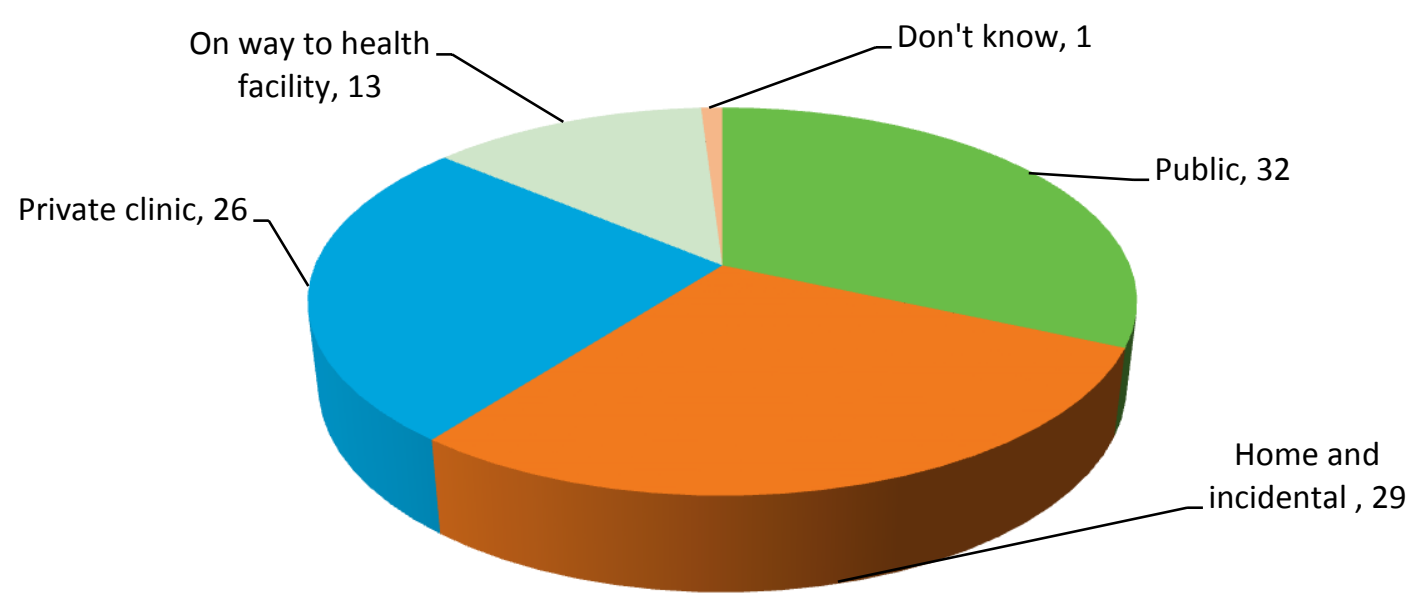

While comparing characteristics of women who had at died home or at a facility, it was seen that a slightly higher percentage of illiterate women, i.e., nearly 76 percent, died at home compared to 70 percent of illiterate women who died at a facility. Proportion of women who died at home were more poor 39 percent compared to 31 percent were from the lower social strata and died at a facility.

\section{Case Study: Continuum of Care}

A woman from tehsil PD Khan, district Jhelum, remained well during the nine months of her pregnancy. She went regularly for antenatal check-ups, and the doctor told her she would deliver the baby normally. When her ninth month ended, the birth attendant was already present in their home, even before she felt labour pains. She delivered the baby normally. But during the delivery, the birth attendant pressed her belly from both sides. She started bleeding right after the delivery. There was no man at home at that time who could arrange a vehicle to take her to the hospital. She bled for 1.5 hours at home and vomited as well during this time.

Then, a vehicle was arranged to take her to a hospital in PD Khan. The roads were bad. The doctor would not admit her at the first hospital and 10 minutes were wasted. She was then taken to Nisar Hospital. Finally, a doctor came and started to check her, but it was too late. After bleeding continuously for three hours since her delivery, she died. 


\subsection{Care Seeking Behavlours: The Delays Model}

According to the model suggested by Thaddeus and Maine (1994), there are three delays that can lead to adverse maternal outcomes. The first delay is at the household level and is related to the time taken to reach a decision as to whether the woman needs help, from whom, and where. The second delay is associated with transporting the woman to a facility. The third delay is associated with the time spent at the facility before she is provided care.

This study found such delays to be operating with fatal consequences in the PRDs identified.

\subsubsection{The First Delay: Making the decision to seek care}

As table 5.3 shows, in an overwhelming majority of cases, it was the woman's husband ( 83 percent) who decided whether she should seek care at a health facility. A very small proportion (6 percent) of the women had reportedly decided themselves. The role of other family members, including the in-laws, was comparatively marginal.

In patriarchal societies such as Pakistan, men are seen as the main decision-makers when it comes to deciding on important family matters. Women are excluded from even the most routine decisions (Jejeebhoy and Sathar, 2001; Bhatta, 2013). This can have a direct impact on the health and wellbeing of women and their families (Gallen et al., 1986). Research conducted by Mullany et al. (2007) shows that educating men and women on maternal healthcare utilization and birth preparedness in urban Nepal led to a positive impact on maternal health behaviours, compared with solely educating women. Reaching out to men with safe motherhood messages could be an important strategy for ensuring that women are able to access appropriate care in time.

Table 5.3: Decision-making to seek care at time of delivery, \%

\begin{tabular}{lcccccc|c}
\hline & Bahawalpur & Bhakkar & Chiniot & Jhelum & Layyah & $\begin{array}{c}\text { T.T. } \\
\text { Singh }\end{array}$ & Total \\
\hline Decision-maker & 2.7 & 0 & 4.1 & 20.9 & 17.9 & 0 & 6.3 \\
Husband & 85.5 & 93.5 & 84.6 & 68.1 & 71.5 & 81.8 & 82.5 \\
Father & 5.5 & 2 & 1.6 & 3.3 & 5.7 & 11.1 & 4.7 \\
Mother & 1.6 & 2 & 3.3 & 4.4 & 1.6 & 0 & 2 \\
Father/Mother/Brother/Sister & 3.1 & 2 & 4.1 & 2.2 & 2.4 & 5.1 & 3.1 \\
in law & 0.4 & 0 & 0 & 0 & 0.8 & 1 & 0.4 \\
Others & 1.2 & 0.7 & 2.4 & 1.1 & 0 & 1 & 1.1 \\
Don't know & $\mathbf{2 5 6}$ & $\mathbf{1 5 3}$ & $\mathbf{1 2 3}$ & $\mathbf{9 1}$ & $\mathbf{1 2 3}$ & $\mathbf{9 9}$ & $\mathbf{8 4 5}$ \\
Total (n) & & & & & &
\end{tabular}

The crucial time period within which a woman needs to reach a health facility, especially in case of an obstetric haemorrhage, is 1 to 2 hours. According to respondents, in most cases, the decision to seek care at a health facility was taken in less than an hour, which is quite swift. As Table 5.4 shows, in majority of cases (92 percent), the decision to seek care at a health facility was taken immediately. 
Table 5.4: Time taken to reach a decision, \%

\begin{tabular}{lccccccc}
\hline & Bahawalpur & Bhakkar & Chiniot & Jhelum & Layyah & T. Singh & Total \\
Less than 1 hour (immediately) & 92 & 96 & 89 & 90 & 91 & 90 & 92 \\
One or more than 1 hour & 5 & 3 & 7 & 7 & 7 & 8 & 6 \\
Don't know & 3 & 1 & 3 & 3 & 2 & 2 & 3 \\
Total $(\mathrm{n})$ & 256 & 153 & 123 & 91 & 123 & 99 & 845 \\
\hline
\end{tabular}

In case of delay, the main reason was due to the lack of readily available funds and the time needed for arranging them (Table 5.5). This was followed by the unavailability of transport. The third biggest (and related) reason was that the health facility was too far away.

Table 5.5: Reasons for delay in decision-making, \%

\begin{tabular}{|c|c|c|c|c|c|c|c|}
\hline Reason & Bahawalpur & Bhakkar & Chiniot & Jhelum & Layyah & T.T. Singh & Total \\
\hline Deceased woman refused & 5 & 0 & 15 & 0 & 18 & 0 & 7 \\
\hline Health facility was too far & 19 & 33 & 23 & 22 & 27 & 10 & 21 \\
\hline No transport was available & 48 & 33 & 0 & 33 & 36 & 30 & 31 \\
\hline No money was available & 33 & 33 & 39 & 11 & 36 & 50 & 34 \\
\hline Husband was away & 19 & 17 & 15 & 22 & 18 & 0 & 16 \\
\hline Husband didn't agree & 0 & 17 & 0 & 11 & 9 & 20 & 7 \\
\hline $\begin{array}{l}\text { Elder woman of HH didn't } \\
\text { agree }\end{array}$ & 5 & 17 & 8 & 11 & 0 & 10 & 7 \\
\hline Don't know & 10 & 33 & 23 & 44 & 9 & 10 & 19 \\
\hline Total (n) & 21 & 6 & 13 & 9 & 11 & 10 & 70 \\
\hline
\end{tabular}

Note: Reason/s for delay was a multiple variable response

As shown in figure 5.3, The families of about two-fifths of deceased women reported they found it difficult to arrange funds for the management of delivery-related complications. By district, respondents in Bahawalpur felt that the costs of treatment were high and difficult to manage. In Jhelum and Layyah, a quarter of the respondents mentioned the high cost of treatment as an obstacle in accessing care. Despite the fact that services at public sector facilities are free, families still have to incur the costs of transportation, arranging blood transfusion, and medicines, etc., which are an obstacle for poorer families. 


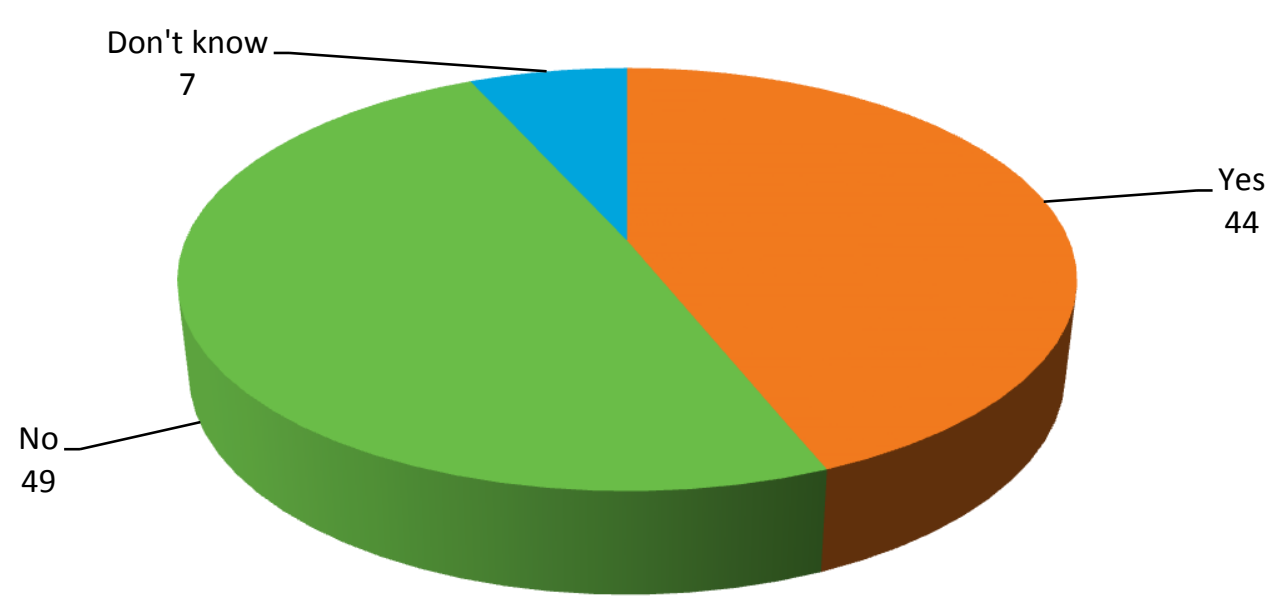

"When our sister in-law went into labour, her in-laws at home insisted on calling a midwife but her husband decided to take her to RHC Dina, Jhelum. A car was arranged to take her to hospital. By the time, the transport was arranged, it was quite late and she delivered in the car on the way to the facility."

Sister-In Law of Deceased, District Jhelum

Decision making as to when and where to seek appropriate care (by the relatives) can be influenced by their level of knowledge and understanding of danger signs in pregnancy (WHO, 2002). Table 5.6 indicates that, except for being aware about excessive bleeding, family members had minimal unprompted knowledge of other danger signs. Nearly half of the respondents knew that an obstetric haemorrhage could lead to maternal death, while one out of ten knew about the importance of loss of foetal movements. Community awareness of these danger signs needs to be enhanced to make them better prepared to recognize early the onset of birth complications. This has always been one of the primary responsibilities of LHWs, and one they should more actively pursue. 
Table 5.6: Proportion of respondents with knowledge of danger signs

\begin{tabular}{|c|c|c|c|c|c|c|c|}
\hline Type of Knowledge & Bahawalpur & Bhakkar & Chiniot & Jhelum & Layyah & T.T. Singh & Total \\
\hline No one was aware & 24 & 8 & 34 & 13 & 42 & 59 & 30 \\
\hline Bleeding & 50 & 71 & 63 & 79 & 48 & 22 & 54 \\
\hline Oedema hand and face & 5 & 16 & 7 & 15 & 7 & 1 & 8 \\
\hline Blurring of vision & 1 & 2 & 2 & 0 & 4 & 0 & 1 \\
\hline Severe headache & 5 & 8 & 10 & 10 & 21 & 3 & 9 \\
\hline Persistent vomiting & 3 & 6 & 2 & 3 & 4 & 1 & 3 \\
\hline Epigastric pain & 0 & 1 & 1 & 2 & 1 & 0 & 1 \\
\hline Tiredness and palpitation & 0 & 1 & 0 & 0 & 1 & 0 & 0 \\
\hline $\begin{array}{l}\text { Jaundice during antenatal } \\
\text { period }\end{array}$ & 2 & 6 & 3 & 0 & 3 & 0 & 2 \\
\hline Loss of fetal movements & 8 & 18 & 7 & 3 & 17 & 1 & 9 \\
\hline $\begin{array}{l}\text { Fever following abortion/ } \\
\text { delivery }\end{array}$ & 7 & 4 & 1 & 4 & 2 & 1 & 4 \\
\hline Low/High blood pressure & 13 & 7 & 1 & 3 & 2 & 14 & 8 \\
\hline Anemia/Weakness & 1 & 1 & 0 & 0 & 0 & 1 & 1 \\
\hline Mal-positioning of fetus & 1 & 1 & 0 & 0 & 0 & 0 & 0 \\
\hline Placenta undelivered/ruptured & 0 & 1 & 0 & 0 & 0 & 1 & 0 \\
\hline Other & 2 & 5 & 1 & 0 & 0 & 0 & 2 \\
\hline Total (n) & 359 & 204 & 164 & 108 & 167 & 180 & 1182 \\
\hline
\end{tabular}

Note: Reason/s for delay was a multiple variable response

\subsubsection{The Second Delay: Time taken to reach a facility}

Nearly half the women who had died at a facility had reached the first contact facility within half an hour of leaving their homes (table 5.7). However, for a fifth of women, it took about an hour to reach a facility.

Table 5.7: Time taken to reach first point of care, \%

\begin{tabular}{|c|c|c|c|c|c|c|c|}
\hline $\begin{array}{l}\text { Time Taken } \\
\text { (Minutes) }\end{array}$ & Bahawalpur & Bhakkar & Chiniot & Jhelum & Layyah & T.T. Singh & Total \\
\hline $1-15$ & 11 & 4 & 14 & 13 & 13 & 19 & 11 \\
\hline $16-30$ & 38 & 40 & 33 & 36 & 49 & 30 & 38 \\
\hline $31-45$ & 14 & 5 & 13 & 7 & 11 & 2 & 10 \\
\hline $46-60$ & 19 & 34 & 24 & 13 & 15 & 18 & 21 \\
\hline $60+\min$ & 9 & 14 & 10 & 21 & 4 & 9 & 11 \\
\hline Don't know & 9 & 3 & 6 & 10 & 8 & 22 & 9 \\
\hline Total (n) & 256 & 153 & 123 & 91 & 123 & 99 & 845 \\
\hline
\end{tabular}




\subsubsection{The Third and "Fourth" Delays}

While relatives did manage to transport most of the women to facilities in time, in many cases, they nevertheless failed to access appropriate timely care due to the third and fourth sources of delay. The third delay was due to the lack of services available at the first point of contact requiring the woman to be referred to another facility. The fourth delay was being referred from the second point of contact to a higher facility.

Among women who did reach health facilities, two-fifths of deaths took place at the first contact facility, 27 percent died upon reaching a second contact facility, and an additional 11 percent had been moved from the second contact facility to the tertiary care facility when they died (Table 5.8).

Table 5.8: Breakdown of PRDs by number of facilities accessed, $\%$

\begin{tabular}{|c|c|c|c|c|c|c|c|}
\hline Access To Facilities & Bahawalpur & Bhakkar & Chiniot & Jhelum & Layyah & T.T. Singh & Total \\
\hline On way to $1^{\text {st }}$ facility & 3 & 1 & 3 & 9 & 2 & 3 & 3 \\
\hline At $1^{\text {st }}$ facility & 48 & 44 & 37 & 39 & 31 & 58 & 44 \\
\hline On way to $2^{\text {nd }}$ facility & 11 & 3 & 4 & 11 & 7 & 3 & 7 \\
\hline At $2^{\text {nd }}$ facility & 28 & 29 & 30 & 14 & 31 & 24 & 27 \\
\hline On way to $3^{\text {rd }}$ facility & 6 & 8 & 12 & 4 & 14 & 7 & 8 \\
\hline At $3^{\text {rd }}$ facility & 4 & 15 & 14 & 23 & 15 & 5 & 11 \\
\hline Total cases (n) & 256 & 153 & 123 & 91 & 123 & 99 & 845 \\
\hline
\end{tabular}

Case Study: A Case of Third Delay

A 37-year-old woman from tehsil Lilian, district Chiniot, was a mother of three children. During her fourth pregnancy, when labour pains started, she was taken to Pinsaray Clinic, where she was checked by a Dr. Munawwar. She was told that she still had time before the delivery, and was sent home. The next day, she again felt pains and was taken to the same hospital; but again, she was told her labour had not begun and sent back. On the third visit, when the doctor checked her, she was told that her child had died and she was referred to Allied Hospital. Her family members had transported her half way to the hospital before she died.

In total 153 women i.e. 18 percent of the PRDs occurred while the women were being transported to a facility. Among these, 25 women died en route to the first contact facility, 59 women died in transit to a second contact facility; while 69 women died in transit to a tertiary care facility. The table 4.9 shows clearly how the unnecessary referral of women from one facility becomes a fourth source of fatal delay.

In the perception of respondents, the major problem at facility level that contributed to the death was provision of incorrect treatment to the deceased, followed by delay in admission, and non-availability of appropriate staff (Table 5.9). 
Table 5.9: Perception of respondents regarding facility level problems $(\mathbf{n}=692)$

\begin{tabular}{lcc}
\hline Type of Problem & $\%$ & $\mathbf{n}$ \\
\hline Medical treatment & 13 & 89 \\
Blood transfusion & 4 & 30 \\
Admission & 3 & 23 \\
Provider's attitude & 2 & 17 \\
Medication & 2 & 13 \\
Staff was not available & 2 & 17 \\
Procedures & 2 & 12 \\
Diagnostic/ Laboratory Tests & 1 & 8 \\
Maintenance of dignity & 1 & 7 \\
Respect shown to her & 1 & 4 \\
\hline
\end{tabular}

\section{The Role of Supply Side Factors Contributing to the Third Delay}

As stated earlier, the third delay contributing to maternal mortality is the inadequate or inefficient care available to the woman upon reaching a health facility. In the course of the study, we carried out a "Rapid Public Sector Health Facility Assessment" in all six districts to examine health service supply factors, such as availability of staff, diagnostic and treatment facilities, and availability of pharmaceutical and medical supplies. Twenty-four public sector secondary and tertiary care facilities offering emergency obstetric services were visited. These included all THQ and DHQ hospitals in each district as well as one teaching hospital in Bahawalpur. The assessment revealed some gaps in service delivery, which are outlined below.

\section{Staff Availability}

Staff availability is a longstanding issue and a major obstacle in the provision of quality maternal healthcare. Except for Layyah, all sanctioned positions for gynaecologists had not been filled in any district. In Jhelum, nearly half the sanctioned positions for gynaecologists were vacant. In Bahawalpur, only 5 out of 13 sanctioned posts of women medical officers had been filled. In Bhakkar, against 15 sanctioned posts, only 5 women medical officers were working, while in Chiniot, only 4 out of 18 posts for WMOs had been filled.

In the case of anaesthetists, the situation was quite alarming. In Bahawalpur, only 2 anaesthetists had been appointed against 16 sanctioned posts, while in Jhelum 4 had been appointed against 9 positions. In the other districts, half of the posts had been filled.

\section{Equipment and Supplies}

All six basic emergency obstetric care (EmOC) signal functions were available in 5 out of 6 facilities in Bahawalpur, 2 out of 3 facilities in Toba Tek Singh and 5 out of 6 facilities in Bhakkar. In Chiniot, all six 
functions were not available in any of the facilities. However, basic EmOC was available in all facilities of Jhelum and Layyah.

Injectable anti-convulsants and antibiotics were not available in 13 out of the 24 facilities visited. Injectable calcium for the management of eclampsia was available in 4 out of 6 facilities in Bahawalpur, 2 out of 4 facilities in Bhakkar, and 1 out of 3 facilities in T.T. Singh. Blood transfusion services were available in only half of the THQ hospitals in Bhakkar, while all THQs in the other five districts had transfusion facilities.

Manual vacuum aspiration (MVA) apparatus for post-abortion care was not available in any of the facilities in the 6 districts. Dilation and curettage (D\&C) was available at all facilities except half of the facilities in T.T. Singh.

Among the contraceptive methods, intrauterine contraceptive devices (IUCD) were available in 5 out of 6 facilities in Bahawalpur, 3 out of 4 facilities in Bhakkar, 2 out of 3 facilities in Chiniot, and all facilities in Jhelum, T.T. Singh and Layyah. Four contraceptive methods, namely pills, condoms, injectables and IUCDs, were available in T.T. Singh, Layyah and Jhelum.

A positive finding of the study was that comprehensive emergency obstetric care (CEmoC) was available at all district headquarter hospitals (DHQs). Each district has one District Headquarter (DHQ) hospital.

\section{Case Study: Facing the Second, Third and Fourth Delay}

A 43-year-old woman from tehsil Dina, district Jhelum, was nine months pregnant. Her labour pains started suddenly, with slight bleeding. A compounder in the village was called immediately to check her. He advised that she be taken to a hospital. She was immediately rushed to the Basic Health Unit in Dina. However, staff at the facility did not open the gate, saying there was no doctor present. She was then taken to a family hospital in Dina. The staff kept her waiting for 20 minutes, and then informed the family that that there was no doctor present.

Finally, the relatives took an ambulance and headed towards Benazir Bhutto Shaheed Hospital (formerly called Rawalpindi General Hospital), Rawalpindi. The driver stopped the ambulance at the CNG stations several times, wasting a lot of time in the process. All this while, the woman had severe abdominal pain and was losing blood. Near Rawat, she lost consciousness, and as they were about to reach Benazir Bhutto Shaheed Hospital, she died, undelivered. According to her relatives, had they received proper care near their home or had the ambulance brought her to Rawalpindi more expeditiously, her life could have been saved.

Figure 5.4 summarizes the key findings of the study regarding the care seeking behaviour and experiences of the deceased women at the time of their death. 
Figure 5.4: Care Seeking Behaviour and Experiences of Deceased Women around Time of Death

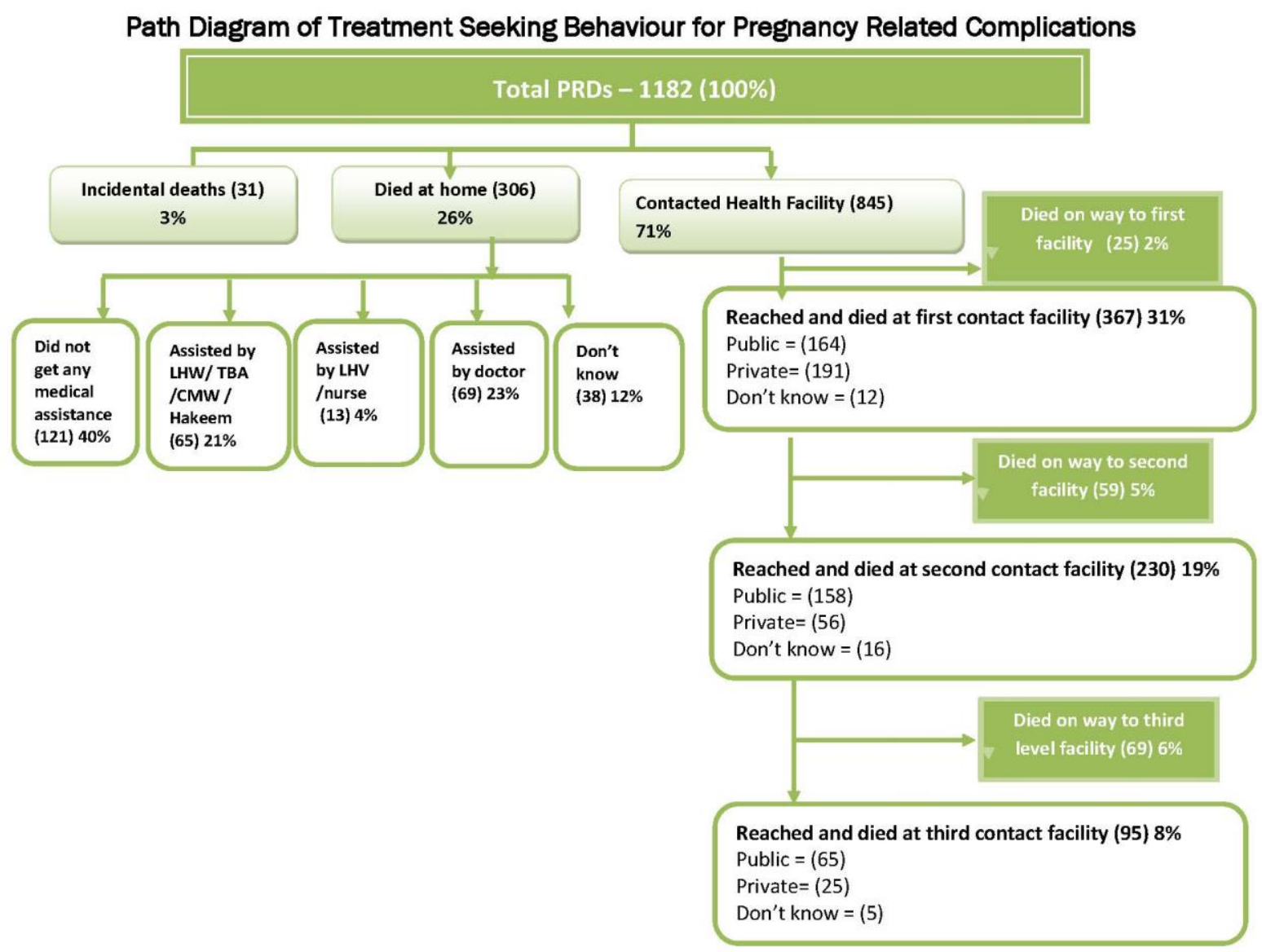

Four key observations stand out from this situation.

- First, had there been widespread awareness among these women regarding where and how to reach an appropriate functional facility, a large proportion of deaths could have been averted.

- Second, if the women who were referred by a first-or second-tier facility had reached an appropriate care facility in time, their deaths might have been avoided.

- Third, if a functional referral system had been in place, these women could have been directly referred to a higher facility without having to go to inappropriate facilities on the way, thereby saving precious time. The major cause of death at these facilities was obstetric haemorrhage that can be treated only within a time span of 1-2 hours.

- Fourth poverty remains an obstacle in accessing timely and appropriate care. Nearly 40 percent of PRDs occurred in the low socioeconomic strata and 35 percent in the medium-low socioeconomic strata; thus, only a quarter of PRDs occurred in medium-high and high socioeconomic strata. These observations are clearly visualized with the help of GIS maps that we have developed that clearly highlight these problems. 
To better understand the reasons of the second, third and fourth delay in terms of accessing appropriate care in a timely manner, all maternal deaths were plotted on georeferenced maps by location to better understand the linkage between deaths and contextual determinants such as local topography; location of facilities; availability of infrastructure, such as road networks; population density; and the existence of a referral system.

While such maps were developed for all six study districts, in the interests of brevity, core findings of the mapping exercise are discussed with reference to two districts that are sufficient for illustrative purposes, i.e., Jhelum, a densely populated district, and Bahawalpur, which has a scattered population due to desert areas.

In both scenarios, certain common features emerge that demonstrate the extent of the predicament faced by poor rural women in accessing obstetric care. Physical access to facilities is hindered by inhospitable topographical features, such as hilly terrain in Jhelum and expansive tracts of barren, sparsely settled land in Bahawalpur. In these areas, many maternal deaths could be averted if functional emergency first aid posts with transport facilities were made available where women can be stabilized before referral to higher level facilities (Figure 5.5).

\section{Figure 5.5: Topography and Location of Services}

"We do not have in our area any delivery services such as midwife or LHV. So we took her to a private hospital in the city."

Husband of a Deceased, District Layyah

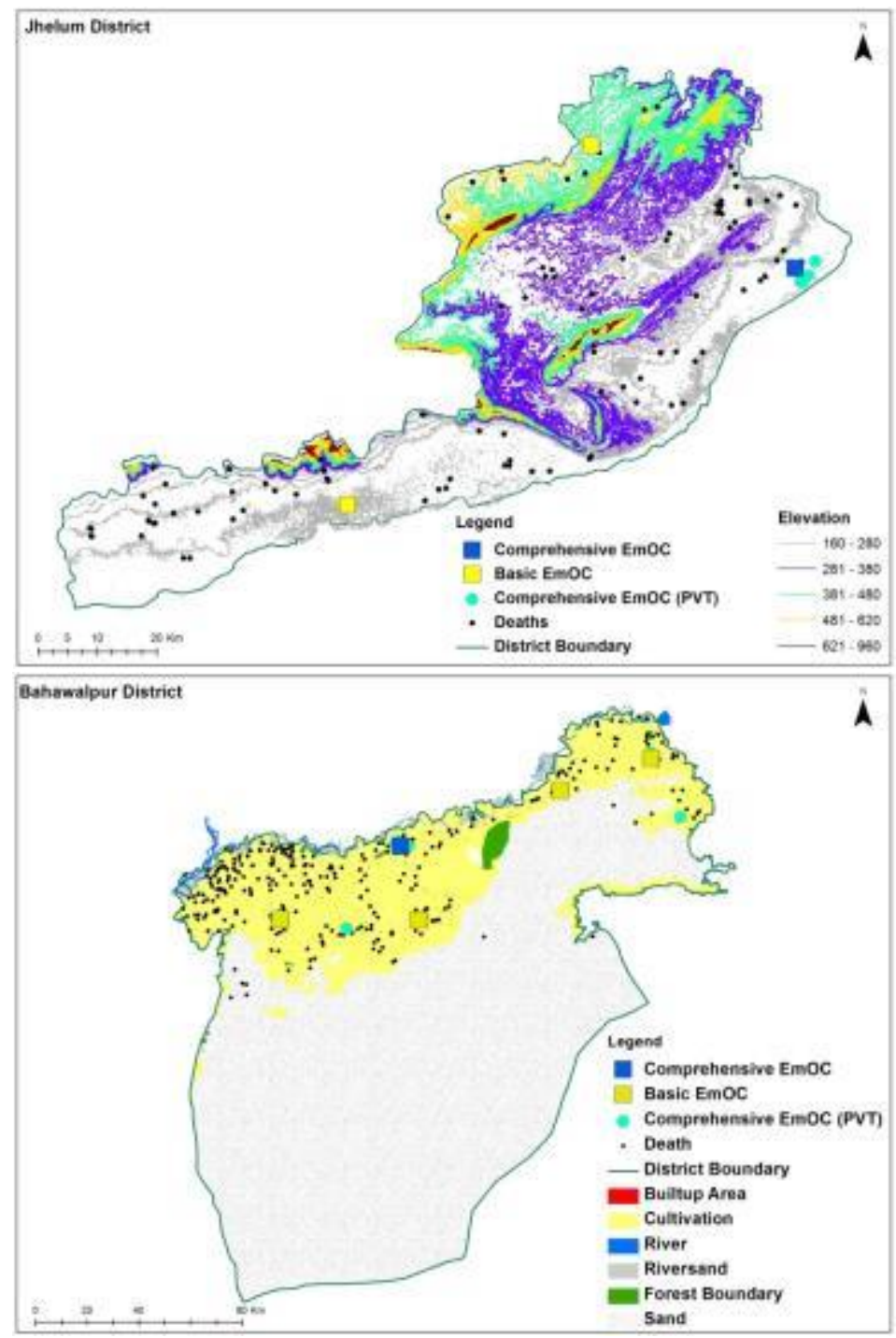


As Figure 5.6 shows, facilities offering comprehensive emergency obstetric care are few and far between in many areas of both Jhelum and Bahawalpur, implying that women have to travel long distances to reach a facility. In both districts, the proportion of deaths in a facility's catchment increased with distance from the facility. In Jhelum, the number of deaths occurring in the zone 5-15 kilometres $(\mathrm{km})$ away from the facility was almost twice as high as the number occurring within a radius of $5 \mathrm{~km}$. In Bahawalpur, the difference between the 0-5 km range and the 5-15 km range was relatively less pronounced; however, the number of deaths in the 15-25 km range was significantly higher than the number in the $5-15 \mathrm{~km}$ range.

\section{Figure 5.6: Distance from facilities and number of deaths}

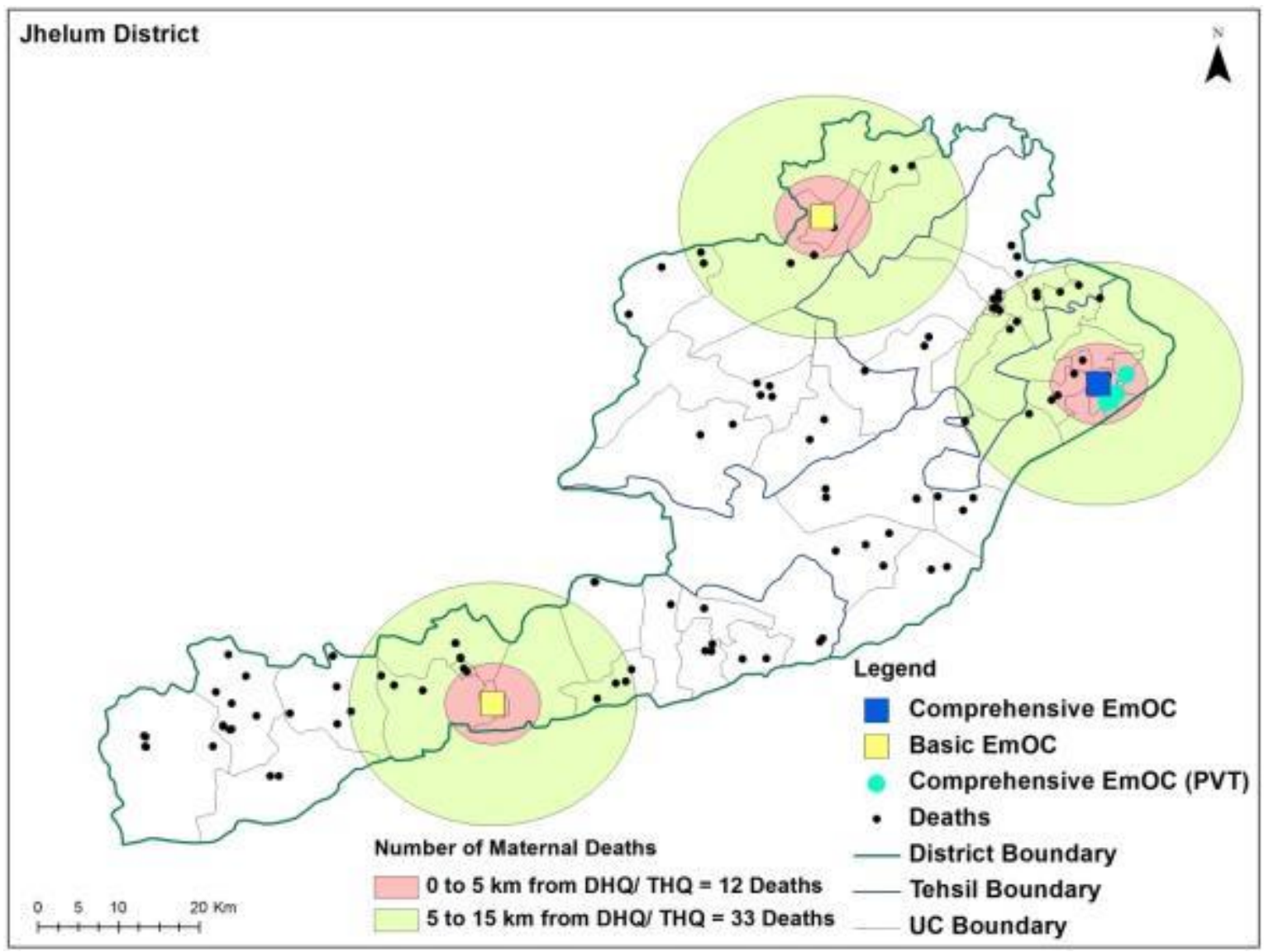




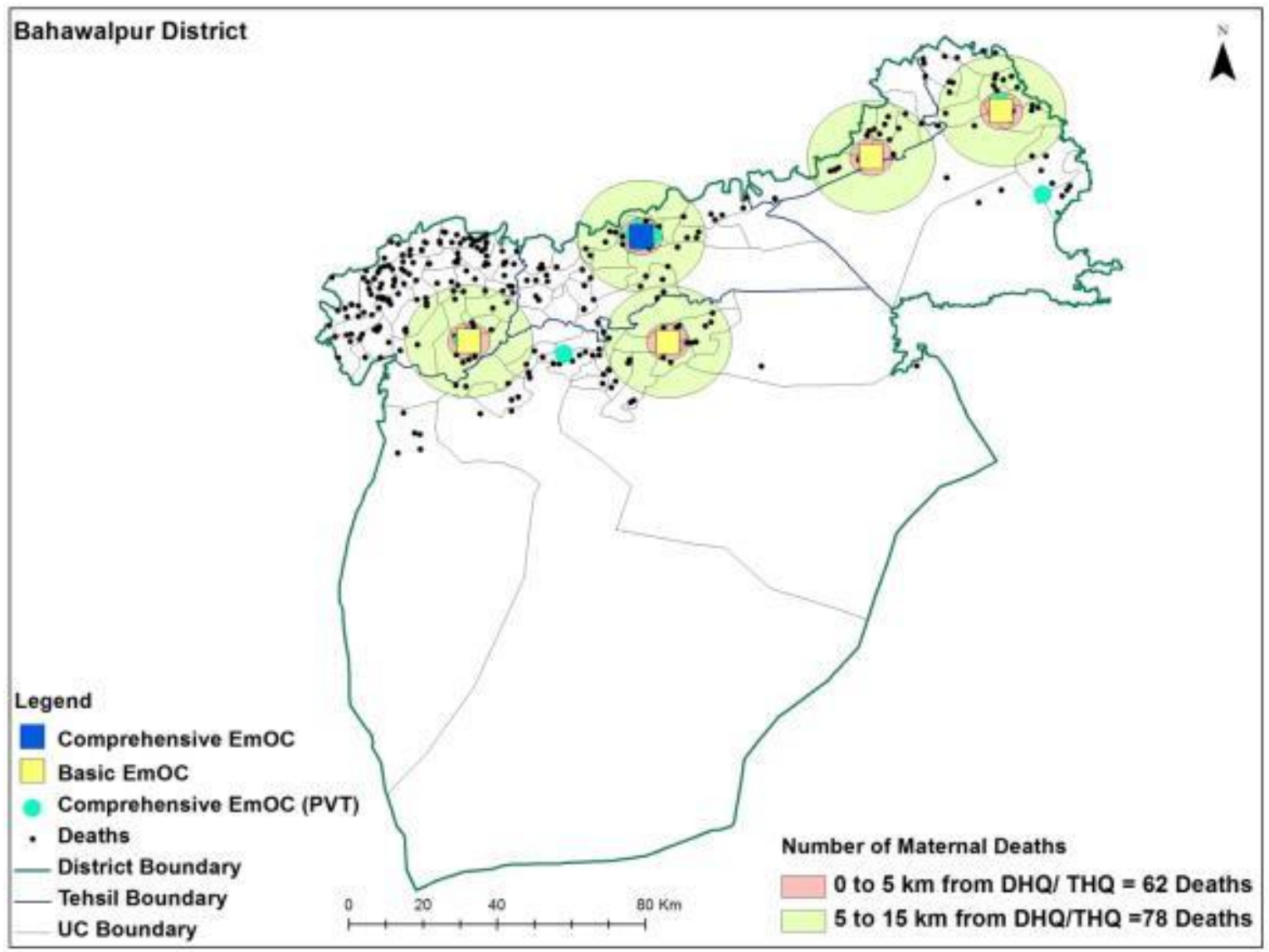


This raises issues of equity. Most deaths of women of lower socioeconomic status occurred in women who were residing farthest from facilities. This shows that poor rural women are more disadvantaged in seeking care because of the location of facilities. As seen in the figure 5.7, on an average, low socioeconomic status had to travel on an average nearly $20 \mathrm{kms}$ to reach an appropriate facility.

Figure 5.7: Location of deaths and standard of living index (SLI)

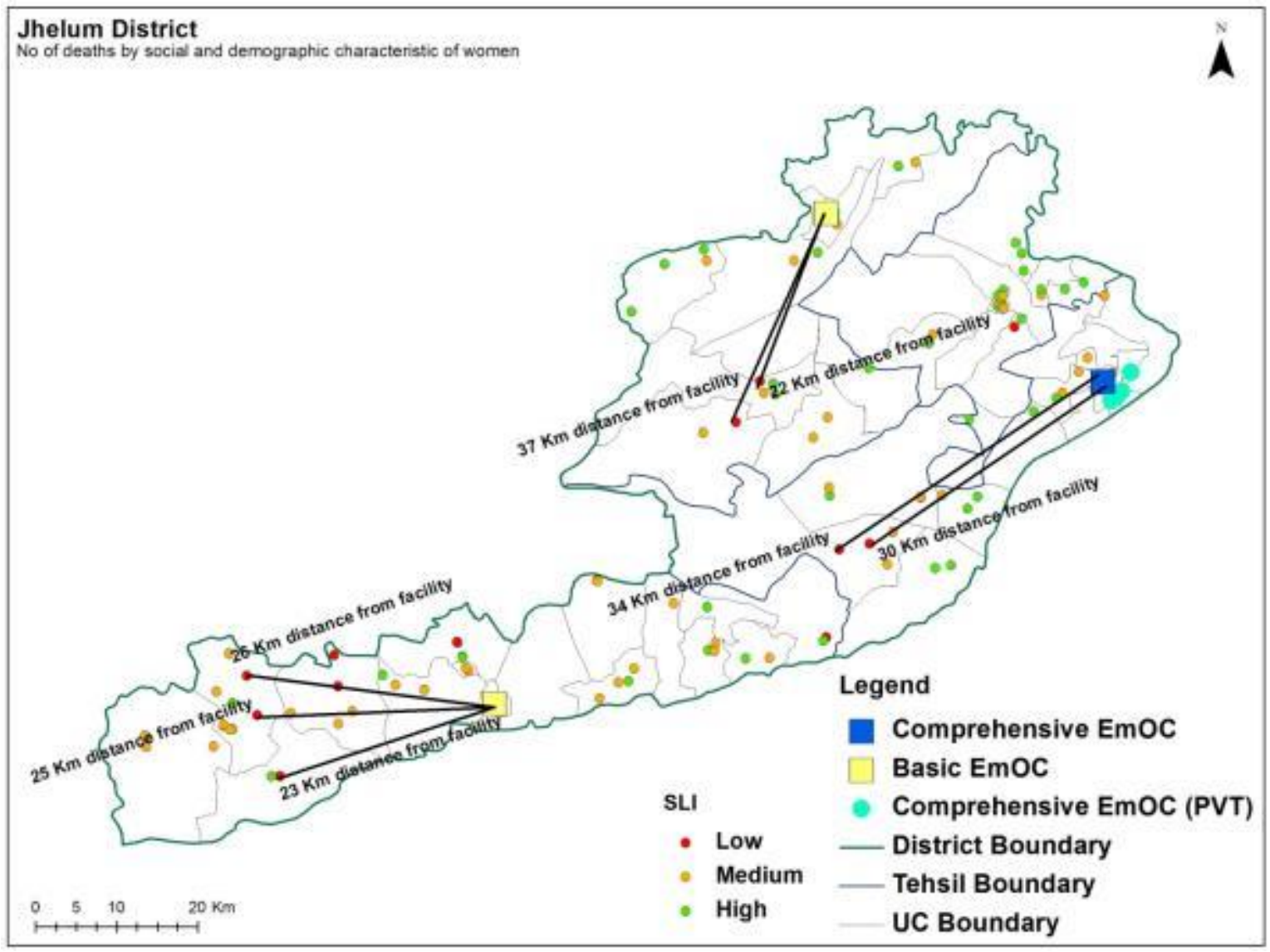




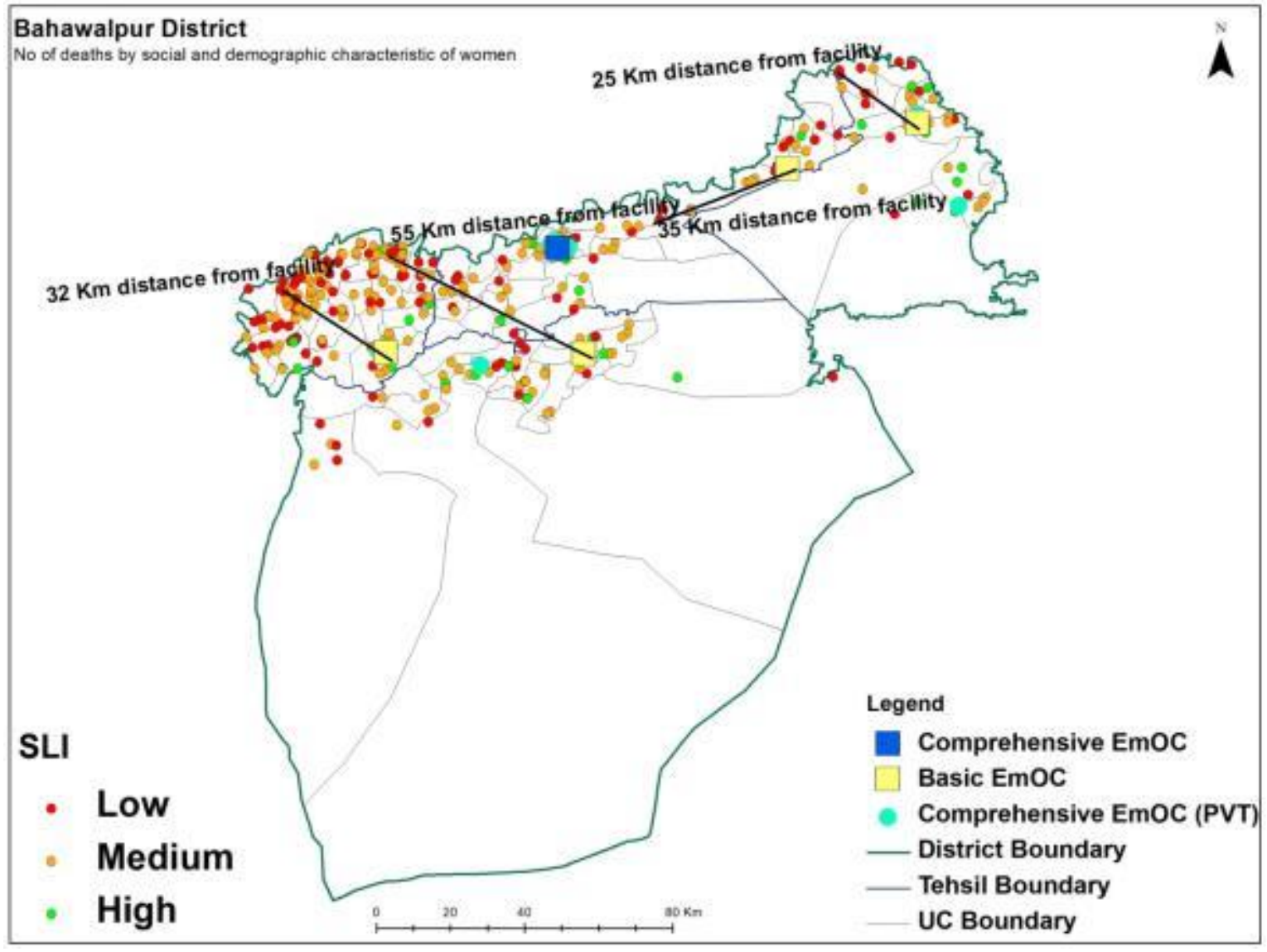


As health facilities are more concentrated in urban centres, large densely populated rural communities remain devoid of services (figure 5.8). The extent of problems in facility location can be gauged from Figure 5.8 which shows clearly that many densely populated areas remain devoid of basic and comprehensive emergency obstetric care.

Figure 5.8: Illogical Placement of Facilities

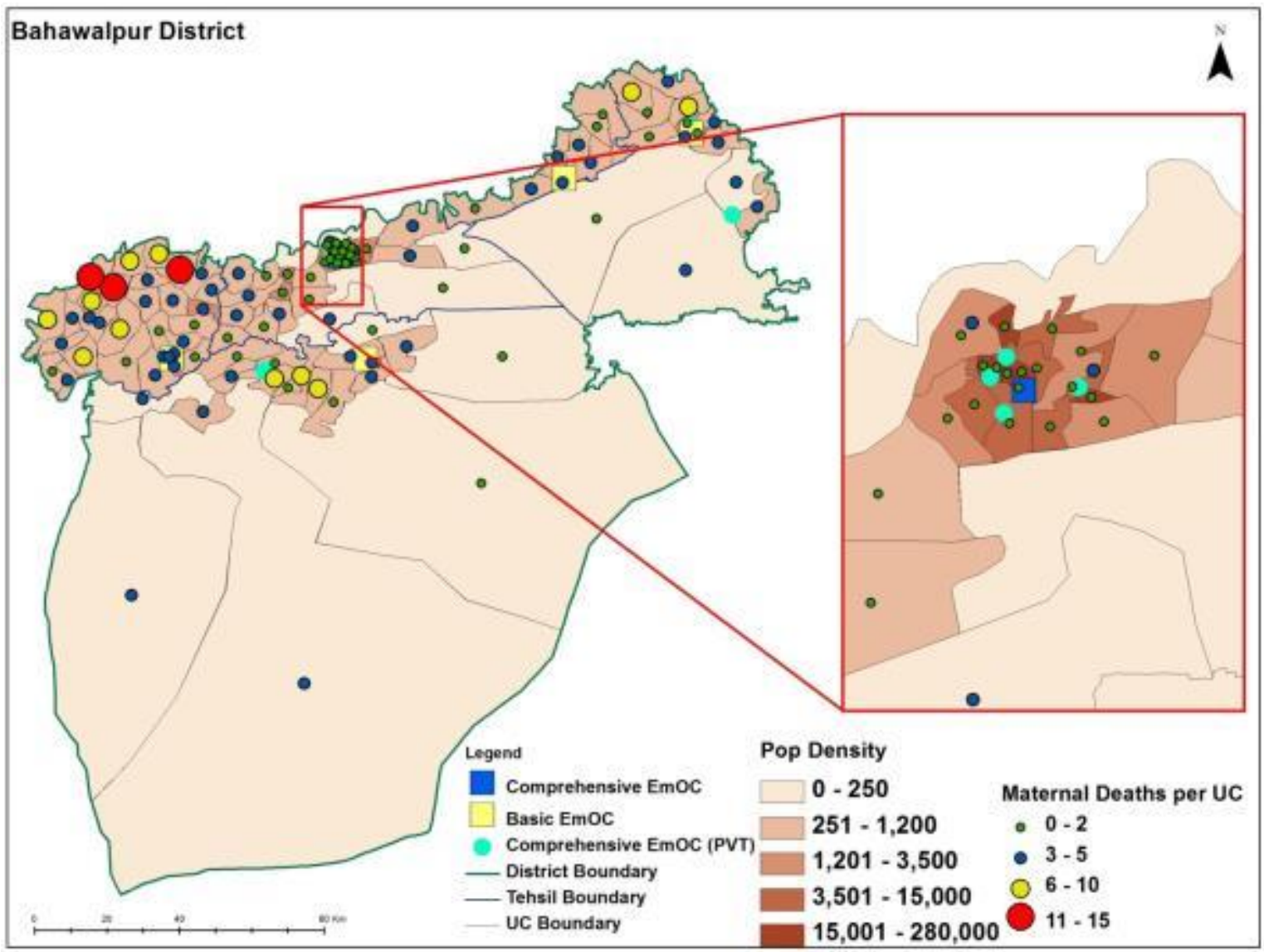





\section{Study Limitations}

The community-based informant (Made-In/Made-For) technique can only be used if there are suitable informant networks available.

Since the data collection relies on families' memory of the circumstances of a death, some events and details may have been overlooked.

In the data collected, deaths among women in early pregnancy may have been missed because respondents were unaware that they were pregnant. Sensitive deaths (e.g., among unmarried women or following an induced abortion) may also have been missed owing to respondents' fear of stigma and reluctance to share.

However, we do stress that this technique's ability to capture deaths is compromised in areas that have scattered communities and far-flung pockets of populations.

Furthermore, our experience shows that the effectiveness of the capture re-capture technique is compromised in areas that have scattered populations spread over large geographical areas because in these areas matching of cases between networks is not possible. 



\section{Discussion}

The maternal mortality situation remains grave in Pakistan. Unfortunately, the country has not been able to achieve MDG 5, which required a 75\% reduction in maternal mortality between 1990 and 2015. In order to assess progress in the attainment of the new Sustainable Development Goals, it will be important to periodically update estimates of maternal mortality, especially at the sub-national level, in order to identify specific geographic areas where interventions are especially required, and to assess the overall impact of existing efforts.

This study has, on the basis of an earlier pilot study conducted in Chakwal, applied the communitybased informant technique (MIMF) to capture maternal deaths at the community level in six districts of Punjab to generate a maternal mortality estimate for the province.

While the main aim of this study was to quantify the estimate of maternal mortality in Punjab, it also had a broad objective to demonstrate to provincial and district health officials the possibility of periodically obtaining data on maternal deaths through community-based networks and local government officials at the union council level. We believe that if district level estimates are made available to provincial program managers and policymakers on a regular basis, the evidence can be utilized to maintain focus on maternal health improvement, and to justify according this sector the high priority and attention it requires. Therefore, in all districts, we tried to develop the capacity of local institutions, such as the District Health Development Centres (DHDCs) and the staff of one medical college, in the use of the MIMF methodology.

The main strength of this study was the participation of entire district administration and health officials who have now become more cognisant of the maternal health problems that rural women face. They are now considering measures to avert such deaths. The district officers for community development, additional district officers (coordination), secretaries of the union councils, and their naib qasids have become fully familiar with the process of collecting data and could continue to use it in the future. The community informant network approach could eventually contribute to improving the registration of vital events (births and deaths by cause) at the union council and, subsequently, district level.

In the long run, these networks could be used to report additional events, e.g., case detection and the incidence of communicable diseases and this was established as another major strength of the study. They could also play a role in controlling epidemics (by identifying the source of outbreaks). Information collected at the union council level could be collated at the district level and communicated to all relevant departments as well as the provincial headquarters. Another major strength of this methodology is that it can be repeated biannually and applied to measure maternal deaths prospectively.

The MMR estimate for Punjab of 302 (95\% Cl 290-320) may be tilted towards the higher side because of adjustments that need to be introduced for areas that are geographically large and have small widely dispersed populations; however, even the unadjusted MMR, which is based on 1,182 physically verified deaths that have been plotted on GIS maps, is quite high.

Our findings are in congruence with the global evidence, which shows that most maternal deaths occur in late pregnancy to about 48 hours after delivery (AbouZahr 1998). This is the time when most mothers 
and neonates die. Therefore, policies and interventions must target this period and focus on improving active management of the third stage of labour.

Maternal complications are unpredictable and it is not possible to prevent, detect or treat all causes of maternal deaths during the antenatal examinations (Rooney, 1992; Carroli et al., 2001). However, good antenatal care can help in screening some high-risk cases where a biomedical risk factor can be identified. In our study, we found that almost two-third of the women had at least one biomedical risk factor, the most important being high parity. Empirical evidence shows that, currently, women in Punjab have one unwanted pregnancy on average. Simply by avoiding this unwanted pregnancy, risk factors for women can be reduced and nearly 2,700 maternal deaths prevented. To avoid unwanted fertility, the unmet need for family planning must be addressed and improving access to family planning services must therefore be a key $\mathrm{MNCH}$ strategy.

The study highlights the conspicuously more acute suffering of poor rural women, reaffirming that economic barriers persist and affect poor women's ability to access appropriate care. In resourceconstrained settings, the difference between the rich and poor in terms of ease of access to emergency care is a major reason for poor maternal health outcomes (Pathak et al., 2010). In most instances, as our GIS maps show, these poor households are also located farthest away from emergency care The majority of PRDs occurred among women of lower socioeconomic status, and respondents admitted that the cost of treatment for the deceased had been prohibitive and beyond their means. This may have been what compelled them to resort to nearby facilities, irrespective of the level of services provided there. Improving the quality of care in terms of providing at least comprehensive emergency obstetric care at the RHC and THQ level would help poor families' access appropriate care closer to their homes.

A positive aspect that has been highlighted both by the quantitative and qualitative component of this study is a discernible change in peoples' behaviour and attitudes. We found that a large proportion of women, realizing the importance of antenatal care, were more frequently getting antenatal check-ups. Husbands were seen to be more supportive and were the main decision-makers in deciding as to when and where to seek care. The high proportion of facility-based deliveries also reflects a change in health seeking behaviours. The role of the mother in-law in decision making is seen to be diminishing while the role of TBAs has also become marginalized.

The ability of this study to identify cause of death through verbal autopsies and their subsequent disaggregation into direct and indirect causes is important from a policy and programmatic perspective. Interventions need to focus on both direct and indirect causes of mortality if maternal mortality is to be lowered. For instance, focusing interventions on the early recognition and management of existing anaemia, which is one of the major indirect causes of mortality, could help improve maternal outcomes. Among direct causes, postpartum haemorrhage was identified as the major direct cause of death i.e. 43 percent. Postpartum haemorrhage was also identified as the leading direct cause of maternal deaths by the PDHS 2006-07. In a hospital-based study conducted at Jinnah Hospital, Karachi, in 1991, it was found that 50 percent of women brought dead to the hospital had died due to PPH (Jafarey \& Korejo, 1993). These figures indicate the persistence of the problem over time.

Moreover, the study demonstrates the utility of GIS maps, which can help in identifying the catchment population of facilities, and in establishing a referral system in which a cluster of facilities refers to the same higher level facility based on spatial considerations. The district maps clearly show that the 
current location of facilities does not take population density into consideration and hence the facility catchment populations are not well defined.

\section{Conclusions and Recommendations:}

- This study has identified specific areas that need strong policy and programmatic interventions to improve maternal health outcomes. It confirms that maternal mortality persistently remains a major public health issue in Pakistan and this problem may be much larger than we assumed.

- The study has successfully identified different networks that can be used at the community level to capture data on deaths in Pakistan. For instance, we have established that the LHW network is a reliable source of mortality information. However, LHWs' ability to capture women's deaths could be improved through proper training and by expanding the age band for capturing women's deaths from 15-45 years to 12-50 years. Supplementing the information captured through a second network enhances the probability of capturing deaths. In areas not covered by LHWs, other networks that could be included are religious leaders, nikah registrars, and women councillors.

- The two major causes of deaths identified among PRDs were obstetric haemorrhage and pregnancy-induced hypertension. These conditions should be kept in mind when designing any future interventions as there are now simple strategies available to prevent the occurrence of both these conditions. One of these interventions is the community based use of misoprostol by the delivering women themselves, and the second is the training of the first level care providers in providing the loading dose of magnesium sulphate before referring the women to a facility where the treatment can be continued.

- The Government of Pakistan has recently initiated a number of programs to improve maternal health. Prominent among these is the MNCH Program, which has introduced a new cadre of trained CMWs to increase the coverage of deliveries conducted by an SBA. However, there is sparse global evidence to show that this indicator alone is correlated with lower maternal mortality (Ronsmans et al., 2003; Borghi et al., 2006). Our findings show that women's lives cannot be saved until or unless SBAs are integrated with a good referral system that is able to transport women in acute emergencies to facilities that can provide comprehensive obstetric care. SBA's should therefore be an integral part of a continuum of care approach that begins with interventions targeting women at home at the level of the community and includes outpatient services and respectful care at clinical care settings.

- The study also raises important issues related to the quality of emergency obstetric care available at the facility level and the lack of a functional referral system in all districts. Sadly, we found that a large proportion of deaths in all 6 districts had occurred during transportation from one facility to other. The lack of functional first level care facilities is one of the major factors contributing to maternal deaths worldwide (Maine, 1991). A global systematic review of the third delay has revealed that, in the developing world, there still exist supply-side barriers that compromise the ability of the health system to effectively deal with severe obstetric complications (Knight et al., Plos one, 2013).

- $\quad$ Amongst the study districts, Bhakkar having the highest maternal mortality ratio needs the specific attention of policy makers with a focus on improving the health infrastructure of the district.

- We found that, in all 6 districts, a substantial number of sanctioned posts for specialists, women medical officers and, most importantly, anaesthetists were lying vacant. Other supply-side issues 
that were identified included the lack of universal availability of Comprehensive Emergency Obstetric Care (EmOC) at the THQ level facilities, mainly due to non-availability of blood transfusion services and functional operation theatres due to the absence of anaesthetists. Among essential drugs, anti-convulsant injections, anti-hypertensive medicines, and magnesium sulphate were not uniformly available. These shortages must be looked into.

- Another aspect highlighted by the study is the lack of advanced resuscitation facilities available at public sector tertiary care facilities to deal with severe complications. This is an aspect that needs the government's urgent attention.

- While no single approach can adequately meet all the requirements for estimating maternal mortality efficiently and with reliable precision, complementary measurement options and opportunities, such as the household census and periodic demographic and health surveys, must also be considered in order to validate results.

Finally, we would like to stress that this study has very clearly highlighted the plight of women who, despite poverty, a stringent caste system, and restrictive socio-cultural norms still managed to reach a health facility but died because of a poorly functioning health system. If progress is to be made and health outcomes for women improved, the health system needs to be revamped. If countries in the region such as Bangladesh can achieve an impressive 3.6 percent decline in MMR per annum (Kassebaum et al., 2014)-12 times higher than Pakistan-there is no excuse for us to lag behind. 


\section{Bibliography}

AbouZahr C, Wardlaw T: Maternal Mortality in 2000: Estimates Developed by WHO, UNICEF and UNFPA. Geneva: World Health Organization; 2003.

AbouZahr C: Maternal mortality overview, In: Health Dimensions of Sex and Reproduction. Global Burden of Disease and Injury Series, Murray CJL, Lopez AD (eds). World Health Organization, Harvard School of Public Health, World Bank; 1998.

Ahmed Z: Maternal Mortality in an Obstetric Unit. J Pak Med Assoc; 1985. 243-248

Application of ICD-10 to deaths during pregnancy, childbirth and the puerperium: ICD maternal mortality (ICD-MM). Geneva, World Health Organization, 2012.

Atrash HK, Alexander S, Berg CJ: Maternal mortality in developed countries: not just concern of the past. Obstet Gynecol; 1995, 86:700-705.

Barnett S, Nair N, Tripathy P, et al: A prospective key informant surveillance system to measure maternal mortality - findings from indigenous populations in Jharkhand and Orissa, India. BMC Pregnancy\& Childbirth; 2008, 8:6.

Bhatia JC: A Study of Maternal Mortality in Anantpur District, Andhra Pradesh, India. Bangalore: Indian Institute of Management; 1988.

Bhatta DN. Involvement of Males in Antenatal Care, Birth Preparedness, Exclusive Breast Feeding and Immunizations for Children in Kathmandu, Nepal. (2013). BMC Pregnancy and Childbirth 2013, 13:14

Bhutta ZA: The Million Death Study in India: Can it help in monitoring the millennium development goals? PLoS medicine; 2006. 3(2):103.

Bongaarts J: The fertility impact of changes in the timing of childbearing in the developing world, Population Studies; 1999. 53:277-289.

Borghi J, Ensor T, Somanathan A, et al:. on behalf of The Lancet Maternal Survival Series steering group 2006. Mobilising financial resources for maternal health. Lancet; 2006. 368: 1457-65 doi: 10.1016/S0140-6736(06)69383-5 .

Briefing Paper Punjab. Achieving MDGs 4 and 5 in Punjab: The Role of Family Planning. Population Council, Islamabad. $2014 . \quad$ Available at: http://www.popcouncil.org/uploads/pdfs/2014RH_AchievingMDGs4-5_Punjab.pdf.

Bureau of Statistics, Government of Punjab. Population projections as on 31-12-2013. Punjab Development Statistics; 2013. Lahore.

Carroli G, Rooney C, Villar J: How effective is antenatal care in preventing maternal mortality and serious morbidity? An overview of the evidence. Paediatr Perinat Epidemiol; 2001. 15(1):1-42).

Cleland J: "The effects of improved survival on fertility: A reassessment," in Global Fertility Transition, eds. Bulatao RA, Casterline JB, Population and Development Review; 2001. (27): 687-712.

Filmer D, Pritchett L. The Effect of Household Wealth on Educational Attainment: Evidence From 35 Countries. Population and Development Review; 1999. 25(1):85-120

Fottrell E, Byass P, Ouedraogo TW, et al: Revealing the burden of maternal mortality: a probabilistic model for determining pregnancy-related causes of death from verbal autopsies. Pop Health Metrics; 2007. 5:1. 
Gallen ME, Liskin L, Kak N: Men-New focus for family planning programs. Population Reports, Series J, No. 33. Baltimore, Johns Hopkins School of Public Health, Population Information Program, 1986. Nov.-Dec. 32 p.

Geubbels E: Epidemiology of Maternal Mortality in Malawi. Malawi Med J.; 2006. (18:4): 206-225.

Graham WJ, Hussein J: Universal reporting of maternal mortality: an achievable goal? Int J Gynaecol Obstet; 2006. 94(3):234-42.

Graham WJ, Ahmed S, Stanton C, et al. Measuring maternal mortality: an overview of opportunities and options for developing countries. BMC Med; 2008. 6:1-8

Hill K, AbouZahr C, Wardlaw T: Estimates of Maternal Mortality for 1995. Bull World Health Organ; 2001. 79(3): 657-664.

Hill K, Arifeen SE, Koenig M, et al:: How should we measure maternal mortality in the developing words? A comparison of household deaths and sibling history approaches. Bull World Health Organ; 2006. 84(3).

Hill K, Thomas KE, Abouzahr C, et al: Estimates of maternal mortality worldwide between 1990 and 2005: an assessment of available data. Lancet; 2007. 370:1311-9.

Hogan MC, Foreman KJ, Naghavi M, et al: Maternal mortality for 181 countries,1980-2008: a systematic analysis of progress towards Millennium Development Goal 5. Lancet; 2010. 375(9726):1609-23.

Jafarey SN, Korejo R: Mothers brought dead: an enquiry into causes of delay. Soc Sci Med; 1993. 36(3):371-2.

Jafarey SN: Maternal mortality in Pakistan-compilation of available data. J Pak Med Assoc; 2002. 52 (12):539-44.

Jejeebhoy SJ, Sathar ZA. Women's autonomy in India and Pakistan: The influence of religion and region. Population and Development Review; 2001. (27) 4.

Kassebaum NJ et al. Global, regional and national levels and causes of maternal mortality during 1990-2013: a systematic analysis for the Global Burden of Disease Study 2013. Lancet; 2014. 13; 384 (9947):980-1004.

Knight HE, Self A, Kennedy SH: Why Are Women Dying When They Reach Hospital on Time? A Systematic Review of the 'Third Delay'. Why Are Women Dying When They Reach Hospital on Time? A Systematic Review of the 'Third Delay. PLOS ONE; 2013. 8(5): e63846. doi: 10.1371/journal.pone.0063846.

Laska EM: The Use of Capture-Recapture Methods in Public Health. Bull World Health Organ; 2002. 80(11).

Maine D: Safe Motherhood Programs: Options and Issues. Center for Population and Family Health. Columbia University: New York; 1991.

Maskey MK, Baral KP, Shah R, Shrestha BD, Lang J, et al. Field test results of the motherhood method to measure maternal mortality. Indian J Med Res; 2011..133: 64-69.

Maternal Mortality Estimates developed by WHO, UNICEF and UNFPA. World Health Organization Geneva; 2004.

Maternal Mortality in India: 1997-2003. Trends, Causes And Risk Factors Registrar General, India, New Delhi In Collaboration With Centre for Global Health Research, University of Toronto, Canada. Registrar General, India, New Delhi ; 2006. 
Measuring Maternal Mortality Challenges, Solutions, and Next Steps. Immpact: Population Reference Bureau; 2007. Available at: http://www.prb.org/pdf07/MeasuringMaternalMortality.pdf

Miller S, Lester F, Hensleigh P: Central European University. Prevention and Treatment of Postpartum Hemorrhage: New Advances for Low-Resource Settings. J Midwifery Women's Health; 2004. 49(4):283-9.

Mswia R, Lewanga M, Moshiro C, et al: Community-based monitoring of safe motherhood in the United Republic of Tanzania. Bull World Health Organ; 2003; 81 (2):87-94.

Mullany BC, Becker S, Hindin MJ. The Impact of Including Husbands in Antenatal Health Education Services on Maternal Health Practices in Urban Nepal: Results from a Randomized Controlled Trial. Health Educ Res; 2007. 22(2): 166-176.

National Institute of Population Studies (NIPS) [Pakistan] and ICF International: Pakistan Demographic and Health Survey 2012-13. Islamabad, Pakistan, and Calverton, Maryland, USA: National Institute of Population Studies (NIPS) [Pakistan] and ICF International; 2013.

National Institute of Population Studies (NIPS), Macro International Inc: Pakistan Demographic and Health Survey (PDHS) 2006-07. National Institute of Population Studies (NIPS), Macro International Inc; 2008. Islamabad, Pakistan.

Obermeyer Z, Rajaratnam JK, Park CH, et al: Measuring adult mortality using sibling survival: a new analytical method and new results for 44 countries, 1974-2006. PLoS Med; 2010. 7: e1000260. doi: 10.1371/journal.pmed.1000260.

Pakistan Social and Living Standards Measurement Survey (2012-13). Pakistan Bureau of Statistics, Statistics Division, Government of Pakistan, Islamabad. 2014.

Pathak PK, Singh A, Subramanian SV: Economic inequalities in maternal health care: prenatal care and skilled birth attendance in India, 1992-2006. PLoS One; 2010. 27;5(10):e13593. doi: 10.1371/journal.pone.0013593

Punjab Multiple Cluster Indicator Survey (MICS) 2011. Bureau of Statistics. Government of Pakistan. 2011.

Qomariyah SR, Braunholtz D, Achadi EL, et al: An option for measuring maternal mortality in developing countries: a survey using community informants. BMC Pregnancy Childbirth; 2010. 10: 74. doi: 10.1186/1471-2393-10-74.

Qureshi RN, Jaleel S, Hamid R, et al: Maternal deaths in a developing country: a study from the Aga Khan University Hospital, Karachi, Pakistan 1988-1999. J Pak Med Assoc; 2001. 51(3):10911.

Ronsmans C, Etard JF, Walraven G, et al: Maternal mortality and access to obstetric services in West Africa. Trop Med Int Health; 2003; 8: 940-8.

Rooney C: Antenatal Care and Maternal Health: How Effective Is It? A Review of the Evidence. Geneva: World Health Organization, Division of Family Health, Maternal Health and Safe Motherhood Programme; 1992.

Rosales A, Galindo J, Flores A: A Community based surveillance system for maternal and early neonatal complications: The Intibucá case study. Baltimore, MD: Catholic Relief Services; 2005. Available at: http://www.crs.org/publications/pdf/Hea1204 e.pdf

Sclar ED, Garau P, Carolini G: The 21st century health challenge of slums and cities. Lancet; 2005. 365: 901-903. 
Setel PW, Macfarlane SB, Szreter S, et al: A scandal of invisibility: Making everyone count by counting everyone. The Lancet; 2007. 370(9598) 1569-1577.

Shahid R, Mushtaq M. Complications of Grand Multiparity. Pak Armed Forces Med J; 2009;4:1-5.

Standards for Maternal and Neonatal Care. Department of Making Pregnancy Safer, World Health Organization. World Health Organization; 2002. Available at: http://www.who.int/reproductivehealth/publications/maternal perinatal health/effective ante natal_care.pdf

Stanton C, Abderrahim N, Hill K: DHS maternal mortality indicators: an assessment of data quality and implications for data use. DHS Analytical Report No. 4; 1997.

Stickler T: Labor and Delivery: Stages of Labor. Healthline; 2012. Available at: http://www.healthline.com/health/pregnancy/labor-and-delivery\#Overview1

Thaddeus S, Maine D: Too far to walk: maternal mortality in context. Soc Sci Med; 1994. 38(8):1091110.

World Health Organization. Trends in maternal mortality: 1990 to 2010. WHO, UNICEF, UNFPA and The World Bank estimates. World Health Organization; 2012. Available at http://www.unfpa.org/webdav/site/global/shared/documents/publications/2012/Trends_in_ maternal_mortality_A4-1.pdf

WHO/UNICEF. The sisterhood method for estimating maternal mortality: guidance notes for potential users. WHO/RHT/97.28 and UNICEF/EPP/97.1. World Health Organization, Geneva; 1997.

World Health Organization. Appropriate technology for birth. Lancet; 1985; 2: 436-7.

World Health Organization. Studying maternal mortality in developing countries: a guidebook. World Health Organization, Geneva; 1987. 


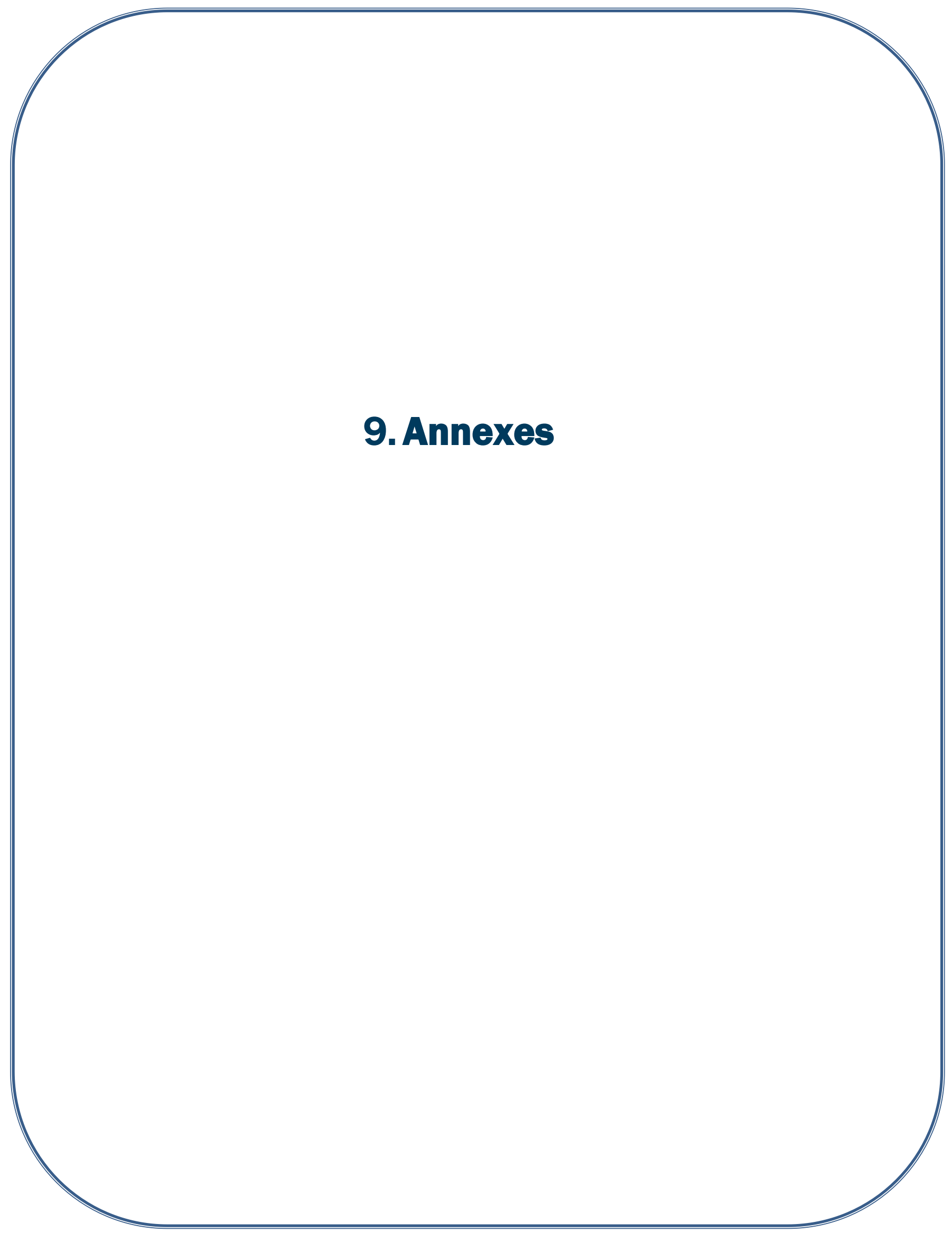





\subsection{Listing Forms}

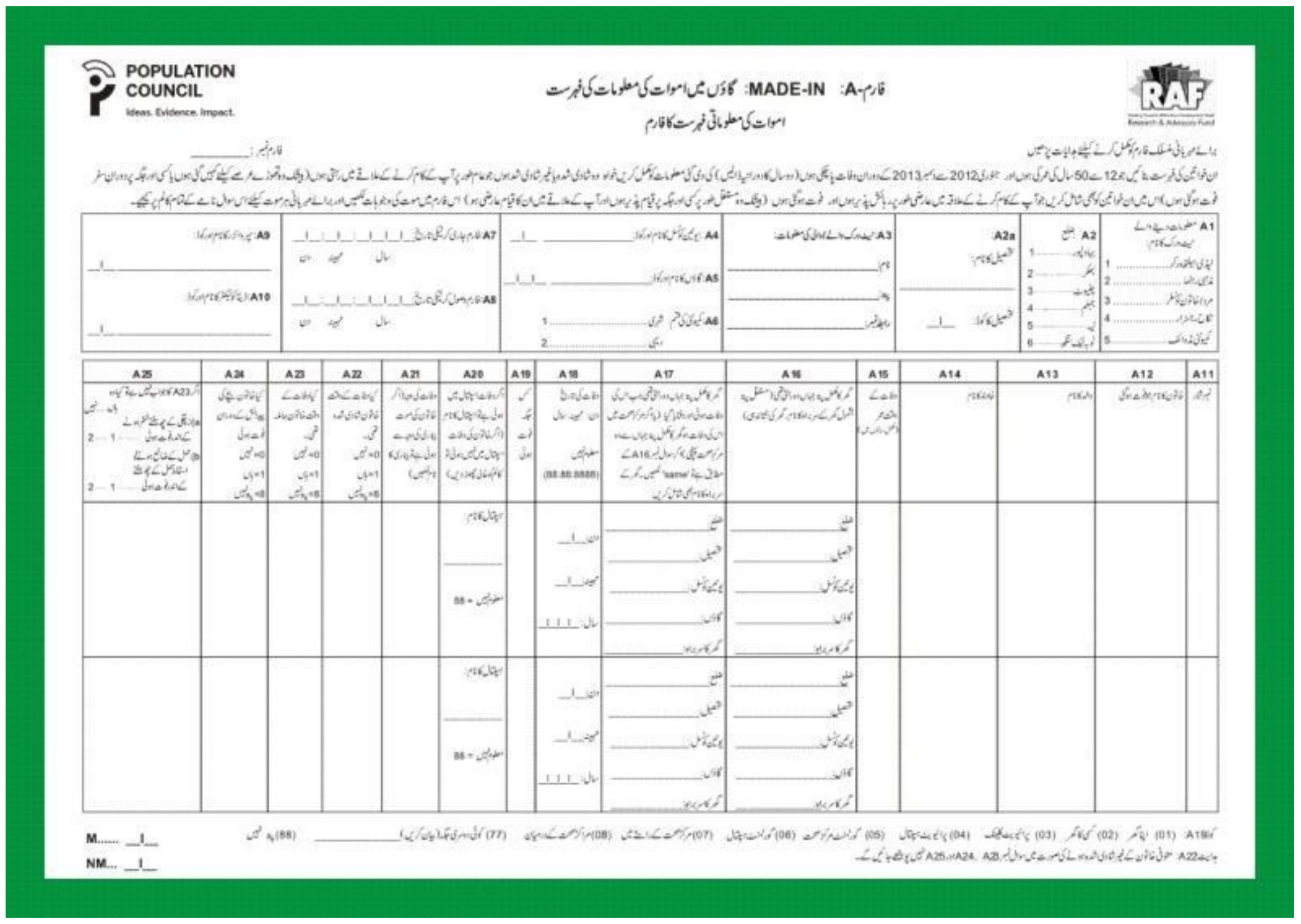




\section{- Population}

COUNCIL

Heas fidence linvact

\section{$=0$ : \\ pares}

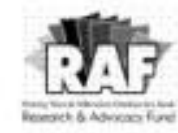

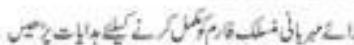

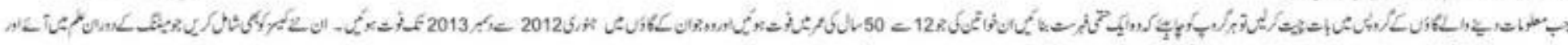

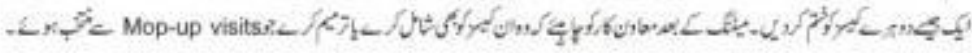

\begin{tabular}{|c|c|c|c|c|}
\hline 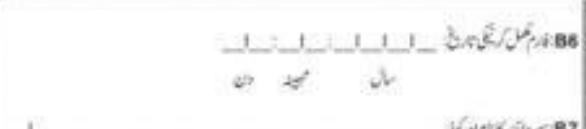 & 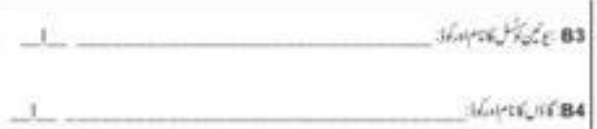 & 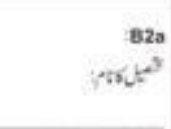 & $\begin{array}{rr}2 \\
1\end{array}$ & 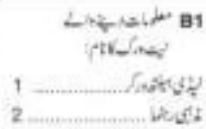 \\
\hline 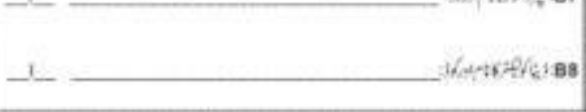 & $\begin{array}{ll}1 & \text { st? } \\
2 & 5\end{array}$ & $1-$ wister & 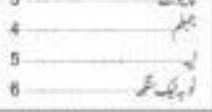 & 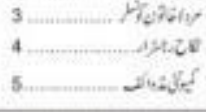 \\
\hline
\end{tabular}

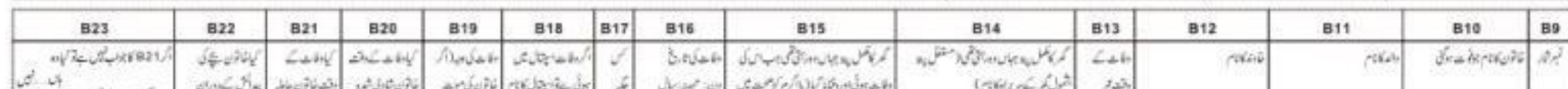

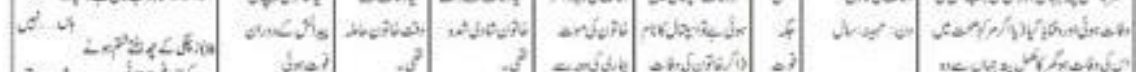

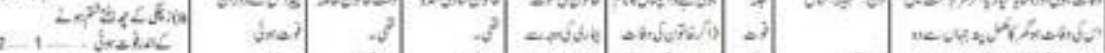

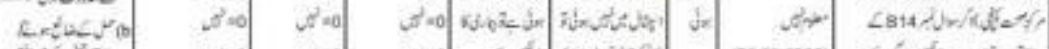

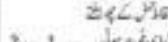

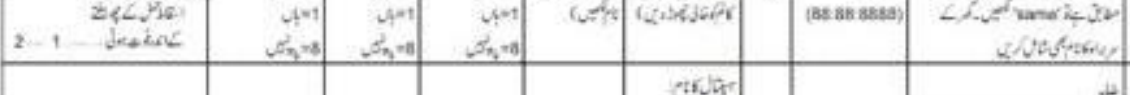

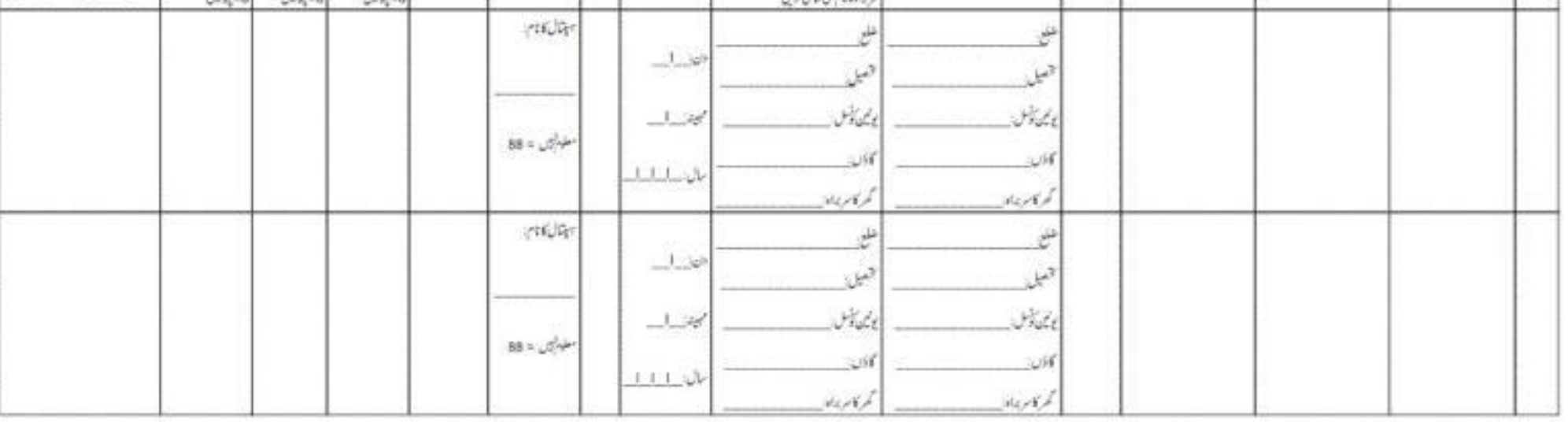

M...... -

$u^{2}$, (as) $=\sin$

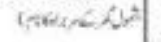

A 723

NM... - I

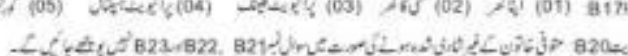




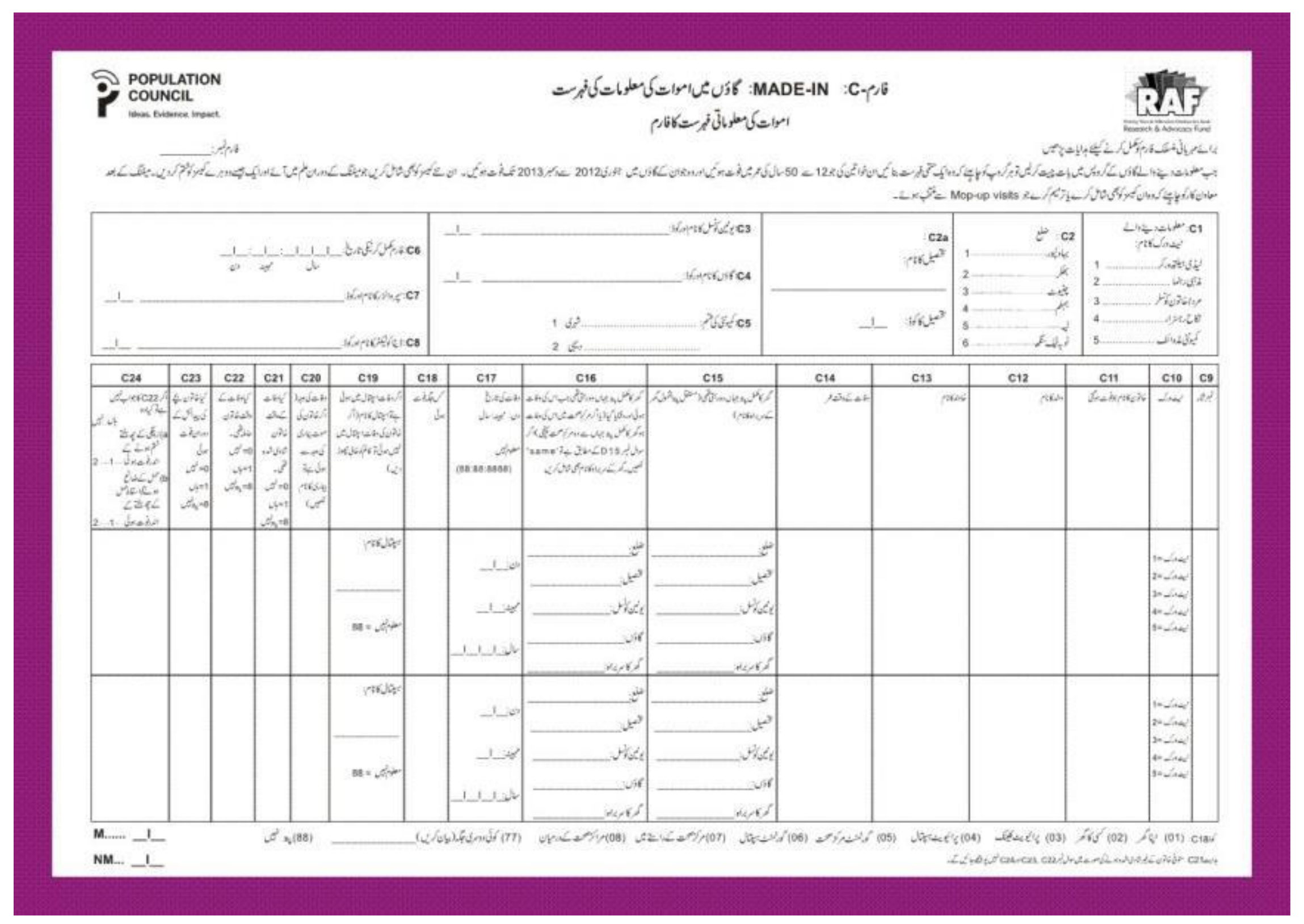




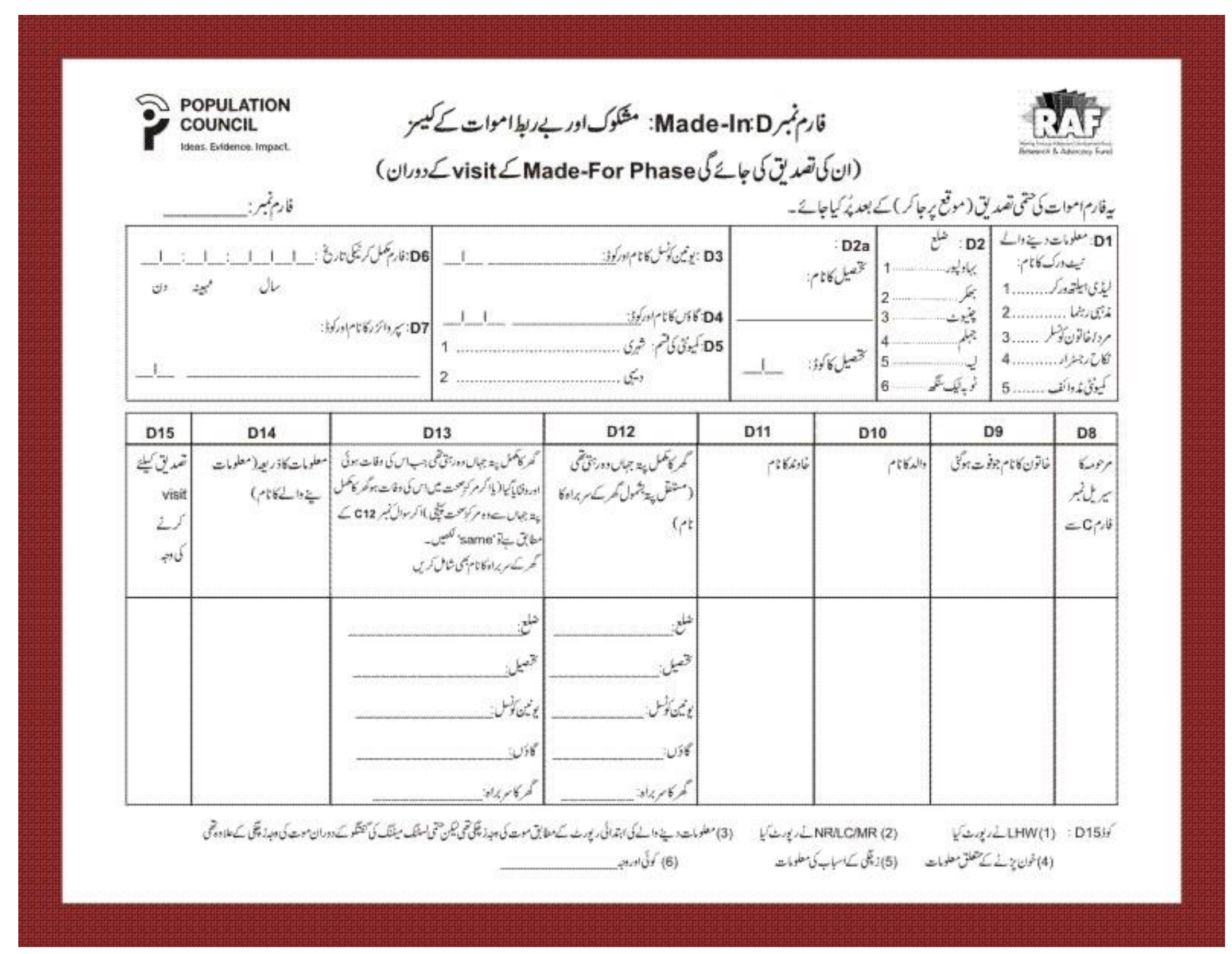




\subsection{Verbal Autopsy Questionnaire}

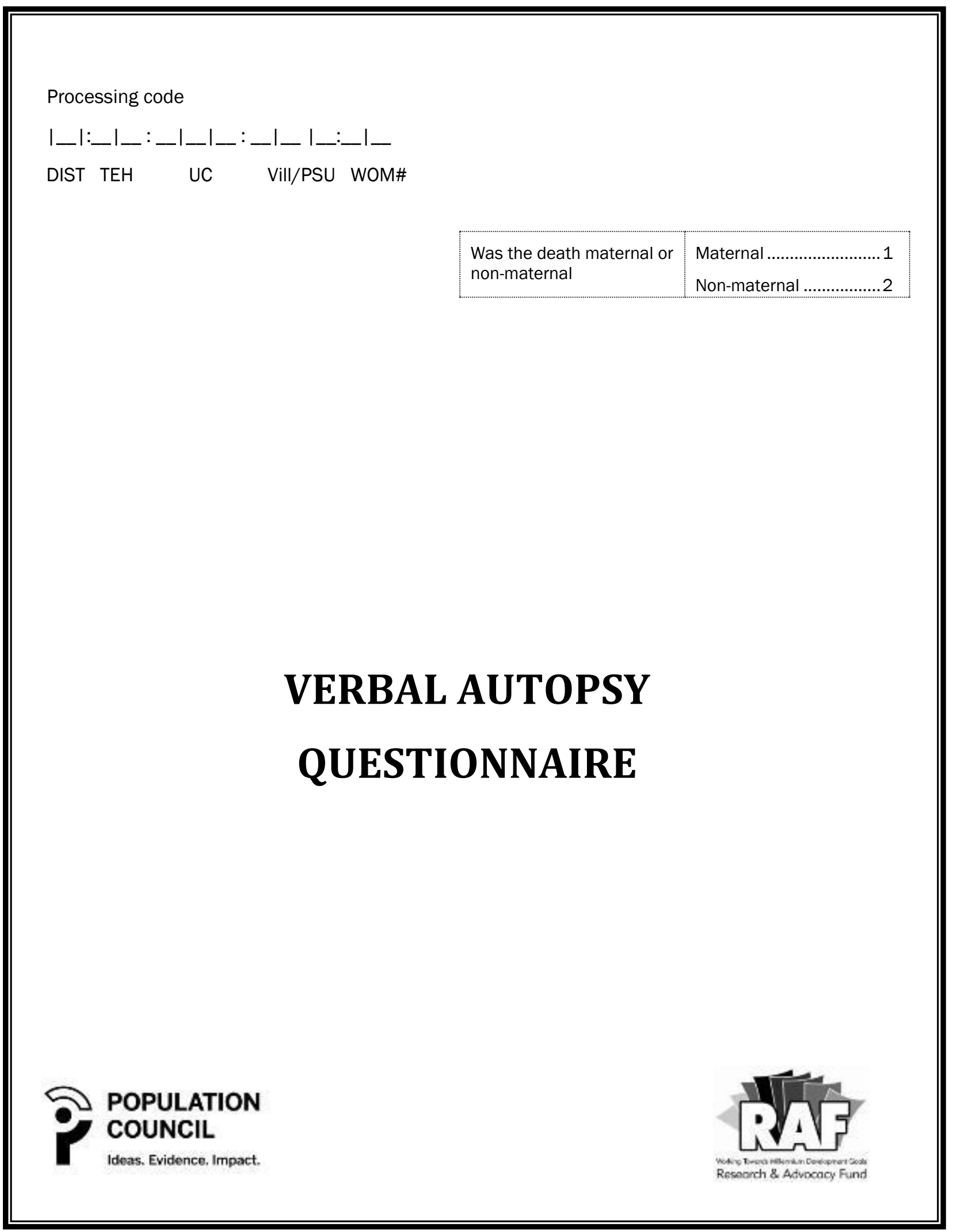




\section{Informed Consent for the Respondents of Verbal Autopsy}

\section{Purpose of the study:}

The purpose of this interview is to find out the circumstances of death of your wife/ daughter/ sister/ aunt/ relative. Your answers are very important to us and will help to find better ways to deliver health services to other women in Pakistan to prevent them from dying during pregnancy and in childbirth.

\section{Procedures to be followed:}

My name is and I am working with an organization called Population Council, which is a research organization working with the Government of Pakistan to improve the wellbeing of the people. We are conducting a study in six districts of the Punjab province to estimate the maternal mortality ratio in Punjab. We would like to seek your cooperation in getting a better idea of the maternal mortality situation in Pakistan, but especially in the Punjab province.

\section{Discomforts and risks:}

If this is not a convenient time for you, we can come later to discuss with you. You may end the interview at any time without penalty or loss. You don't have to answer any questions that you don't want to answer, and you may end this interview at any time you want to. You may feel sad, distressed in recalling the past events. If you do so and want to discontinue the interview you can do so at any time.

\section{Benefits:}

There are no direct benefits to you for participating in the study. You may find an indirect benefit in knowing you have participated in an important study that could help others in the future.

\section{Duration of the procedures and study:}

We will greatly appreciate if you base your answers on your knowledge regarding the circumstances and cause of death of the deceased woman (to be filled in after exploring relationship). We request you however, to answer as fully as possible because your perceptions and opinions are valuable information.

Your responses to this questionnaire will be completely confidential and will be used for research purposes only. No personal reference will be made to your participation in this survey. We will combine your responses with those of other participants in a report to estimate the maternal mortality and causes of death to get the broader picture regarding maternal health situation in Pakistan.

The interview will take 30-45 minutes to complete. The duration of the entire study is three months. We may need to contact you again if we need clarification to clear a point, for which you can agree or disagree.

\section{Compensation:}

Your participation in this study is purely voluntary and will not be paid any compensation for participation in the study. There is no penalty for refusing to take part. If you agree to participate in this study, you may end your participation at any time without.

\section{Whom to call in case of an emergency:}

If you have a concern about any aspect of the study, you should ask to speak to the researchers who will do their best to answer your questions. Any complaint about the way you have been treated during the study or any possible harm you might suffer will be addressed. You may call Dr Saleem Shaikh at this number 0092-51-8445566 Ext. 195 for any complaints. For information about your rights or in case of violation of rights you may contact Dr. Ameeruddin Chauhan, Deputy Provincial Coordinator, LHW Program, Health Department, Government of Punjab, at this number 0092-321-4745076. 


\section{Offer to answer questions and freedom to withdraw from the study:}

Your participation in this study is purely voluntary. If you do not agree to participate in the study, you can withdraw from the study at any time without prejudice.

\section{Confidentiality:}

Your responses to this questionnaire will be completely confidential and will be used for research purposes only. No personal reference will be made to your participation in this study of measuring maternal mortality. We will combine your responses with those of other participants to describe the general picture in Pakistan. Data will be stored in a locked cabinet dedicated to this study that only the study team can access.

\section{Subject's statement:}

"I have been given an opportunity to ask any questions I may have, and all such questions or inquiries have been answered to my satisfaction."

"I further understand that my records will be kept confidential and that I may withdraw from this study at any time.

"My withdrawal from this study or my refusal to participate will in no way affect my medical care from the hospital or clinic.

"I have been informed orally and in writing of whom to contact in case of an emergency. I agree to participate in this study as a volunteer subject."

$\overline{\text { Date }} \quad \overline{\text { Signature of Volunteer }}$

\section{Investigator's statement:}

An example of a suggested statement is as follows:

"I, the undersigned, have explained to the volunteer in a language he/she understands the procedures to be followed in the study and the risks and benefits involved.

Date Signature of Investigator

Date Signature of Witness to the Above Signatures and Explanations

The Informed Consent must include any additional information that applicable Federal, State, or local laws require to be disclosed in order for informed consent to be legally effective. 
SECTION-A: IDENTIFICATION

\section{A1- Name of District}

1 - Bahawalpur

2 - Bhakkar

3 - Chiniot

4 - Jhelum

5 - Layyah

6 - TT. Singh

\section{A2- Name of Tehsil}

\begin{tabular}{l|l}
11 - Ahmedpur East & 21 - Bhakkar \\
12 - Bahawalpur City & 22 - Darya Khan \\
13 - Bahawalpur Sadar & 23 - Kalour Kot \\
14 - Hasilpur & 24 - Mankera \\
15 - Khairpur Tamewali & \\
16 - Yazman & \\
\hline
\end{tabular}

\begin{tabular}{|l|l|l|l}
31 - Bhowana & 41 - Dina & 51 - Choubara & 61 - Gojra \\
32 - Chiniot & 42 - Jehlum & 52 - Karor & 62 - Kamalia \\
33 - Lalian & 43 - PD. Khan & 53 - Layyah & 63 - Pirmahal \\
& 44 - Sohawa & & $64-$ TT. Singh
\end{tabular}

A3- Name and code of Union Council

$-1+1$

A4- Name and code of village/PSU $-1+1$

A5- Woman sequence number $-1$

A6- Number of visits to complete the interview $-1$

A7-Date of last visit for interview _l________l_l_ DD MM YYYY

A8-Name and code of interviewer

\begin{tabular}{|c|c|c|c|}
\hline A9-Result of interview & 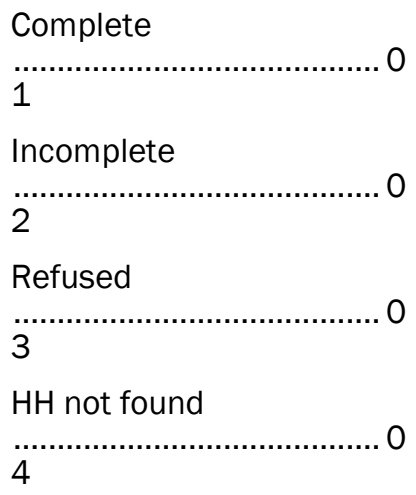 & 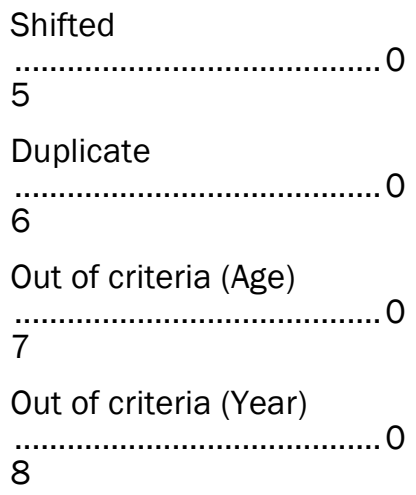 & $\begin{array}{l}\text { Others (Specify) } \\
\ldots \ldots \ldots \ldots \ldots \ldots \ldots \ldots \ldots \ldots \ldots \ldots \ldots . . . \\
7\end{array}$ \\
\hline
\end{tabular}

If $A 9>02$ then end interview

A10- Duration of interview $-1$

(Minutes)

Complete address of household 
SECTION-B: INFORMATION ABOUT THE RESPONDENT

\begin{tabular}{|c|c|c|}
\hline Q.NO. & Questions and Filters & Coding Categories \\
\hline $\begin{array}{c}\text { B1 } \\
(2 \mathrm{~A} 120)\end{array}$ & $\begin{array}{l}\text { Name of verbal autopsy respondent: } \\
\text { Complete address of respondent: }\end{array}$ & 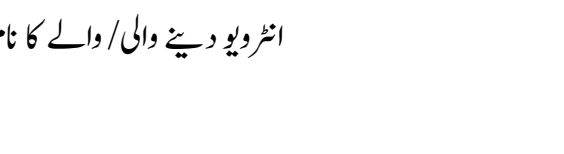 \\
\hline $\begin{array}{c}\text { B2 } \\
(2 \mathrm{~A} 110)\end{array}$ & What is your relationship to the deceased? & 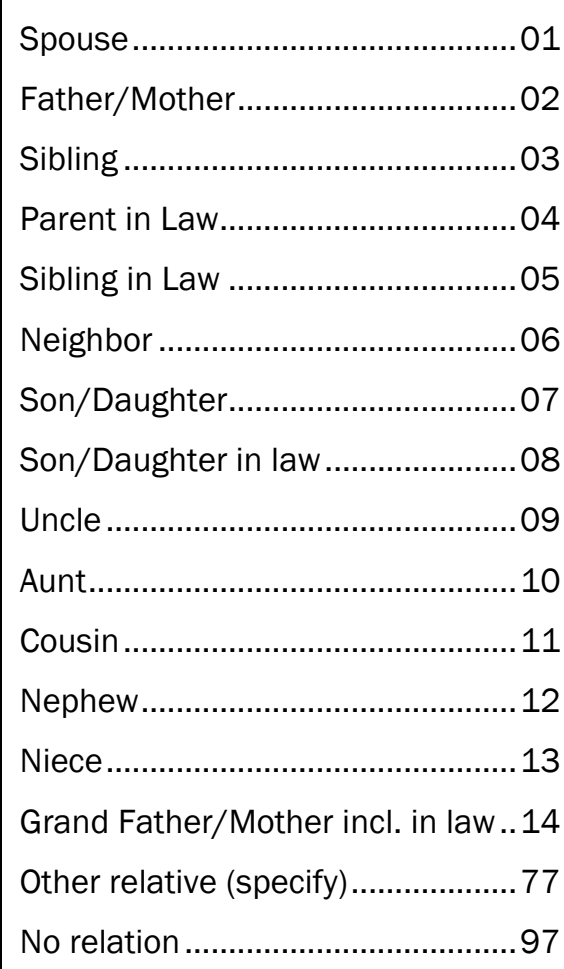 \\
\hline B3 & Gender of the Respondent & Male \\
\hline $\begin{array}{c}\text { B4 } \\
\text { (2A115) }\end{array}$ & 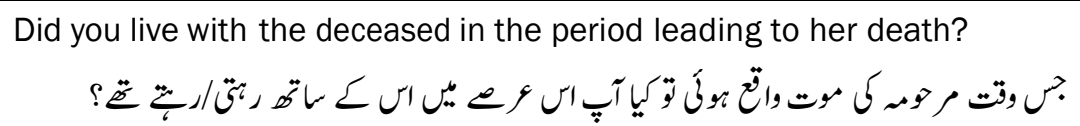 & Yes \\
\hline B5 & 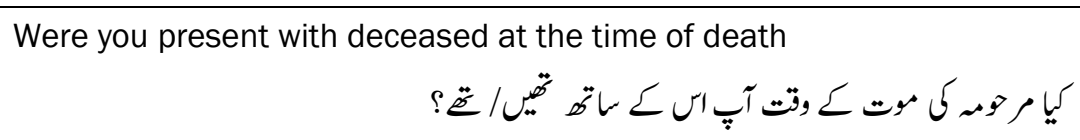 & Yes \\
\hline
\end{tabular}




\section{SECTION-C: DECEASED WOMAN'S HOUSEHOLD CHARACTERISTICS}

In order to get an idea of the socio-economic conditions of the deceased woman we shall ask a few questions related to her (deceased woman's) living conditions

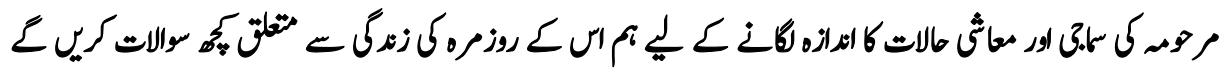

\begin{tabular}{|c|c|c|}
\hline Q.NO. & Questions and Filters & Coding Categories \\
\hline 9.2 .1 & $\begin{array}{l}\text { What is the main source of drinking water of } \\
\text { deceased's household. }\end{array}$ & 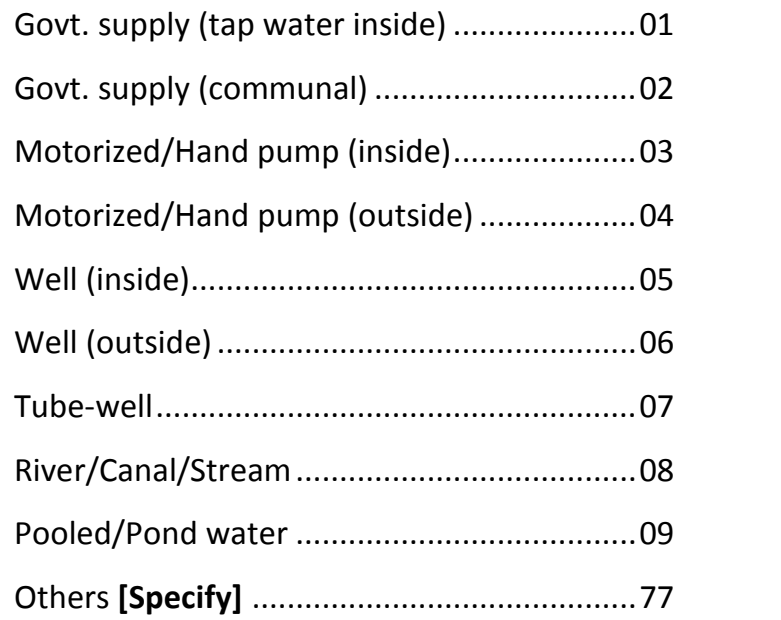 \\
\hline $\mathrm{C} 2$ & 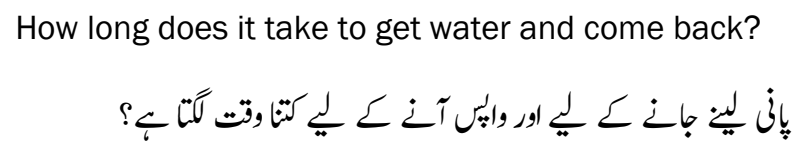 & 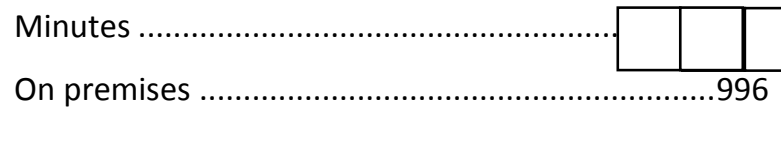 \\
\hline C3 & 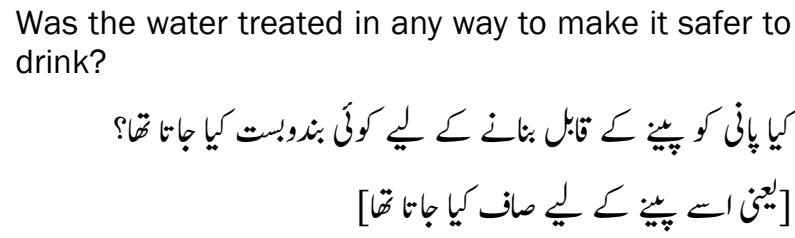 & Yes \\
\hline $\mathrm{C4}$ & $\begin{array}{l}\text { What did deceased's household members usually do } \\
\text { to make water safer to drink? } \\
\text { (Multiple responses are allowed) }\end{array}$ & $\begin{array}{l}\text { Boild bleach/chlorine } \\
\text { Strain through a cloth } \\
\text { Use water filter }\end{array}$ \\
\hline C5 & 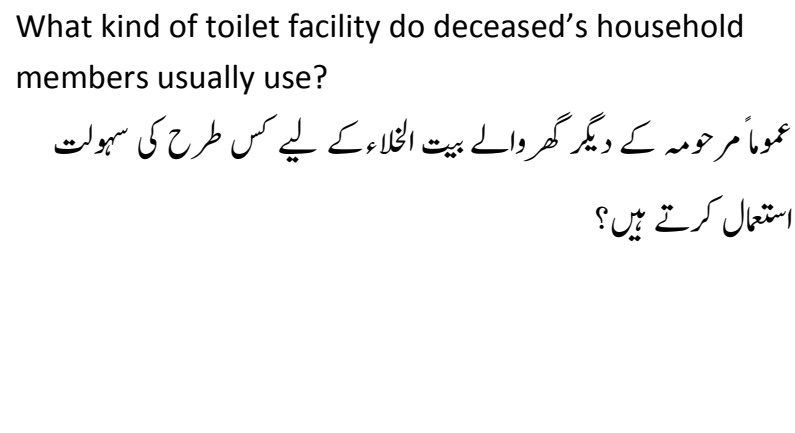 & 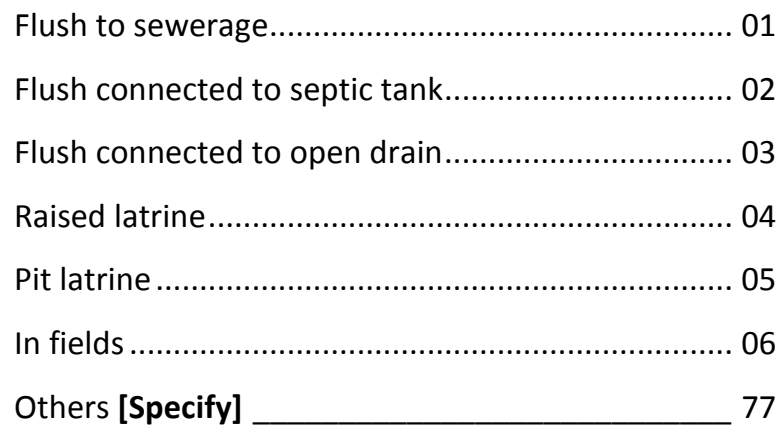 \\
\hline
\end{tabular}




\begin{tabular}{|c|c|c|}
\hline Q.NO. & Questions and Filters & Coding Categories \\
\hline C6 & 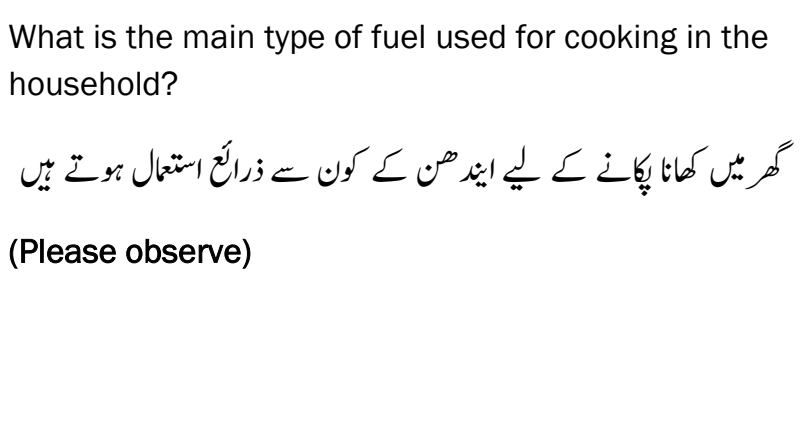 & 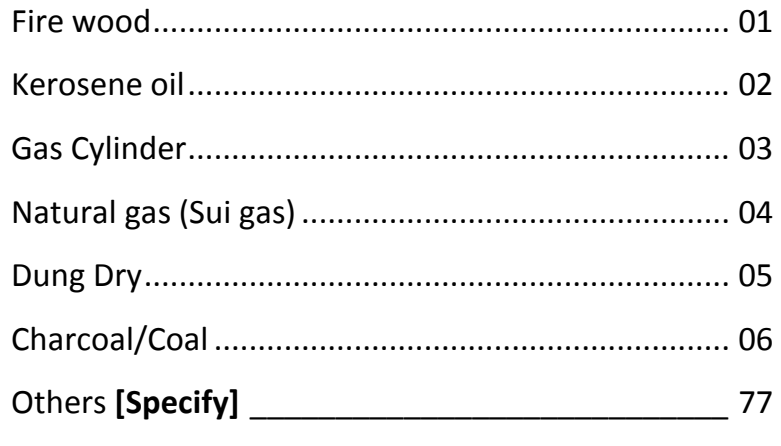 \\
\hline C7 & $\begin{array}{l}\text { How many separate rooms are there for sleeping in } \\
\text { the dwelling? }\end{array}$ & 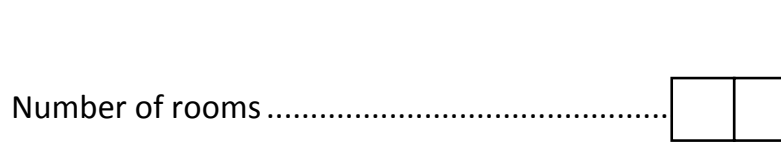 \\
\hline C8 & 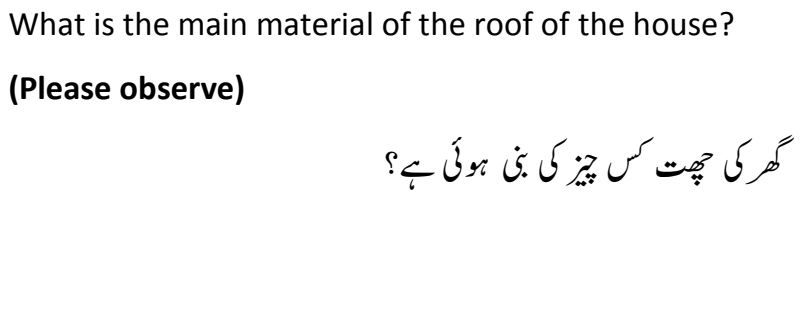 & 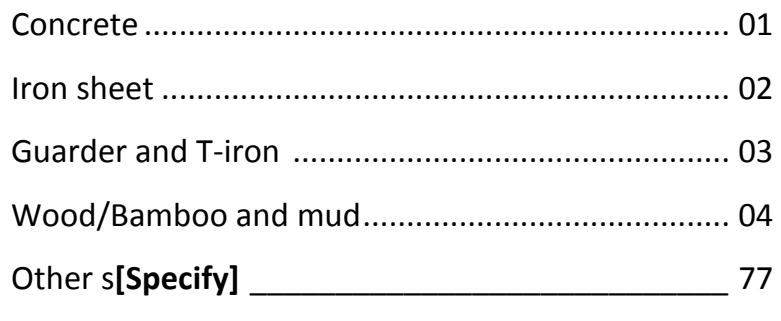 \\
\hline C9 & $\begin{array}{l}\text { What is the main material of the floor of the house? } \\
\text { (Please observe) }\end{array}$ & Carth/sand/mud \\
\hline C10 & $\begin{array}{l}\text { What is the main material of the walls of the house? } \\
\text { (Please observe) }\end{array}$ & 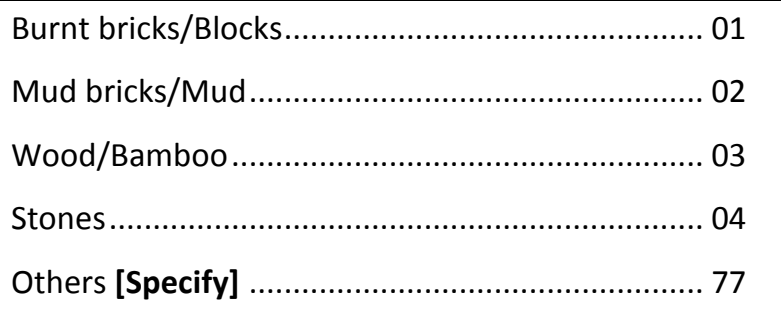 \\
\hline
\end{tabular}




\begin{tabular}{|c|c|c|c|}
\hline \multirow[t]{2}{*}{ C11 } & \multicolumn{2}{|c|}{ 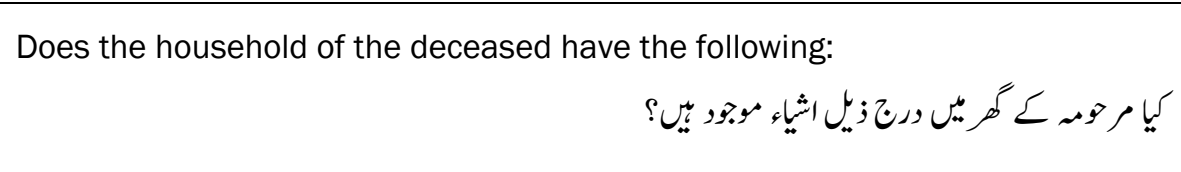 } & $\begin{array}{l}\text { [If Yes in C11] } \\
\text { C12 Is it currently } \\
\text { functioning? }\end{array}$ \\
\hline & Household possessions & Yes & Yes \\
\hline a. & Wall Clock & 1 & \\
\hline b. & Chairs & 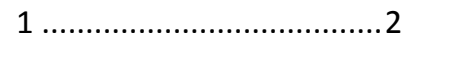 & \\
\hline c. & Bed & $1 \ldots \ldots \ldots \ldots \ldots \ldots \ldots \ldots \ldots \ldots \ldots . . .2$ & \\
\hline d. & Sofa & 1 & \\
\hline e. & Electricity & $1 \ldots \ldots \ldots \ldots \ldots \ldots \ldots \ldots \ldots \ldots \ldots \ldots . . .2$ & \\
\hline f. & Sewing Machine & 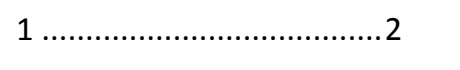 & 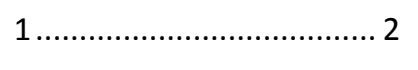 \\
\hline g. & Camera & 1 & 1 .............................. 2 \\
\hline h. & Radio/tape recorder & 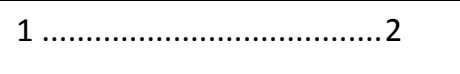 & 1 \\
\hline i. & Television & 1 & 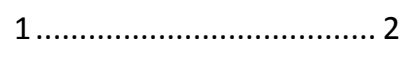 \\
\hline j. & Refrigerator & $1 \ldots \ldots \ldots \ldots \ldots \ldots \ldots \ldots \ldots . . .2$ & $1 \ldots \ldots \ldots \ldots \ldots \ldots \ldots \ldots \ldots \ldots \ldots . . .2$ \\
\hline k. & Land line telephone & 1 & 1 \\
\hline I. & Mobile telephone & 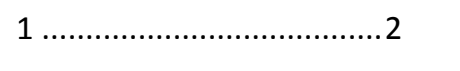 & 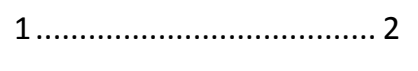 \\
\hline $\mathrm{m}$. & Room cooler/ air conditioner & 1 & 1 \\
\hline $\mathrm{n}$. & Washing machine & 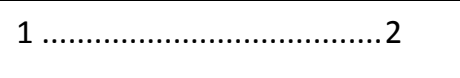 & 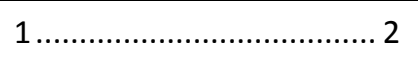 \\
\hline 0. & Cycle & $1 \ldots \ldots \ldots \ldots \ldots \ldots \ldots \ldots \ldots \ldots \ldots \ldots . .2$ & $1 \ldots \ldots \ldots \ldots \ldots \ldots \ldots \ldots \ldots \ldots . . .2$ \\
\hline p. & Motor cycle & 1 & 1 \\
\hline q. & Jeep/car & 1 & 1 \\
\hline r. & Tractor & 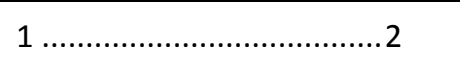 & $1 \ldots 2$ \\
\hline s. & Personal computer & 1 & 1 \\
\hline
\end{tabular}


SECTION-D: DECEASED WOMAN'S BACKGROUND CHARACTERISTICS

Now I would like to ask you some questions related to deceased woman's background characteristics

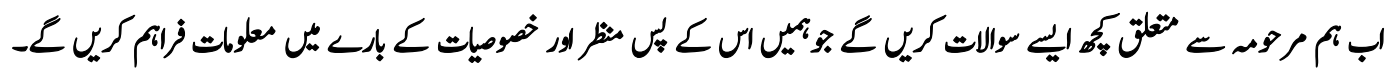

\begin{tabular}{|c|c|c|}
\hline Q.NO. & Questions and Filters & Coding Categories \\
\hline $\begin{array}{c}\mathrm{D} 1 \\
(1 \mathrm{~A} 100)\end{array}$ & What was the name of the deceased woman? & روتمـ كنام كيا تقا؟ _ــــ \\
\hline $\begin{array}{c}\text { D2 } \\
(1 \mathrm{~A} 200)\end{array}$ & Is date of birth known? & 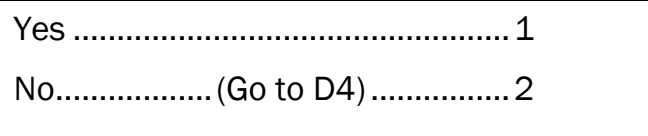 \\
\hline $\begin{array}{c}\text { D3 } \\
(1 \mathrm{~A} 210)\end{array}$ & When was the deceased born? & $-I_{\text {DD }}: I_{\mathrm{MM}}:-I_{\text {YYY }}$ \\
\hline $\begin{array}{c}\mathrm{D} 4 \\
(1 \mathrm{~A} 220)\end{array}$ & Is date of death known? & 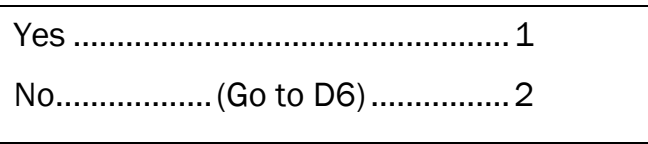 \\
\hline $\begin{array}{c}\mathrm{D} 5 \\
(1 \mathrm{~A} 230)\end{array}$ & When did she die? & ${ }_{\text {DD }}$ MM \\
\hline $\begin{array}{c}\mathrm{D} 6 \\
(1 \mathrm{~A} 240)\end{array}$ & 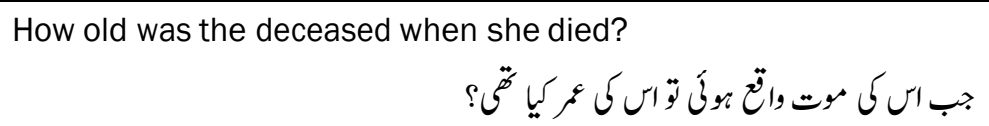 & Age in years ..................................... \\
\hline $\begin{array}{c}\text { D7 } \\
(1 \mathrm{~A} 500)\end{array}$ & What was her citizenship/nationality? & 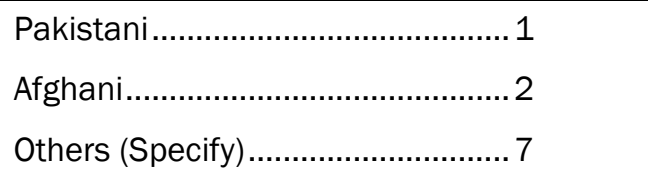 \\
\hline $\begin{array}{c}\mathrm{D} 8 \\
(1 \mathrm{~A} 510)\end{array}$ & What was her ethnicity? & 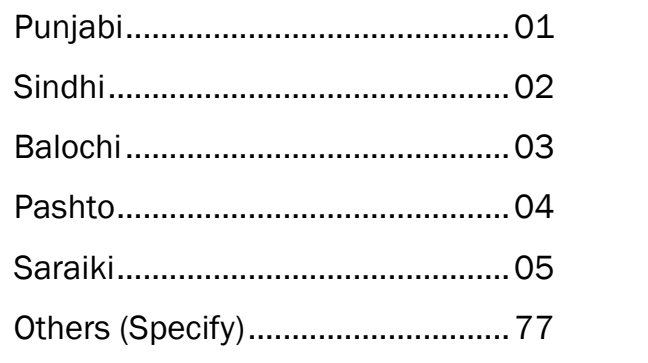 \\
\hline $\begin{array}{c}\text { D9 } \\
(1 \mathrm{~A} 520)\end{array}$ & What was her place of birth? & a) Province \\
\hline $\begin{array}{c}\mathrm{D} 10 \\
(1 \mathrm{~A} 630)\end{array}$ & What was the name of her mother? & اسكى نال ك نام كيا ثقا؟ \\
\hline $\begin{array}{c}\mathrm{D} 11 \\
(1 \mathrm{~A} 620)\end{array}$ & What was the name of her father? & اس ع بإب كايِ نام ثقا؟ \\
\hline
\end{tabular}




\begin{tabular}{|c|c|c|}
\hline Q.NO. & Questions and Filters & Coding Categories \\
\hline $\begin{array}{c}\text { D12 } \\
\text { (1A640) }\end{array}$ & Was she able to read and write? & 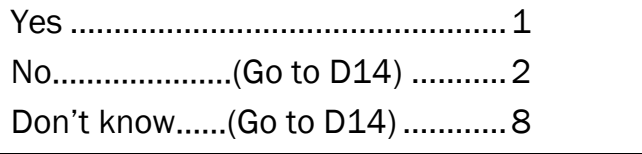 \\
\hline $\begin{array}{c}\text { D13 } \\
(1 \mathrm{~A} 650)\end{array}$ & What was her highest level of schooling? & 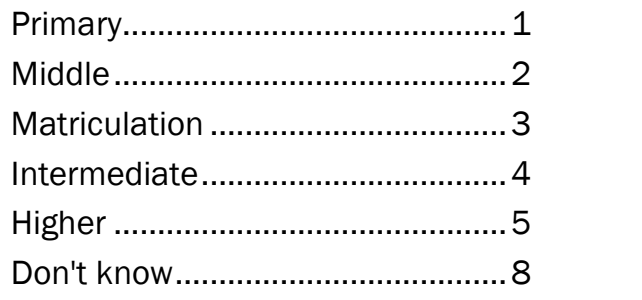 \\
\hline $\begin{array}{c}\text { D14 } \\
(1 \mathrm{~A} 670)\end{array}$ & 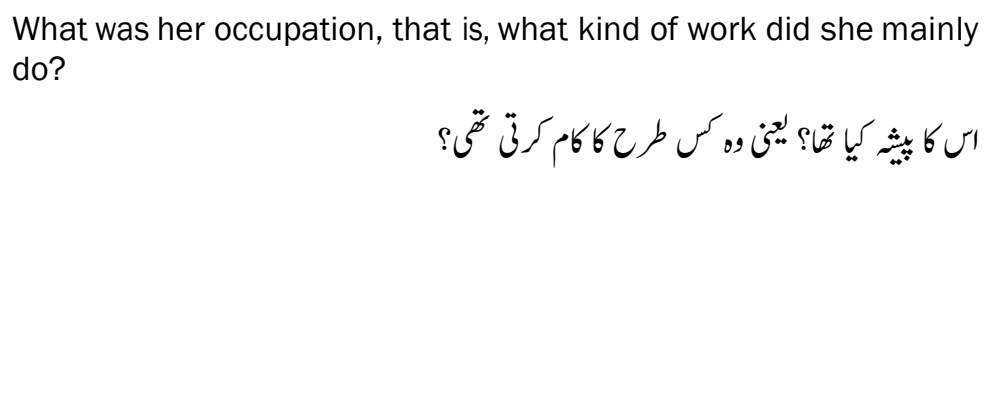 & 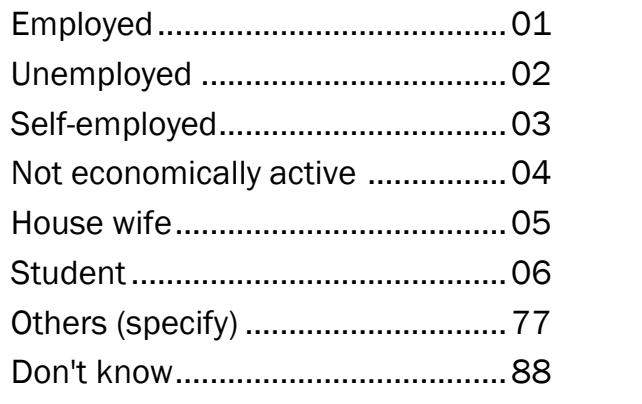 \\
\hline $\begin{array}{c}\text { D15 } \\
\text { (1A680) }\end{array}$ & 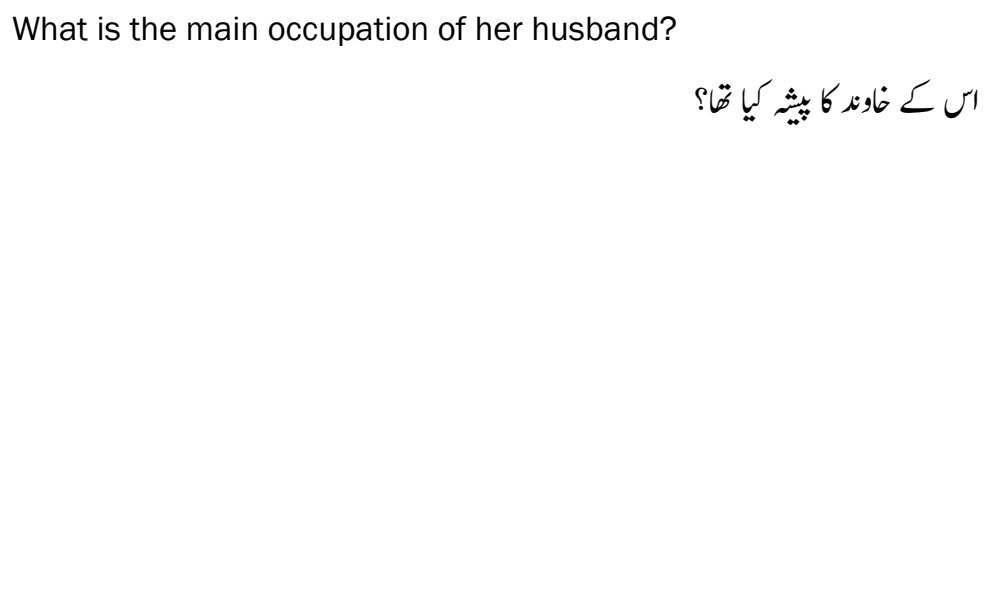 & 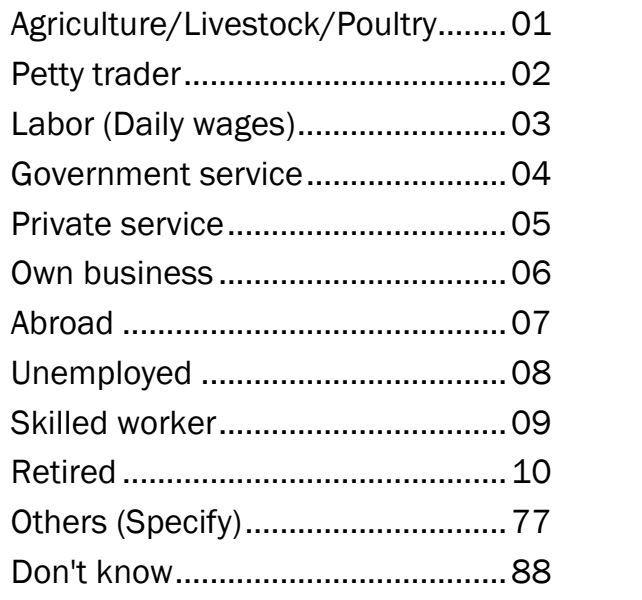 \\
\hline D16 & 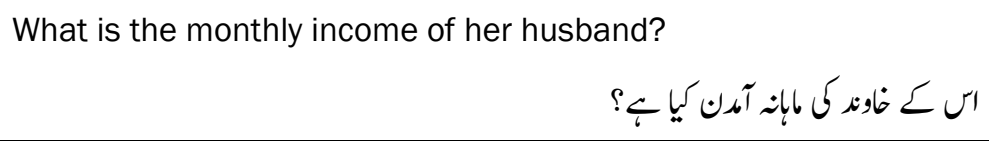 & 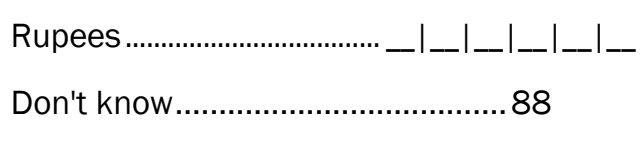 \\
\hline D17 & What is the level of schooling of her husband? & 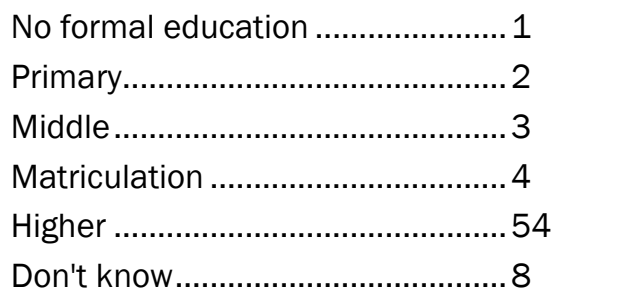 \\
\hline
\end{tabular}




\section{SECTION-E: BIRTH AND PREGNANCY INFORMATION}

Now I would like to ask you some questions related deceased woman's pregnancies and births.

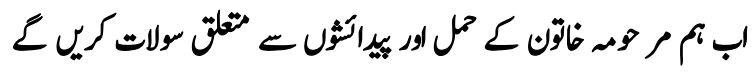

\begin{tabular}{|c|c|c|}
\hline Q.NO. & Questions and Filters & Coding Categories \\
\hline $\begin{array}{c}\text { E1 } \\
(1 \mathrm{~A} 600)\end{array}$ & 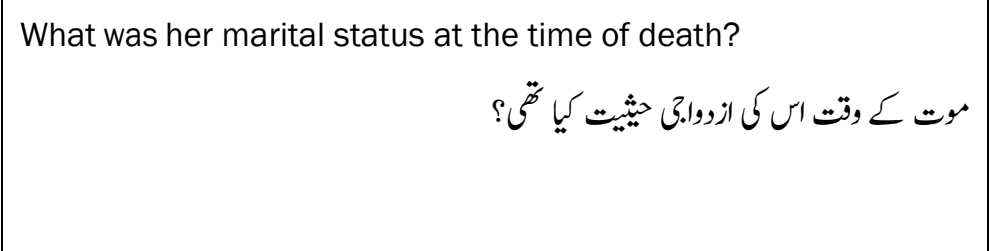 & 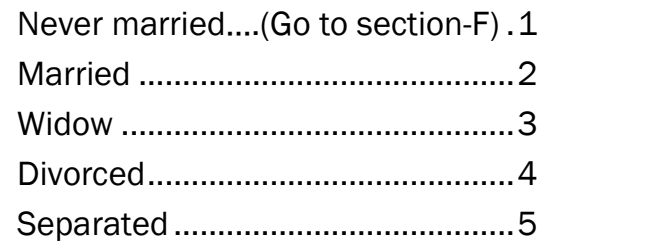 \\
\hline $\begin{array}{c}\text { E2 } \\
(1 \mathrm{~A} 610)\end{array}$ & What was the date of marriage? & 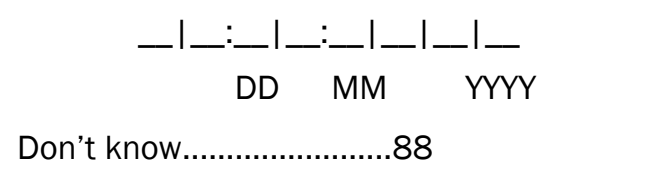 \\
\hline E3 & 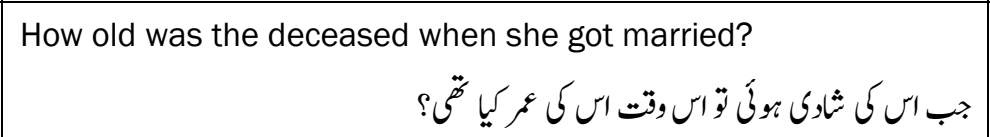 & 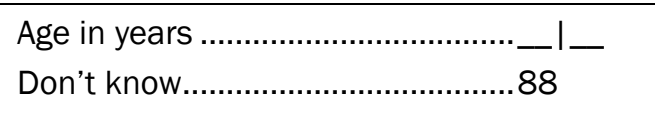 \\
\hline E4 & Did she get pregnant in her lifetime? & 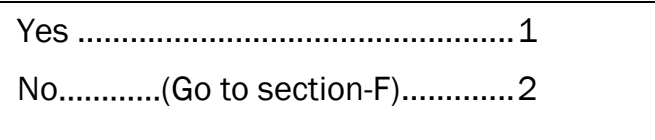 \\
\hline E5 & 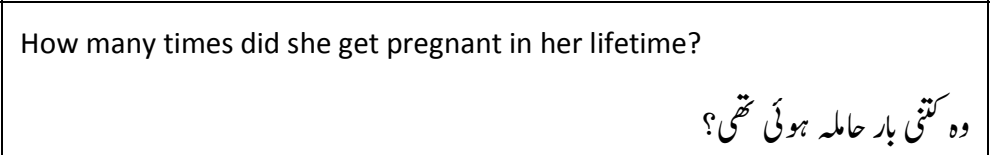 & 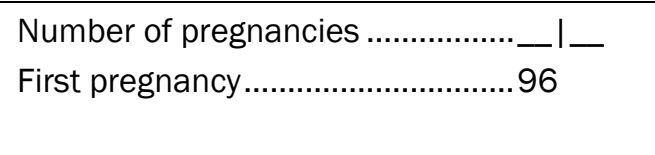 \\
\hline $\begin{array}{c}\text { E6 } \\
(3 \mathrm{C} 230)\end{array}$ & $\begin{array}{l}\text { How many live births did she have in her lifetime? } \\
\text { (If no live birth write " } \underline{\mathbf{0 0}} \text { " in total, if don't know write "88") }\end{array}$ & (b) Son(s) \\
\hline E7 & $\begin{array}{l}\text { How many stillbirths did she have in her lifetime? } \\
\text { (If no stillbirth write "므" in total, if don't know write "88") }\end{array}$ & (b) Son(s) \\
\hline E8 & 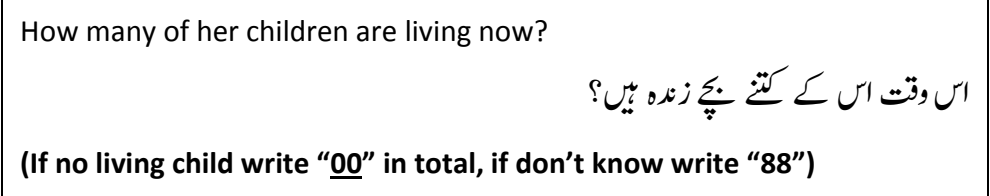 & 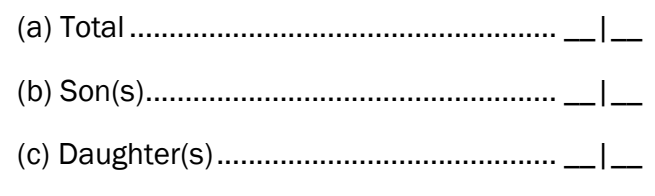 \\
\hline E9 & 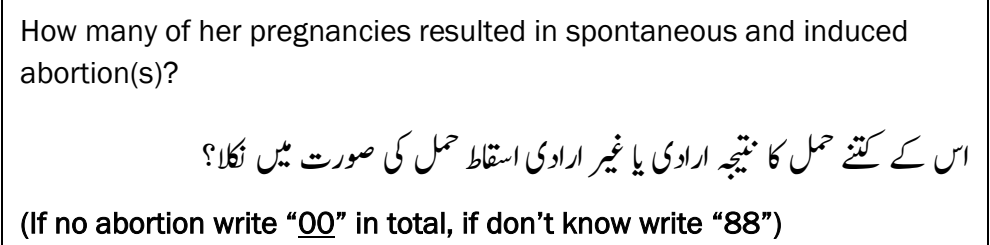 & 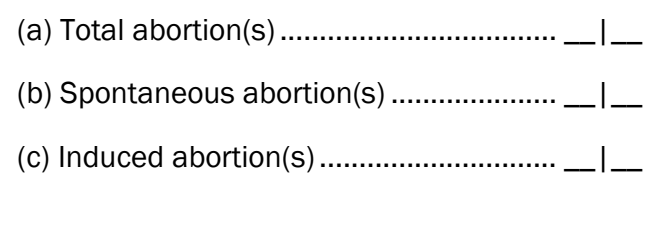 \\
\hline
\end{tabular}


Pregnancy History

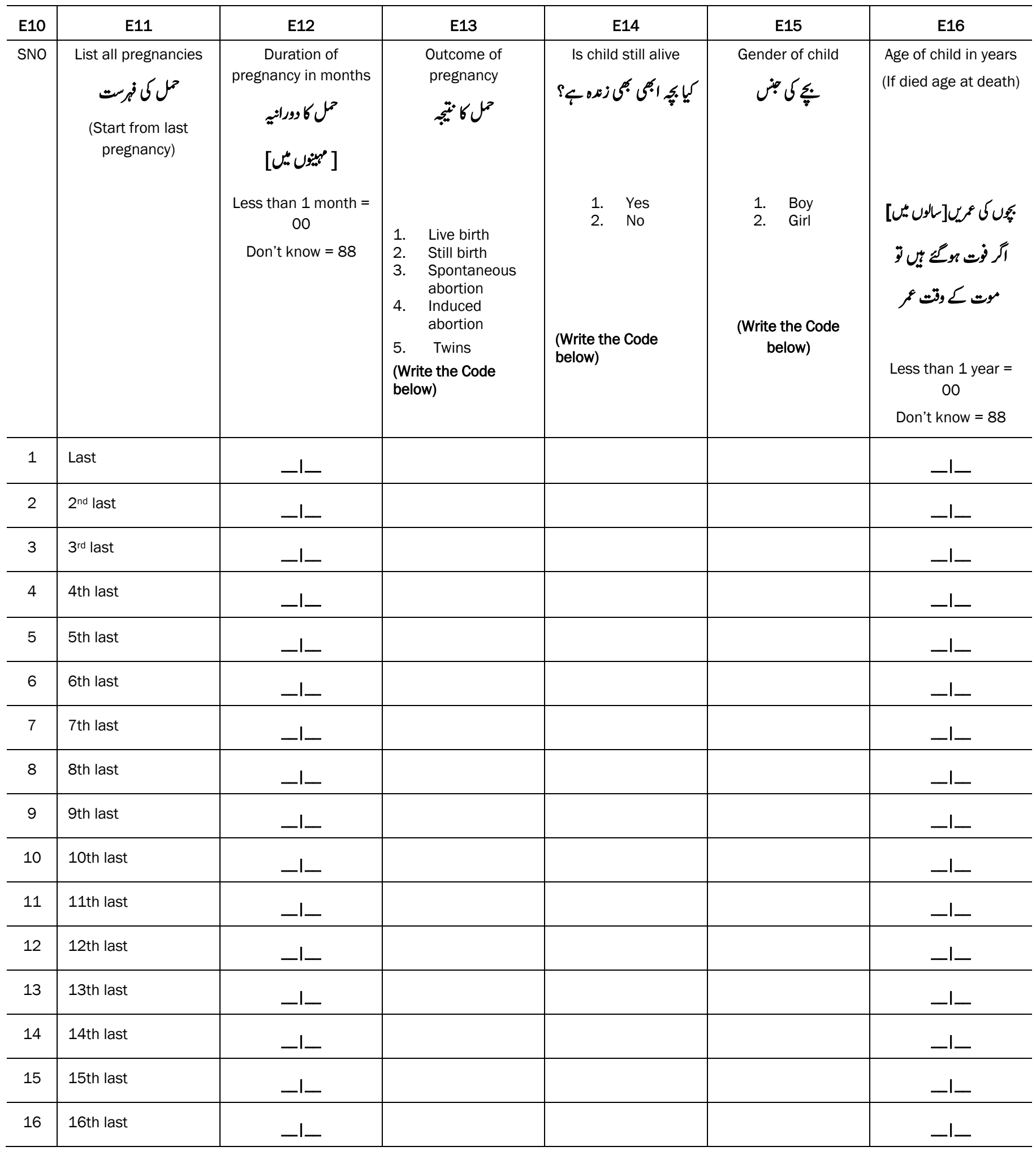


SECTION-F: INFORMATION RELATED TO PLACE OF DEATH

موت كن جك ــ مثلق معلوات

\begin{tabular}{|c|c|c|}
\hline Q.NO. & Questions and Filters & Coding Categories \\
\hline $\begin{array}{c}\mathrm{F} 1 \\
(1 \mathrm{~A} 530)\end{array}$ & What was her place of usual residence? & 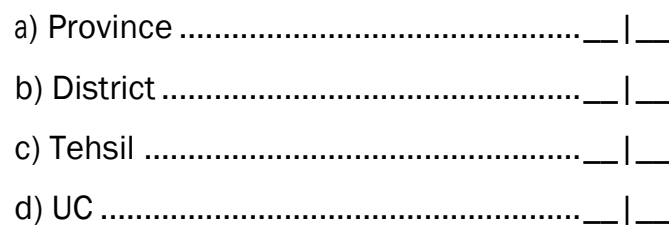 \\
\hline $\begin{array}{c}\mathrm{F} 2 \\
(1 \mathrm{~A} 540)\end{array}$ & 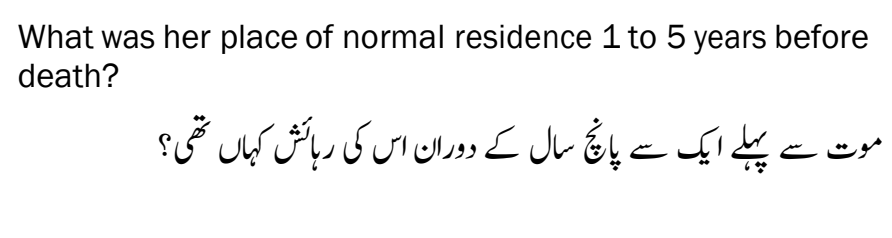 & 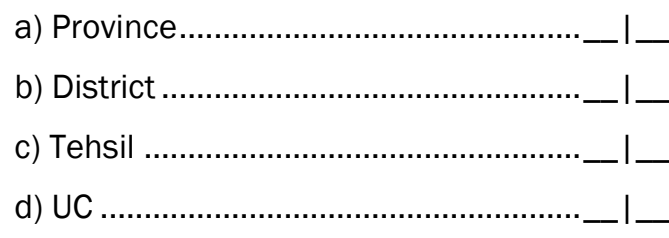 \\
\hline $\begin{array}{c}\mathrm{F} 3 \\
(1 \mathrm{~A} 550)\end{array}$ & 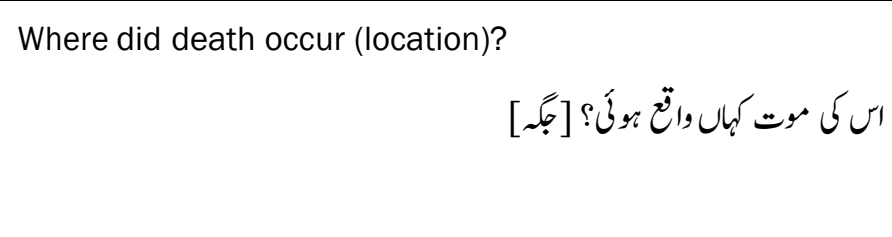 & 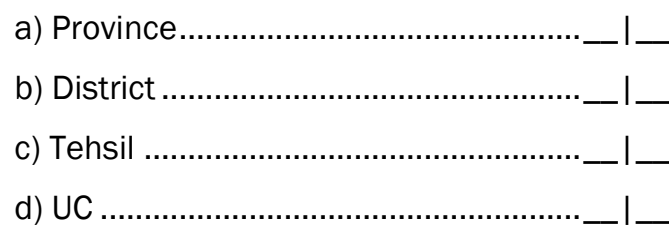 \\
\hline $\begin{array}{c}\mathrm{F} 4 \\
(1 \mathrm{~A} 560)\end{array}$ & What was the place of death? & 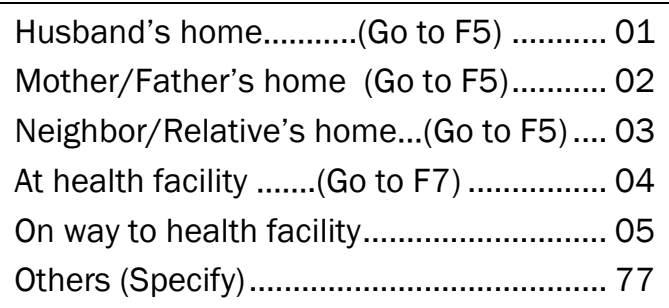 \\
\hline F5 & 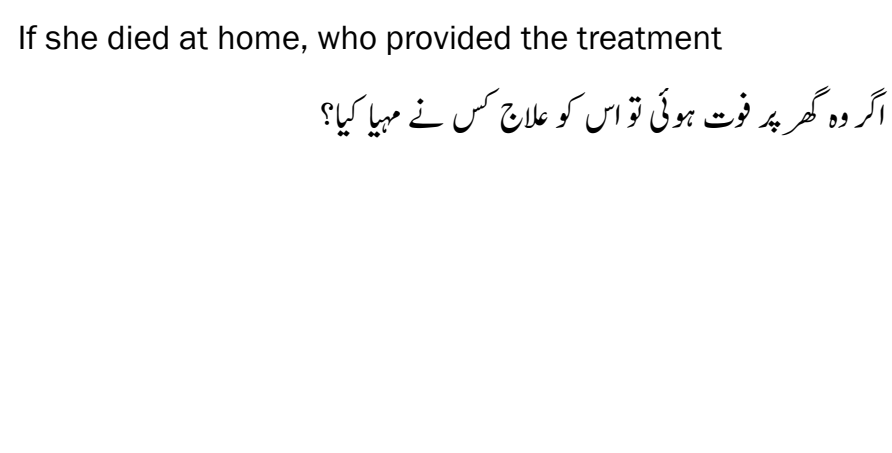 & 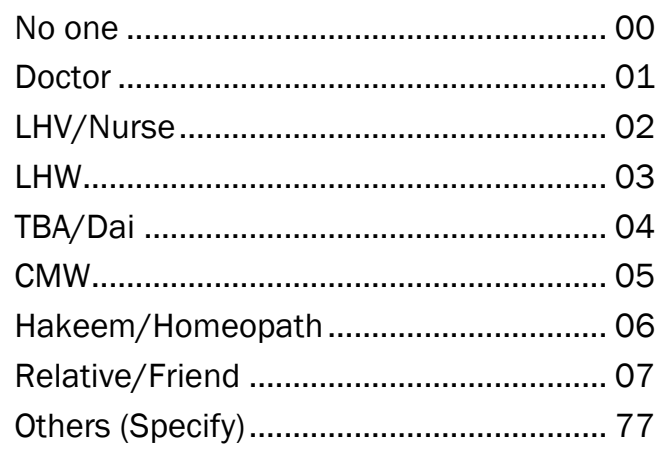 \\
\hline F6 & 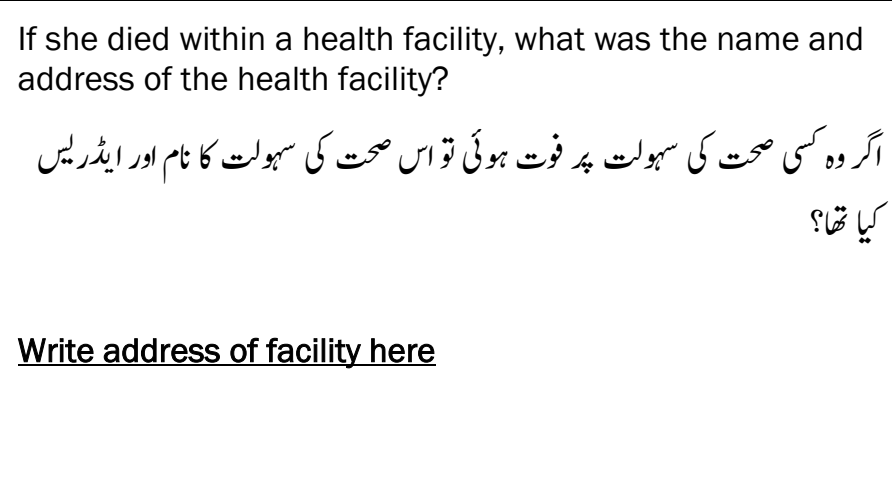 & $\begin{array}{l}\text { DHQ } \\
\text { THQ } \\
\text { RHC } \\
\text { BHU } \\
\text { Peaching Hospital } \\
\text { Private hospital }\end{array}$ \\
\hline F7 & 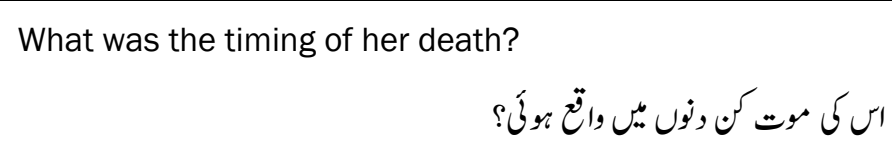 & 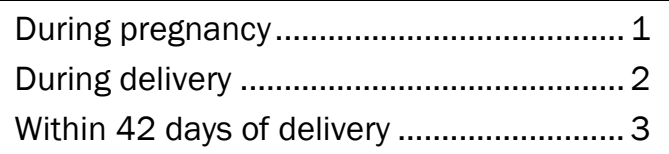 \\
\hline
\end{tabular}




\begin{tabular}{|c|c|c|}
\hline Q.NO. & Questions and Filters & Coding Categories \\
\hline & & After 42 days but less than 1 year.............. 4 \\
\hline F8 & 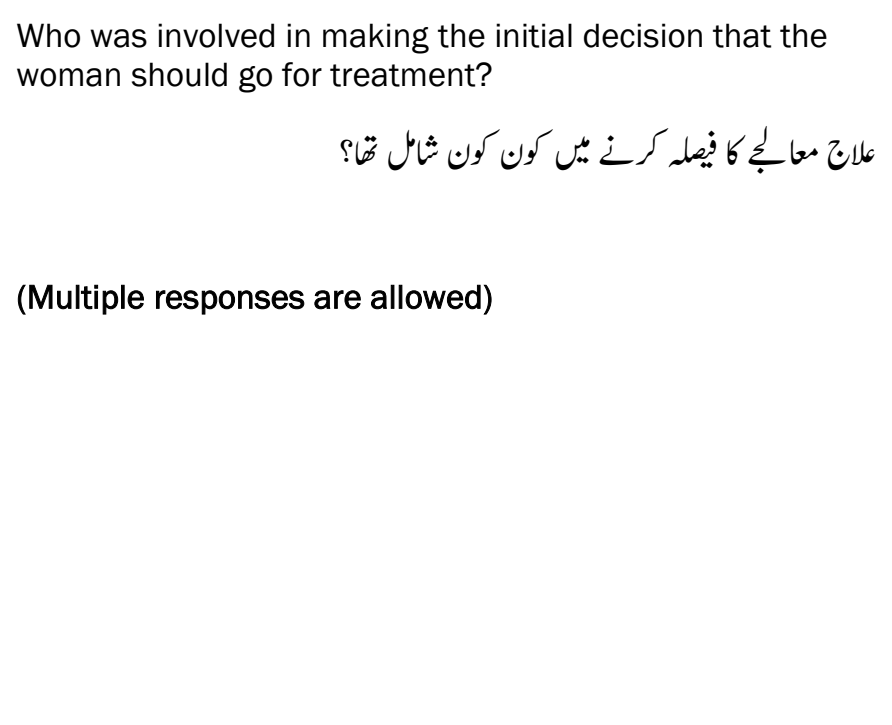 & Patient herself \\
\hline F9 & Was the decision taken Immediately? & 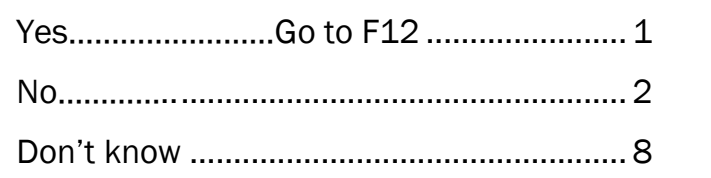 \\
\hline F10 & 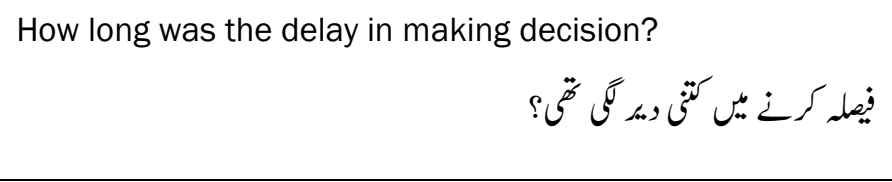 & $\begin{array}{l}\text { (a) Number of hours................................... } \\
\text { (b) Number of days ...................................... } \\
\text { Don't know }\end{array}$ \\
\hline F11 & 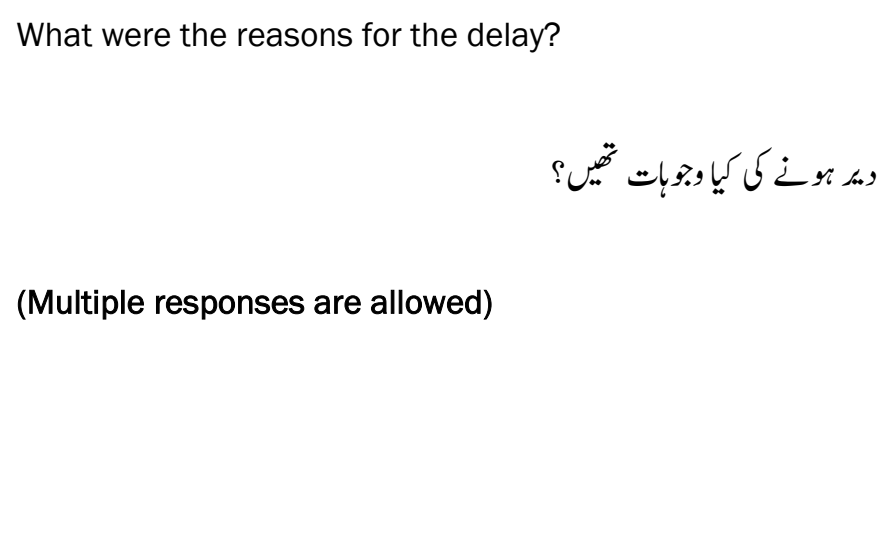 & 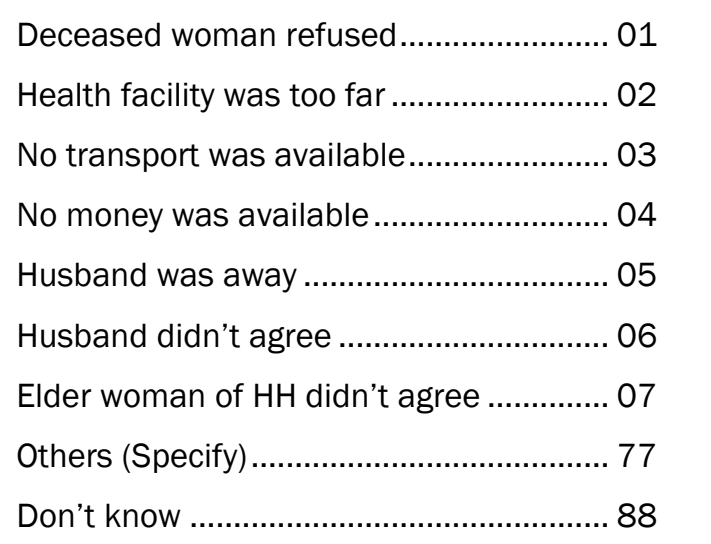 \\
\hline F12 & 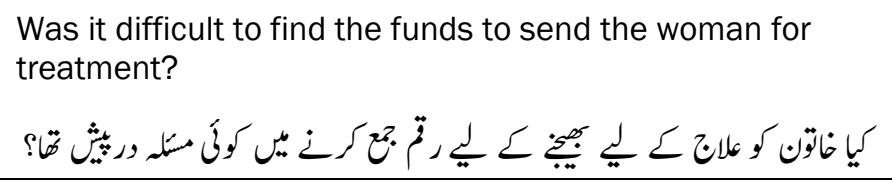 & 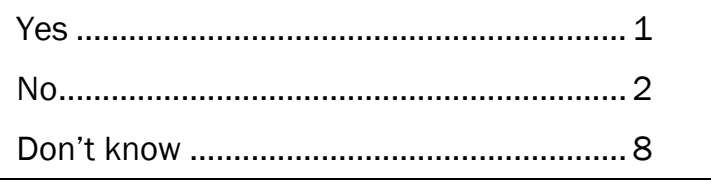 \\
\hline $\begin{array}{c}\text { F13 } \\
(4 A 100)\end{array}$ & 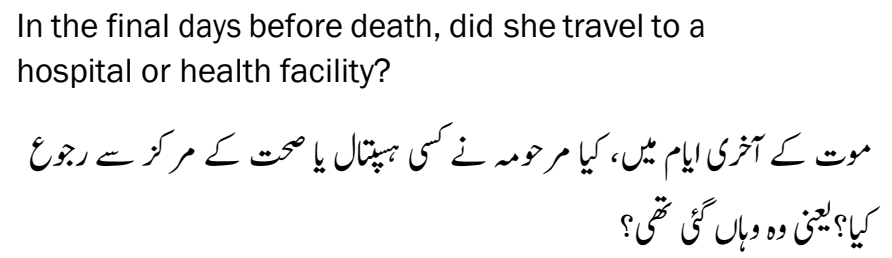 & 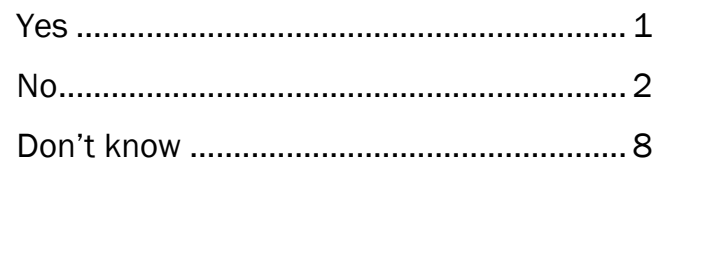 \\
\hline F14 & $\begin{array}{l}\text { After leaving home, what type of transport did } \\
\text { she use to reach the health facility? }\end{array}$ & On foot \\
\hline
\end{tabular}




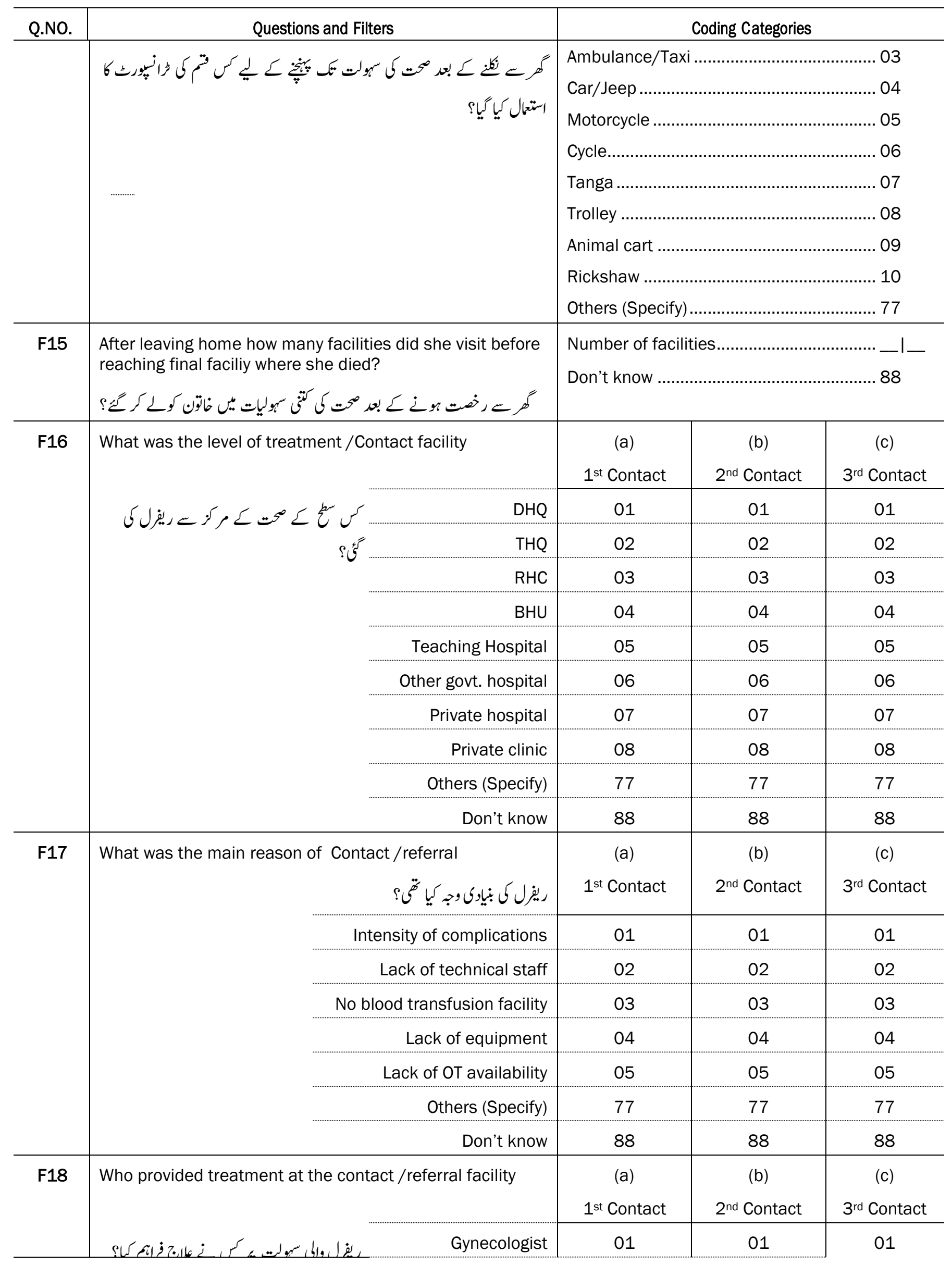




\begin{tabular}{|c|c|c|c|c|}
\hline \multirow[t]{11}{*}{ Q.NO. } & Questions and Filters & \multicolumn{3}{|c|}{ Coding Categories } \\
\hline & Doctor & 02 & 02 & 02 \\
\hline & Nurse & 03 & 03 & 03 \\
\hline & LHV & 04 & 04 & 04 \\
\hline & LHW & 05 & 05 & 05 \\
\hline & TBA & 06 & 06 & 06 \\
\hline & Dispenser & 07 & 07 & 07 \\
\hline & FHT & 08 & 08 & 08 \\
\hline & MHT & 09 & 09 & 09 \\
\hline & Others (Specify) & 77 & 77 & 77 \\
\hline & Don't know & 88 & 88 & 88 \\
\hline \multirow[t]{4}{*}{ F19 } & $\begin{array}{l}\text { What was the time taken to reach the facility } \\
\text { (From home to } 1^{\text {st }}, 1^{\text {st }} \text { to } 2^{\text {nd }}, 2^{\text {nd }} \text { to } 3^{\text {rd }} \text { facility) }\end{array}$ & $\begin{array}{c}\text { (a) } \\
1^{\text {st }} \text { Contact }\end{array}$ & $\begin{array}{c}\text { (b) } \\
2^{\text {nd }} \text { Contact }\end{array}$ & $\begin{array}{c}\text { (c) } \\
3^{\text {rd }} \text { Contact }\end{array}$ \\
\hline & \multirow{3}{*}{ 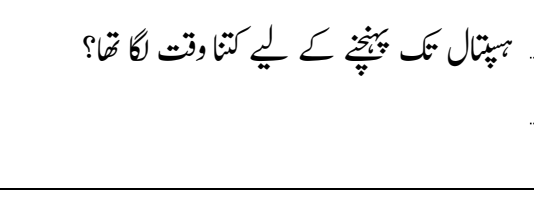 } & $-1-$ & -1 & -1 \\
\hline & & -1 & -1 & -1 \\
\hline & & 88 & 88 & 88 \\
\hline \multirow[t]{4}{*}{ F20 } & 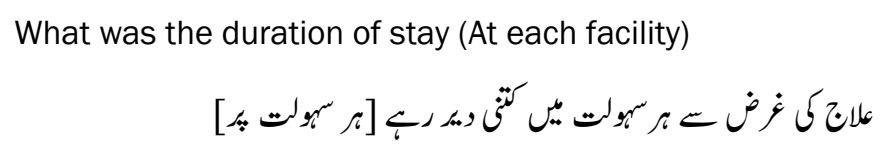 & $\begin{array}{c}\text { (a) } \\
\text { 1st }^{\text {st }} \text { Contact }\end{array}$ & $\begin{array}{c}\text { (b) } \\
2^{\text {nd }} \text { Contact }\end{array}$ & $\begin{array}{c}\text { (c) } \\
\text { 3rd Contact }\end{array}$ \\
\hline & Minutes & -1 & -1 & -1 \\
\hline & Hours & -1 & -1 & -1 \\
\hline & Don't know & 88 & 88 & 88 \\
\hline \multirow[t]{4}{*}{ F21 } & Where did the death occur & $\begin{array}{c}\text { (a) } \\
1^{\text {st }} \text { Contact }\end{array}$ & $\begin{array}{c}\text { (b) } \\
2^{\text {nd }} \text { Contact }\end{array}$ & $\begin{array}{c}\text { (c) } \\
3^{\text {rd }} \text { Contact }\end{array}$ \\
\hline & \multirow[t]{2}{*}{ موت كمال واقع نوكُ؟ } & 1 & 1 & 1 \\
\hline & & 2 & 2 & 2 \\
\hline & At home & 3 & 3 & 3 \\
\hline $\begin{array}{c}\mathrm{F} 22 \\
(4 \mathrm{~A} 120)\end{array}$ & 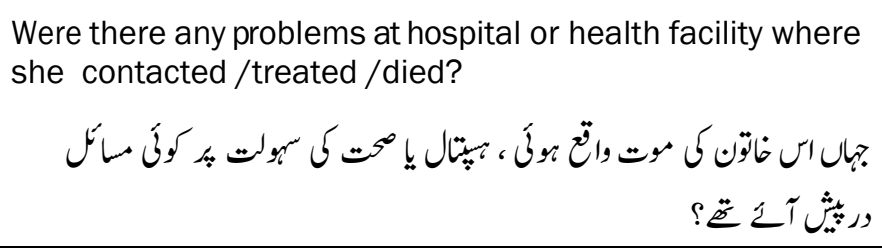 & \multicolumn{3}{|c|}{ 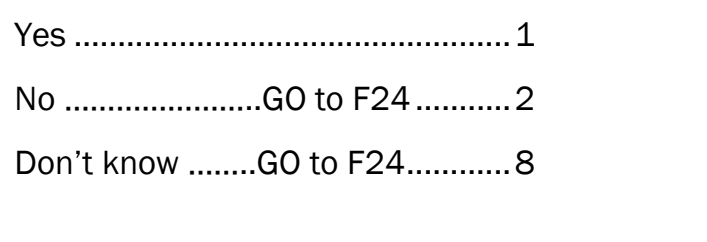 } \\
\hline
\end{tabular}




\begin{tabular}{|c|c|c|c|c|}
\hline Q.NO. & Questions and Filters & \multicolumn{3}{|c|}{ Coding Categories } \\
\hline \multirow{13}{*}{$\begin{array}{c}\mathrm{F} 23 \\
(4 \mathrm{~A} 130)\end{array}$} & \multirow{3}{*}{$\begin{array}{l}\text { Were there any problems in the following with the way she was } \\
\text { treated in the hospital or health facility? }\end{array}$} & Yes (1) & No & Don't know \\
\hline & & (a) & (b) & (c) \\
\hline & & $1^{\text {st }}$ Contact & $2^{\text {nd }}$ Contact & $3^{\text {rd }}$ Contact \\
\hline & \multirow{10}{*}{ 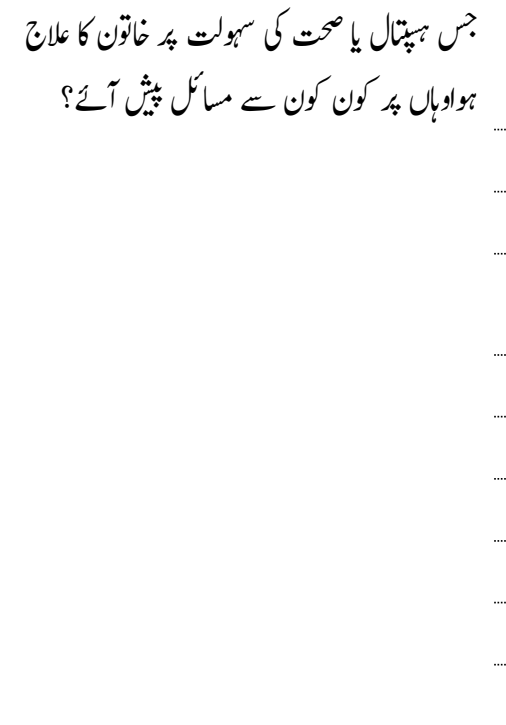 } & 1 & 2 & 8 \\
\hline & & 1 & 2 & 8 \\
\hline & & 1 & 2 & 8 \\
\hline & & 1 & 2 & 8 \\
\hline & & 1 & 2 & 8 \\
\hline & & 1 & 2 & 8 \\
\hline & & 1 & 2 & 8 \\
\hline & & 1 & 2 & 8 \\
\hline & & 1 & 2 & 8 \\
\hline & & 1 & 2 & 8 \\
\hline F24 & 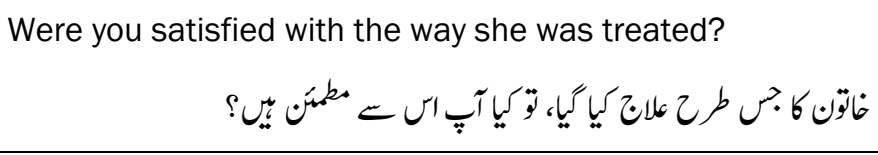 & \multicolumn{3}{|c|}{ Yes } \\
\hline $\begin{array}{c}\mathrm{F} 25 \\
(4 \mathrm{~A} 170)\end{array}$ & 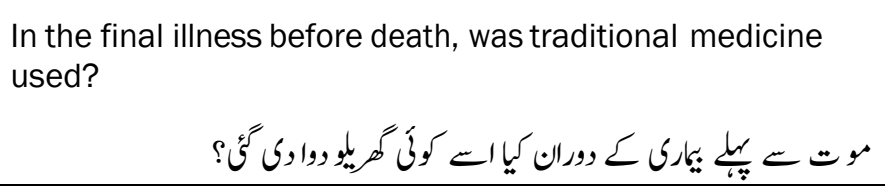 & \multicolumn{3}{|c|}{ 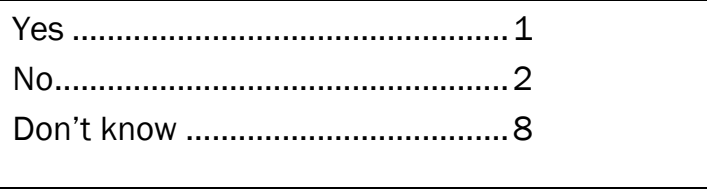 } \\
\hline $\begin{array}{c}\text { F26 } \\
(4 A 180)\end{array}$ & 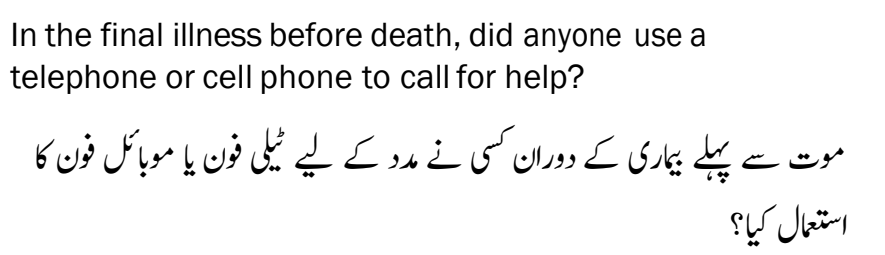 & \multicolumn{3}{|c|}{ 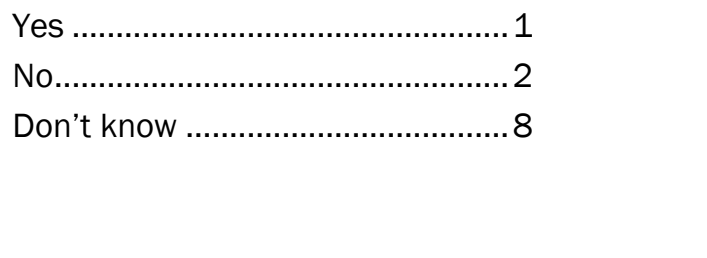 } \\
\hline $\begin{array}{c}\text { F27 } \\
(4 A 190)\end{array}$ & 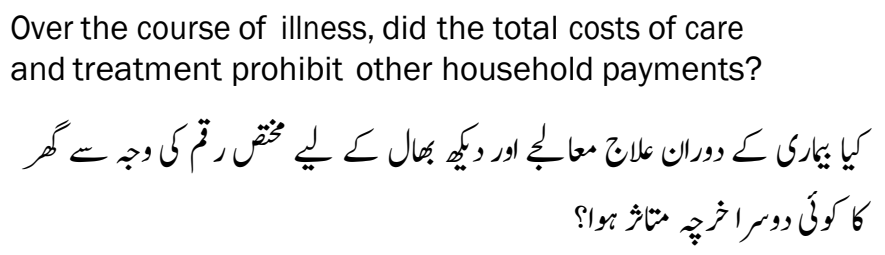 & \multicolumn{3}{|c|}{ 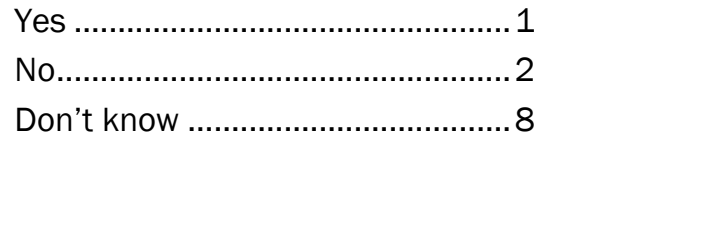 } \\
\hline
\end{tabular}


I would like to ask you some questions concerning the context and previously known medical conditions the deceased had; read each disease below and record if respondent answers 'yes', ask: for how many months or years prior to death she was diagnosed with name of disease?

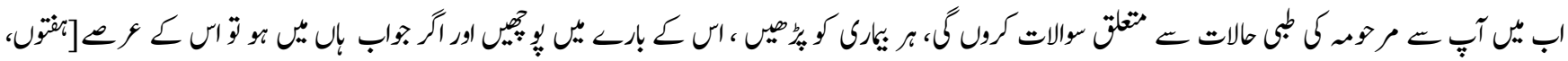

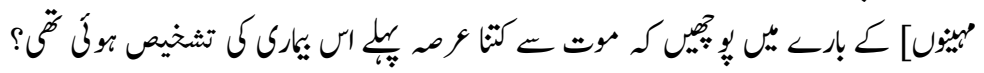

\begin{tabular}{|c|c|c|c|}
\hline \multirow[t]{2}{*}{ S.No. } & \multirow[t]{2}{*}{ Disease } & Response & Duration \\
\hline & & (a) & (b) \\
\hline $\begin{array}{c}\text { G1 } \\
(3 A 100)\end{array}$ & Tuberculosis & $\begin{array}{l}\text { Yes...........(Go to G2)..........2 } \\
\text { Don't know....(Go to G2) ..8 }\end{array}$ & 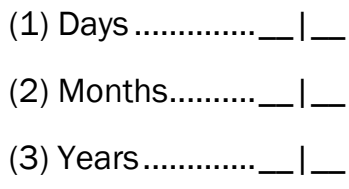 \\
\hline $\begin{array}{c}\text { G2 } \\
(3 A 110)\end{array}$ & 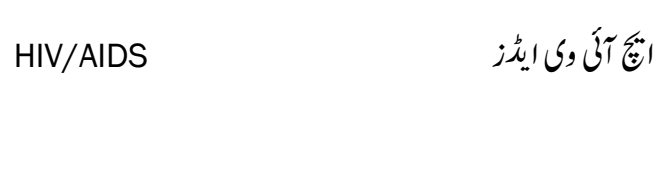 & 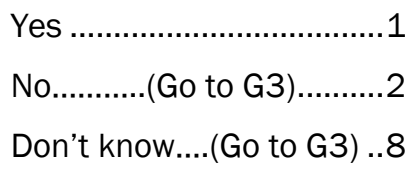 & 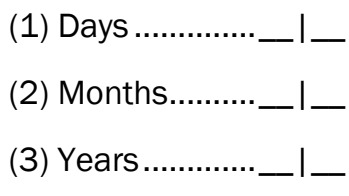 \\
\hline $\begin{array}{c}\text { G3 } \\
\text { (3A120) }\end{array}$ & 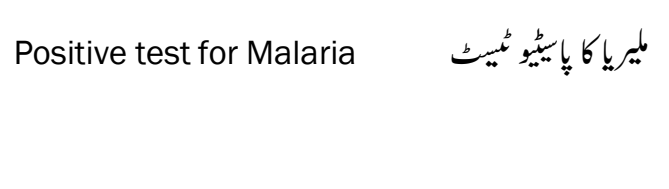 & $\begin{array}{l}\text { Yes } \\
\text { No...........(Go to G4).......... } \\
\text { Don't know....(Go to G4) ..8 }\end{array}$ & 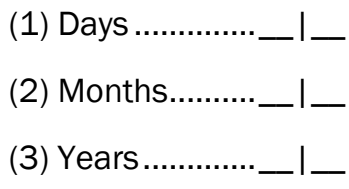 \\
\hline $\begin{array}{c}\text { G4 } \\
(3 \mathrm{~A} 130)\end{array}$ & Negative test for Malaria & 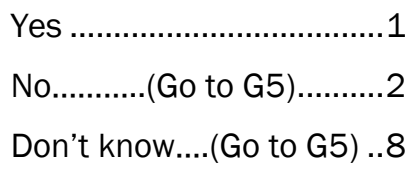 & 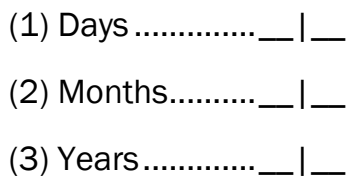 \\
\hline $\begin{array}{c}\text { G5 } \\
(3 \mathrm{~A} 140)\end{array}$ & Measles & $\begin{array}{l}\text { Yes } \\
\text { No............(Go to G6)............................................ } \\
\text { Don't kno to G6) ..8 }\end{array}$ & 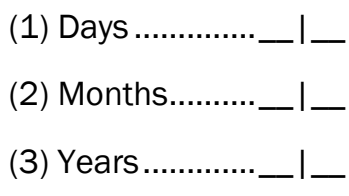 \\
\hline $\begin{array}{c}\text { G6 } \\
(3 A 150)\end{array}$ & 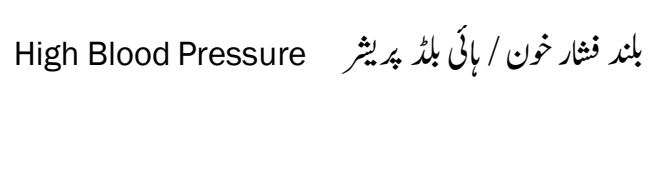 & 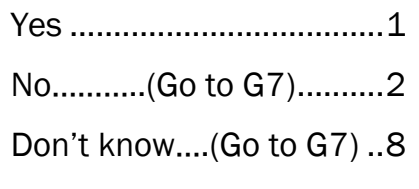 & 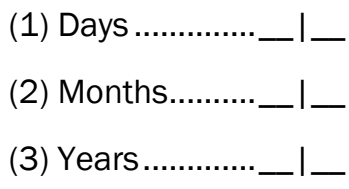 \\
\hline $\begin{array}{c}\text { G7 } \\
(3 A 160)\end{array}$ & Heart Disease & $\begin{array}{l}\text { No..........(Go to G8).........2 } \\
\text { Don't know....(Go to G8) ..8 }\end{array}$ & 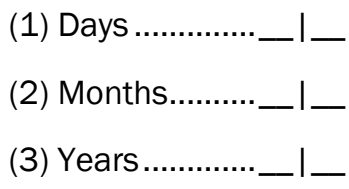 \\
\hline $\begin{array}{c}\text { G8 } \\
(3 A 170)\end{array}$ & Diabetes & $\begin{array}{l}\text { Yes } \\
\text { No.................................................. } \\
\text { Don't ko to G9) ..8 }\end{array}$ & 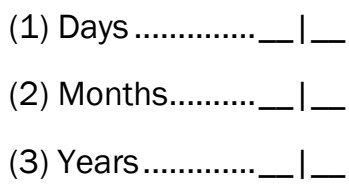 \\
\hline
\end{tabular}




\begin{tabular}{|c|c|c|c|}
\hline $\begin{array}{c}\text { G9 } \\
(3 \mathrm{~A} 180)\end{array}$ & Asthma & $\begin{array}{l}\text { Yes ...................................1 } \\
\text { No............(Go to G10) ........2 } \\
\text { Don't know...(Go to G10).8 }\end{array}$ & 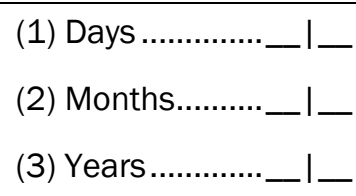 \\
\hline $\begin{array}{l}\text { G10 } \\
\text { (3A190) }\end{array}$ & Epilepsy & 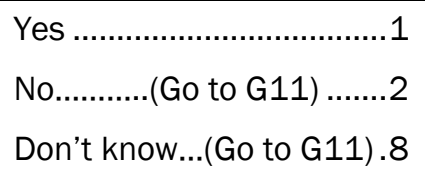 & 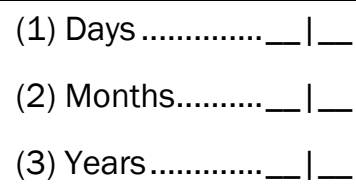 \\
\hline $\begin{array}{c}\text { G11 } \\
(3 A 200)\end{array}$ & Cancer & $\begin{array}{l}\text { Yes .........................................(Go to G12) .......2 } \\
\text { No............. (Go to G12).8 }\end{array}$ & 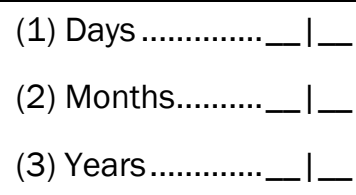 \\
\hline $\begin{array}{c}\text { G12 } \\
(3 \mathrm{~A} 210)\end{array}$ & 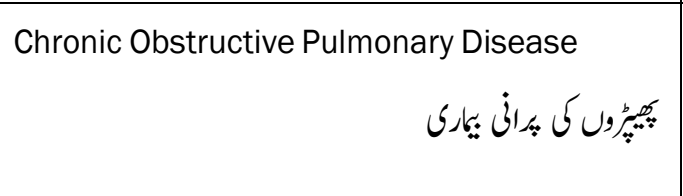 & $\begin{array}{l}\text { Yes ................................... } \\
\text { No...........(Go to G13) .......2 } \\
\text { Don't know...(Go to G13).8 }\end{array}$ & 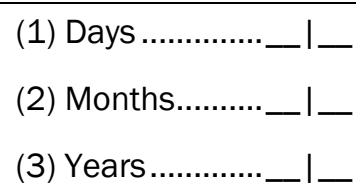 \\
\hline $\begin{array}{c}\text { G13 } \\
(3 \mathrm{~A} 220)\end{array}$ & Dementia & $\begin{array}{l}\text { Yes ...................................1 } \\
\text { No...........(Go to G14) .......2 } \\
\text { Don't know...(Go to G14).8 }\end{array}$ & $\begin{array}{l}\text { (1) Days ..............._- } \\
\text { (2) Months..........___ } \\
\text { (3) Years.............___ }\end{array}$ \\
\hline $\begin{array}{c}\text { G14 } \\
(3 \mathrm{~A} 230)\end{array}$ & Depression & $\begin{array}{l}\text { Yes .........................................(Go to G15) .......2 } \\
\text { No.............(Go to G15).8 } \\
\text { Don't know... }\end{array}$ & $\begin{array}{l}\text { (1) Days ................___ } \\
\text { (2) Months..........___ } \\
\text { (3) Years.............___ }\end{array}$ \\
\hline $\begin{array}{c}\text { G15 } \\
(3 \mathrm{~A} 240)\end{array}$ & Stroke & $\begin{array}{l}\text { Yes ................................1 } \\
\text { No..........(Go to G16) .......2 } \\
\text { Don't know...(Go to G16).8 }\end{array}$ & $\begin{array}{l}\text { (1) Days ................_- } \\
\text { (2) Months...........___ } \\
\text { (3) Years..............___ }\end{array}$ \\
\hline $\begin{array}{c}\text { G16 } \\
(3 A 250)\end{array}$ & Sickle Cell disease & 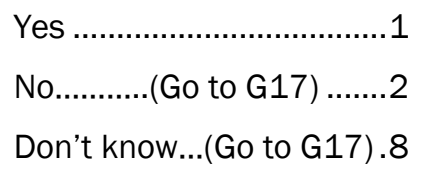 & $\begin{array}{l}\text { (1) Days ................_- } \\
\text { (2) Months..........._- } \\
\text { (3) Years.............._- }\end{array}$ \\
\hline $\begin{array}{c}\text { G17 } \\
(3 \mathrm{~A} 260)\end{array}$ & Kidney disease & 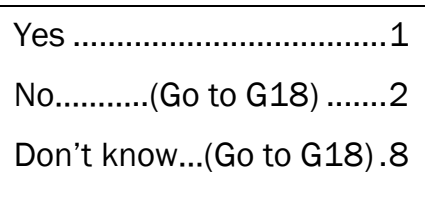 & $\begin{array}{l}\text { (1) Days ...............___ } \\
\text { (2) Months..........___ } \\
\text { (3) Years.............____ }\end{array}$ \\
\hline $\begin{array}{c}\text { G18 } \\
(3 \mathrm{~A} 270)\end{array}$ & Liver disease / Jaundice & $\begin{array}{l}\text { Yes } \\
\text { No...................................................... } \\
\text { Don't kno to H1) ..8 }\end{array}$ & 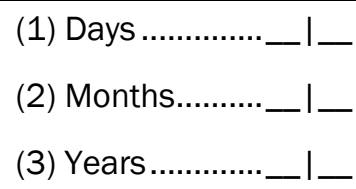 \\
\hline
\end{tabular}




\section{SECTION-H: HISTROY OF DEATH DUE TO INJURY/ACCIDENTS/VOILENCE}

I would like to ask you some questions concerning the context and previously known medical conditions the deceased had; injuries and accidents that the deceased suffered; and signs and symptoms that the deceased had/showed when she was ill. Some of these questions may not appear to be directly related to her death. Possible symptoms that the deceased had.

\begin{tabular}{|c|c|c|}
\hline Q.NO. & Questions and Filters & Coding Categories \\
\hline $\begin{array}{c}\mathrm{H} 1 \\
(3 \mathrm{~A} 300)\end{array}$ & 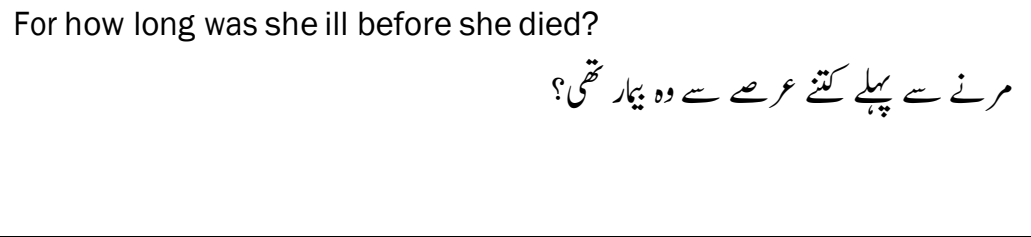 & 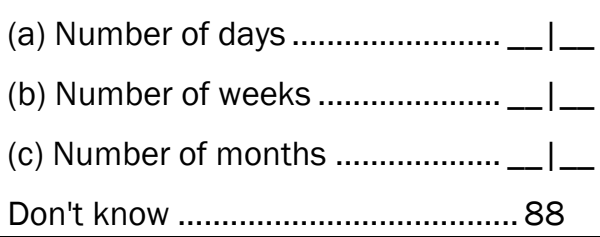 \\
\hline $\begin{array}{c}\mathrm{H} 2 \\
(3 \mathrm{E} 100)\end{array}$ & 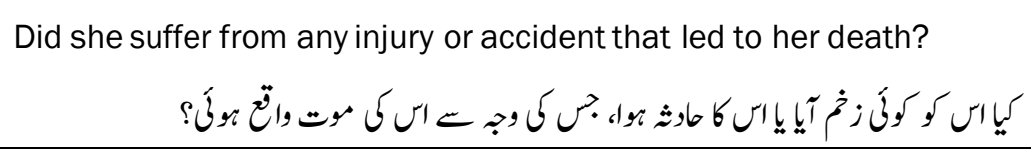 & 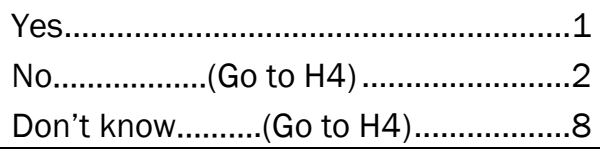 \\
\hline H3 & What kind of injury/accident was it? & 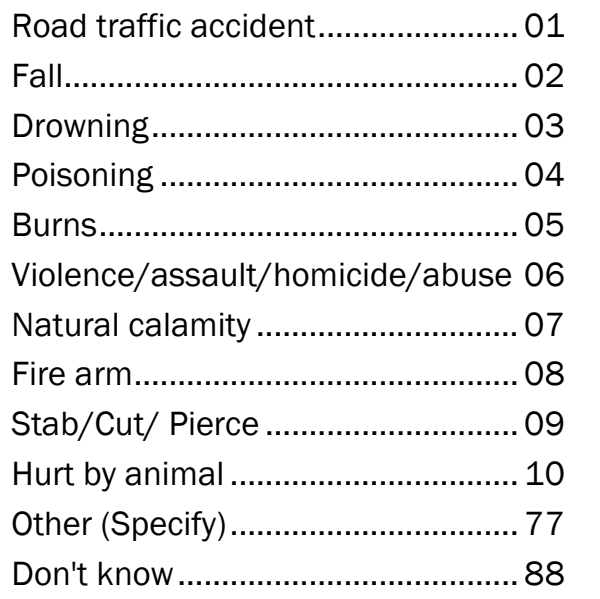 \\
\hline H4 & 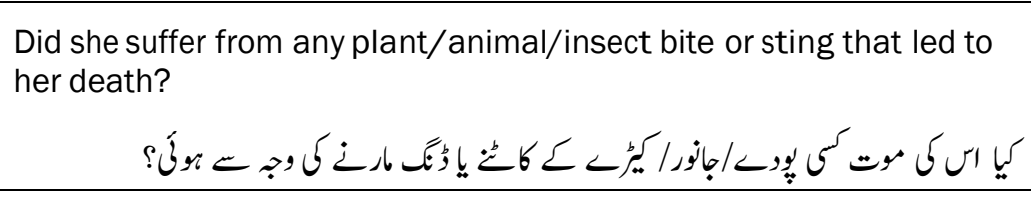 & 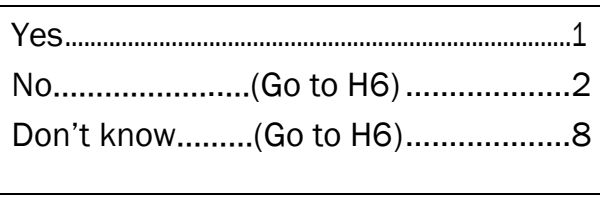 \\
\hline H5 & What type of animal/insect was it? & 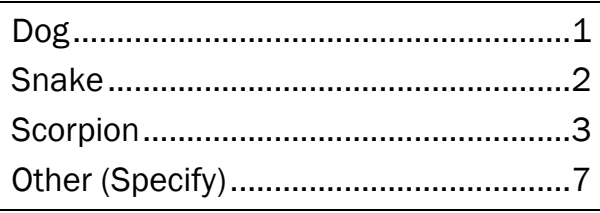 \\
\hline $\begin{array}{c}\mathrm{H6} \\
(3 \mathrm{E} 700)\end{array}$ & 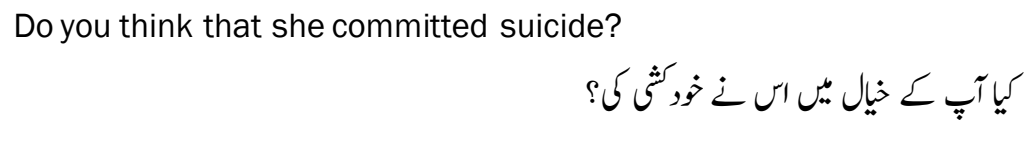 & 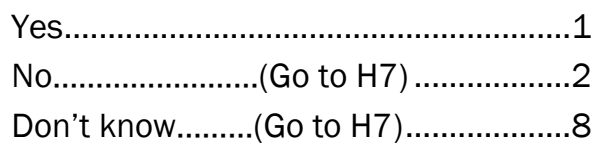 \\
\hline $\begin{array}{c}\mathrm{H} 7 \\
(3 \mathrm{~A} 310)\end{array}$ & Did she die suddenly? & 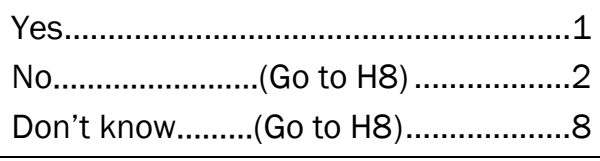 \\
\hline $\begin{array}{c}\mathrm{H} 8 \\
(\mathrm{Q} 1305)\end{array}$ & Did someone else hurt her? & 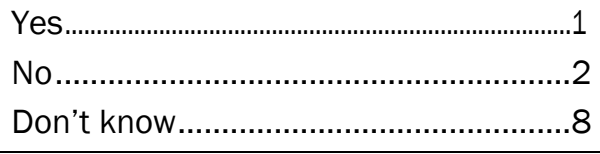 \\
\hline
\end{tabular}


SECTION-I: SYMPTOMS AND SIGNS ASSOCIATED WITH ILLNESS OF WOMEN

ناوتن كن يارى

\begin{tabular}{|c|c|c|}
\hline Q.NO. & Questions and Filters & Coding Categories \\
\hline \multirow{3}{*}{$\begin{array}{c}\text { I1 } \\
\text { (3B720) }\end{array}$} & Did she have an ulcer or swelling in the breast? & Yes........................................................ \\
\hline & 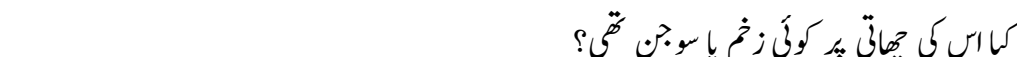 & No \\
\hline & & Don't know.......... \\
\hline \multirow{3}{*}{$\begin{array}{c}12 \\
(3 B 800)\end{array}$} & Did she have excessive vaginal bleeding in between menstrual & Yes.................................................................1 \\
\hline & periods? & 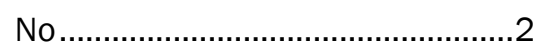 \\
\hline & 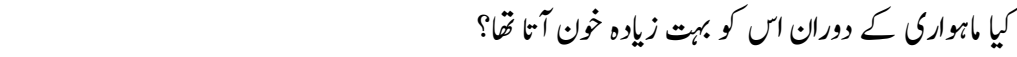 & 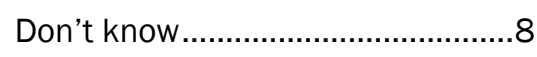 \\
\hline \multirow{3}{*}{$\begin{array}{c}\text { I3 } \\
\text { (3B810) }\end{array}$} & Did her vaginal bleeding stop naturally during menopause? & Yes \\
\hline & & 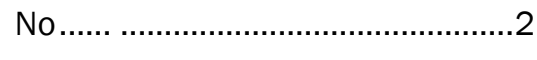 \\
\hline & كيا اس كن انوارى قردرق طور بـ رك تئ قّى؟ & 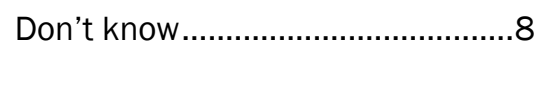 \\
\hline \multirow{3}{*}{$\begin{array}{c}14 \\
(3 B 820)\end{array}$} & Did she have vaginal bleeding after menopause? & Yes \\
\hline & 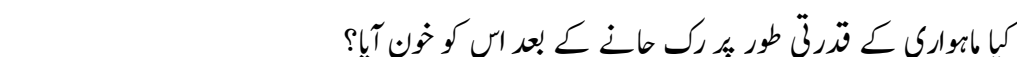 & No \\
\hline & & Don't know....... \\
\hline
\end{tabular}

SECTION-J: SYMPTOMS AND SIGNS ASSOCIATED WITH PREGNANCY

حل س متلق علاتات

\begin{tabular}{|c|c|c|}
\hline Q.NO. & Questions and Filters & Coding Categories \\
\hline $\begin{array}{c}\mathrm{J} 1 \\
(3 \mathrm{C} 110)\end{array}$ & Was she pregnant at the time of death? & 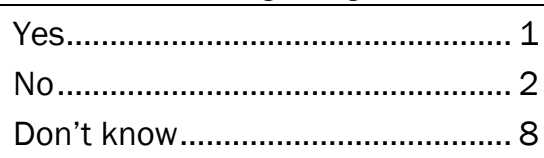 \\
\hline $\begin{array}{c}\mathrm{J} 2 \\
(3 \mathrm{C} 100)\end{array}$ & 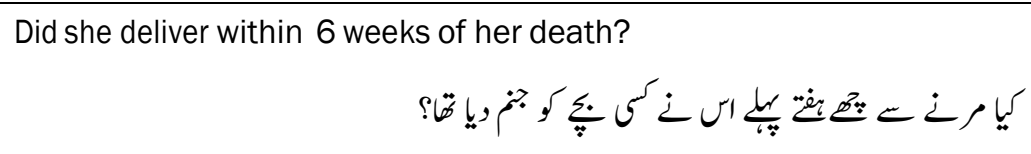 & 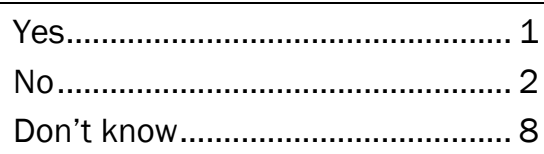 \\
\hline $\begin{array}{c}\mathrm{J3} \\
(3 \mathrm{C} 130)\end{array}$ & 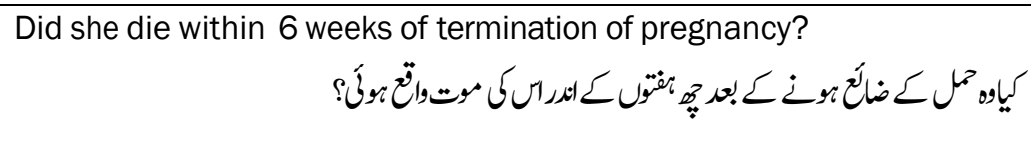 & 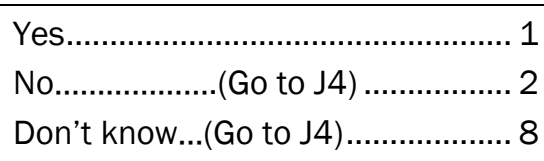 \\
\hline $\begin{array}{c}\mathrm{J} 4 \\
(3 \mathrm{C} 210)\end{array}$ & 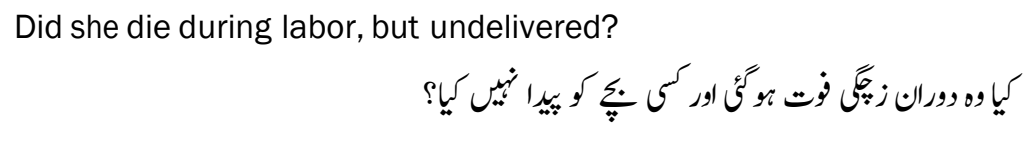 & 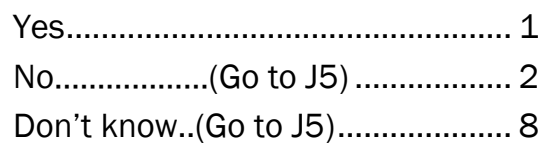 \\
\hline $\begin{array}{c}\mathrm{J} 5 \\
(3 \mathrm{C} 200)\end{array}$ & 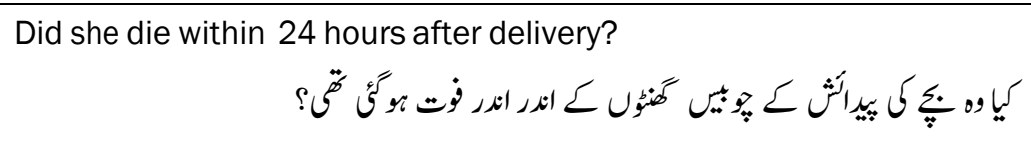 & 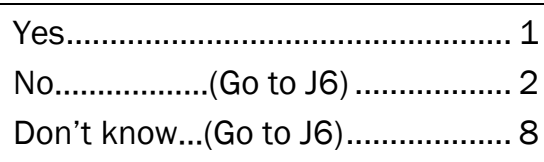 \\
\hline $\begin{array}{c}\mathrm{J} 6 \\
(3 \mathrm{C} 120)\end{array}$ & 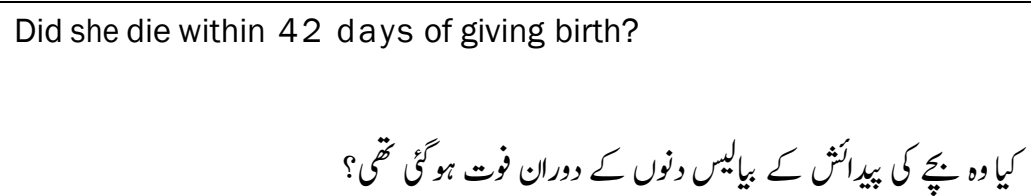 & 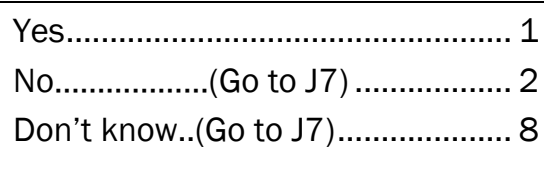 \\
\hline $\mathrm{J} 7$ & 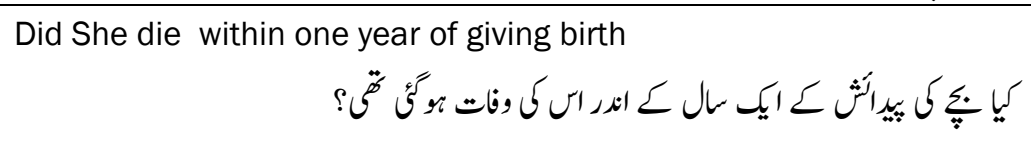 & 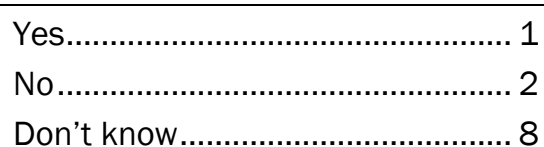 \\
\hline
\end{tabular}




\begin{tabular}{|c|c|c|}
\hline Q.NO. & Questions and Filters & Coding Categories \\
\hline 18 & 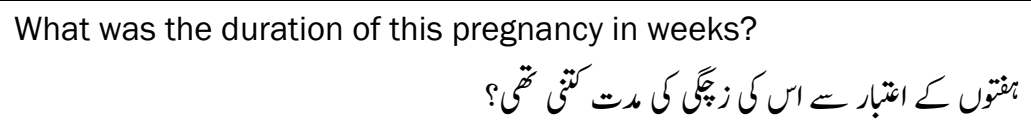 & 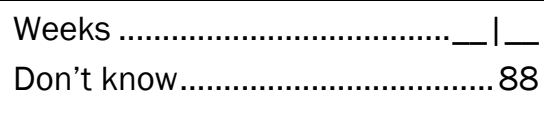 \\
\hline J9 & $\begin{array}{l}\text { When she died, did she suffer from following: } \\
\text { (Multiple responses are allowed) }\end{array}$ & 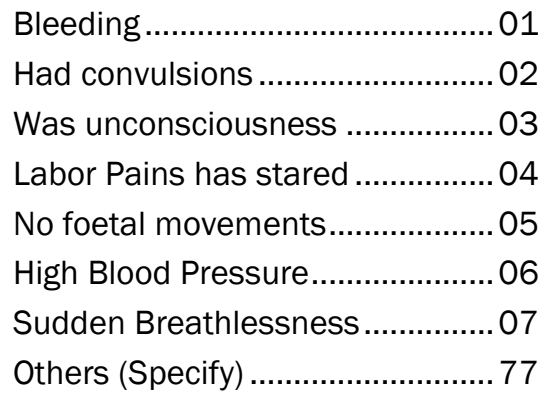 \\
\hline $\begin{array}{c}\text { J10 } \\
3 \mathrm{C} 220\end{array}$ & Was she breastfeeding at death? & 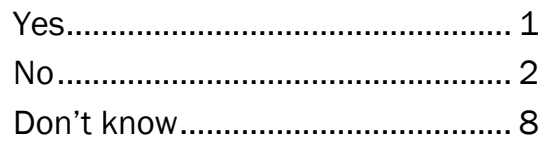 \\
\hline $\begin{array}{c}J 11 \\
(3 \mathrm{C} 240)\end{array}$ & 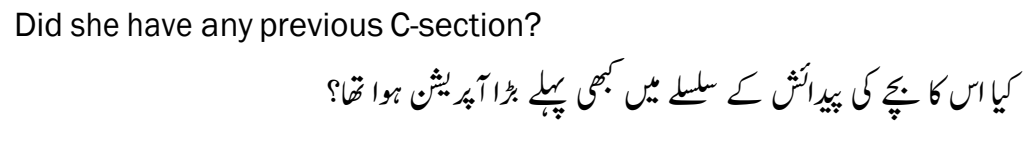 & 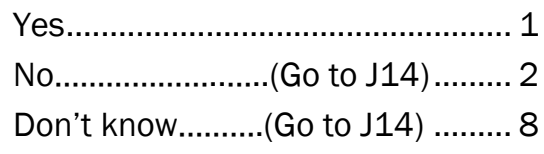 \\
\hline $\mathrm{J} 12$ & 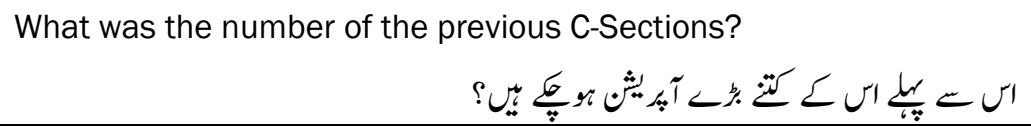 & -1 \\
\hline J13 & 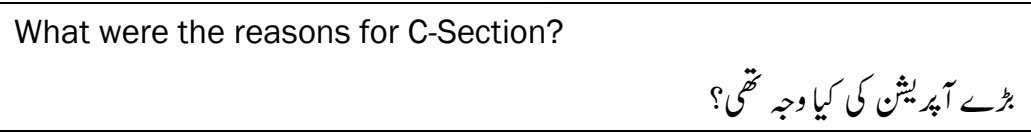 & \\
\hline $\begin{array}{c}J 14 \\
(3 \mathrm{C} 250)\end{array}$ & 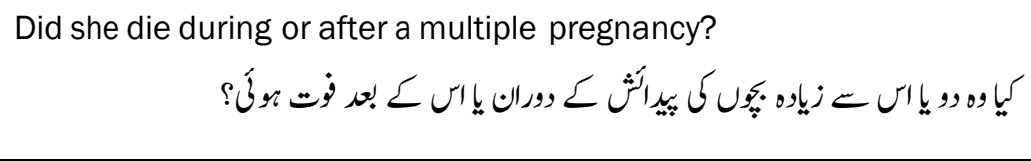 & Yes \\
\hline $\begin{array}{c}J 15 \\
(3 C 400)\end{array}$ & 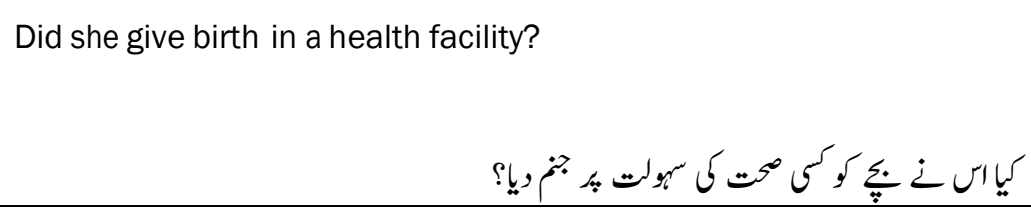 & 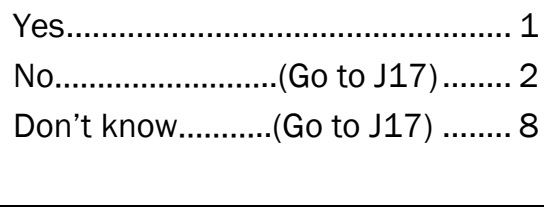 \\
\hline J16 & What was the type of facility? & 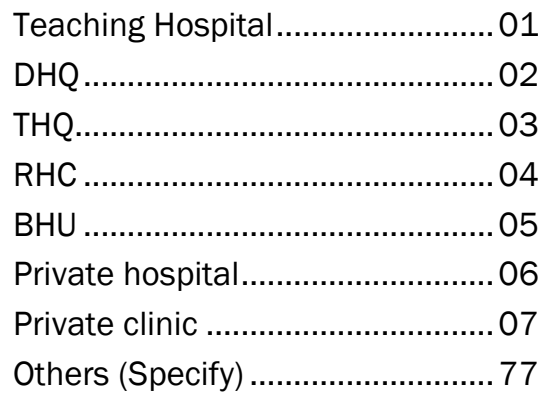 \\
\hline $\begin{array}{c}J 17 \\
(3 C 410)\end{array}$ & Did she give birth at home? & 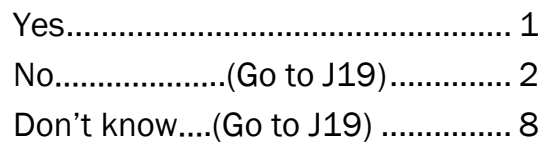 \\
\hline $\begin{array}{c}J 18 \\
(3 C 420)\end{array}$ & 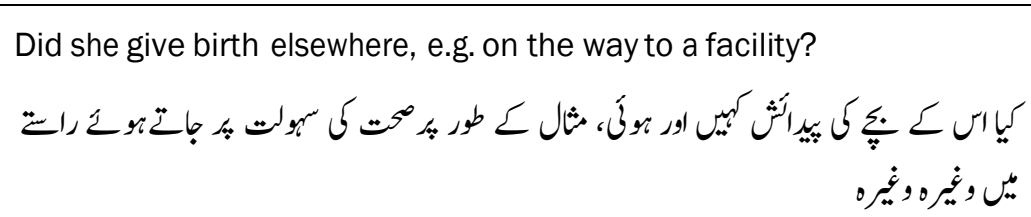 & 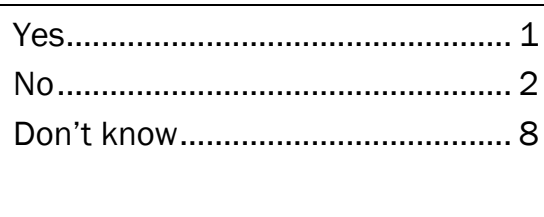 \\
\hline
\end{tabular}




\begin{tabular}{|c|c|c|}
\hline Q.NO. & Questions and Filters & Coding Categories \\
\hline $\begin{array}{c}J 19 \\
(3 \mathrm{C} 430)\end{array}$ & 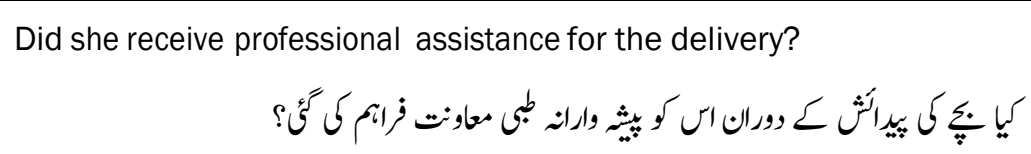 & 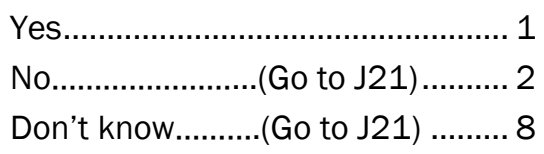 \\
\hline $\mathrm{J} 20$ & If yes, by whom & 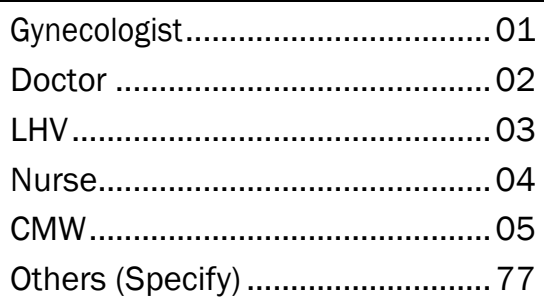 \\
\hline$J 21$ & If no, by whom & 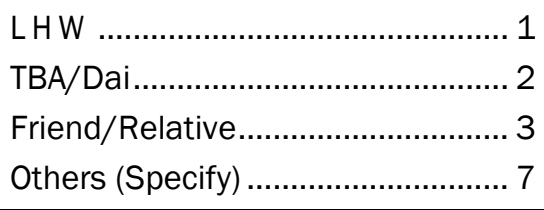 \\
\hline $\begin{array}{c}J 22 \\
(3 \mathrm{C} 450)\end{array}$ & 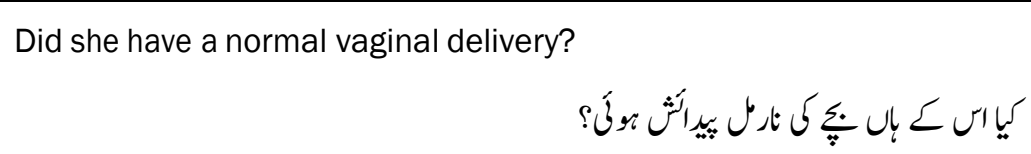 & 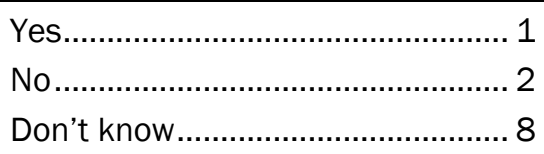 \\
\hline $\begin{array}{c}J 23 \\
(3 C 460)\end{array}$ & 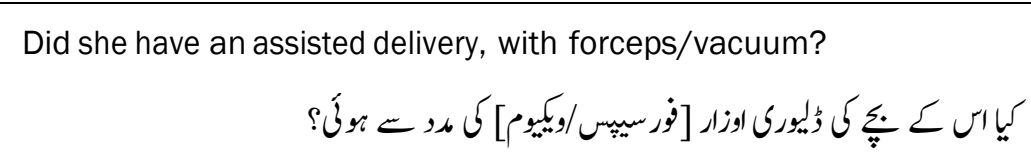 & 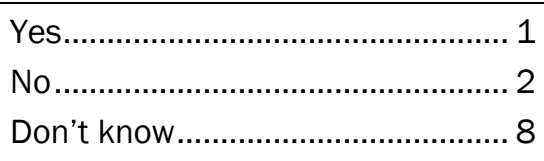 \\
\hline $\begin{array}{c}J 24 \\
(3 C 470)\end{array}$ & 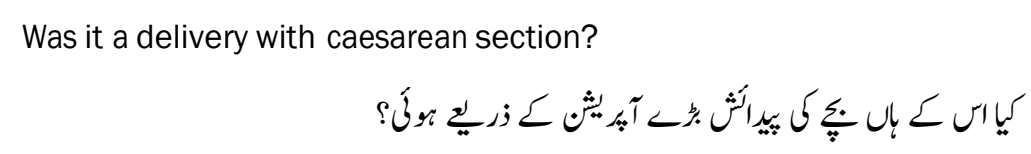 & 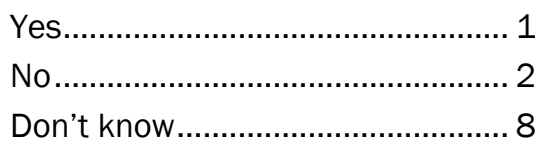 \\
\hline $\begin{array}{c}J 25 \\
(3 C 440)\end{array}$ & 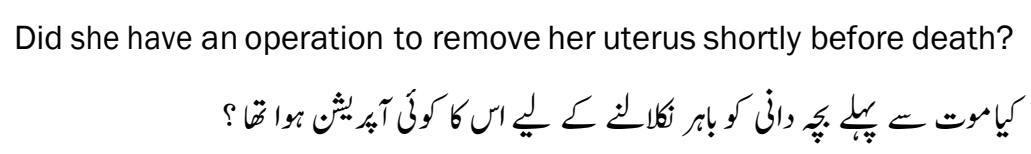 & 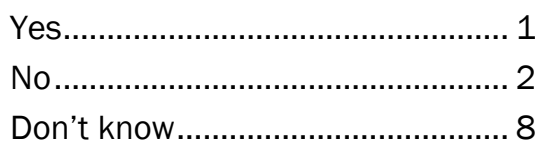 \\
\hline J26 & 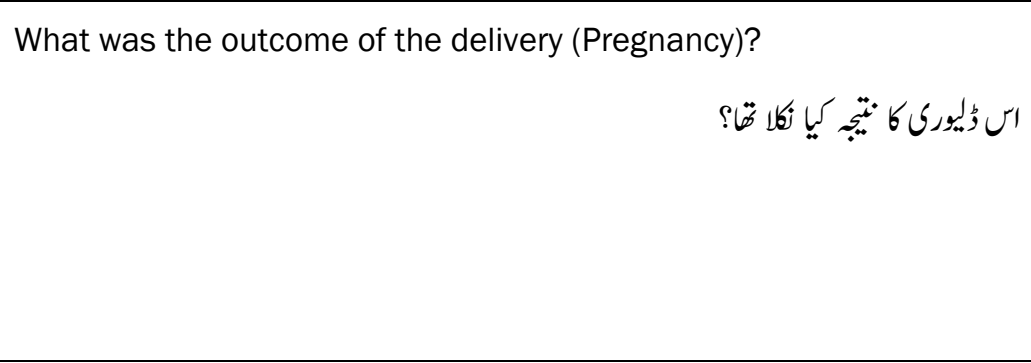 & 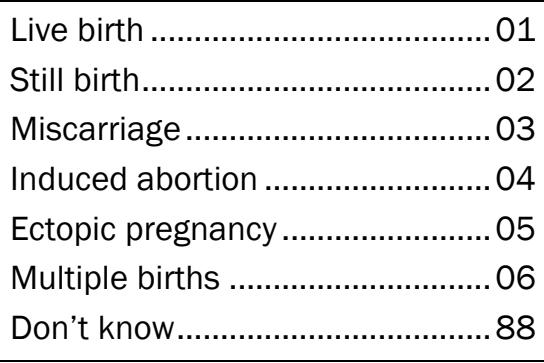 \\
\hline $\mathrm{J} 27$ & 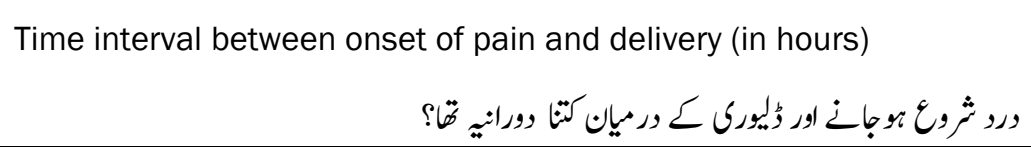 & 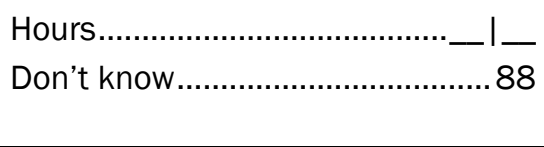 \\
\hline
\end{tabular}




\begin{tabular}{|c|c|c|}
\hline Q.NO. & Questions and Filters & Coding Categories \\
\hline $\mathrm{J} 28$ & 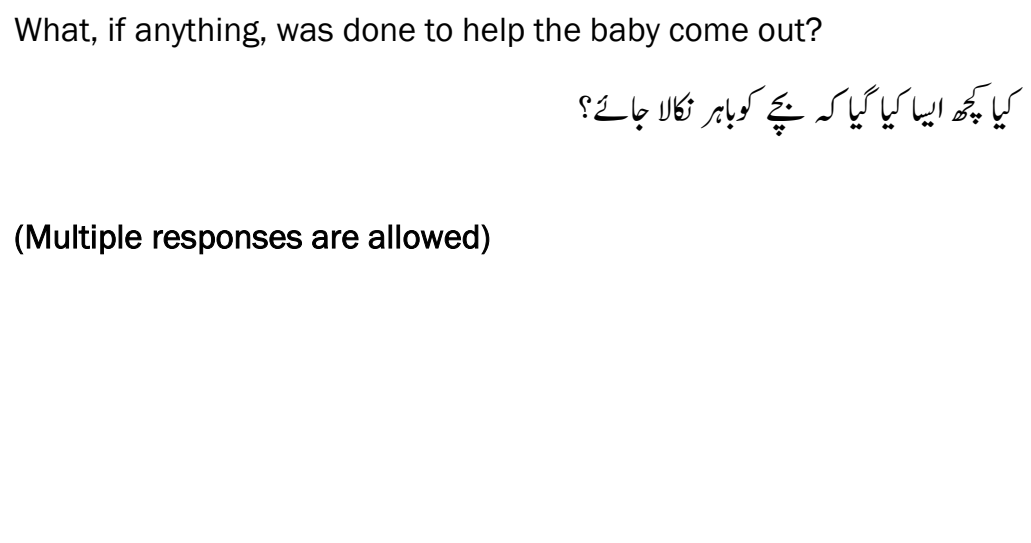 & 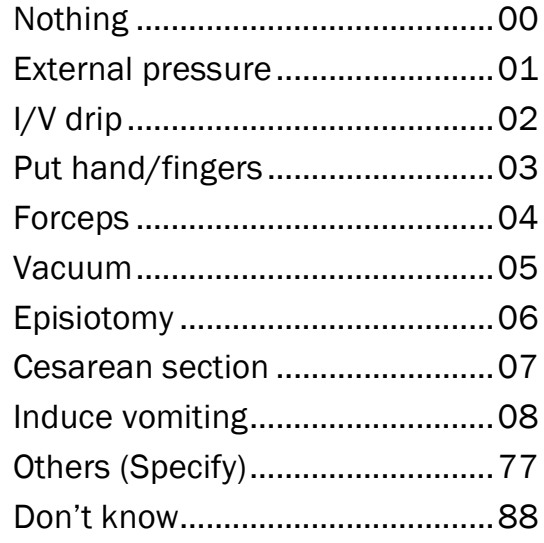 \\
\hline $\begin{array}{c}J 29 \\
(3 C 480)\end{array}$ & 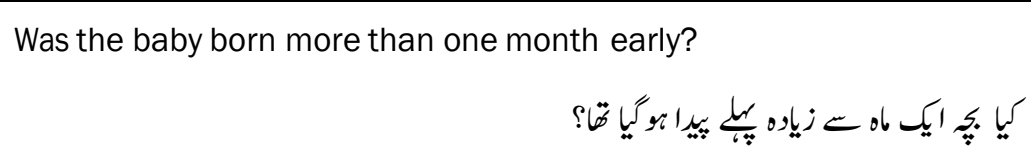 & 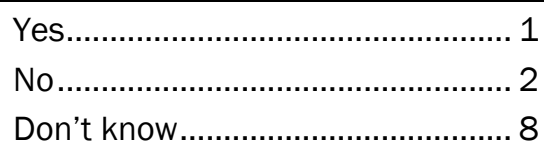 \\
\hline $\begin{array}{c}J 30 \\
(3 \mathrm{C} 260)\end{array}$ & 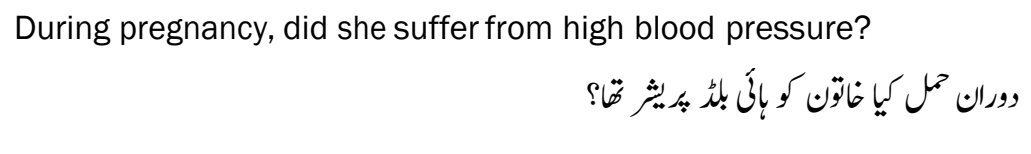 & 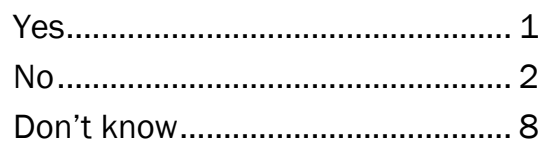 \\
\hline J31 & 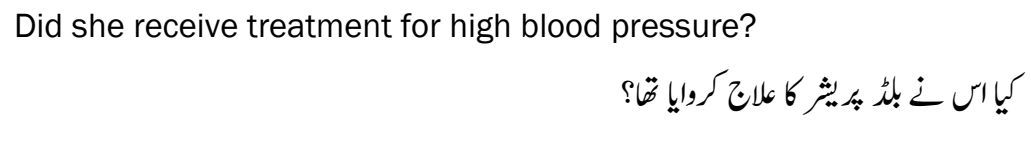 & 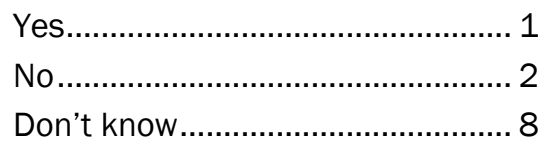 \\
\hline $\begin{array}{c}\text { J32 } \\
(3 \mathrm{C} 270)\end{array}$ & 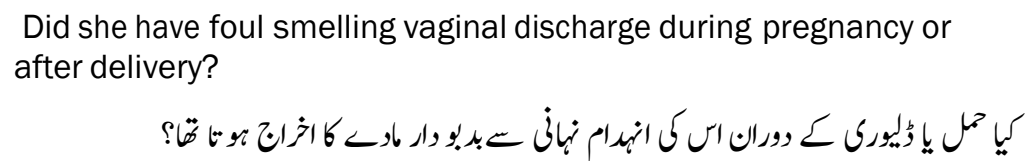 & Yes \\
\hline $\begin{array}{c}\text { J33 } \\
(3 \mathrm{C} 280)\end{array}$ & 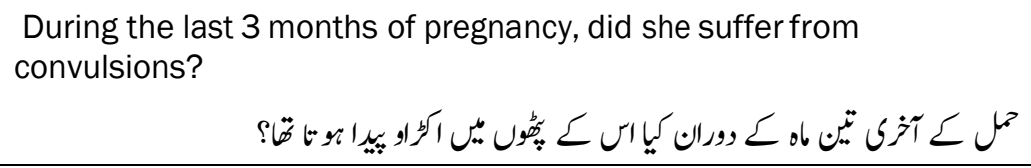 & 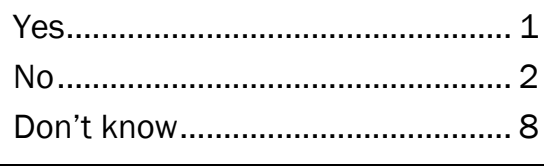 \\
\hline $\begin{array}{c}J 34 \\
(3 \mathrm{C} 290)\end{array}$ & 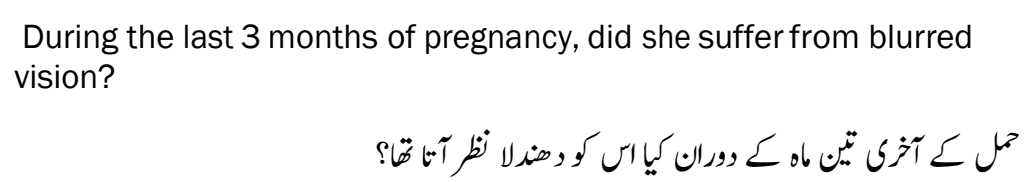 & 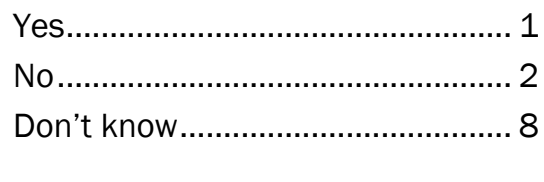 \\
\hline $\begin{array}{c}J 35 \\
(3 \mathrm{C} 300)\end{array}$ & 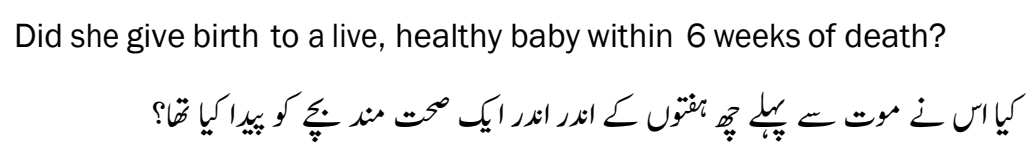 & 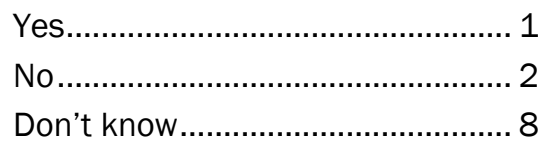 \\
\hline $\begin{array}{c}J 36 \\
(3 \mathrm{C} 310)\end{array}$ & 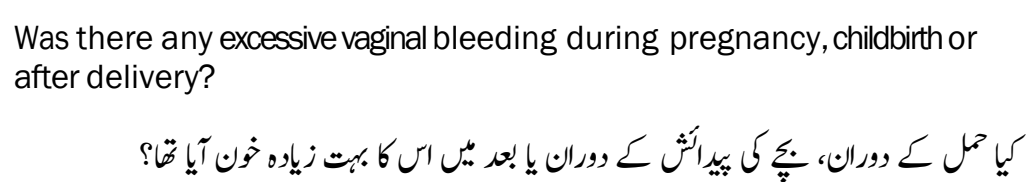 & 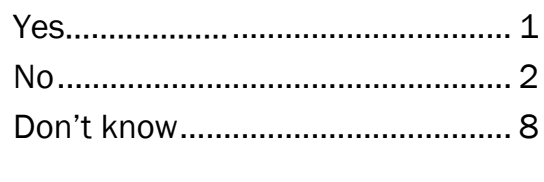 \\
\hline $\begin{array}{c}J 37 \\
(3 \mathrm{C} 320)\end{array}$ & 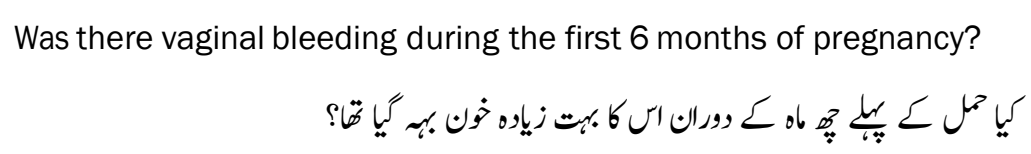 & 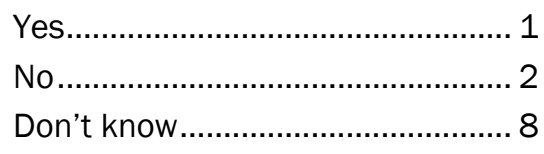 \\
\hline $\begin{array}{c}J 38 \\
(3 c 330)\end{array}$ & 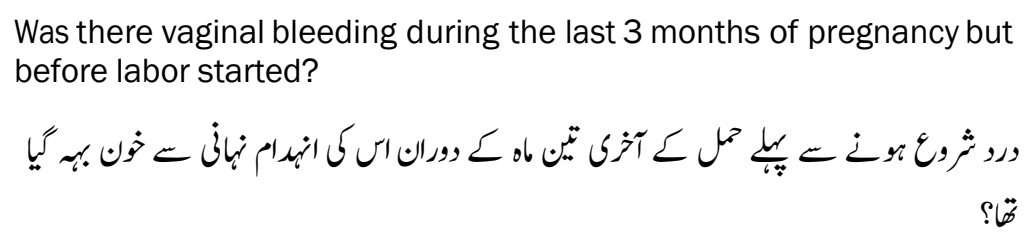 & 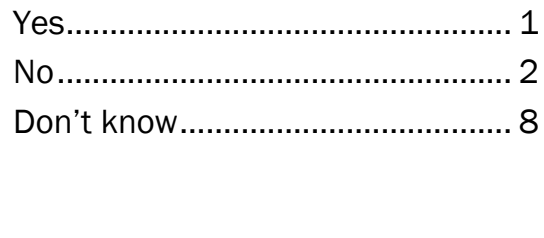 \\
\hline
\end{tabular}




\begin{tabular}{|c|c|c|}
\hline Q.NO. & Questions and Filters & Coding Categories \\
\hline $\begin{array}{c}J 39 \\
(3 \mathrm{C} 340)\end{array}$ & 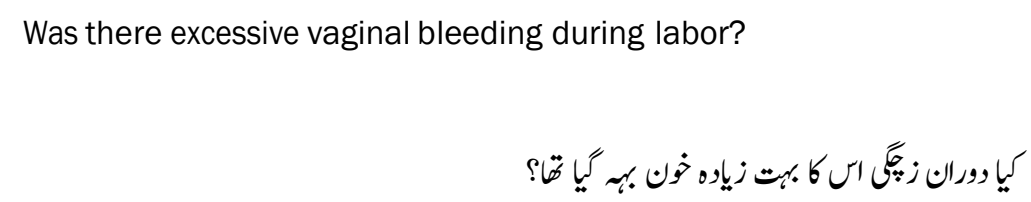 & 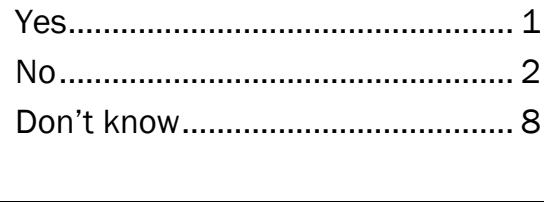 \\
\hline $\begin{array}{c}J 40 \\
(3 \mathrm{C} 350)\end{array}$ & 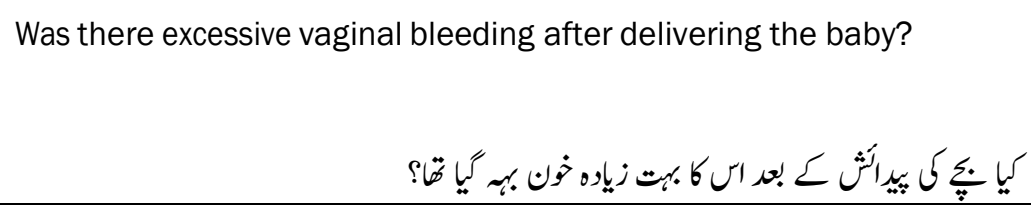 & 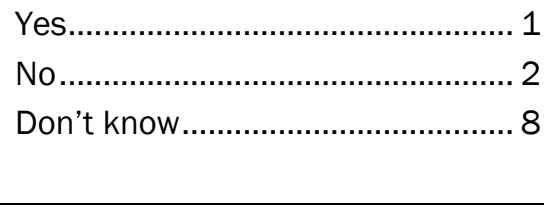 \\
\hline $\begin{array}{c}J 41 \\
(3 \mathrm{C} 360)\end{array}$ & 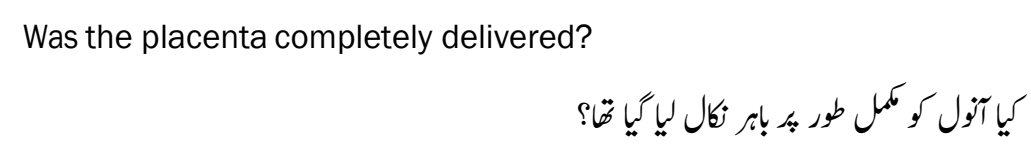 & 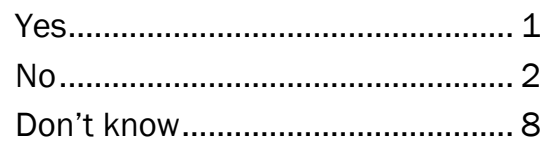 \\
\hline$J 42$ & 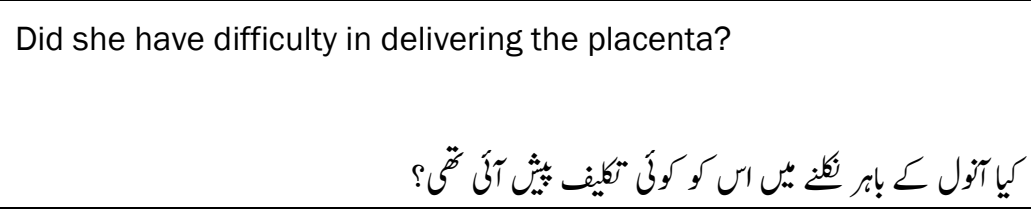 & 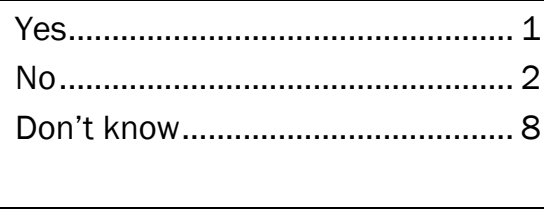 \\
\hline$\underset{(3 \mathrm{C} 365)}{\mathrm{J}}$ & 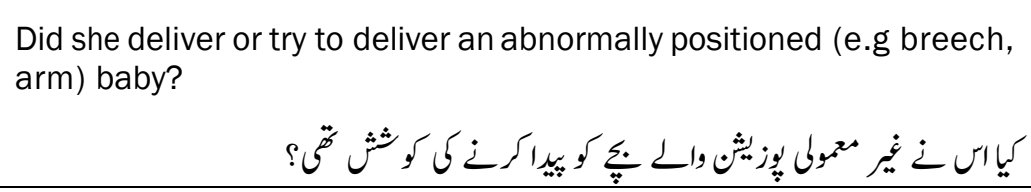 & 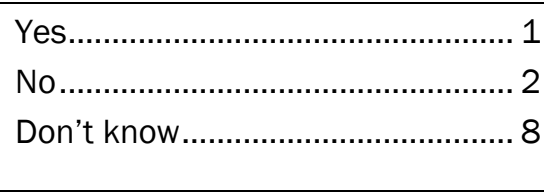 \\
\hline $\begin{array}{c}J 44 \\
(3 \mathrm{C} 370)\end{array}$ & 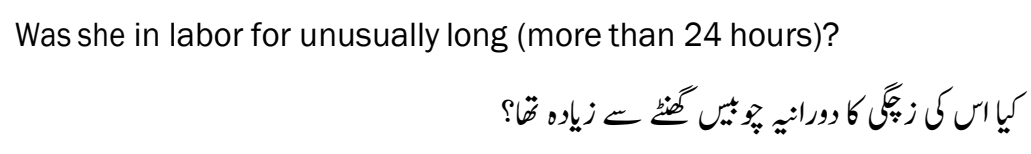 & 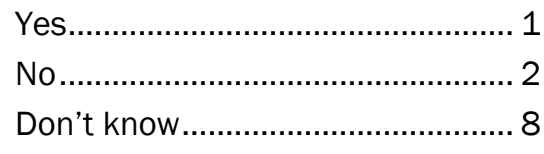 \\
\hline $\mathrm{J} 45$ & What was the duration of the Labor in Hours? & Number of Hours __ \\
\hline $\begin{array}{c}J 46 \\
(3 \mathrm{C} 380)\end{array}$ & 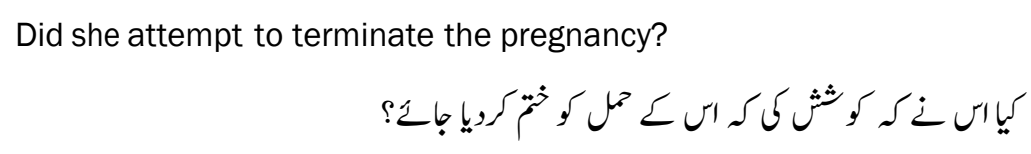 & 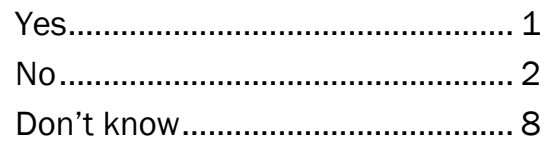 \\
\hline $\begin{array}{c}J 47 \\
(3 \mathrm{C} 390)\end{array}$ & 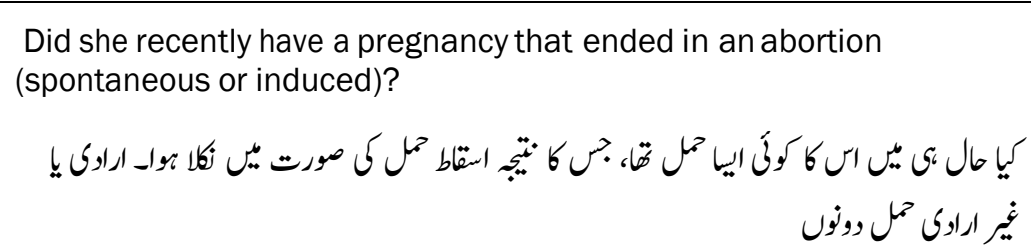 & 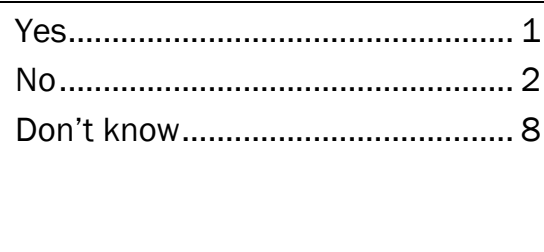 \\
\hline $\mathrm{J} 48$ & 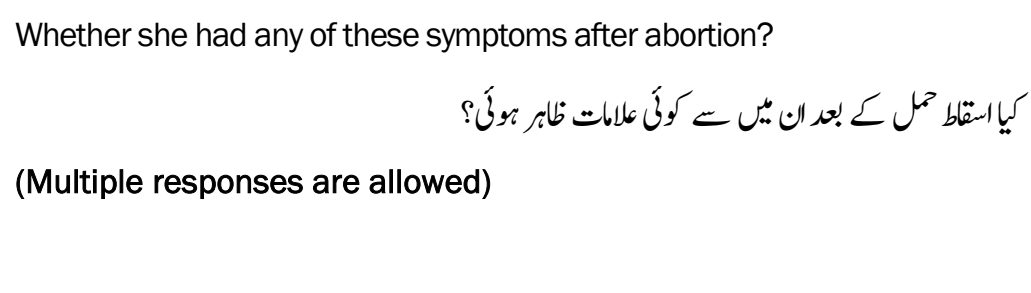 & 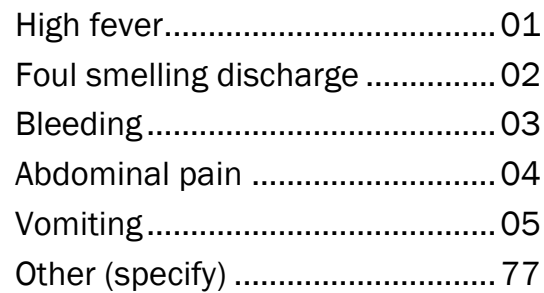 \\
\hline
\end{tabular}


SECTION-K: SYMPTOMS NOTED DURING THE FINAL ILLNESS

\begin{tabular}{|c|c|c|}
\hline Q.NO. & Questions and Filters & Coding Categories \\
\hline $\begin{array}{c}\mathrm{K} 1 \\
(3 \mathrm{~B} 100)\end{array}$ & موت ع به كيا اس كو بخار ثق؟ & 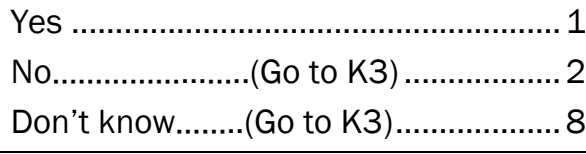 \\
\hline $\begin{array}{c}\mathrm{K} 2 \\
\text { (3B110) }\end{array}$ & For how long did she have a fever? & 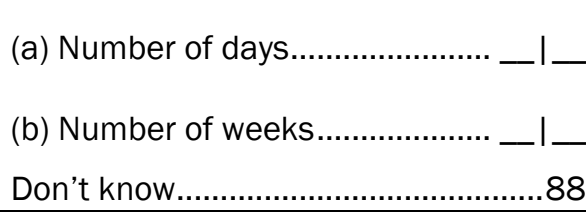 \\
\hline $\begin{array}{c}\text { K3 } \\
(3 \mathrm{~B} 120)\end{array}$ & Did she have night sweats? & 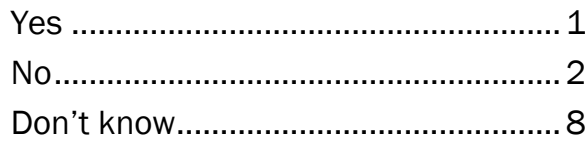 \\
\hline $\begin{array}{c}\mathrm{K} 4 \\
(3 \mathrm{~B} 130)\end{array}$ & Did she have a cough? & 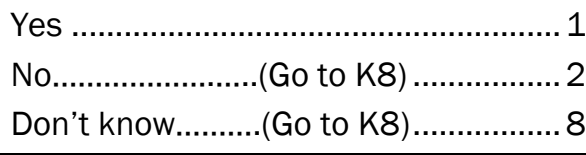 \\
\hline $\begin{array}{c}\mathrm{K} 5 \\
(3 \mathrm{~B} 140)\end{array}$ & For how long did she have a cough? & (a) Number of days....................... \\
\hline $\begin{array}{c}\mathrm{K} 6 \\
(3 \mathrm{~B} 150)\end{array}$ & 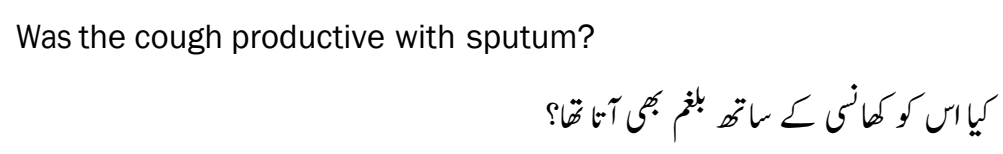 & Yes \\
\hline $\begin{array}{c}\mathrm{K} 7 \\
(3 \mathrm{~B} 160)\end{array}$ & Did she cough out blood? & 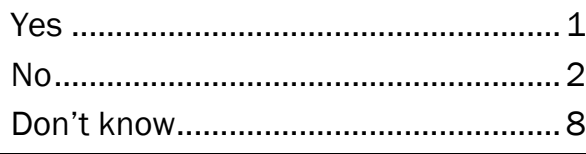 \\
\hline $\begin{array}{c}\mathrm{K} 8 \\
(3 \mathrm{~B} 180)\end{array}$ & Did she have any breathing problem? & 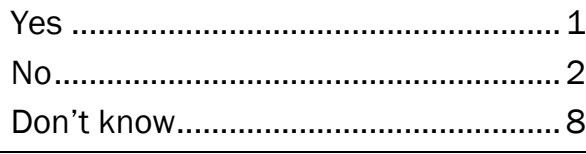 \\
\hline $\begin{array}{c}\text { K9 } \\
(3 \mathrm{~B} 190)\end{array}$ & Did she have fast breathing? & 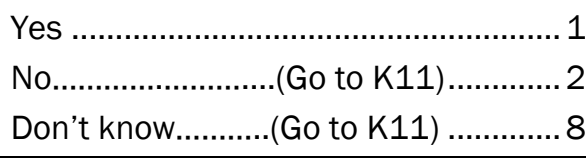 \\
\hline $\begin{array}{l}\mathrm{K} 10 \\
(3 \mathrm{~B} 200)\end{array}$ & For how long did she have fast breathing? & (a) Number of days....................... \\
\hline $\begin{array}{l}\mathrm{K} 11 \\
\text { (3B210) }\end{array}$ & Did she have breathlessness? & 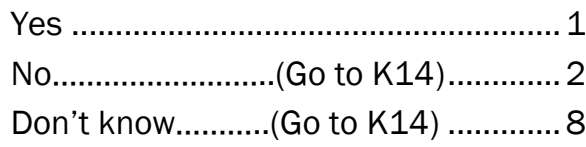 \\
\hline
\end{tabular}




\begin{tabular}{|c|c|c|}
\hline Q.NO. & Questions and Filters & Coding Categories \\
\hline $\begin{array}{c}\mathrm{K} 12 \\
(3 \mathrm{~B} 220)\end{array}$ & For how long did she have breathlessness? & 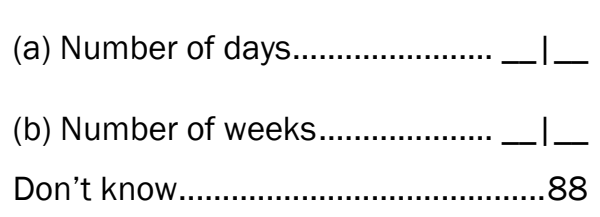 \\
\hline $\begin{array}{c}\mathrm{K} 13 \\
(3 \mathrm{~B} 230)\end{array}$ & 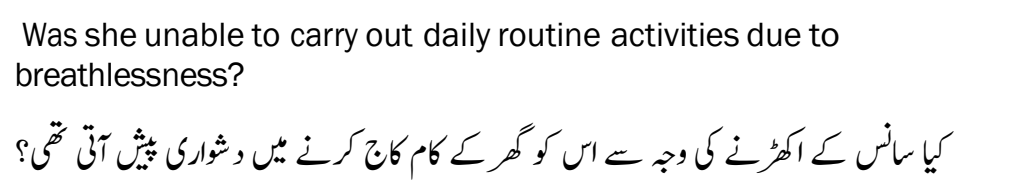 & Yes \\
\hline $\begin{array}{c}\mathrm{K} 14 \\
(3 \mathrm{~B} 240)\end{array}$ & 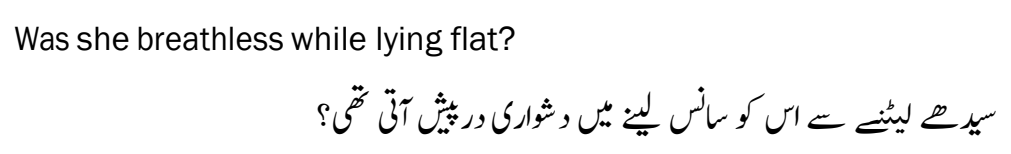 & 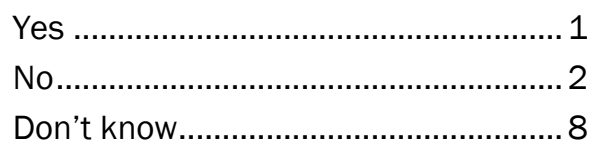 \\
\hline $\begin{array}{l}\mathrm{K} 15 \\
(3 \mathrm{~B} 260)\end{array}$ & 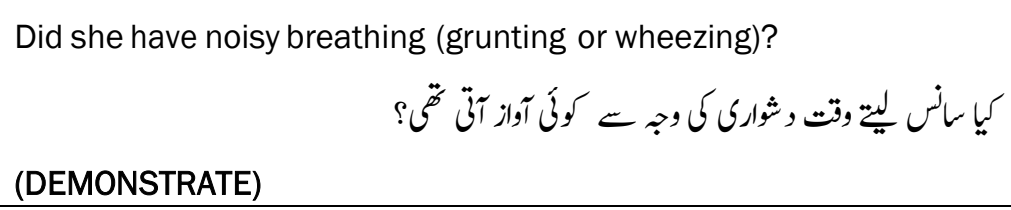 & 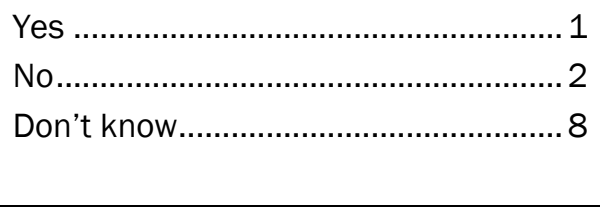 \\
\hline $\begin{array}{c}\mathrm{K} 16 \\
(3 \mathrm{~B} 270)\end{array}$ & Did she have severe chest pain? & 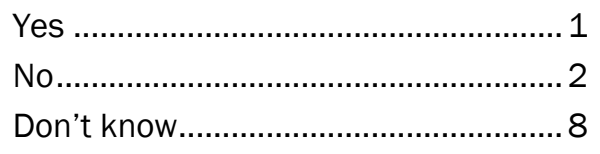 \\
\hline $\begin{array}{c}\mathrm{K} 17 \\
(3 \mathrm{~B} 280)\end{array}$ & Did she have diarrhea? & 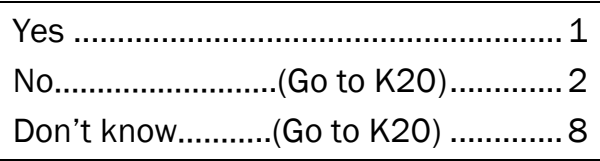 \\
\hline $\begin{array}{c}\mathrm{K} 18 \\
(3 \mathrm{~B} 290)\end{array}$ & For how long did she have diarrhea? & 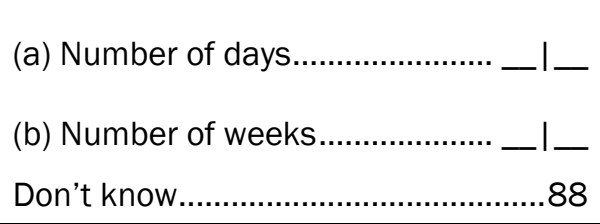 \\
\hline $\begin{array}{c}\mathrm{K} 19 \\
(3 \mathrm{~B} 300)\end{array}$ & 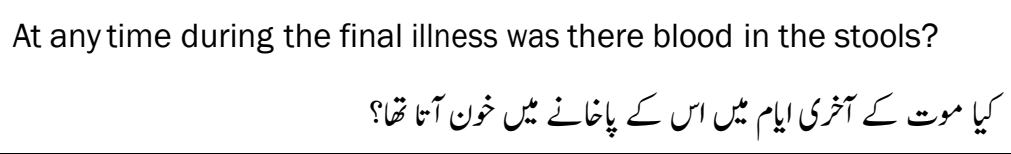 & 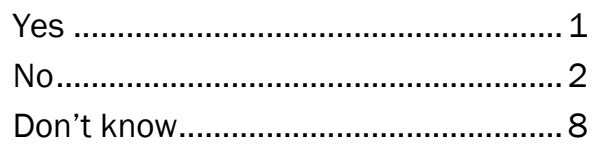 \\
\hline $\begin{array}{c}\mathrm{K} 20 \\
(3 \mathrm{~B} 310)\end{array}$ & كيا اس ـق آنَ قُى & 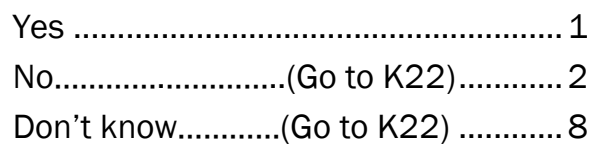 \\
\hline $\begin{array}{c}\mathrm{K} 21 \\
(3 \mathrm{~B} 320)\end{array}$ & 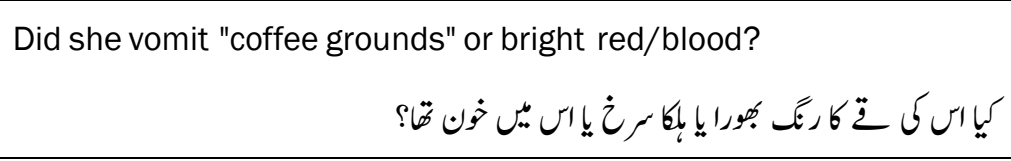 & Yes \\
\hline $\begin{array}{c}\mathrm{K} 22 \\
(3 \mathrm{~B} 330)\end{array}$ & Did she have any abdominal problem? & 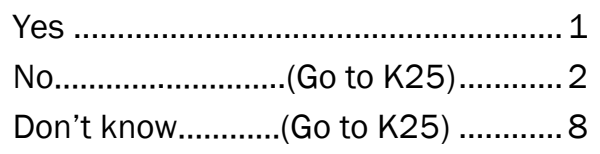 \\
\hline $\begin{array}{c}\mathrm{K} 23 \\
(3 \mathrm{~B} 340)\end{array}$ & Did she have severe abdominal pain? & 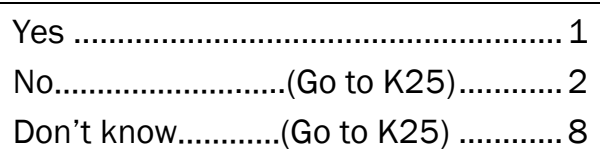 \\
\hline
\end{tabular}




\begin{tabular}{|c|c|c|}
\hline Q.NO. & Questions and Filters & Coding Categories \\
\hline $\begin{array}{c}\mathrm{K} 24 \\
\text { (3B350) }\end{array}$ & 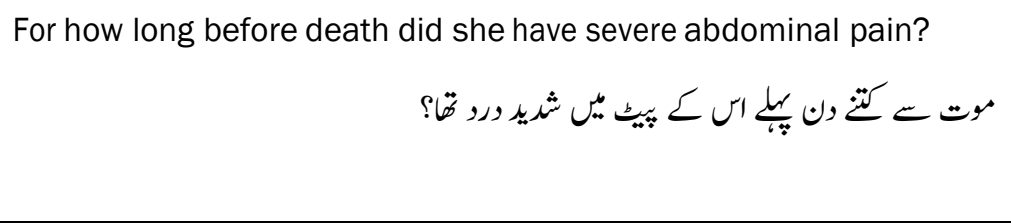 & 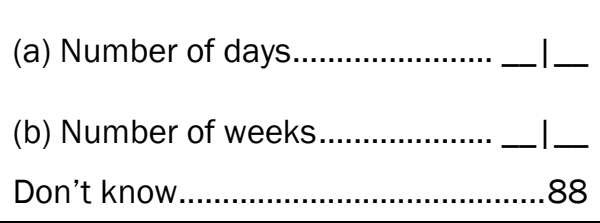 \\
\hline $\begin{array}{c}\text { K25 } \\
\text { (3B360) }\end{array}$ & 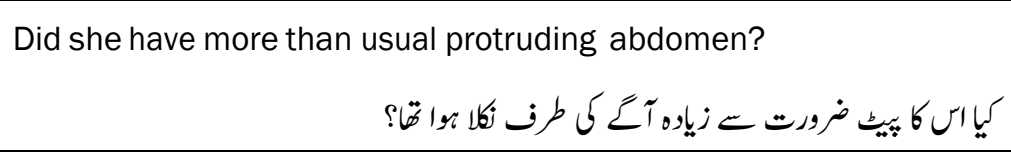 & 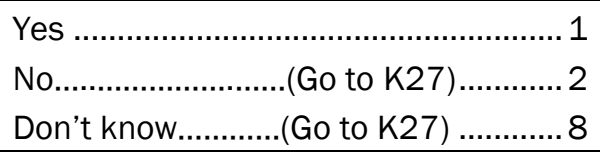 \\
\hline $\begin{array}{c}\text { K26 } \\
\text { (3B370) }\end{array}$ & 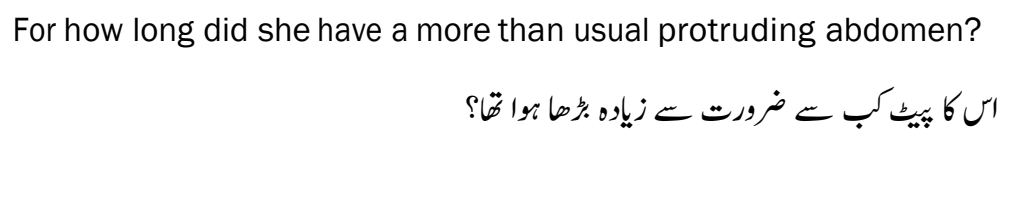 & 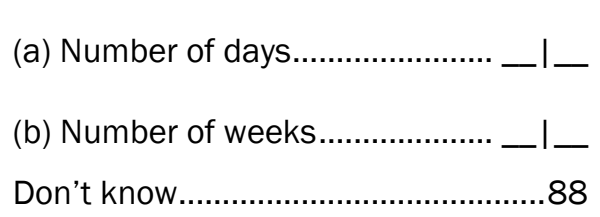 \\
\hline $\begin{array}{c}\text { K27 } \\
\text { (3В380) }\end{array}$ & 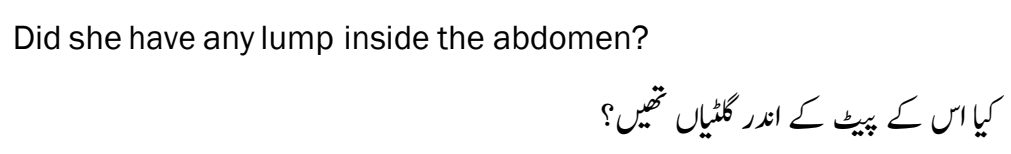 & 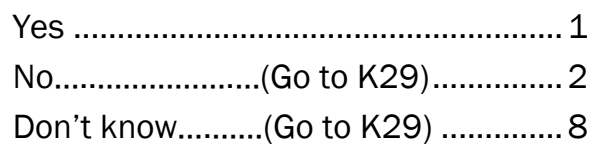 \\
\hline $\begin{array}{c}\text { K28 } \\
\text { (3B390) }\end{array}$ & 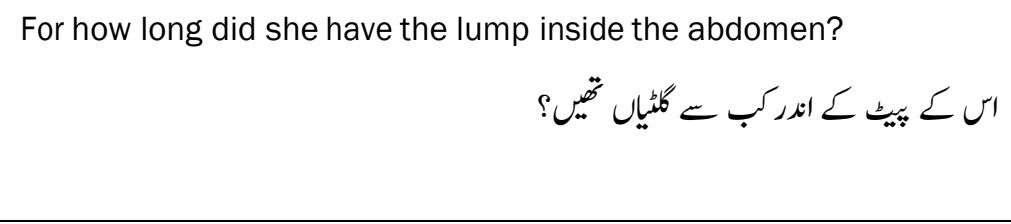 & 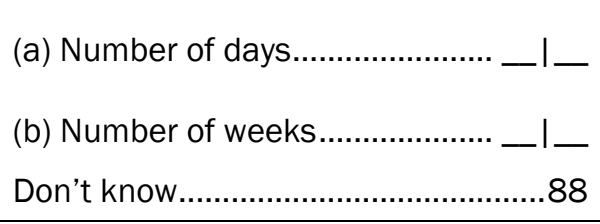 \\
\hline $\begin{array}{c}\text { K29 } \\
(3 B 400)\end{array}$ & كيا اس ك عر بي شريد ورو تو تاثا & 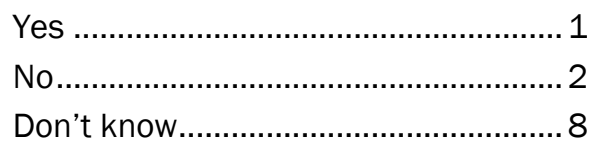 \\
\hline $\begin{array}{c}\text { K30 } \\
\text { (3B405) }\end{array}$ & 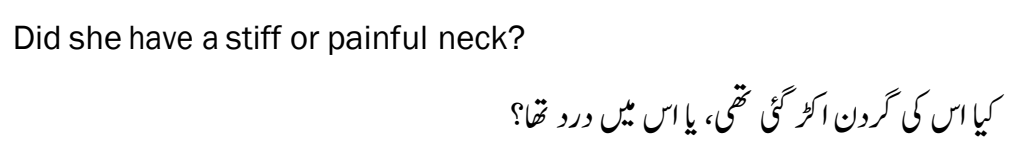 & 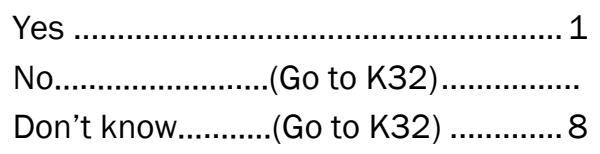 \\
\hline $\begin{array}{c}\text { K31 } \\
\text { (3B410) }\end{array}$ & 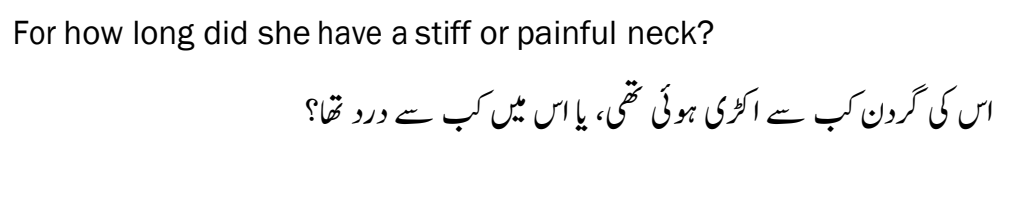 & 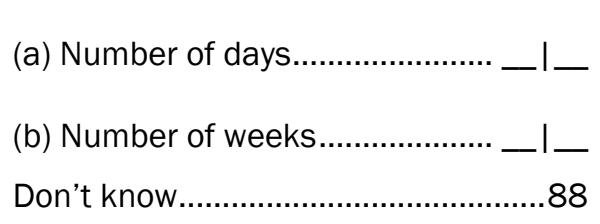 \\
\hline $\begin{array}{c}\text { K32 } \\
\text { (3B420) }\end{array}$ & Did she have mental confusion? & 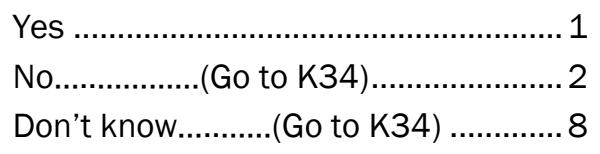 \\
\hline $\begin{array}{c}\text { K33 } \\
\text { (3B430) }\end{array}$ & For how long did she have mental confusion? & 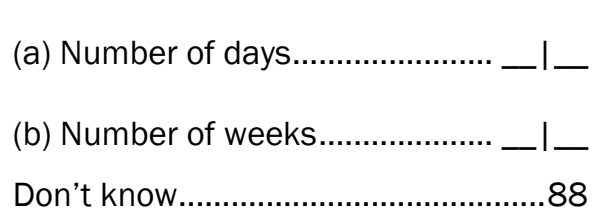 \\
\hline $\begin{array}{c}\text { K34 } \\
\text { (3B440) }\end{array}$ & 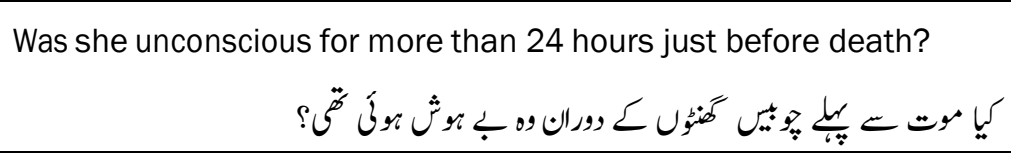 & 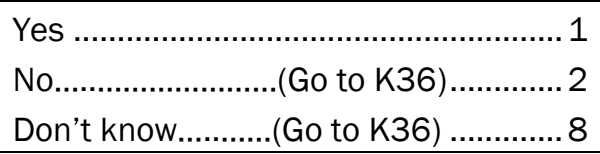 \\
\hline $\begin{array}{c}\text { K35 } \\
\text { (3B450) }\end{array}$ & 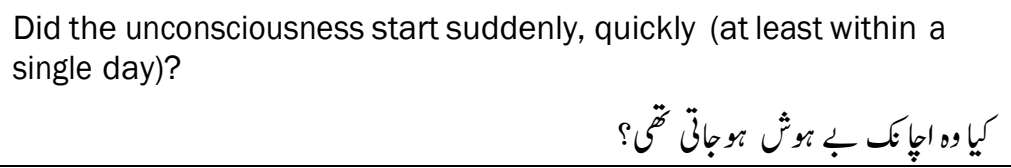 & 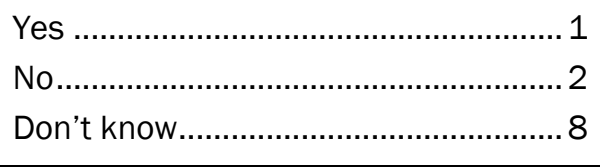 \\
\hline
\end{tabular}




\begin{tabular}{|c|c|c|}
\hline Q.NO. & Questions and Filters & Coding Categories \\
\hline $\begin{array}{c}\mathrm{K} 36 \\
(3 \mathrm{~B} 460)\end{array}$ & Did she have convulsions? & 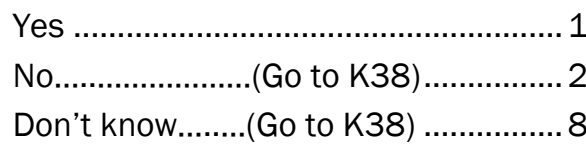 \\
\hline $\begin{array}{c}\mathrm{K} 37 \\
(3 \mathrm{~B} 470)\end{array}$ & For how long did she have convulsions? & 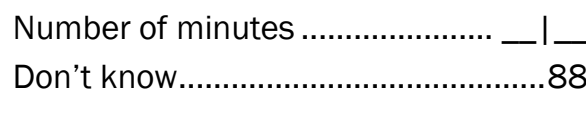 \\
\hline $\begin{array}{c}\mathrm{K} 38 \\
(3 \mathrm{~B} 480)\end{array}$ & 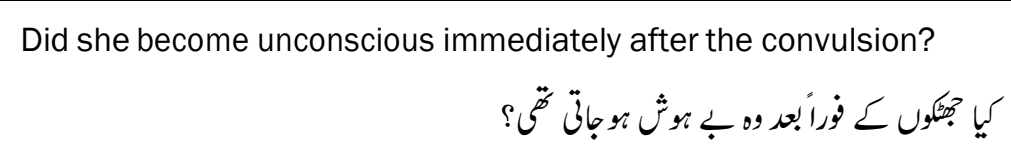 & 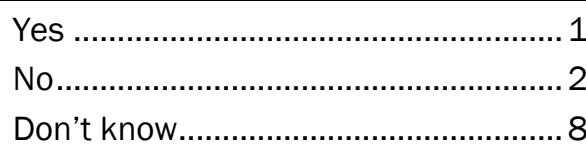 \\
\hline $\begin{array}{c}\text { K39 } \\
(3 B 490)\end{array}$ & Did she have any urine problems? & 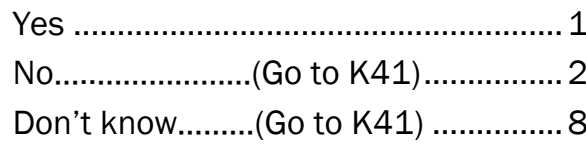 \\
\hline $\begin{array}{c}\mathrm{K} 40 \\
(3 \mathrm{~B} 500)\end{array}$ & Did she pass no urine at all? & 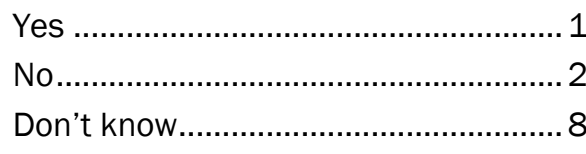 \\
\hline $\begin{array}{l}\mathrm{K} 41 \\
(3 \mathrm{~B} 510)\end{array}$ & 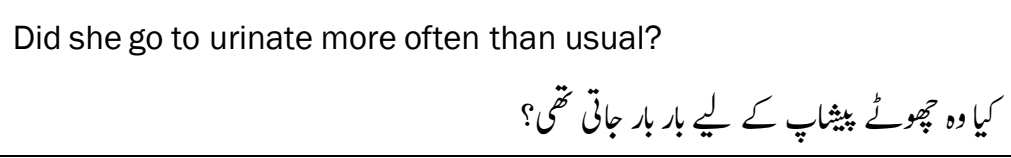 & 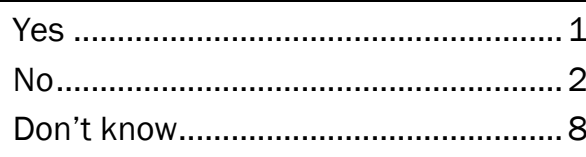 \\
\hline $\begin{array}{c}\mathrm{K} 42 \\
(3 \mathrm{~B} 520)\end{array}$ & 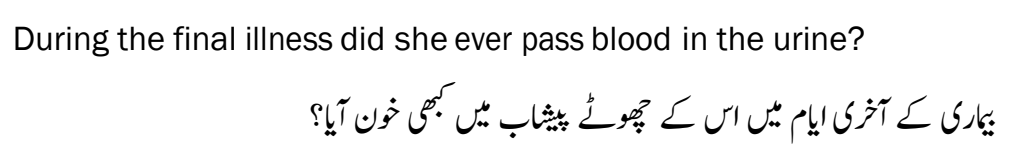 & 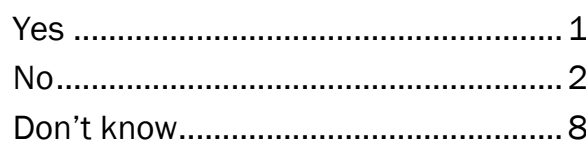 \\
\hline $\begin{array}{c}\mathrm{K} 43 \\
(3 \mathrm{~B} 530)\end{array}$ & Did she have any skin problems? & 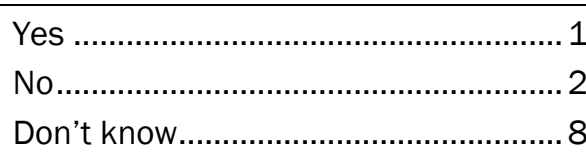 \\
\hline $\begin{array}{c}\mathrm{K} 44 \\
(3 \mathrm{~B} 540)\end{array}$ & 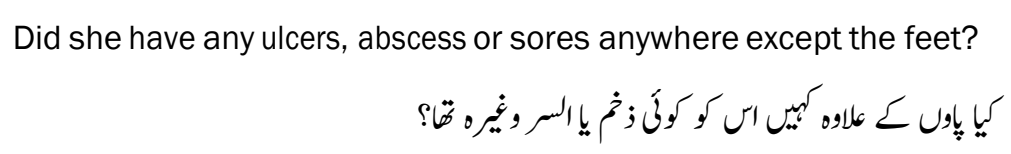 & Yes \\
\hline $\begin{array}{c}\mathrm{K} 45 \\
(3 \mathrm{~B} 550)\end{array}$ & 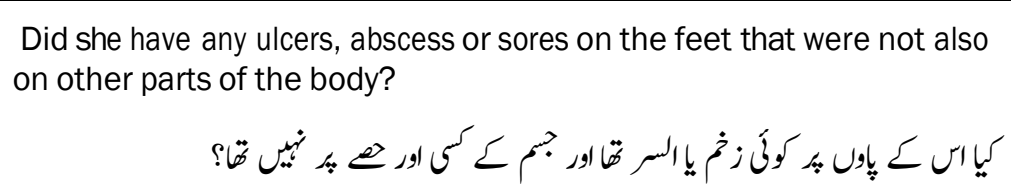 & 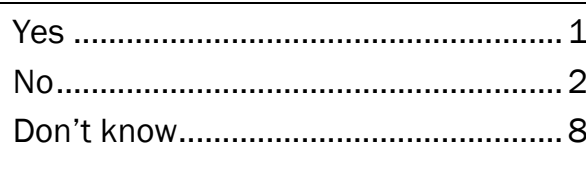 \\
\hline $\begin{array}{c}\mathrm{K} 46 \\
(3 \mathrm{~B} 560)\end{array}$ & 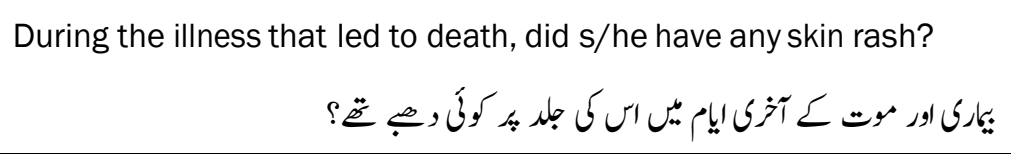 & 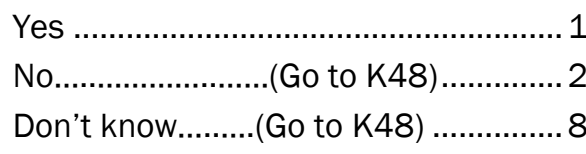 \\
\hline $\begin{array}{c}\mathrm{K} 47 \\
(3 \mathrm{~B} 570)\end{array}$ & For how long did she have the skin rash? & 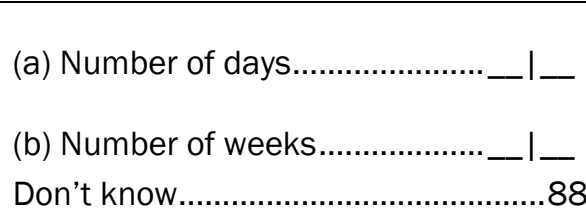 \\
\hline $\begin{array}{c}\mathrm{K} 48 \\
(3 \mathrm{~B} 580)\end{array}$ & 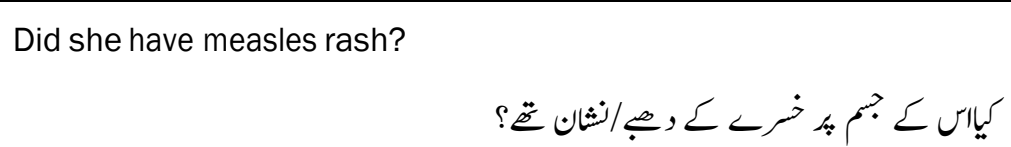 & 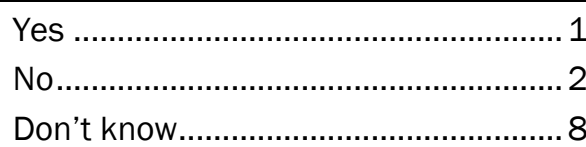 \\
\hline
\end{tabular}




\begin{tabular}{|c|c|c|}
\hline Q.NO. & Questions and Filters & Coding Categories \\
\hline $\begin{array}{c}\text { K49 } \\
\text { (3B590) }\end{array}$ & 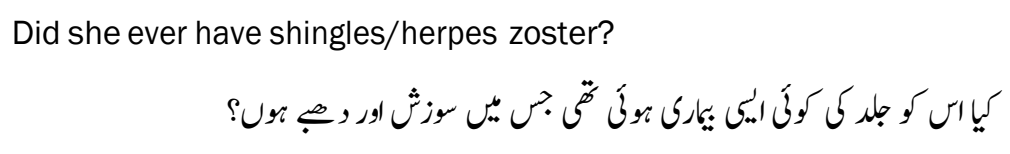 & 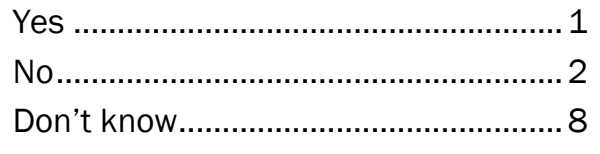 \\
\hline $\begin{array}{c}\text { K50 } \\
(3 B 600)\end{array}$ & 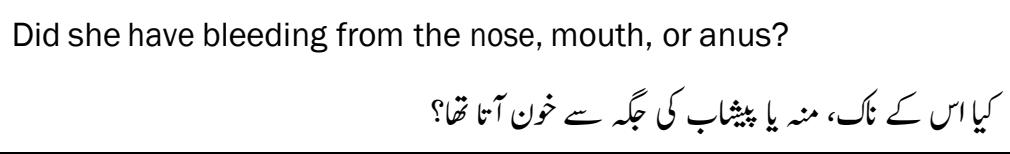 & 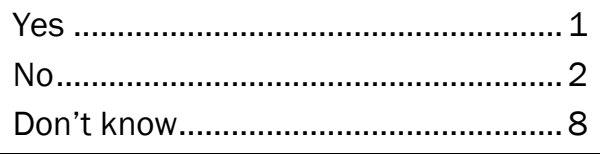 \\
\hline $\begin{array}{c}\text { K51 } \\
\text { (3B610) }\end{array}$ & Did she have weight loss? & 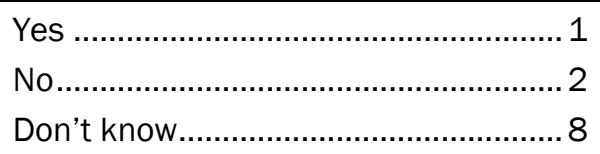 \\
\hline $\begin{array}{c}\text { K52 } \\
(3 B 620)\end{array}$ & Was she severely thin or wasted? & 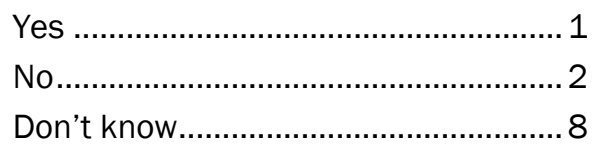 \\
\hline $\begin{array}{c}\text { K53 } \\
\text { (3B630) }\end{array}$ & 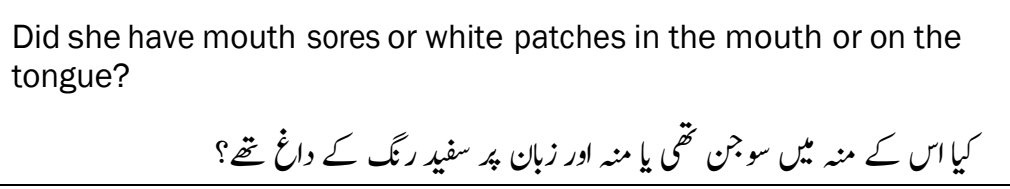 & 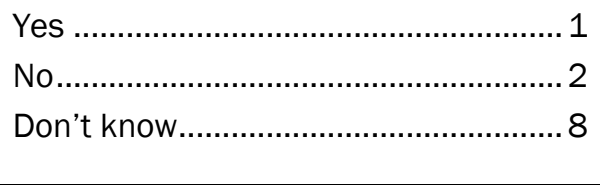 \\
\hline $\begin{array}{c}\mathrm{K} 54 \\
(3 \mathrm{~B} 640)\end{array}$ & 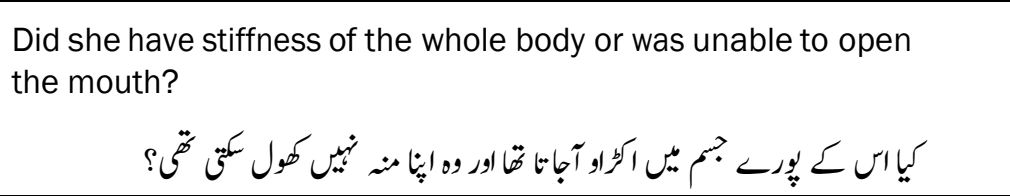 & 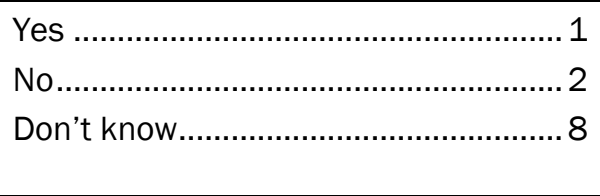 \\
\hline $\begin{array}{c}\text { K55 } \\
\text { (3B650) }\end{array}$ & Did she have swelling (puffiness) of the face? & 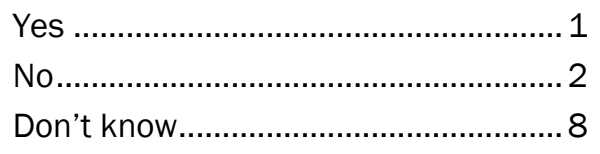 \\
\hline $\begin{array}{c}\text { K56 } \\
\text { (3B660) }\end{array}$ & Did she have both feet swollen? & 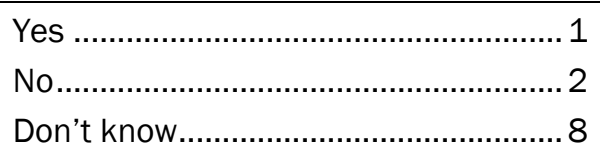 \\
\hline $\begin{array}{c}\text { K57 } \\
\text { (3B670) }\end{array}$ & Did she have any lumps? & 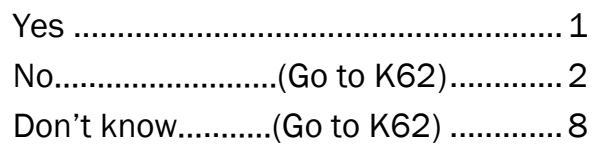 \\
\hline $\begin{array}{c}\text { K58 } \\
(3 B 680)\end{array}$ & 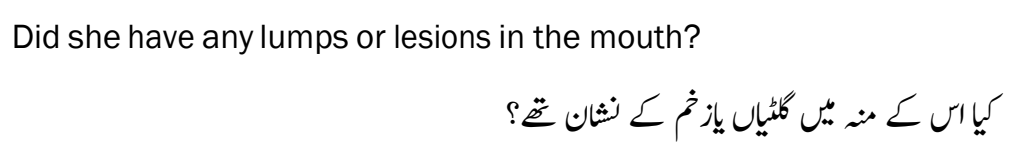 & 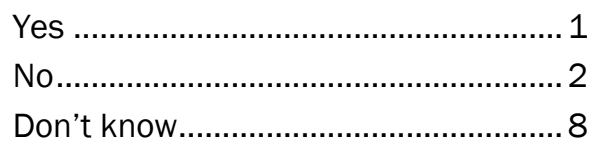 \\
\hline $\begin{array}{c}\text { K59 } \\
\text { (3B690) }\end{array}$ & Did she have any lumps on the neck? & 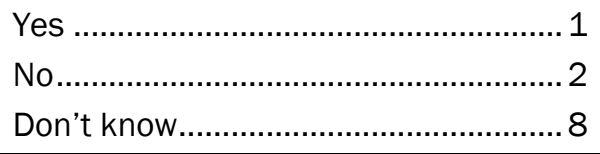 \\
\hline $\begin{array}{c}\text { K60 } \\
(3 B 700)\end{array}$ & Did she have any lumps on the armpit? & 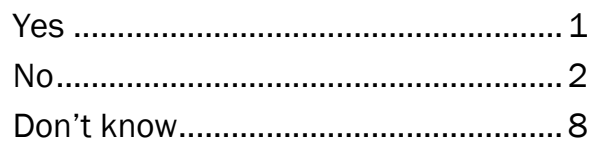 \\
\hline $\begin{array}{c}\text { K61 } \\
\text { (3B710) }\end{array}$ & Did she have any lumps on the groin? & 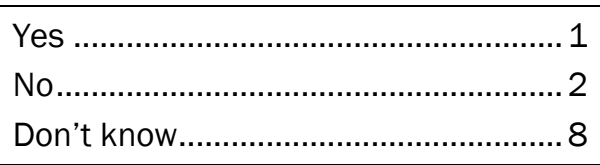 \\
\hline $\begin{array}{c}\text { K62 } \\
(3 B 730)\end{array}$ & 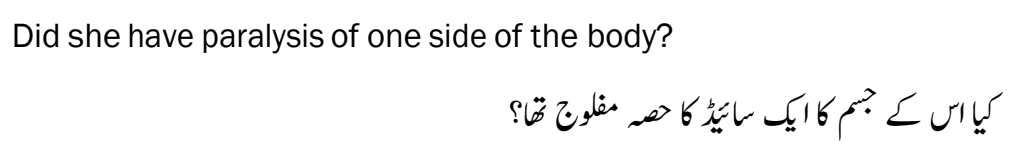 & 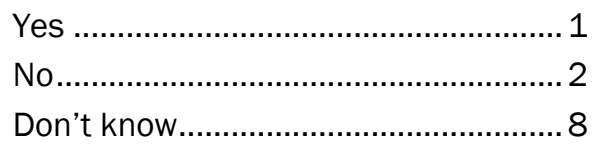 \\
\hline
\end{tabular}




\begin{tabular}{|c|c|c|}
\hline Q.NO. & Questions and Filters & Coding Categories \\
\hline $\begin{array}{c}\text { K63 } \\
(3 B 740)\end{array}$ & 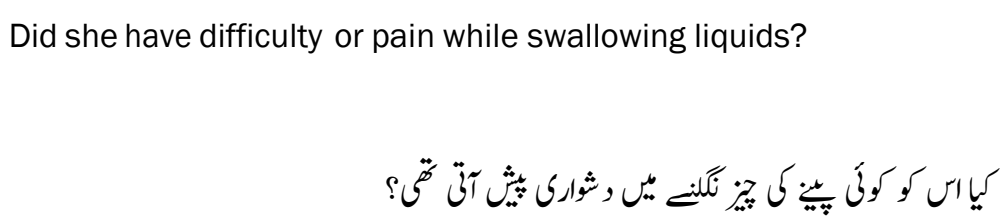 & Yes \\
\hline $\begin{array}{c}\text { K64 } \\
\text { (3B750) }\end{array}$ & 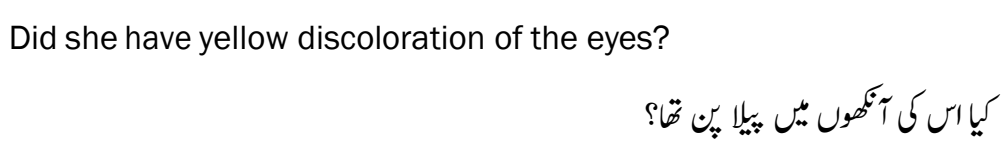 & 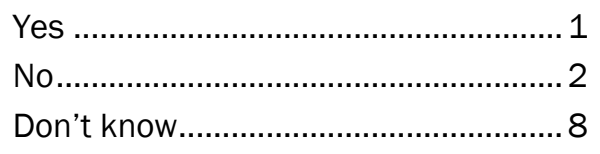 \\
\hline $\begin{array}{c}\text { K65 } \\
(3 B 760)\end{array}$ & 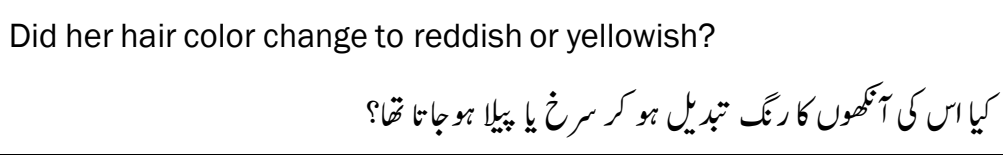 & Yes \\
\hline $\begin{array}{c}\text { K66 } \\
\text { (3B770) }\end{array}$ & 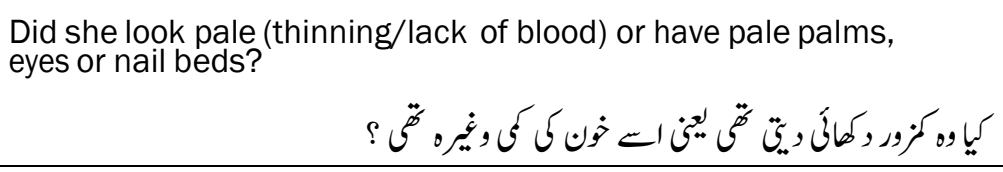 & 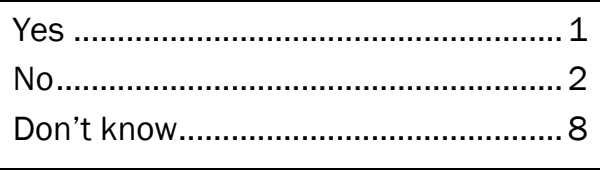 \\
\hline $\begin{array}{c}\text { K67 } \\
\text { (3B780) }\end{array}$ & Did she have sunken eyes? & 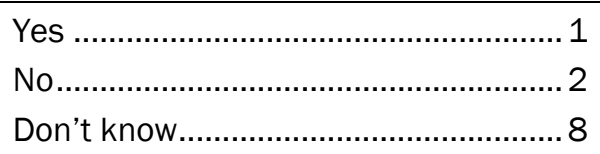 \\
\hline $\begin{array}{c}\text { K68 } \\
\text { (3B790) }\end{array}$ & 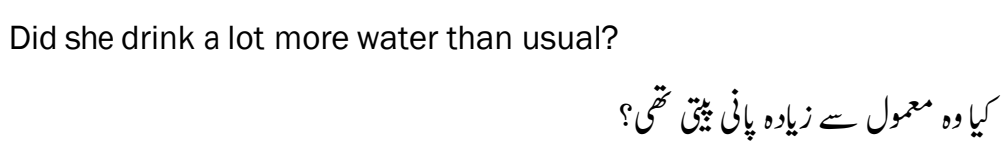 & 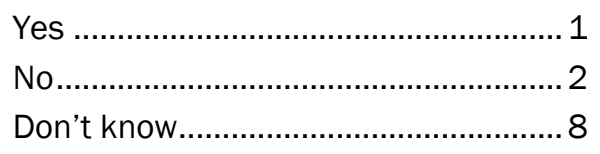 \\
\hline $\begin{array}{c}\text { K69 } \\
(3 F 110)\end{array}$ & 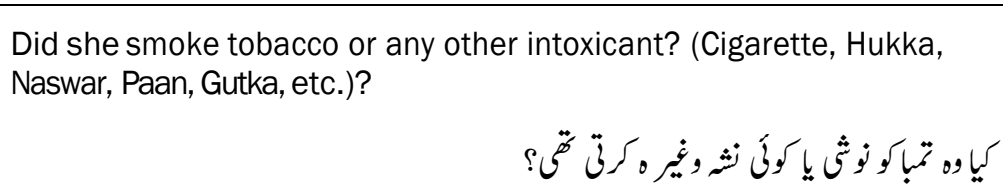 & 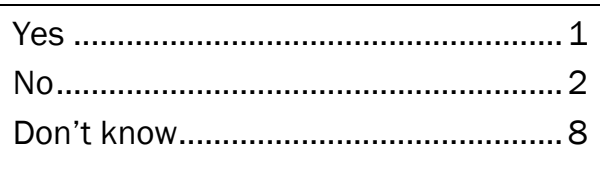 \\
\hline $\begin{array}{c}\text { K70 } \\
\text { (Q1306) }\end{array}$ & 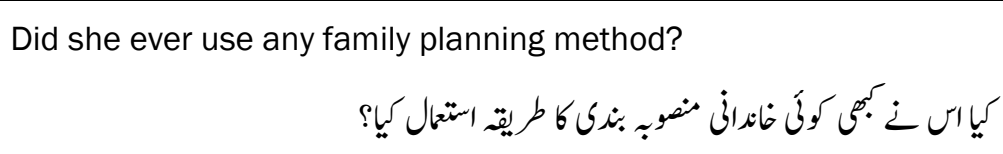 & 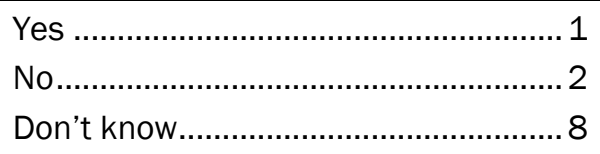 \\
\hline
\end{tabular}


SECTION-L: TREATMENT AND HEALTH SERVICE USE FOR THE FINAL ILLNESS

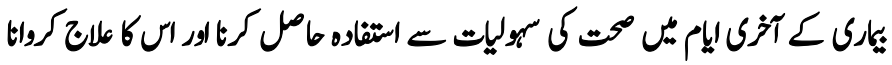

\begin{tabular}{|c|c|c|}
\hline Q.NO. & Questions and Filters & Coding Categories \\
\hline $\begin{array}{c}\text { L1 } \\
\text { (3G110) }\end{array}$ & 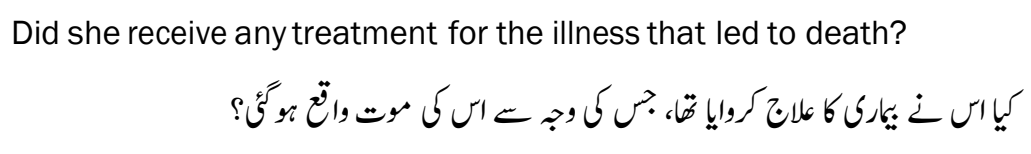 & 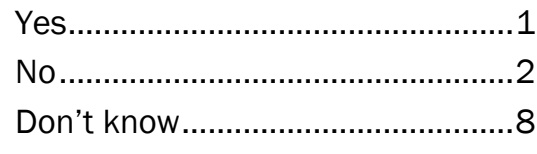 \\
\hline $\begin{array}{c}\text { L2 } \\
\text { (3G120) }\end{array}$ & 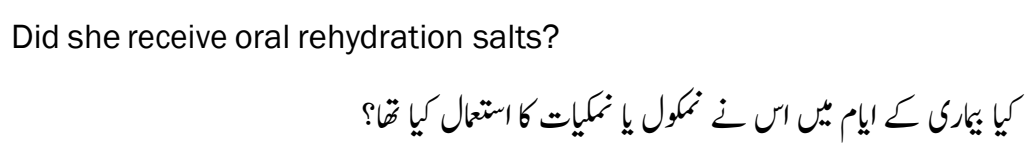 & 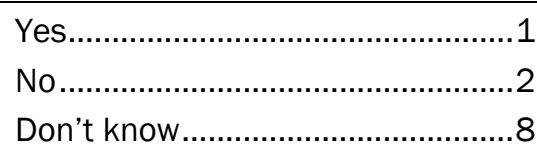 \\
\hline $\begin{array}{c}\text { L3 } \\
\text { (3G130) }\end{array}$ & 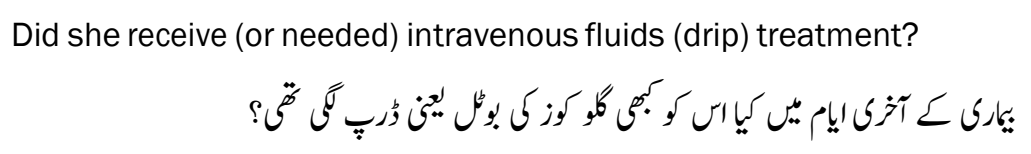 & 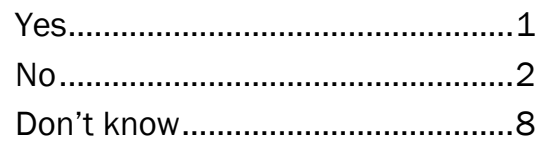 \\
\hline $\begin{array}{c}\text { L4 } \\
\text { (3G140) }\end{array}$ & 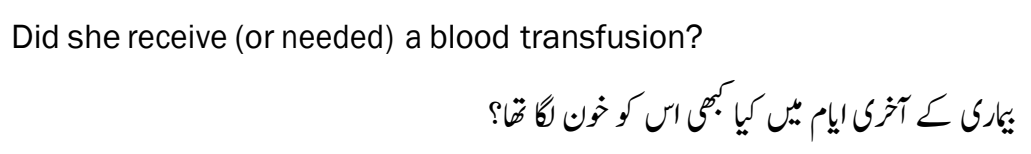 & 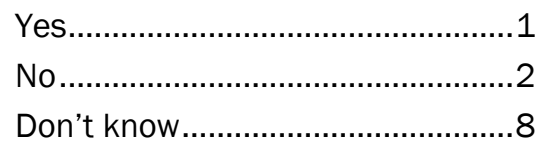 \\
\hline $\begin{array}{c}\text { L5 } \\
\text { (3G150) }\end{array}$ & 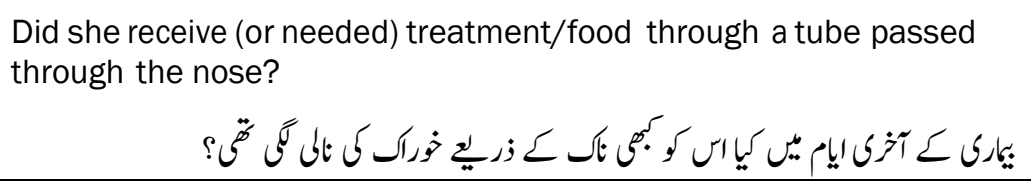 & 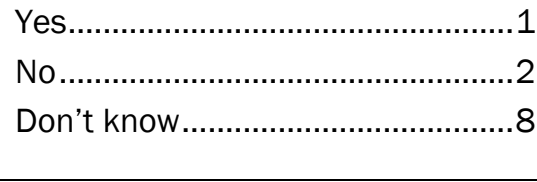 \\
\hline $\begin{array}{c}\text { L6 } \\
\text { (3G160) }\end{array}$ & 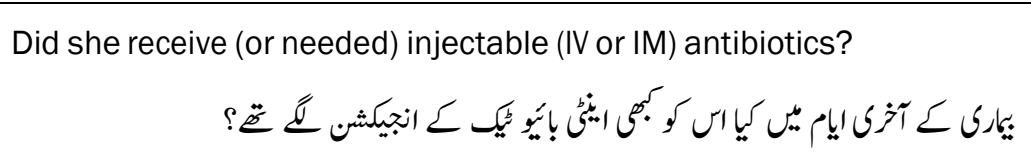 & 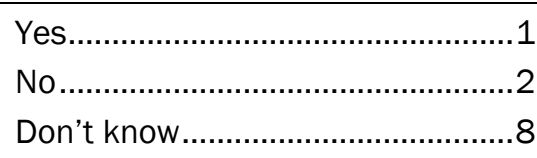 \\
\hline $\begin{array}{c}\text { L7 } \\
\text { (3G170) }\end{array}$ & 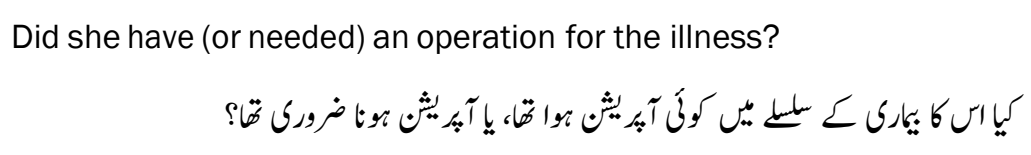 & Yes \\
\hline $\begin{array}{c}\text { L8 } \\
\text { (3G180) }\end{array}$ & 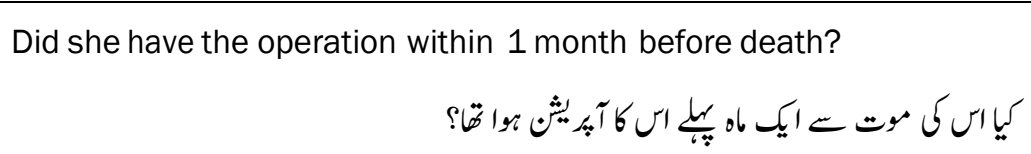 & 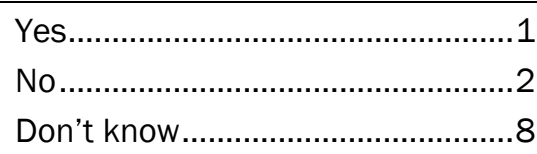 \\
\hline $\begin{array}{c}\text { L9 } \\
\text { (3G190) }\end{array}$ & 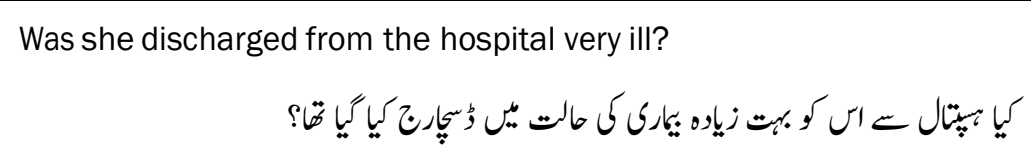 & 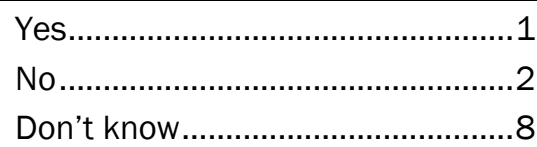 \\
\hline
\end{tabular}




\section{SECTION-M: HEALTH CARE INCLUDING ANTENATAL CARE BEFORE DEATH DURING MOST RECENT PREGNANCY/DELIVERY}

(Both Delivered Alive or Stillbirth)

\begin{tabular}{|c|c|c|}
\hline Q.NO. & Questions and Filters & Coding Categories \\
\hline M1 & 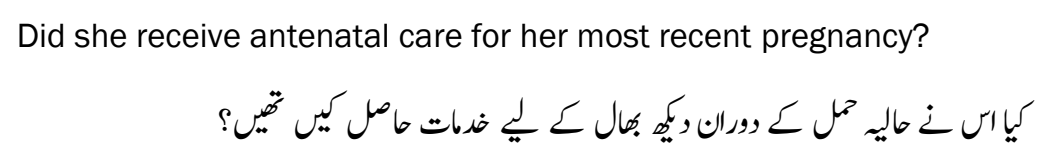 & 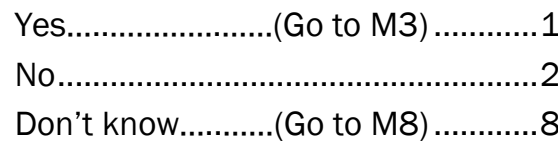 \\
\hline M2 & 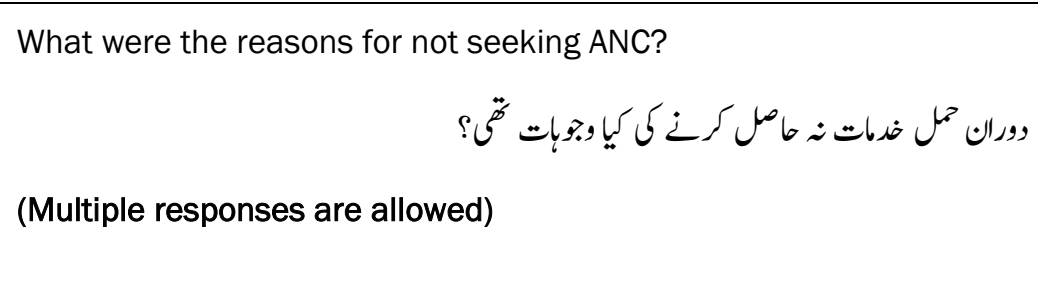 & 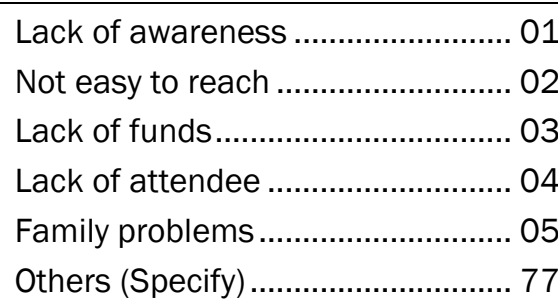 \\
\hline
\end{tabular}

\section{After asking $\mathrm{M} 2-$ Go to $\mathrm{M} 8$}

\begin{tabular}{|c|c|c|}
\hline M3 & 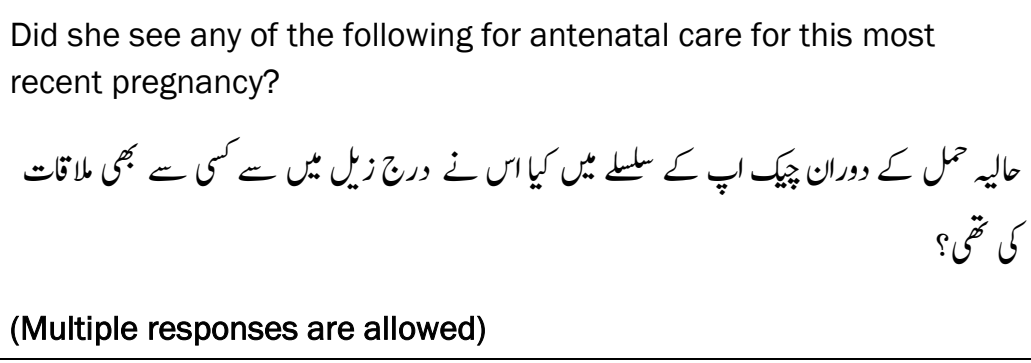 & 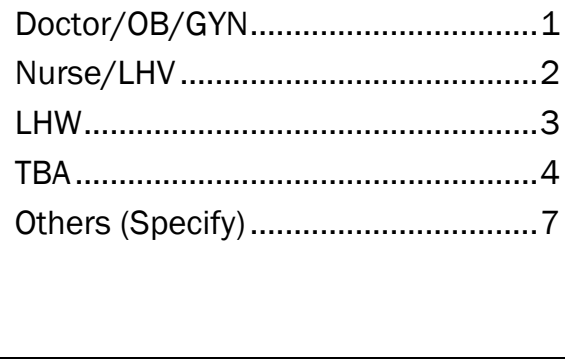 \\
\hline M4 & 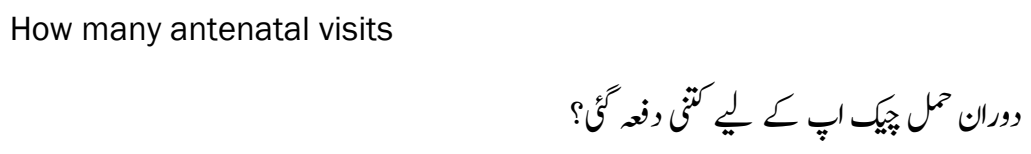 & 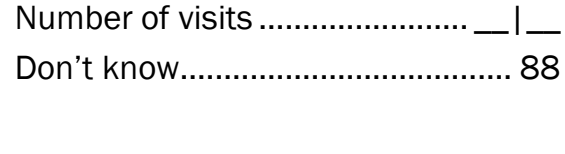 \\
\hline M5 & 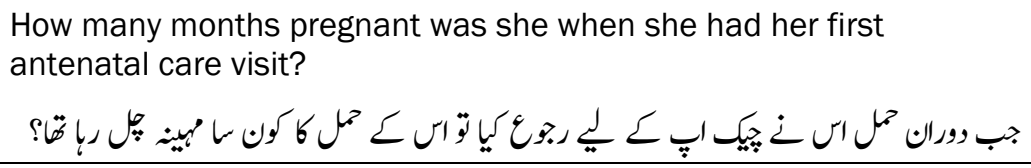 & 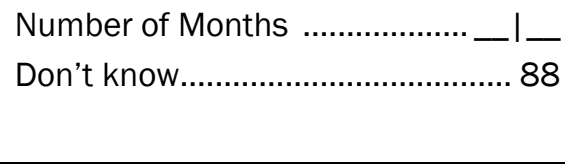 \\
\hline M6 & 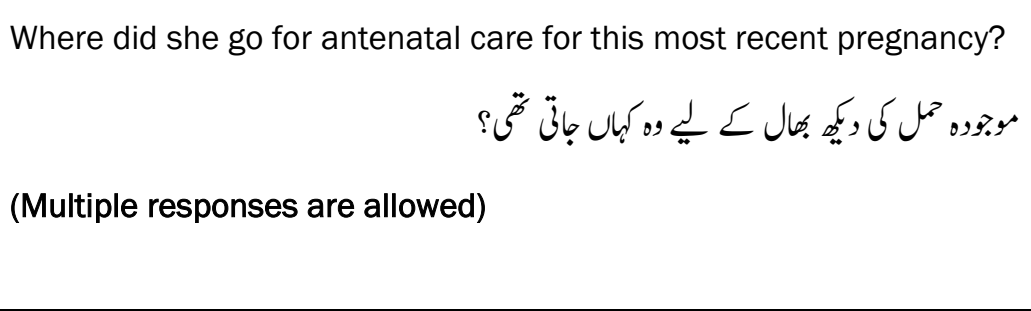 & $\begin{array}{l}\text { Private Clinic/ Hospital ..................... } 01 \\
\text { Government hospital ....................... } 02 \\
\text { LHW House ..................................... } 03 \\
\text { Community health center ................ } 04 \\
\text { TBA }\end{array}$ \\
\hline M7 & 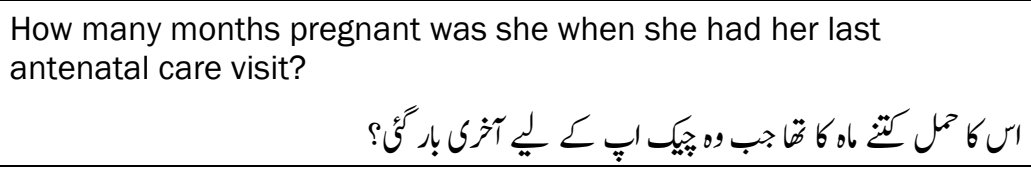 & 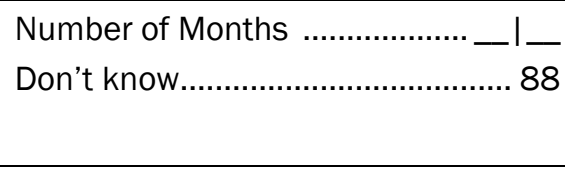 \\
\hline M8 & 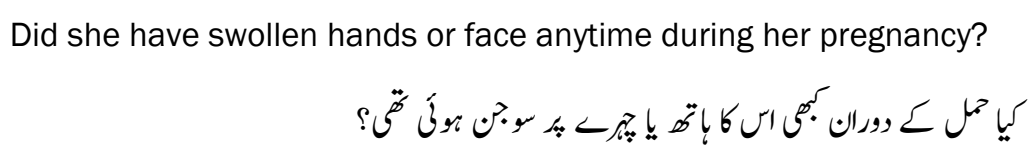 & Yes \\
\hline
\end{tabular}




\begin{tabular}{|c|c|c|}
\hline Q.NO. & Questions and Filters & Coding Categories \\
\hline M9 & 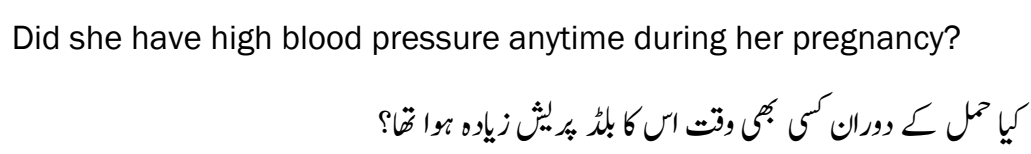 & 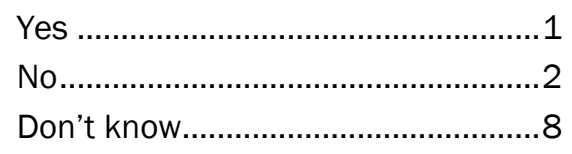 \\
\hline M10 & 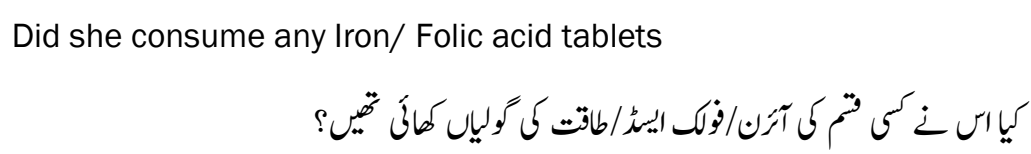 & 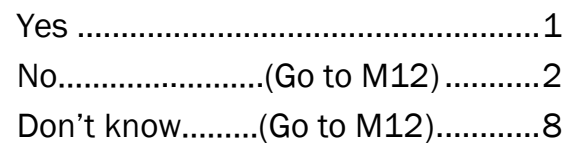 \\
\hline M11 & How many tablets? & 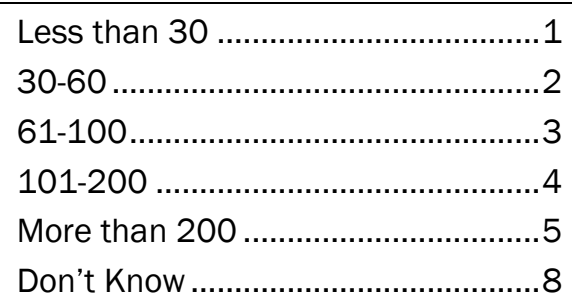 \\
\hline M12 & 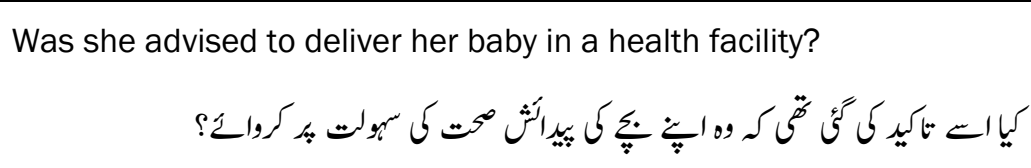 & 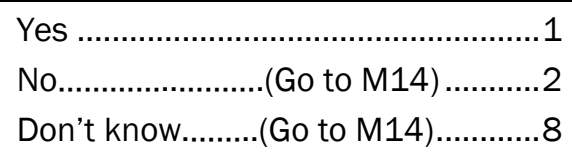 \\
\hline M13 & 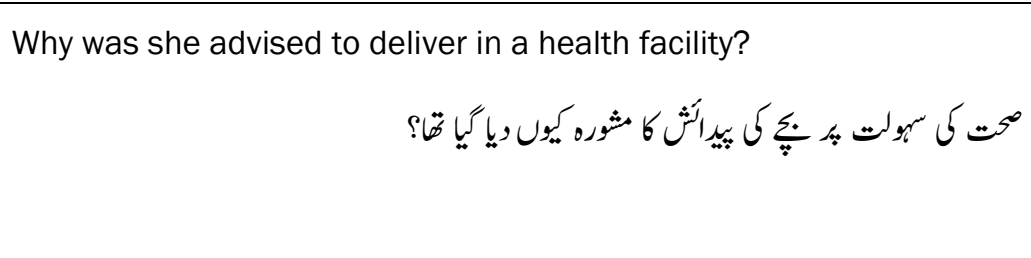 & 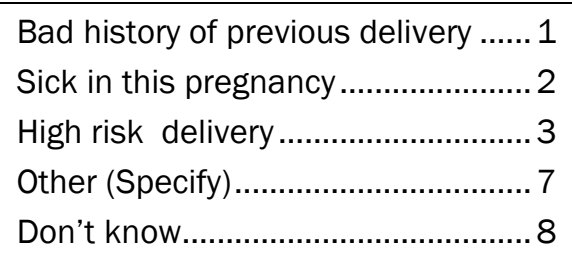 \\
\hline $\begin{array}{l}\text { M14 } \\
\text { (3G100) }\end{array}$ & Was she adequately vaccinated for tetanus? & Yes \\
\hline M15 & Did she get the urine test? & Yes \\
\hline M16 & 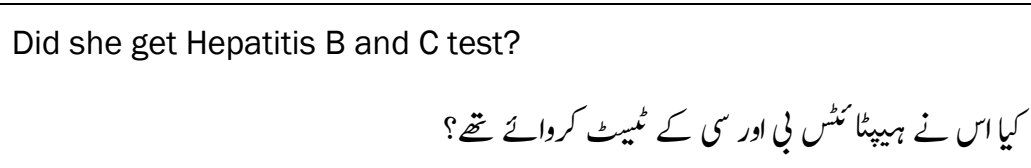 & Yes \\
\hline M17 & Did she get the Hemoglobin test? & 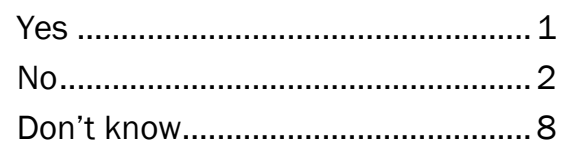 \\
\hline M18 & 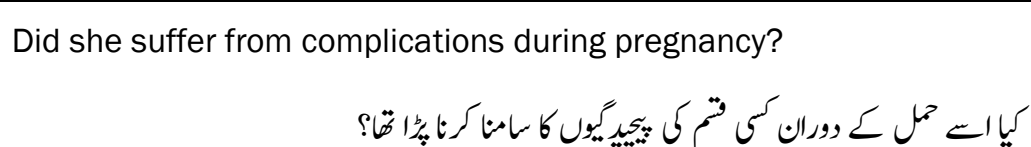 & 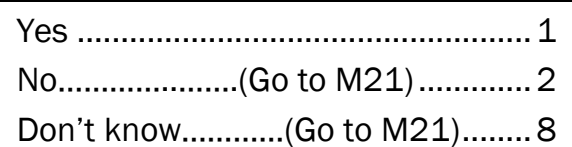 \\
\hline
\end{tabular}




\begin{tabular}{|c|c|c|}
\hline Q.NO. & Questions and Filters & Coding Categories \\
\hline M19 & $\begin{array}{l}\text { What type of the complications? } \\
\text { (Multiple responses are allowed) }\end{array}$ & 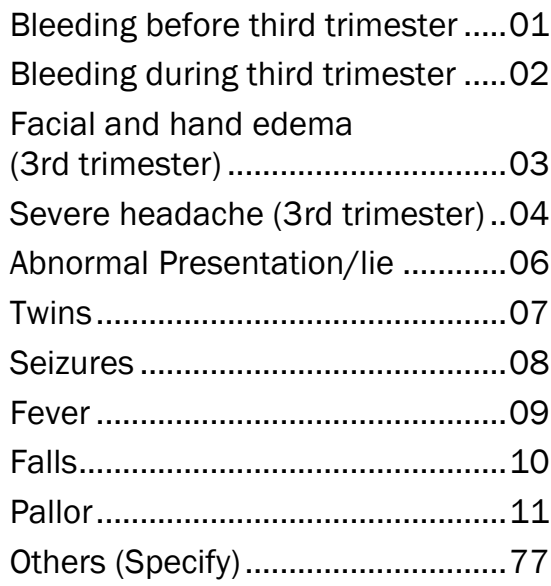 \\
\hline M20 & 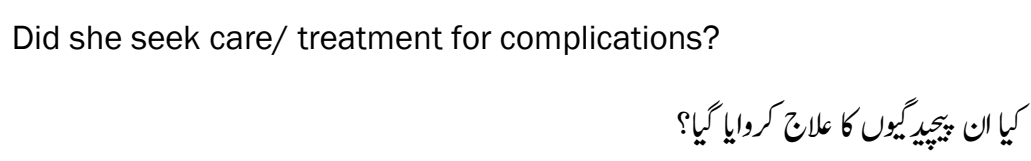 & 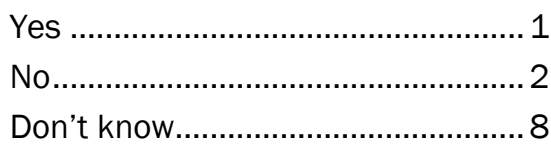 \\
\hline M21 & 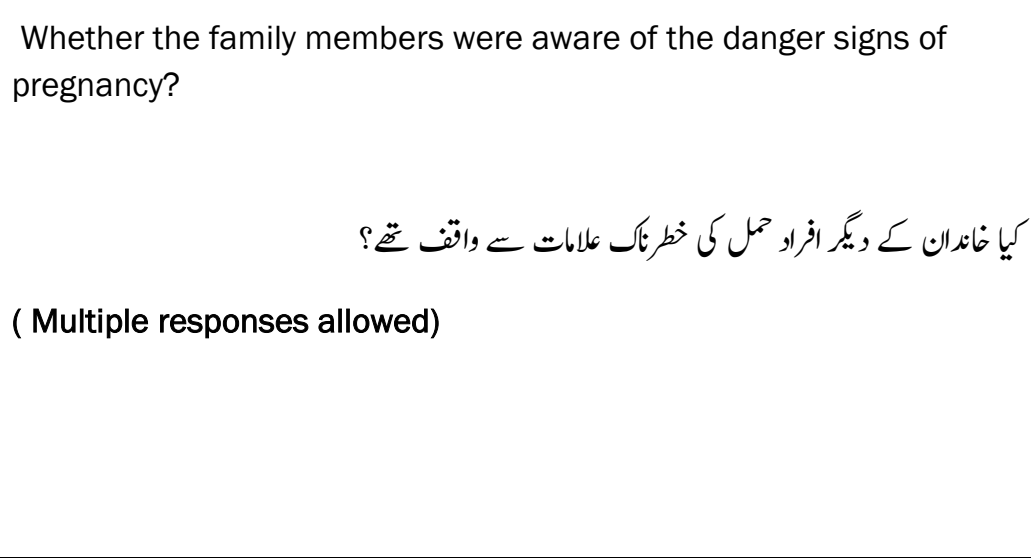 & 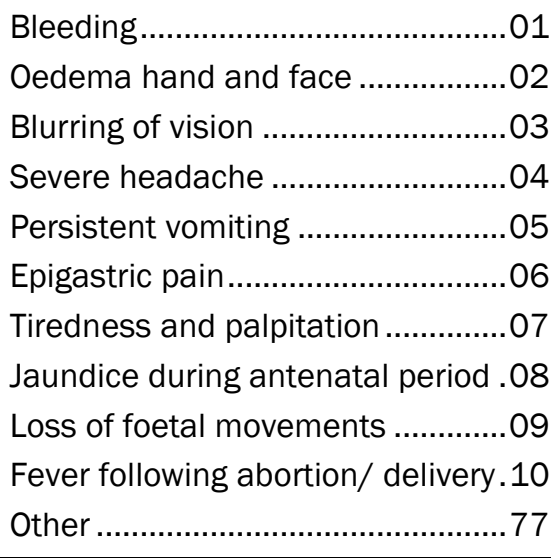 \\
\hline M22 & 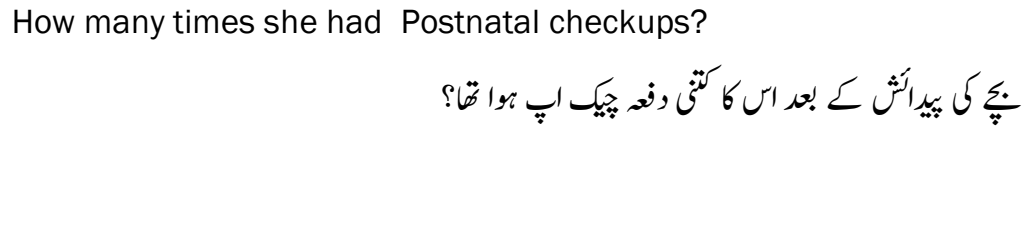 & 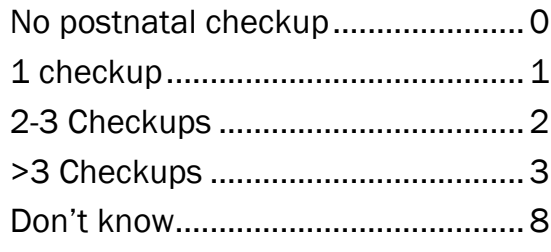 \\
\hline M23 & 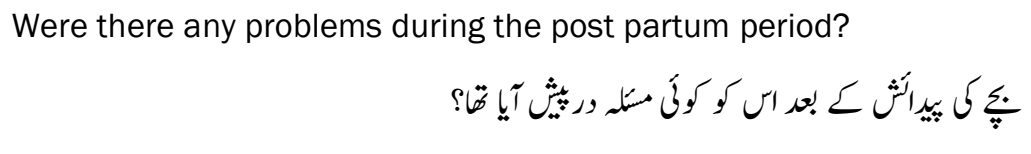 & 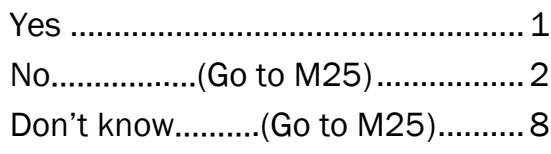 \\
\hline
\end{tabular}




\begin{tabular}{|c|c|c|}
\hline Q.NO. & Questions and Filters & Coding Categories \\
\hline M24 & $\begin{array}{l}\text { What were the problems? } \\
\text { (Multiple responses are allowed) }\end{array}$ & 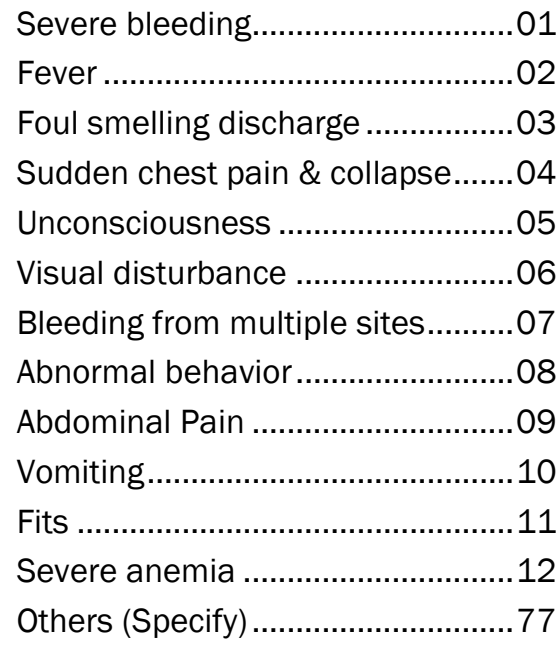 \\
\hline M25 & Did she seek treatment? & 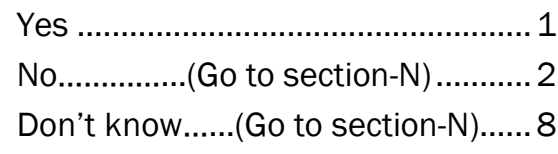 \\
\hline M26 & اكر بال توك س علانج كروايا تقا؟ & 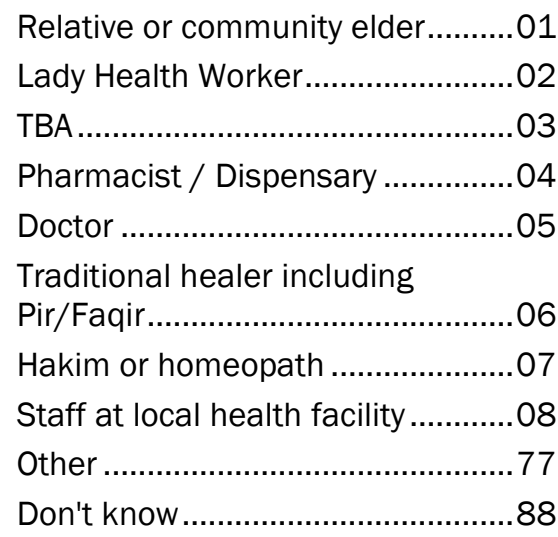 \\
\hline
\end{tabular}

Could you tell me about the illness/events that led to her death? What happened at start of her pregnancy until she died?

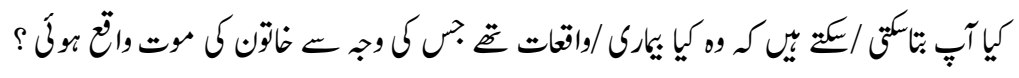

Cause of death: According to respondent

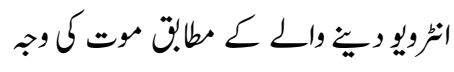




\section{INTERVIEWER'S OBSERVATIONS}

To be filled in after completing interview

What happened at start of her pregnancy until she died?

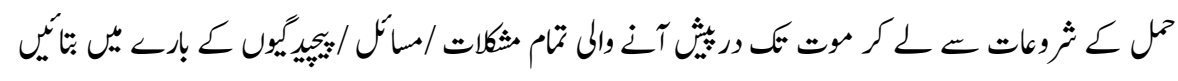

What were the circumstances around the death (Household circumstances)

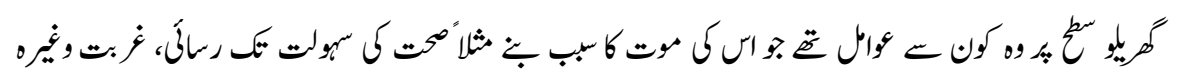

What do you think could have changed or prevent the death?

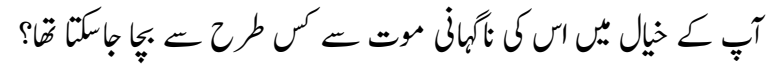

Suggestion for improvement in maternity care

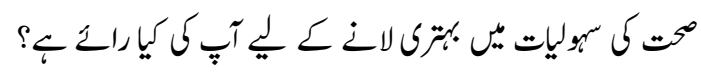


SECTION-O: DEATH REGISTERATION AND CERTIFICATION

\begin{tabular}{|c|c|c|}
\hline Q.NO. & Questions and Filters & Coding Categories \\
\hline $\begin{array}{c}01 \\
(1 \mathrm{~A} 700)\end{array}$ & Was the death registered? & 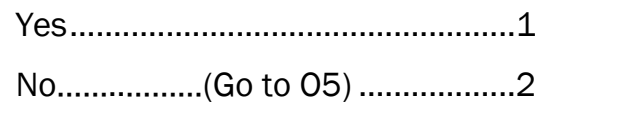 \\
\hline $\begin{array}{c}02 \\
(1 \mathrm{~A} 710)\end{array}$ & Death registration number & \\
\hline $\begin{array}{c}03 \\
(1 \mathrm{~A} 720)\end{array}$ & Date of registration & 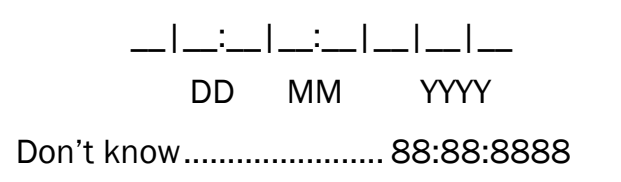 \\
\hline $\begin{array}{c}04 \\
(1 \mathrm{~A} 730)\end{array}$ & 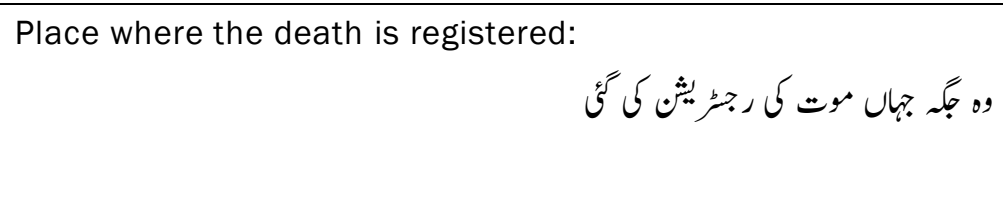 & 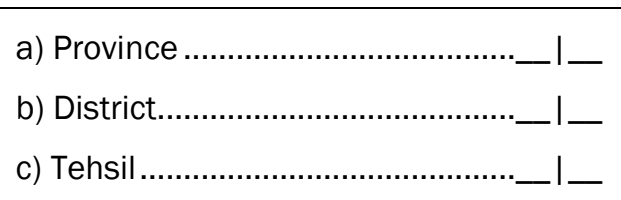 \\
\hline $\begin{array}{c}05 \\
(1 \mathrm{~A} 740)\end{array}$ & 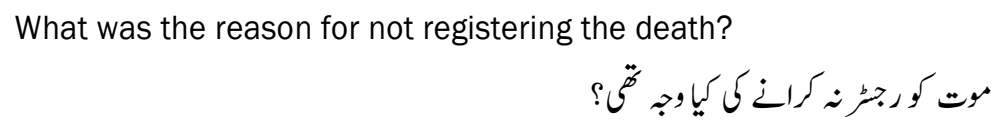 & \\
\hline
\end{tabular}

Would it be all right if we come back to talk to you again after some time

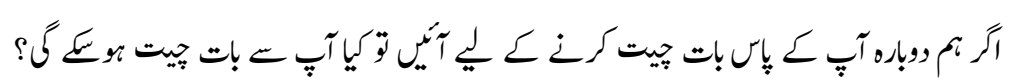

Yes........ .1

No . .2

Thank you very much for the information you provided and the time you spared for me.

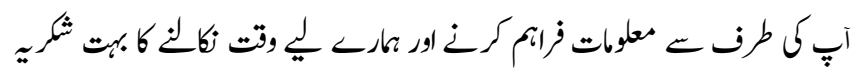

\section{SUPERVISOR'S OBSERVATIONS}

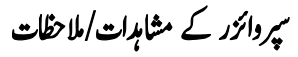




\title{
9.3 Ethical Approval from National Bioethics Committee of Pakistan and the Institutional Review Board of the Population Council, New York
}

\section{Population Council}

\author{
Institutional Review Board \\ Population Council \\ 1230 York Avenue \\ New York, NY 10065
}

APPROVAL OF PROTOCOL

DATE: July 25, 2014

TO: $\quad$ A. M. Mir, Principal Investigator

FROM: Nick Gontarz, IRB Administrator, on behalf of John Bongaarts, Chairman Institutional Review Board (IRB)

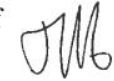

RE: Approval of Protocol 653 - Using the community informant based (made-in and made-for) methodology for estimating MMR in Punjab, Pakistan

The Institutional Review Board (IRB) on human research of the Population Council has approved the above request to involve humans as research subjects.

APPROVAL DATE OF PROTOCOL: JULY 9, 2014

ADVERSE REACTIONS/COMPLICATIONS: All serious and/or unexpected side effects must be reported immediately by email to the Population Council's SAE Desk (Safety@popcouncil.org) which will notify the IRB of the Population Council.

MODIFICATIONS: All protocol changes involving subjects must have prior IRB approval.

If this project is to continue, it must be renewed as specified by the IRB. THE EXPIRATION DATE FOR THIS PROJECT IS JULY 9, 2015. This renewal application consists of a brief status report summarizing the results obtained during the past period and a short statement of the research plan for the coming year.

If you have any questions, please contact Nick Gontarz at telephone number [212] 327-7112, email ngontarz@popcouncil.org or fax number [212] $327-7678$.

cc: IRB Records and Reports File for Protocol 653 


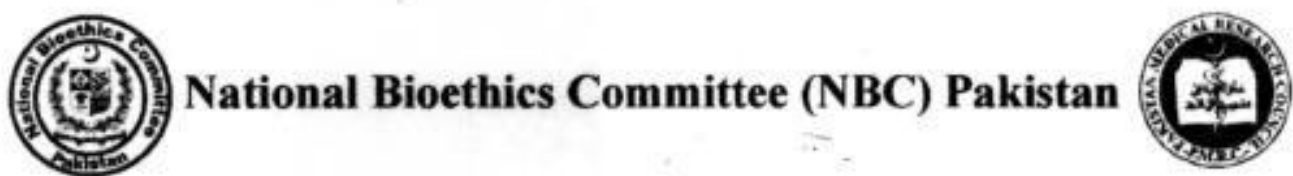

Ref: №.4-87/14/NBC-157/RDCl 267

Date: August 06, 2014

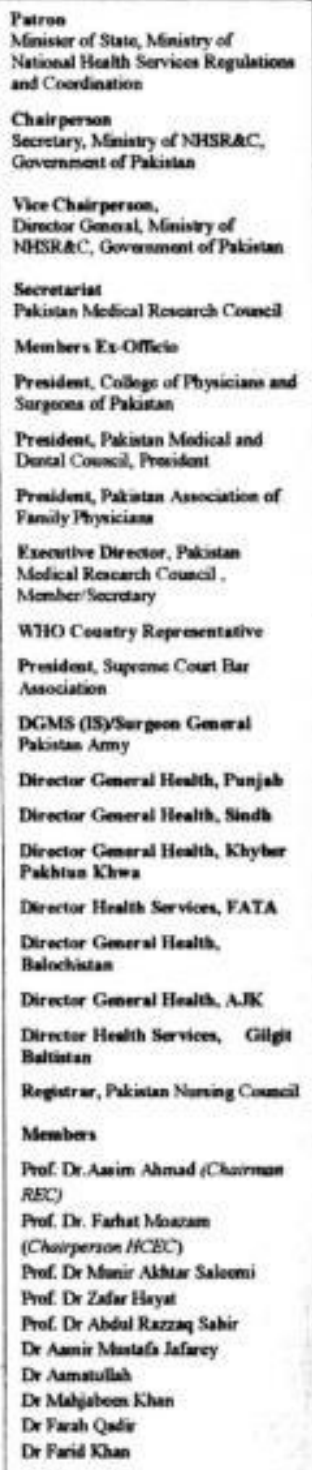

NBC Secretariat:

Pakistan Medieal Research Council, Stashrah-e-Jamhuriat, Off Constetution Avenie, Sector G-5/2, Islamabed

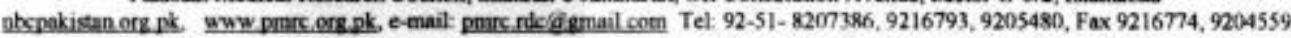

Dr. Sara Hall

Programme Manager

Research \& Advocacy Fund

House No 9, Street 64

Sector F-8/4

Islamabad

Subject: Conducting a pilot study to assess the feasibility for testing the made-in and made-for methodology for estimating the MMR in Pakistan

\section{Dear Dr Sara,}

This is with reference to your letter No RAF/PM/001, dated 11 July 2014 regarding expansion of project in another 6 districts of Punjab with no change in methodology.

I am pleased to inform you that the above mentioned project has been cleared by "Research Ethics Committee of National Bioethics Committee".

Kindly keep the National Bioethics Committee Secretariat updated with the progress of the project and submit the formal final report on completion.

Yours sincerely

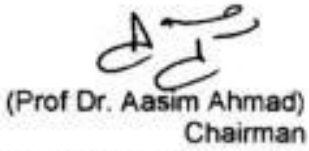

Chairman

NBC-Research Ethics Committee 


\subsection{Study Support Letters}

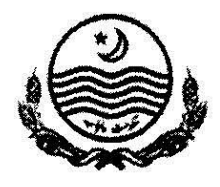

\section{OFFICE OF THE DISTRICT OFFICER COMMUNITY ORGANIZATION JHELUM}

Phone \# 0544-610890

No. $257-\sqrt{3 / 100 C O}$

Dated: $12 / 8 / 2014$

To,

The Administrators Union Councils,

Tehsil Jhelum, Dina, Sohawa, PD Khan,

District Jhelum

Subject:

COOPERATION IN PROVICIAL RSEEARCH STUDY ON MEASURING MATERNAL MORTALITY RATIO.

With reference to the request received from the Director Programs, population council, Islamabad on 07.08.2014.

You are requested to direct incharge secretaries of Union Council under your jurisdiction to extend maximum cooperation \& help with the research team.

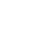

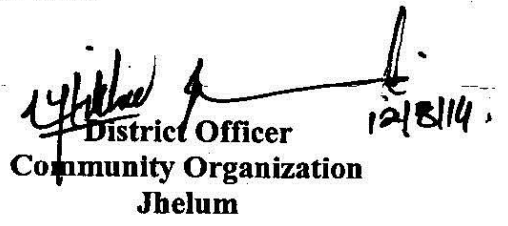

Ce:-

1. The Director General Health, Punjab, Lahore.

$\checkmark$. The Director Programs, Population Council, Islamabad. 
"TO PREVENT DENGUE, KEEP YOUR PREMISES, HOUSES AND ENVIRONMENT DRY \& CLEAN"

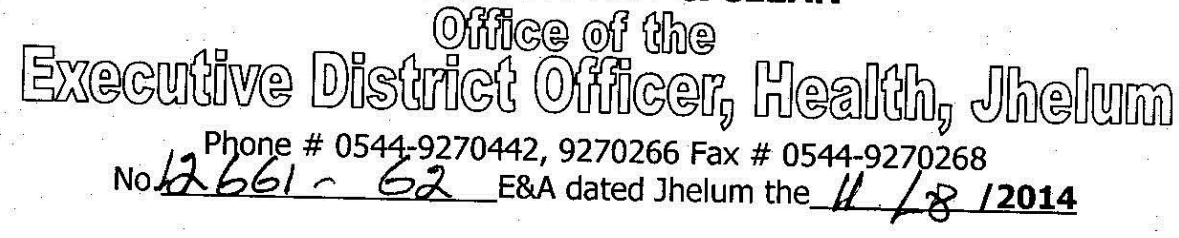

To,

Dr. Ali Mohammad Mir

Director Programs, Population Council

Islamabad

Subject:-

SUPPORT LETTER FOR PROVINCIAL RESEARCH STUDY ON MEASURING

MATERNAL RATIO

Kindly refer Director General Health Services, Lahore office letter No. 6126-31 /PA dated 11/07.2014 on the subject noted above.

It is intimated that after mutual discussion on various aspects of this programme has been discussed and ensured, that full support will be provided regarding this study.

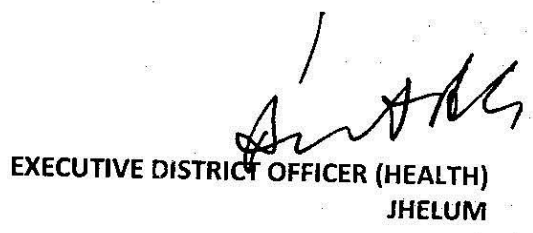

Cc:-

1. The Director General Health Services, Punjab, Lahore for information $w / r$ to his letter referred above. 


\author{
No. Esttl. 12273 IEDO (H) \\ Dated: 2110712014
}

To,

Dr. Muhammad Saleem Shaikh

Project Manager Population Council.

\title{
Subject: - REQUEST FOR A MEETING TO PROVIDE A BRIEFING ON \\ "MEASURING PROVINCIAL ESTIMATES FOR MATERNAL MORTALITY RATIO IN PUNJAB".
}

Reference to your office letter No. Nil dated 21.07.2014, a meeting regarding the subject cited above has been carried out in the office of the undersigned on dated 21.07.2014

A mutual discussion on various aspects of this program has been discussed and ensured, that full support will be provided regarding this study. IEDO (H)

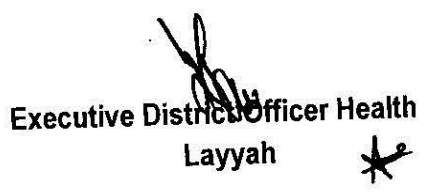

No. Estt

dated $\quad 1 \quad 12014$

A copy is forwarded to the District Officer Health Layyah for information.

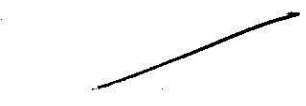

Executive District Officer Health

Layyah 


\section{OFFICE OF THE EXECUTIVE DISTRICT OFFICER (HEALTH) CHINIOT}

No. $548 /$ /EDOH Chiniot Dated/6-7-.2014

To,

Dr. Mohammad Saleem Shaikh

Project Manager Population Council

Subject: REQUEST FOR A MEETING TO PROVIDE A BRIEFING ON

"MEASURING PROVINCIAL ESTIMATES FOR MATERNAL
MORTALITY RATIO IN PUNJAB",

Reference your office letter No. Nil dated 14.07.2014, a meeting regarding the subject cited above has been carried out in the office of undersigned on dated 16.07.2014.

A mutual discussion on various aspects of this program has been discussed and ensured, that full support will be provided regarding this study.

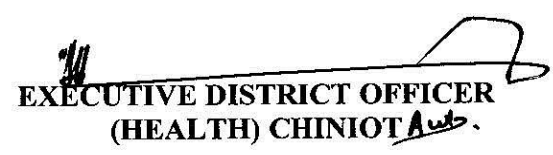

Copy forwarded to

No.

/EDOH Chiniot Dated

.2014

1. The District Officer Health Chiniot

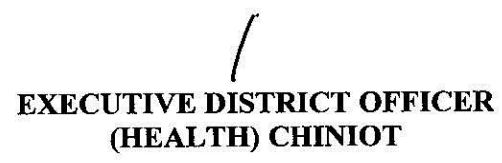




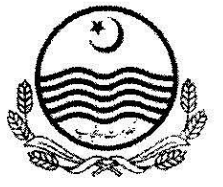

To

1- The Administrator Union Councils, District Chiniot.

2- All Secretaries Union Councils District Chiniot.

No.DO(CO)/CHT/3C3-308 Dated $17-7-14$

Subject: COOPRATION IN PROVINCIAL RESEARCH STUDY ON MEASURING MATERIAL MORTALITY RATIO.

Please refer to the subject cited letter received from Director

General Health Punjab vide No.6126-31/PA dated $11^{\text {th }}$ July ,2014.

Please extend full cooperation with the research team of population Council.

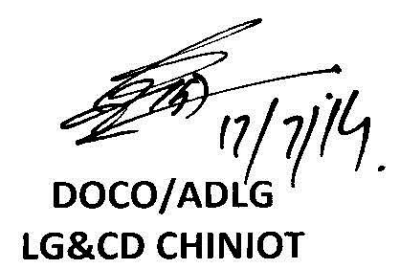

C.C

1. The Director General health Punjab Lahore

2. The District Coordination Officer, Chiniot

3. The Executive District Officer Health, Chiniot

4. The Director Programs Population Council, Islamabad 
To,

1-The Administrator Union Councils, District T.T.Singh.

2- All Secretaries Union Councils District T.T.Singh.

No. DOCOITTS/489-573 Dated: $19 / 07 \mid 12014$.

Subject; $\quad$ COOPERATION IN PROVINCIAL RESEARCH STUDY ON MEASURING MATERIAL MORTALITY RATIO.

Please refer to the letter received from Director General Health

Punjab vide NO.626-31/PA dated 11-07-2014 on the subject noted above.

Please extend full cooperation with the research team of population

Council.

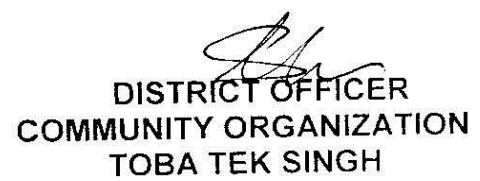

CC:-

1- The Director General Health Punjab, Lahore.

2- The District Coordination Officer, T.T.Singh.

3- The Executive District Officer Health, T.T.Singh.

4- The Director Programs Population Council, Islamabad. 


\section{OFFICE OF THE EXECUTIVE DISTRICT OFFICER (HEALTH) TOBA TEK SINGH}

No. 17628 /E (Gen-14-132) dated T.T. Singh, the $\quad 19$ /07/2014

To,

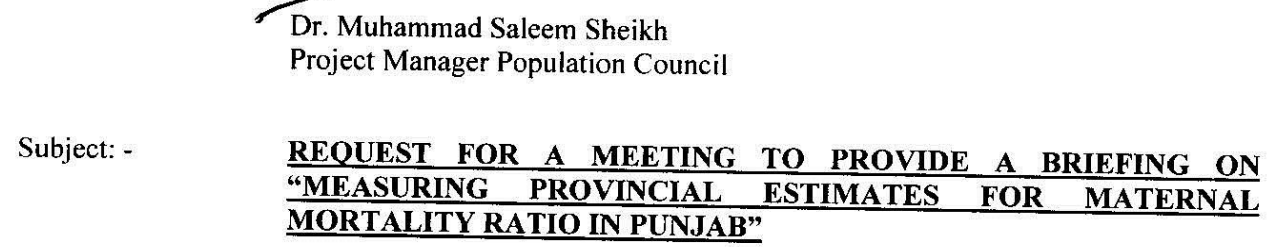

Reference your office letter No. Nil, dated 19-07-2014, a meeting regarding the subject cited has been carried out in the office of the undersigned on dated 19-07-2014.

A mutual discussion on various aspects of this program has been discussed and ensured, that full support will be provided regarding this study.

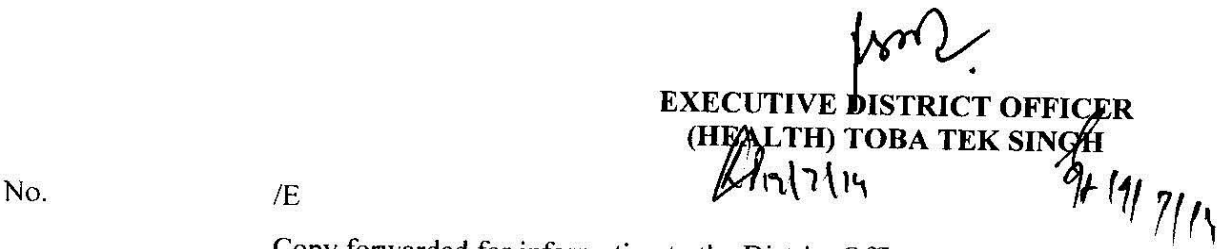

Copy forwarded for information to the District Officer (Health) Toba Tek Singh.

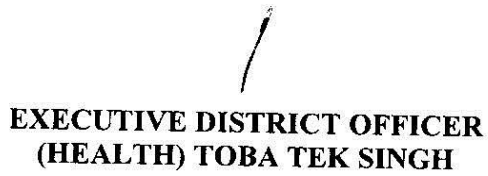




\begin{abstract}
OFFICE OF THE
EXECUTIVE DISTRICT OFFICER

(HEALTH) TOBA TEK SINGH
\end{abstract}

No. $\quad$ E (Gen-14-135) dated T.T. Singh, the $/ 9 / 07 / 2014$

To,

The District Officer Community Organization

Toba Tek Singh (DOCO)

Subject: -

PROVINCIAL RESEARCH STUDY MEASURING MATERNAL
MORTALITY RATIO IN PUNJAB"

With reference to letter No. 6126-31/PA, dated 11-07-2014 received from the Director General Health Services, Punjab Lahore on the subject cited above. Kindly extend cooperation with the research team of Population of Islamabad.

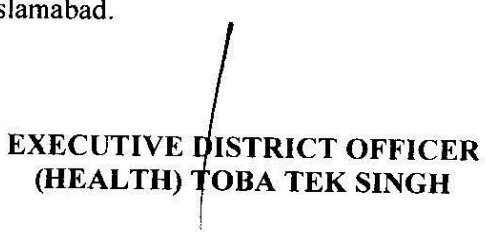

No.17631-32/E

Copy forwarded for information to: -

1. The District Coordination Officer, Toba Tek Singh.

2. The Director Programs Population Council, Islamabad.

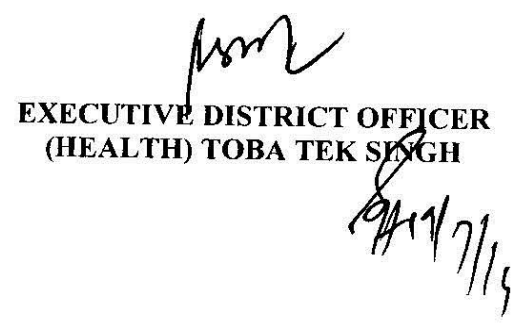




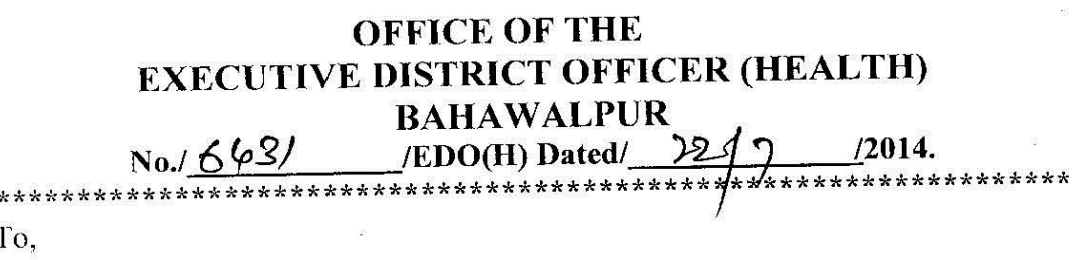

Dr. Muhammad Salecm.

Programme Manager, Population Concil

Islamabad.

\section{SUBJIECT: - $\quad$ SUPPORT LETTER FOR PROVINCIAL RESERCH STUDY ON MEASURING MATERNAL MORTALITY RATIO.}

Kindly refer Director General Health Services Lahore office letter No. 6126-31 /PA dated 11.07.2014 on the subject noted above.

It is intimated that after mutual discsuion on various aspects of this programme has been discussed and ensured, that full support will be provided regarding this study.

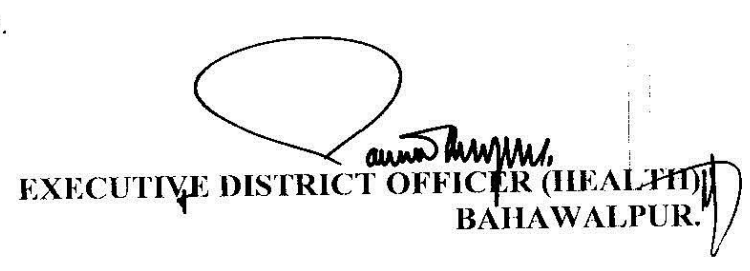

Cc:-

1. The Director Gencral Health Services, Punjab Lahore for information $w / \mathbf{r}$ to his letter referred above. 


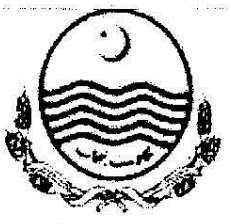

\section{OFFICE OF THE PROVINCIAL COORDINATOR NATIONAL PROGRAMME}

For Family Planning and Primary Health Care PPIU Punjab 5-Montgomary Road, Lahore Phone 042-99205325-31 Fax. 042-99205329 E-mail pc.punjab@gmail.com

No. Pb/PPIU-2014/5827 MIS.

Dated Lahore the 1) tU July, 2014

To

Dr. Ali Mohammad Mir

Director Programs

Population Council, Islamabad

Subject:- $\quad$ SUPPORT LETTER FOR THE PILOT STUDY ON "MEASURING MATERNAL MORTALITY RATIO IN BAHAWALPUR, T. T. SINGH, LAYYAH, BHAKKAR, CHINIOT AND JHELUM DISTRICT"

Reference your letter dated $07^{\text {th }}$ July, 2014 on the subject cited above.

National Program for FP \& PHC Punjab agrees with the conduction of provincial level study using a regionally representative sampling approach to obtain MMR estimate for Punjab by using the existing network of Lady Health Workers in Bahawalpur, T. T. Singh, Layyah, Bhaklear, Chiniot and Jhelum districts during the month of September-November, 2014

This issues with the approval of Director General Health Services, Punjab.

$\sqrt{2}$

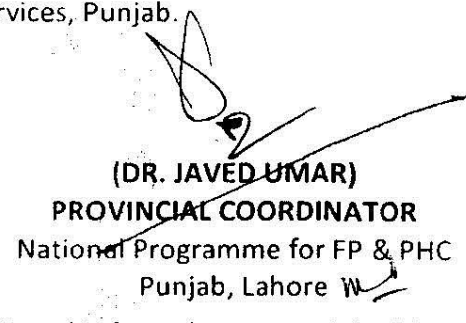

No. Pb/PPIU-2014/

MIS.

Dated Lahore the July, 2014

Copy forwarded for information and necessary action to

1. The Director General Health Services, Punjab Lahore

2. The Executive District Officer Heath, Bahawalpur, T. T. Singh, Layyah, Bhakkar, Chiniot and Jhelum

3. The District Coordinator IRMNCH/Incharge National Program for FP \& PHC, Bahawalpur, T. T. Singh, Layyah, Bhakkar, Chiniot and Jhelum with the direction to facilitate the Population Council team in conduction of the provincial level study to assess the maternal mortality ratio.

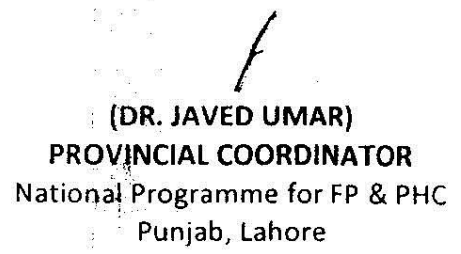




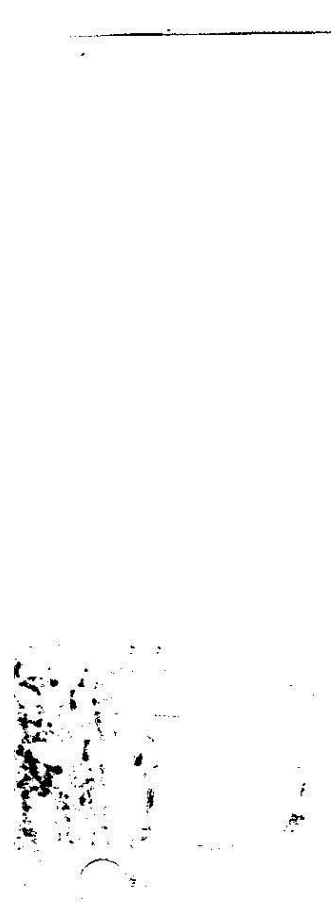

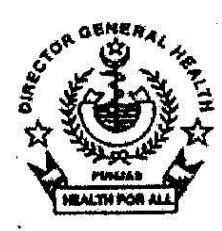

To

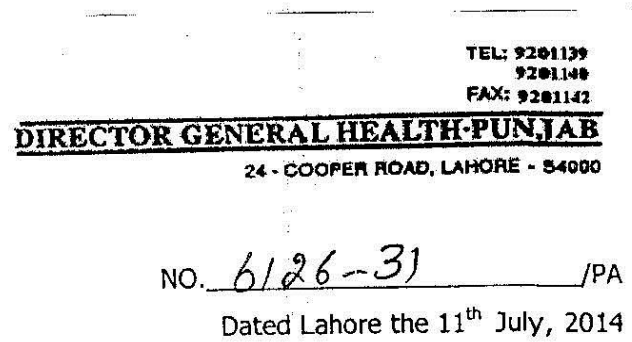

1. Executive District Officer (Health), Bahawalpur.

2. Executive District Officer (Health), Layyah.

3. Eyecutive District Officer (Health), Chiniot.

4. Executive District Officer (Health), Bhakkar.

5. Executive District Officer (Health), Jehium.

6. Executive District Officer (Health), T.T. Singh.

SUBJECT: SUPPORT LETTER FOR PROVINCIAL RESEARCH STUDY ON

* MEASURING MATERNAL MORTALITY RATIO.

Population Council, Islamabad intends to conduct research study to assess the potential of community level reporting on maternal deaths and measuring maternal mortality ratio to update the estimate required for maternal mortality to plan new initiative. The Population Council is planning to carry out the Provincial Research Study during the month of September to November, 2014 in your district.

You are requested to facilitate the team of Population Council to conduct research study in your district.

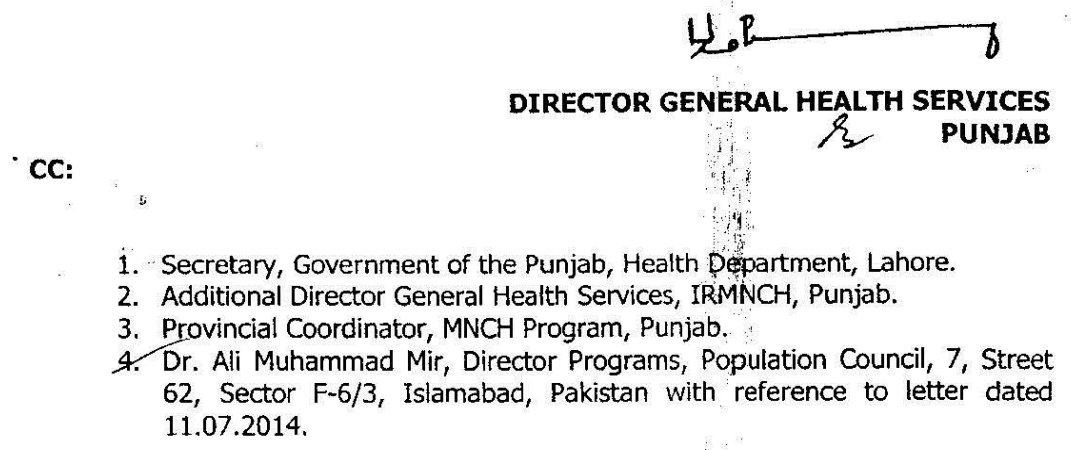




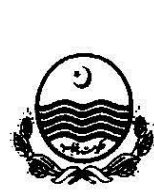

To

\section{AO: 30 . \\ O/O PROVINCIAL PROGRAM COORDINATOR

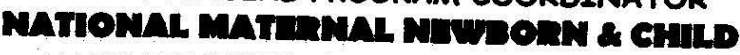

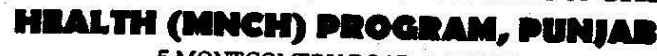 \\ 5 MONTGOMERY ROAD, LAHORE}

Email address: pb.mnch@gmail.com

S 99200982, 99201098; Fax: 99203394

Dated Lahore the 10 July, 2014 The District Coordinator, Integrated RMNCH \& Nutrition Program,
District

\section{SUBJECT: SUPPORT OF CMWS IN CONDUCTING MMR STUDY.}

Reference to the subject cited above. A

Pakistan is listed as one of the top five countries contributing most to the global burden of maternal mortality. The most recent Maternal Mortality Ratio now widely accepted, is 276 maternal deaths per 100,000 births according to the PDHS survey 2006-07. This figure is now six years old and an updated estimate is required for maternal mortality to plan new initiatives and introducing greater accountability. A new measure MADE IN and MADE_FOR technique has been introduced by the University of Aberdeen, UK.

The Population council conducted the pilot study in district Chakwal to assess the feasibility of using community based informant networks to estimate Maternal Mortality in Pakistan. Now Population Council is going to estimate the Provincial Maternal Mortality Ratio
in Punjab.

You are hereby directed to facilitate and provide necessary support to the Population Council team for conduction of MMR study in your district.

\section{A copy is forwarded for information to the:}

DR. ZAFAR KRAM

1. PSO to the Secretary, Government of the Punjab, Health Department, Lahore

2. PA to the Director General Health Services (DGHS) Punjab, Lahore.

3. Executive District Officer (Health)

4. Dr. Ali Muhammad Mir, Director Programs, Population council, Islamabad.

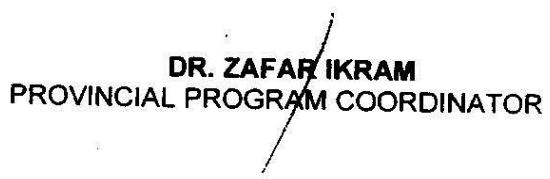




\subsection{Dates of Trainings and Field Activities}

\begin{tabular}{|c|c|c|c|c|c|}
\hline \multicolumn{6}{|c|}{ MMR STUDY ACTIVITY SHEDULE } \\
\hline \multirow{2}{*}{$\mathrm{Sr}$} & \multirow{2}{*}{ DISTRICT NAME } & \multicolumn{2}{|c|}{ TRAINING } & \multicolumn{2}{|c|}{ FIELD WORK } \\
\hline & & START & END & START & \\
\hline 1 & JHELUM & $\begin{array}{l}17 \text { SEPTEMBER } \\
2014\end{array}$ & $\begin{array}{l}22 \text { SEPTEMBER } \\
2014\end{array}$ & $\begin{array}{l}23 \text { SEPTEMBER } \\
2014\end{array}$ & $\begin{array}{l}29 \text { OCTOBER } \\
2014\end{array}$ \\
\hline 2 & BAHAWALPUR & $\begin{array}{l}26 \text { SEPTEMBER } \\
2014\end{array}$ & 01 OCTOBER 2014 & 2 OCTOBER 2014 & $\begin{array}{l}5 \text { DECEMBER } \\
2014\end{array}$ \\
\hline 3 & TT SINGH & 13 OCTOBER 2014 & 16 OCTOBER 2014 & 17 OCTOBER 2014 & $\begin{array}{l}5 \text { DECEMBER } \\
2014\end{array}$ \\
\hline 4 & CHINNIOT & 20 OCTOBER 2014 & 23 OCTOBER 2014 & 24 OCTOBER 2014 & $\begin{array}{l}5 \text { DECEMBER } \\
2014\end{array}$ \\
\hline 5 & BHAKKAR & 25 OCTOBER 2014 & 28 OCTOBER 2014 & 29 OCTOBER 2014 & $\begin{array}{l}\text { O6 DECEMBER } \\
2014\end{array}$ \\
\hline 6 & LAYYAH & $\begin{array}{l}10 \text { NOVEMBER } \\
2014\end{array}$ & $\begin{array}{l}14 \text { NOVEMBER } \\
2014\end{array}$ & $\begin{array}{l}16 \text { NOVEMBER } \\
2014\end{array}$ & $\begin{array}{l}\text { O8 DECEMBER } \\
2014\end{array}$ \\
\hline
\end{tabular}




\subsection{Pictures of Trainings in Six Districts}
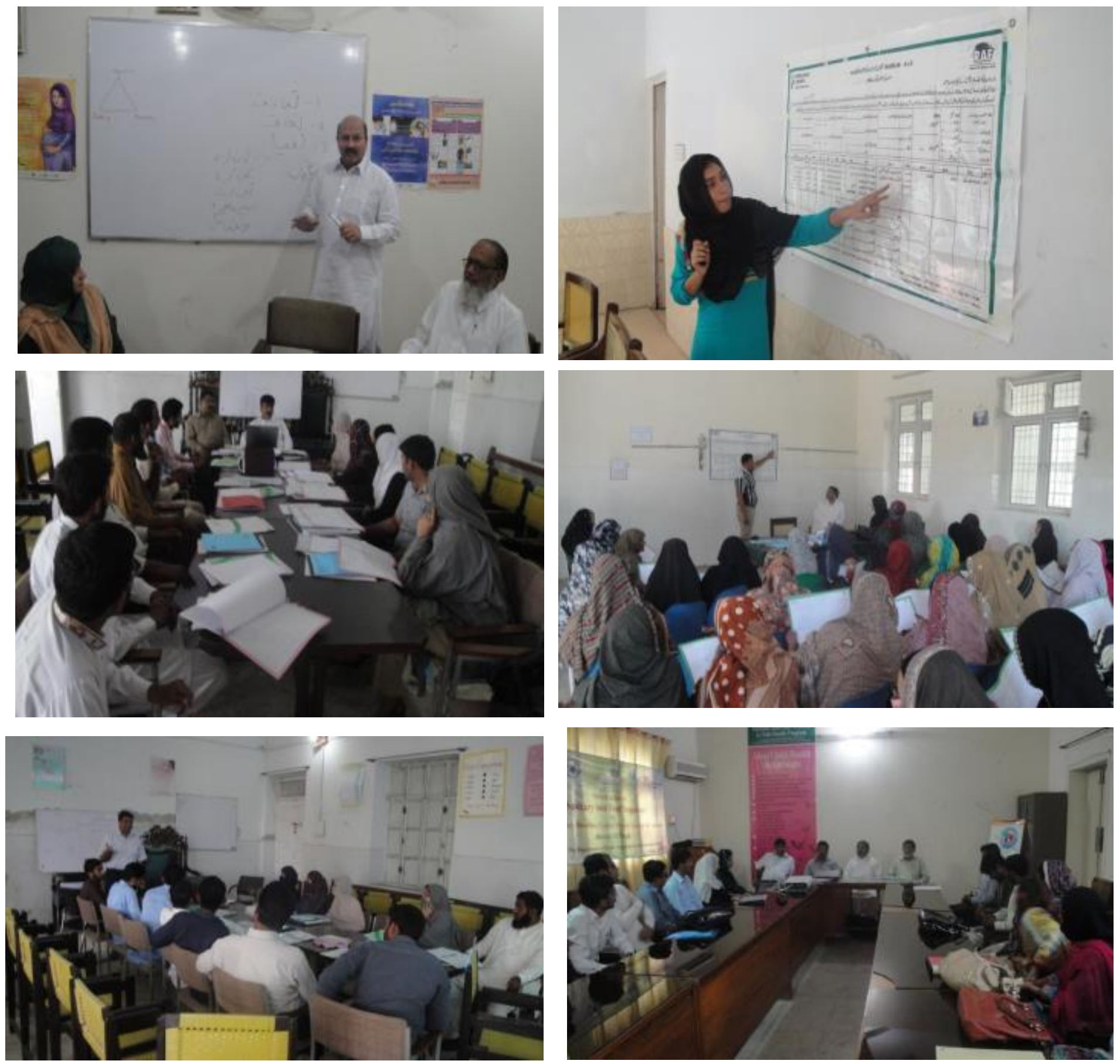


\subsection{List of Health Department Staff Who Were Trained}

\section{BHAKKAR}

\begin{tabular}{|c|c|c|}
\hline Name & Designation & Address \\
\hline $\begin{array}{l}\text { Dr. Muhammad } \\
\text { Ashraf Javaid }\end{array}$ & EDO-Health & DHDC BHAKKAR \\
\hline $\begin{array}{l}\text { Dr. Muhammad } \\
\text { Ishaq }\end{array}$ & $\begin{array}{l}\text { Program Director, DHDC, } \\
\text { Bhakkar }\end{array}$ & DHDC BHAKKAR \\
\hline $\begin{array}{l}\text { Dr. Rao } \\
\text { Muhammad } \\
\text { Suleman Zahid }\end{array}$ & $\begin{array}{l}\text { District Coordinator, IRMNCH } \\
\text { \& Nutrition Program, Bhakkar }\end{array}$ & $\begin{array}{l}\text { HOUSING COLONY, NEAR FOJIA MOSQUE, } \\
\text { MANDI TOWN, TEHSIL \& DISTRICT BHAKKAR }\end{array}$ \\
\hline $\begin{array}{l}\text { Dr. Akram } \\
\text { Mubarik }\end{array}$ & $\begin{array}{l}\text { District Officer-Health, DHDC, } \\
\text { Bhakkar }\end{array}$ & $\begin{array}{l}\text { Officer Colony, DHQ Road, Tehsil \& District } \\
\text { Bhakkar }\end{array}$ \\
\hline \multirow{3}{*}{$\begin{array}{l}\text { Dr. Muhammad } \\
\text { Aslam Shaheen }\end{array}$} & Senior Technologist & \multirow{3}{*}{$\begin{array}{l}\text { House No. 1/128-N, Near Jamiah Mosque } \\
\text { Talab Wali, Mandi Town Bhakkar, Tehsil \& } \\
\text { District Bhakkar }\end{array}$} \\
\hline & $(\mathrm{E} \& \mathrm{CM}-\mathrm{T}) /$ District & \\
\hline & $\begin{array}{l}\text { Trainings \& Course } \\
\text { Coordinator, Senior Planning } \\
\text { Officer/ District Monitoring, } \\
\text { Research \& Evaluation } \\
\text { Officer, District Health } \\
\text { Department, DHDC, Bhakkar }\end{array}$ & \\
\hline Azra Afzal & Chief Technician, MCH & $\begin{array}{l}\text { Near Liaqat Nursery, Mandi Town Bhakkar, } \\
\text { Tehsil \& District Bhakkar }\end{array}$ \\
\hline
\end{tabular}

\section{BAHAWALPUR}

\begin{tabular}{|l|l|l|}
\hline Name & Designation & Address \\
\hline Dr. Wajahat & Medical Doctor & BVH Bahawalpur \\
\hline Dr. Huda & Medical Doctor & BVH Bahawalpur \\
\hline $\begin{array}{l}\text { Dr. Saeed Asghar } \\
\text { Chaudhry }\end{array}$ & DHO & EDO Health Office, Bahawalpur \\
\hline \begin{tabular}{l} 
Dr. Shahid Khaliq \\
\hline
\end{tabular} & DEO & EDO Health Office, Bahawalpur \\
\hline
\end{tabular}




\section{CHINIOT}

\begin{tabular}{|l|l|l|}
\hline Name & Designation & Address \\
\hline Dr. Munawar Ahmad & EDO Health (Focal Person) & $\begin{array}{l}\text { EDO Complex, Government Girls Degree } \\
\text { College, Chiniot }\end{array}$ \\
\hline Dr. Mumtaz Chohan & Acting DOH (Focal Person) & $\begin{array}{l}\text { EDO Complex, Government Girls Degree } \\
\text { College, Chiniot }\end{array}$ \\
\hline Dr. Munir Ahmad & $\begin{array}{l}\text { District Coordinator, } \\
\text { Maternal, Newborn and } \\
\text { Child Health (MNCH) }\end{array}$ & $\begin{array}{l}\text { EDO Complex, Government Girls Degree } \\
\text { College, Chiniot }\end{array}$ \\
\hline Mr. Muhammad Kashi & Coordinator, DHIS Cell & $\begin{array}{l}\text { EDO Complex, Government Girls Degree } \\
\text { College, Chiniot }\end{array}$ \\
\hline Ms. Saira & Data Assistant & $\begin{array}{l}\text { EDO Complex, Government Girls Degree } \\
\text { College, Chiniot }\end{array}$ \\
\hline
\end{tabular}

\section{JHELUM}

\begin{tabular}{|l|l|l|}
\hline Name & Designation & Address \\
\hline Dr. Imtiaz Dar & MNCHP & $\begin{array}{l}\text { District Coordinator, (IRMNCH) \& Nutrition Program, District } \\
\text { Health Office, Jhelum }\end{array}$ \\
\hline Nadia Jabeen & ADC & $\begin{array}{l}\text { ADC National Program for Family Planning \& Primary Health } \\
\text { Care, EDO Health Office, Jhelum }\end{array}$ \\
\hline Rana Jameel & SO MNCH & Social Organizer, MNCH Program, EDO Health Office, Jhelum \\
\hline Iftikhar Bhatti & DOCO & $\begin{array}{l}\text { District Officer Community Organization, Local Government } \\
\text { Office, District Kachehri, Jhelum }\end{array}$ \\
\hline
\end{tabular}

\section{LAYYAH}

\begin{tabular}{|l|l|l|}
\hline Name & Designation & Address \\
\hline Shaheeda Kausar & ADC & DHDC, EDO Complex, District Layyah \\
\hline Ms. Azra & $\begin{array}{l}\text { Lady Health } \\
\text { Visitor (LHV) }\end{array}$ & DHDC, EDO Complex, District Layyah \\
\hline Dr. Rashid Olakh & Medical Doctor & DHDC, EDO Complex, District Layyah \\
\hline
\end{tabular}




\section{TOBA TEK SINGH}

\begin{tabular}{|l|l|l|}
\hline Name & Designation & Address \\
\hline Raja Nasir lqbal & Director DHDC & Department of Health, Toba Tek Singh \\
\hline Samina Bibi & $\begin{array}{l}\text { Statistical } \\
\text { Officer }\end{array}$ & Department of Health, Toba Tek Singh \\
\hline Shagufta Parveen & ADC & Department of Health, Toba Tek Singh \\
\hline
\end{tabular}




\subsection{Pictures of Field Activities}
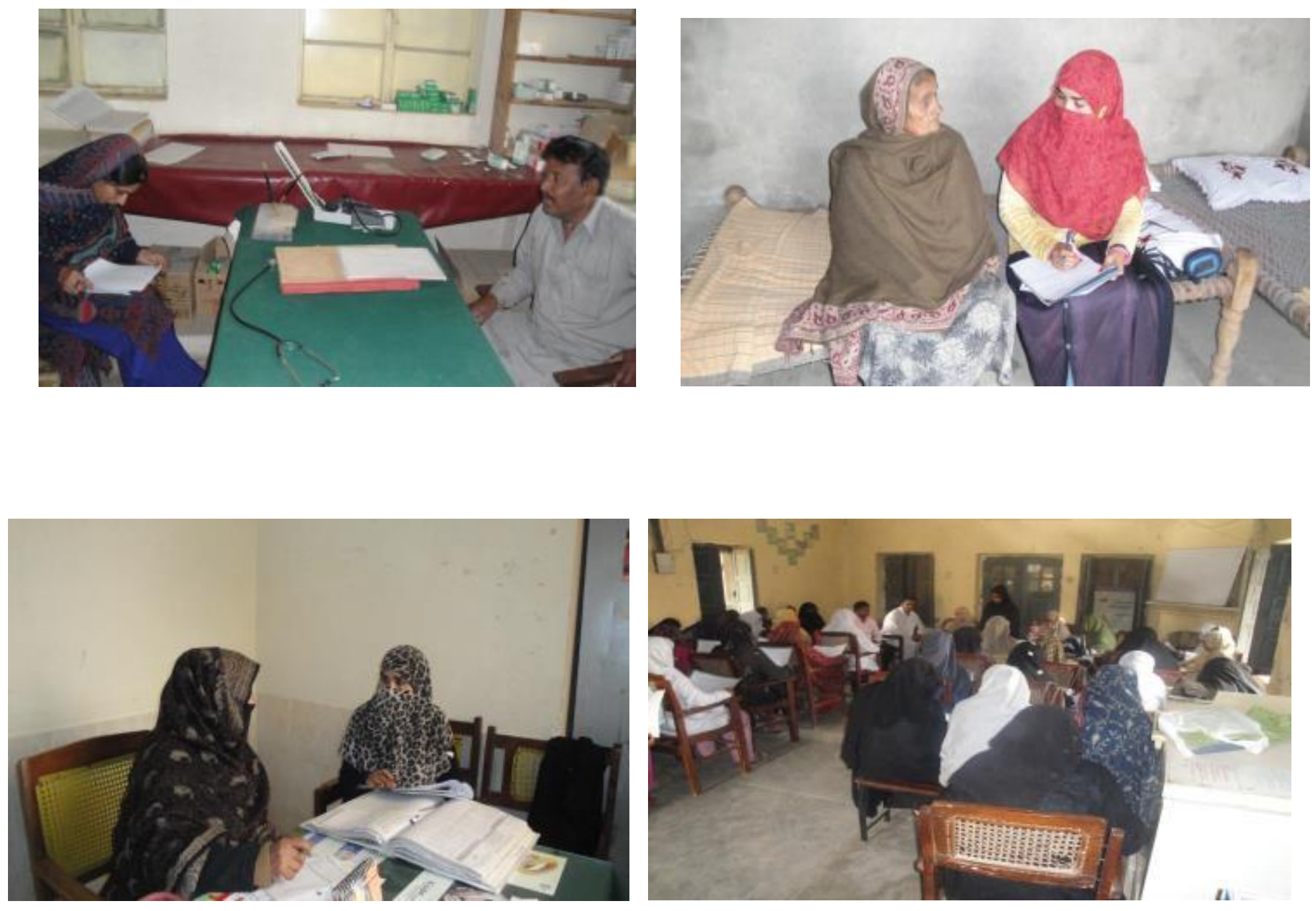


\subsection{Healthcare Structure in Pakistan}

\section{Primary Care facilities:}

These include $\mathrm{MCH}$ Centres (MCHC), Basic Health Units (BHUs) and Rural Health Centres (RHCs). There is at least one primary health care centre present in each Union Council catering to population ranging from ten to twenty five thousand people. MCHCs and BHUs are to operate from 8 am to 3 pm, except on Sundays, while RHCs are to provide 24-hour services. $\mathrm{MCH}$ centres are being managed by LHVs and provide basic antenatal care, normal delivery, post-natal and family planning services, and treatment of minor ailments to women and children.

In 2005, the Federal Government launched a country-wide program, known as the People's Primary Health care Initiative PPHI (formerly known as President's Primary Healthcare Initiative) for improving the service delivery at First Level Care Facilities (FLCFs). The purpose of this initiative was to strengthen the curative and preventive services provided in FLCFs, by handing over the management and finances of running the BHUs to the Rural Support Programs (RSPs) in their respective provinces. The objective of the initiative was to reorganize and re-structure the management of all the BHUs in the district with a central role for community-based support groups.

BHUs have a staff of 10 people consisting of a male doctor, a LHV or a FHT, a Male Medical Technician or/and a dispenser and other support staff. They are required to offer first level curative care, $\mathrm{MCH}$ services including obstetric first aid, family planning and preventive services through doctors and paramedics.

RHCs provide more extensive outpatient services and some inpatient services, usually limited to short-term observation and treatment of patients who are not expected to require transfer to a higher level facility. They serve a catchment population of about 50,000 to 100,000 people, with about 30 staff including 2 male medical officers, 1 female medical officer, 1 dental surgeon and a number of paramedics. They typically have 10 to 20 beds, an $\mathrm{x}$-ray machine, a laboratory and minor surgery facilities. RHCs are mandated to provide Basic Emergency Obstetric Care. 


\section{Referral level facilities:}

These include Tehsil Headquarters (THQ - sub district units) and District Headquarters (DHQ) Hospitals that are located at respective levels and offer first line referral services. Tehsil Headquarters Hospitals (THQH) serves a catchment population of about 100,000 to 300,000 people. They typically have $40-60$ beds and appropriate support services including $x$-ray, laboratory and surgery facilities. The staff includes at least three specialists: an obstetrician and gynaecologist, a paediatrician and a general surgeon. District Headquarters Hospitals (DHQH) serve a catchment population of about 1 to 2 million people and typically have about 100-150 beds. There are at least 8 specialists including an obstetrician and an anaesthetist. These hospitals provide Comprehensive EmOC services.

\section{Tertiary care facilities:}

The teaching hospitals in Pakistan provide tertiary as well as sub-specialty care. These hospitals mainly provide curative services and to a limited extent some preventive services. 


\subsection{Indicators for Measuring Maternal Mortality}

A number of different indicators have been developed for the measurement of maternal mortality. The most commonly used indicator is the maternal mortality ratio (MM Ratio), which refers to the number of maternal deaths per live birth, multiplied by a conventional factor of 100,000:

MM Ratio $=$ Number of maternal deaths $* 100,000$

Number of live births

The MM Ratio was designed to express obstetric risk. In fact, the MM Ratio may overestimate obstetric risk by excluding from the denominator pregnancies which do not terminate in a live birth.

The MM Ratio is frequently, though erroneously, referred to as the maternal mortality rate (MM Rate). The MM Rate is an indicator of the risk of maternal death among women of reproductive age. The MM Rate is usually multiplied by a factor of 1,000 . 


\subsection{Demographic Description of All Study Districts}

District Bahawalpur is one of the largest district of southern Punjab, consisting of six sub-divisions (Tehsils) i.e. Bahawalpur City, Bahawalpur Saddar, Ahmad Pur East, Yazman, Khairpur Tamewali, Hasil Pur. The greater part of the district is desert which is locally known as Cholistan or Rohi desert. District Bahawalpur spreads over an area of 24,830 square kilometres with an estimated population of 3.5 Million with 70 percent urban and population density of 518 persons per sq. km. (Three Years Rolling Plan (2010-2013) District Chiniot)

Table: Key reproductive health indicators: Bahawalpur and Punjab

\begin{tabular}{|c|c|c|}
\hline \multirow{2}{*}{ Indicator } & \multicolumn{2}{|c|}{ MICS 2011} \\
\hline & Punjab & Bahawalpur \\
\hline TFR for women aged $15-49$ & 3.58 & 3.53 \\
\hline $\begin{array}{l}\text { Percent of currently married women aged } 15-49 \text { years who are using (or whose } \\
\text { husband is using) a contraceptive method }\end{array}$ & 35.2 & 34.3 \\
\hline $\begin{array}{l}\text { Percent of currently married women aged } 15-49 \text { years with an unmet need for } \\
\text { family planning }\end{array}$ & 17.1 & 17.5 \\
\hline Percent distribution of delivery by an SBA & 58.5 & 37.3 \\
\hline Infant mortality rate & 82 & 100 \\
\hline
\end{tabular}

District Layyah is basically an agricultural area with no significant industry, divided into 3 tehsils i.e. Layyah, Karor and Choubara. According to the 1998 Census of Pakistan it had a population of 1616928 (2010 Est.) of which 87.1 percent were rural. The district covers 6291 square kilometres with population density of 178 persons per square km (Three Years Rolling Plan (2010-2013) District Chiniot)

Table: Key reproductive health indicators: Layyah and Punjab

\begin{tabular}{lcr}
\hline \multirow{2}{*}{ Indicator } & MICS 2011 \\
\cline { 2 - 3 } & Punjab & Layyah \\
\hline TFR for women aged 15-49 & 3.58 & 3.97 \\
\hline $\begin{array}{l}\text { Percent of currently married women aged 15-49 years who are using (or whose } \\
\text { husband is using) a contraceptive method }\end{array}$ & 35.2 & 26.3 \\
\hline $\begin{array}{l}\text { Percent of currently married women aged 15-49 years with an unmet need for } \\
\text { family planning }\end{array}$ & 17.1 & 18.0 \\
\hline $\begin{array}{l}\text { Percent distribution of delivery by an SBA } \\
\text { Infant mortality rate }\end{array}$ & 58.5 & 48.6 \\
\hline
\end{tabular}


District Chiniot lies in the middle of Punjab. It was upgraded to district level on 1st July 2009 and became 36th administrative district of Punjab with 3 tehsils. The district has an estimated population of 1246176 people and population density $\quad$ of 476 persons per sq. km. (Three Years Rolling Plan (2010-2013) District Chiniot)

Table: Key reproductive health indicators: Chiniot and Punjab

\begin{tabular}{|c|c|c|}
\hline \multirow{2}{*}{ Indicator } & \multicolumn{2}{|c|}{ MICS 2011} \\
\hline & Punjab & Chiniot \\
\hline TFR for women aged 15-49 & 3.58 & 3.81 \\
\hline $\begin{array}{l}\text { Percent of currently married women aged } 15-49 \text { years who are using (or whose } \\
\text { husband is using) a contraceptive method }\end{array}$ & 35.2 & 41.4 \\
\hline $\begin{array}{l}\text { Percent of currently married women aged } 15-49 \text { years with an unmet need for } \\
\text { family planning }\end{array}$ & 17.1 & 13.7 \\
\hline Percent distribution of delivery by an SBA & 58.5 & 57.9 \\
\hline Infant mortality rate & 82 & 97 \\
\hline
\end{tabular}

Toba Tek Singh is located in central Punjab and occupies 3259 square kilometres. Most of the land in the district is suitable for agricultural purposes. However the border area along with district Jhang is sandy. The district is divided in 3 tehsils; Gojra, Toba Tek Singh and Kamalia. The district has an estimated population of 2085795 with 81.20 percent rural and population density 640 persons per sq. km. (Three Years Rolling Plan (2010-2013) District Toba Tek Singh)

Table: Key reproductive health indicators: Toba Tek Singh and Punjab

\begin{tabular}{lcr}
\hline \multirow{2}{*}{ Indicator } & \multicolumn{1}{c}{ MICS 2011 } \\
\cline { 2 - 3 } & Punjab & TT Singh \\
\hline TFR for women aged 15-49 & 3.58 & 3.43 \\
\hline $\begin{array}{l}\text { Percent of currently married women aged 15-49 years who are using (or whose } \\
\text { husband is using) a contraceptive method }\end{array}$ & 35.2 & 33.6 \\
$\begin{array}{l}\text { Percent of currently married women aged 15-49 years with an unmet need for } \\
\text { family planning }\end{array}$ & 17.1 & 58.4 \\
Percent distribution of delivery by an SBA & 58.5 & 85 \\
\hline Infant mortality rate & 82 & 85.4 \\
\hline
\end{tabular}


District Jhelum was constituted under the British regime on $23^{\text {rd }}$ March 1849. This district is situated in the north-eastern part of Pakistan and was one of the four districts of former Rawalpindi division. The district consists of four major towns i.e. Jhelum city, Dina, Pind Dadan Khan and Sohawa. Total area of the district is 3587 sq. kilometers. Geographically, district Jhelum is divided into three regions and are called riverine, upland and plateau. The district has an estimated population of 1226031 people with 70 percent rural population. The population density of district is 3587 Sq. Km. (Three Years Rolling Plan (2010-2013) District Jhelum)

Table: Key reproductive health indicators: Jhelum and Punjab

\begin{tabular}{lrr}
\hline \multirow{2}{*}{ Indicator } & \multicolumn{2}{c}{ MICS 2011 } \\
\cline { 2 - 3 } TFR for women aged 15-49 & Punjab & Jhelum \\
\hline $\begin{array}{l}\text { Percent of currently married women aged 15-49 years who are using (or whose } \\
\text { husband is using) a contraceptive method }\end{array}$ & 3.58 & 3.45 \\
$\begin{array}{l}\text { Percent of currently married women aged 15-49 years with an unmet need for } \\
\text { family planning }\end{array}$ & 35.2 & 34.8 \\
Percent distribution of delivery by an SBA & 17.1 & 15.5 \\
Infant mortality rate & 58.5 & 79.9 \\
\hline
\end{tabular}

Bhakkar district was created in 1981 with Bhakkar city as the capital. The district consists of land along the Indus called "Kacha" and the "Thal" historically called "Chol-e-Jalali". Most of its area consists of greater "Thal". District Bhakkar is linked with Provincial Head quarter Lahore \& industrial city Faisalabad by BhakkarJhang Road. Bhakkar district is divided in 4 tehsils; Bhakkar, Kallur Kot, Darya Khan and Mankera. Total area of the district is $8,153 \mathrm{Km}^{2}$. The district has an estimated population of 1450946 persons with 86 percent rural population. The population density of district is 159 persons per sq. km. (Three Years Rolling Plan (20102013) District Bhakkar)

Table: Key reproductive health indicators: Bhakkar and Punjab

\begin{tabular}{lrr}
\hline \multirow{2}{*}{ Indicator } & \multicolumn{1}{c}{ MICS 2011 } \\
\cline { 2 - 3 } & Punjab & Bhakkar \\
\hline TFR for women aged 15-49 & 3.58 & 3.45 \\
$\begin{array}{l}\text { Percent of currently married women aged 15-49 years who are using (or whose } \\
\text { husband is using) a contraceptive method }\end{array}$ & 35.2 & 21.8 \\
$\begin{array}{l}\text { Percent of currently married women aged 15-49 years with an unmet need for } \\
\text { family planning }\end{array}$ & 17.1 & 19.3 \\
Percent distribution of delivery by an SBA & 58.5 & 49.8 \\
Infant mortality rate & 82 & 91 \\
\hline
\end{tabular}




\subsection{Identified networks for data collection}
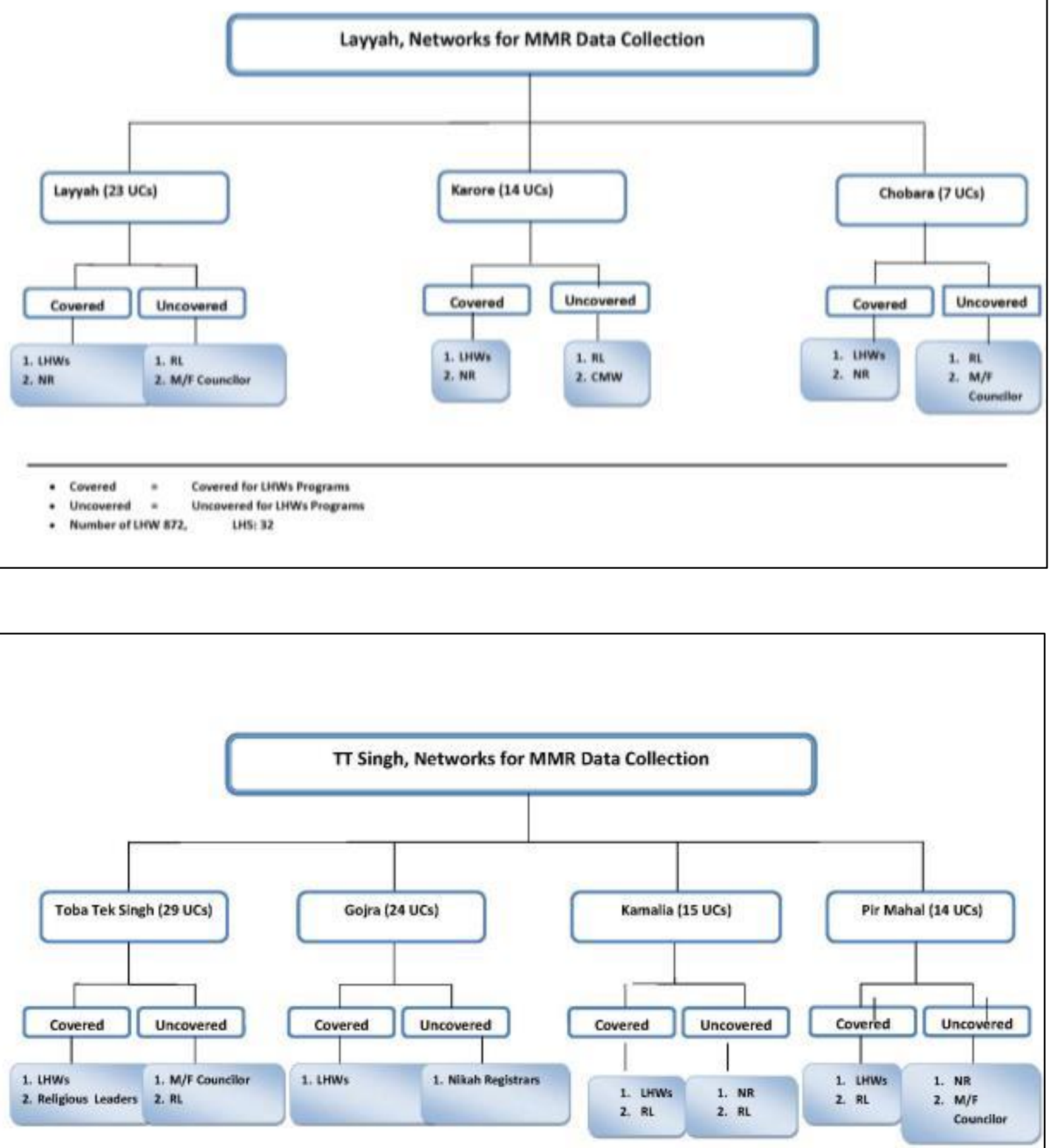

- Covered = Covered for LHWs Programs

- Uncovered = Uncovered for LHWs Programs 


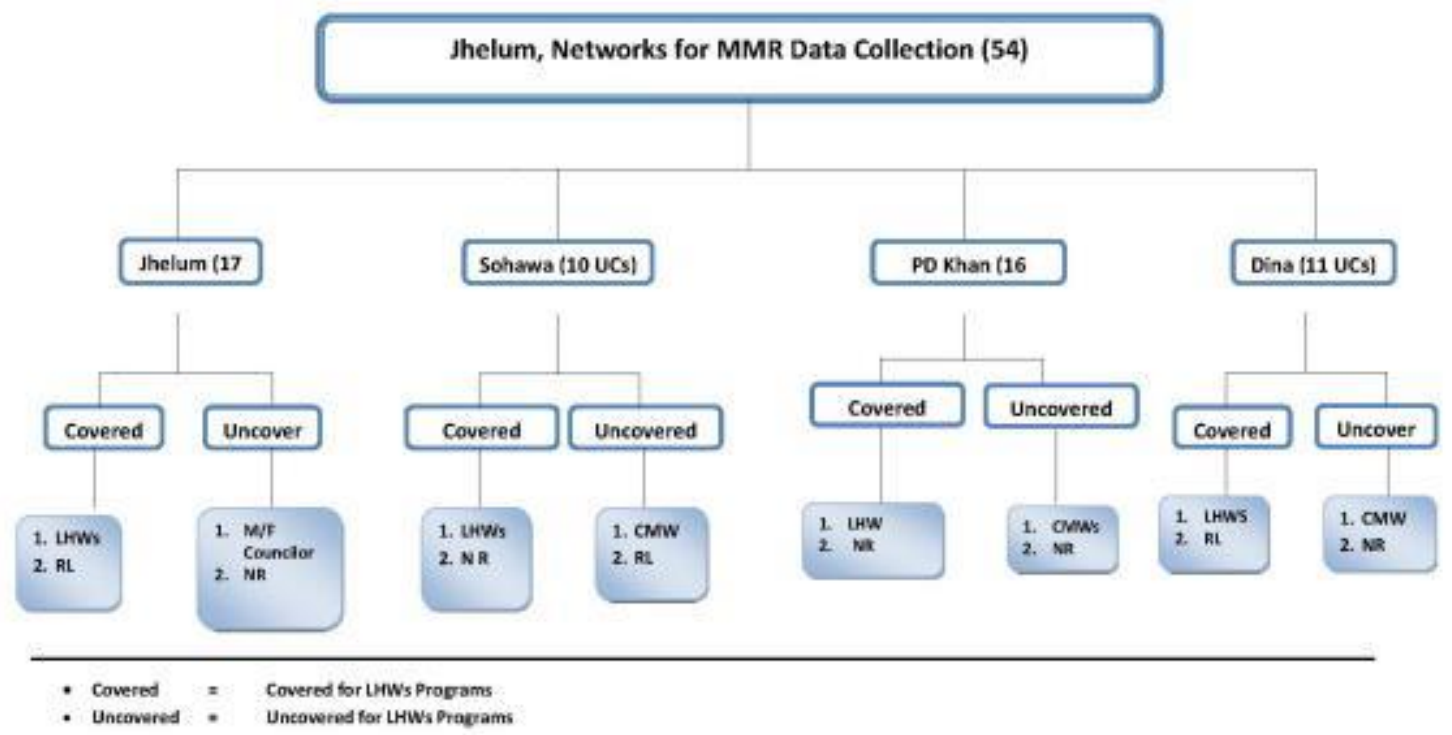

Bahawalpur, Networks for MMR Data Collection

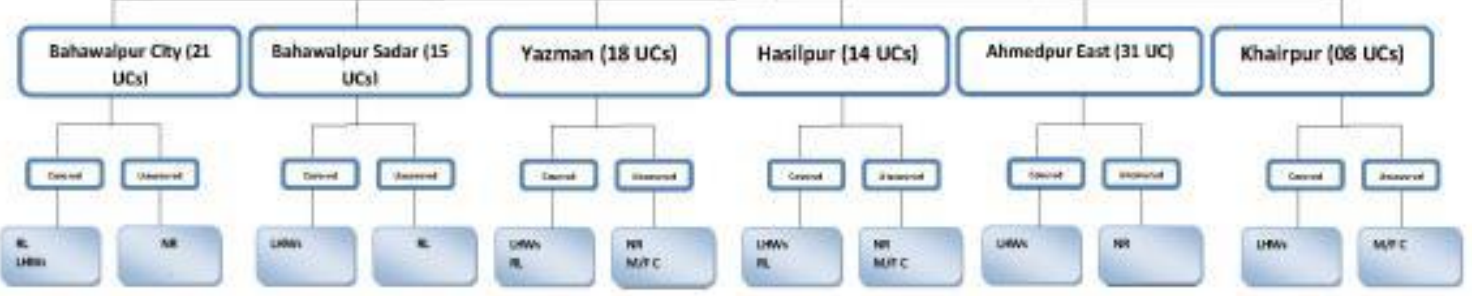

- Covered = Covered for LHWs Programs

- Uncovered = Uncovered for LKWs Programs 

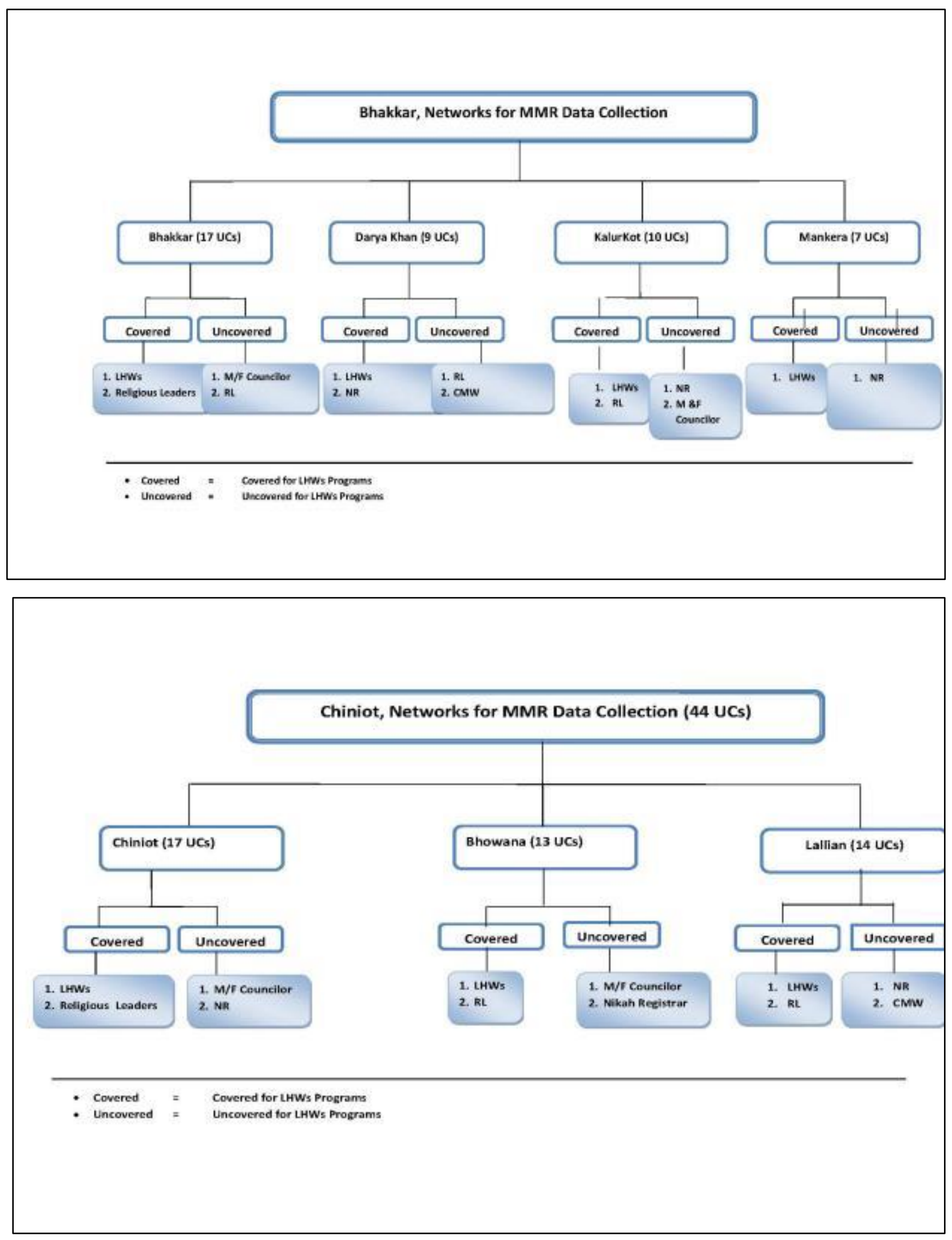
